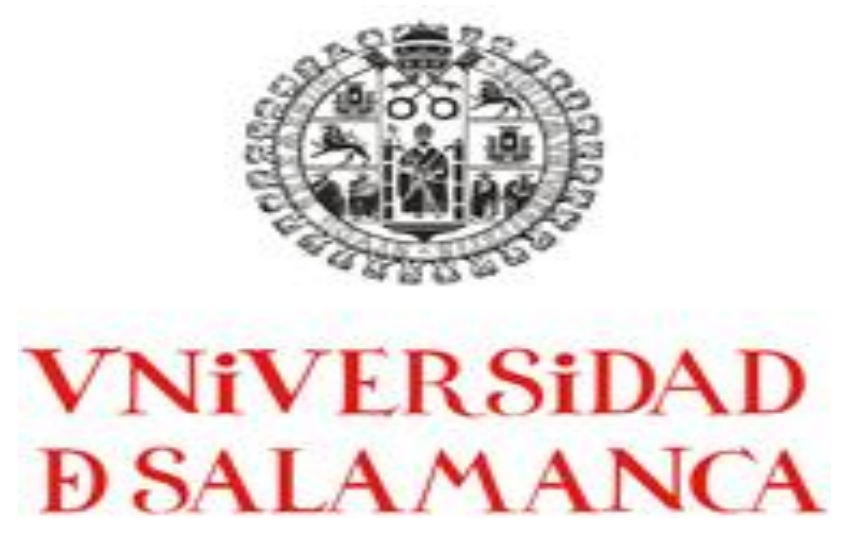

FACULTAD DE PSICOLOGIA

Departamento de Psicología Social y Antropología

\title{
LA PERSONALIDAD \\ $Y$ \\ LOS VALORES SOCIALES: \\ INFLUENCIA EN EL EMPRENDIZAJE
}

Amaia Yurrebaso Macho

\author{
DIRECCION \\ José Carlos Sánchez García \\ Ángel Infestas Gil
}

Salamanca, 2012 


\section{Amaia Yurrebaso Macho}

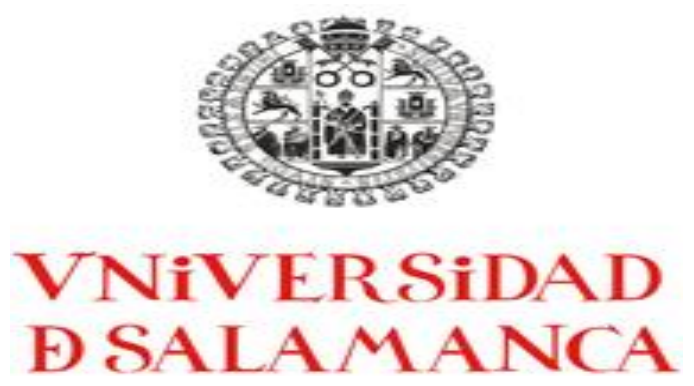

LA PERSONALIDAD Y LOS VALORES SOCIALES: INFLUENCIA EN EL EMPRENDIZAJE

Tesis presentada en el Departamento de Psicología Social y Antropología de la Universidad de Salamanca, dirigida por los Profesores Dr. D. José Carlos Sánchez García y Dr. D. Ángel Infestas Gil. 


\section{Universidad de Salamanca Facultad de Psicología}

VNIVERSIDAD

DSALAMANCA

Amaia Yurrebaso Macho con DNI 16.300.385-D, alumna del Doctorado en Psicología Social y Antropología de las Organizaciones,

Solicita sea aceptada a trámite de evaluación y lectura para optar al Título de doctor, la tesis La personalidad y los valores sociales; influencia en el emprendizaje.

Junio de 2012

Fdo. Prof. Dr. D. José Carlos Sánchez García Director de la tesis

Fdo. Prof. Dr. D. Ángel Infestas Gil Director de la Tesis

Alumna

Amaia Yurrebaso Macho

Sr. DIRECTOR DEL DPTO. DE PSICOLOGIA SOCIAL Y ANTROPOLOGIA 
LA PERSONALIDAD Y LOS VALORES SOCIALES: INFLUENCIA EN EL EMPRENDIZAJE

Lan hau nire aitari (in memoriam) eskainiko diot bere irakaspen jakintsuengatik. 


\section{AGRADECIMIENTOS}

A José Miguel y Ainhoa, razón de mi existencia y motor de mi capacidad de superación.

A mi protectora y paciente familia, por su entrega.

A José Miguel llundain, amigo incondicional, por su fe ciega en mí, por su ejemplo y apoyo.

A Perico, por su disponibilidad y ayuda.

A mis directores Ángel y José Carlos, por su comprensión, guía y estímulo intelectual.

A la Cátedra de Emprendedores de la Universidad de Salamanca por su ayuda incondicional y asesoramiento técnico.

A mis alumnos de la Facultad de Psicología por su ayuda en la recogida de la muestra. Mi especial gratitud a Raquel Aldana, por su tiempo y esfuerzo.

A todos los que han contestado el cuestionario y los que han colaborado desinteresadamente.

Gracias 


\section{INDICE GENERAL}

$\begin{array}{ll}\text { Índice de figuras, cuadros y tablas } & 7\end{array}$

Introducción $\quad 9$

\section{Parte I. Marco Teórico}

Capítulo 1 La figura del emprendedor $\quad 12$

1.1. Emprendedor y emprendedorismo 13

1.1.1. Etimología y Origen del Término 13

1.1.2. El concepto de emprendedor $\quad 16$

1.1.3. Conclusiones 31

1.2. El estudio del emprendedor $\quad 32$

1.2.1. La perspectiva económica 33

1.2.2. La perspectiva Sociológica $\quad 40$

1.2.3. La perspectiva psicológica $\quad 58$

1.2.3.1.El enfoque de la personalidad; la orientación de los rasgos 63

$\begin{array}{ll}\text { 1.2.3.1.1. Los rasgos de la personalidad emprendedora } & 70\end{array}$

$\begin{array}{ll}\text { 1.2.3.1.1.1. Locus de control } & 73\end{array}$

$\begin{array}{lr}\text { 1.2.3.1.1.2. Autoeficacia } & 75\end{array}$

1.2.3.1.1.3. Propensión al riesgo y Tolerancia a la ambigüedad 78

1.2.3.1.1.4. Proactividad 84

1.2.3.1.1.5. La Necesidad de Logro 85

1.2.3.1.2. Nuevas orientaciones en el enfoque de la personalidad 86

$\begin{array}{ll}\text { 1.2.3.2. La orientación de la conducta } & 91\end{array}$

$\begin{array}{ll}\text { 1.2.3.2.1. La conducta emprendedora } & 92\end{array}$

1.2.3.2.1.1. El modelo de las intenciones aplicado a la conducta 96 emprendedora

$\begin{array}{ll}\text { 1.2.3.3. La orientación cognitiva } & 101\end{array}$

$\begin{array}{ll}\text { 1.2.4. Conclusiones } & 104\end{array}$

\section{Capítulo 2 La cultura emprendedora}

2.1. La cultura 109

2.1.1. Definición de cultura 09

$\begin{array}{lr}\text { 2.1.2. Transmisión social de la cultura } & 122\end{array}$

$\begin{array}{lr}\text { 2.1.2.1. Socialización y personalidad básica } & 126\end{array}$

$\begin{array}{ll}\text { 2.1.3. Contenidos de la cultura } & 134\end{array}$

2.2. Modelos conceptuales significativos en el estudio de Valores 145

2.2.1. Teorías de los valores culturales $\quad 153$

$\begin{array}{ll}\text { 2.3. Cultura y emprendimiento } & 167\end{array}$

2.4.Conclusiones 174 


\section{Parte II Marco Empírico}

\section{Capitulo 3. Método}

3.1. Justificación del problema 181

3.2. Muestra 182

3.3. Instrumento 183

$\begin{array}{ll}\text { 3.4. Procedimiento } & 184\end{array}$

$\begin{array}{ll}\text { 3.5. Hipótesis } & 184\end{array}$

3.6. Análisis 188

\section{Resultados}

4.1. Fiabilidad 192

4.2. Correlaciones 193

4.3. Diferencias de Medias 202

4.4. Análisis de Regresión 208

5. Discusión y Conclusiones 213

$\begin{array}{ll}\text { Bibliografía } & 224\end{array}$

\section{ÍNDICE DE FIGURAS, CUADROS Y TABLAS}

\section{Figuras}

Figura 1.1: El proceso emprendedor según Krueger.

Figura 1.2: Factores socioeconómicos y culturales que influyen en el emprendimiento

Figura 1.3: Teoría de la Conducta Planeada de Azjen, $\quad 100$

Fig. 1.4. Modelo de intenciones de la conducta emprendedora 101

Figura 2.1: Niveles de Cultura y su intervención según Schein 114

Figura 2.2: Los tres niveles de programación mental. 131

Figura 2.3: Modelo General del Sistema de Creencias. 139

Figura 2.4: Teoría de la Jerarquía de Necesidades de Maslow. 152

Figura 2.5: Modelos teóricos de la relaciones entre los tipos de motivaciones de valores y dimensiones bipolares en Schwartz.. 156

Figura 2.6: Estructura de los Valores Culturales en la teoría de Schwartz. $\quad 158$

Figura 2.7: Dimensiones culturales de Hofstede $\quad 160$ 


\section{Cuadros}

Cuadro 1.1: Acepciones idiomáticas del término emprendedor.

Cuadro 1.2: Principales corrientes de investigación sobre el emprendimiento según Chu

Cuadro 1.3: Líneas de investigación en el campo del emprendimiento.

Cuadro 1.4: los acercamientos en el estudio del emprendedor según 22

Cunnigham y Lischeron (1991)

Cuadro 1.5: Formas de emprendimientos identificadas por Kyrö

Cuadro 1.6: Contenidos del emprendimiento según la investigación de Parker

Cuadro 1.7: Contenidos de la Economía Geográfica

Cuadro 1.8: Enfoque teóricos en el estudio de las redes de emprendimiento

Cuadro 1.9: Características más comunes atribuidas a los emprendedores por los especialistas en el comportamiento según Filion

Cuadro 2.1: Características de los estudios tradicionales de cultura

Cuadro 2.2: Definiciones de valor, según diversos autores.

Cuadro 2.3: Teorías de los valores Culturales

Cuadro 2.4: Características de los valores según Schwartz.

Cuadro 2.5: Características de los 10 tipo motivacionales de valores de Schwartz

Cuadro 2.6: Dimensiones de valores cultuales de Hofstede en base a los problemas sociales de Inkeles y Levinson

\section{Tablas}

4.1: Correlaciones entre las escalas LCI, LCE, Autoeficacia, Proactividad, Riesgo e Iniciativa emprendedora

4.2: Correlaciones entre escalas/variables de personalidad y motivos propios

4.3: Correlaciones entre las escalas "LCI", "LCE", Autoeficacia", "Proactividad", "Riesgo" e "Iniciativa emprendedora" y "Recursos".

4.5: Correlaciones entre variables personales y variables circunstanciales $\quad 198$

4.6: Correlaciones entre variables personales y la intención laboral

4.7: Correlaciones entre variables personales y la edad; variables personales y la experiencia 


\section{INTRODUCCIÓN}

Las personas pasamos gran parte de la vida en nuestro puesto de trabajo, lo que configura a éste como un espacio importante no solo profesional, sino vital. Se trata de una dimensión económica, social y cultural de gran trascendencia, por la inversión personal de tiempo y esfuerzo a cambio de una contraprestación que nos permite satisfacer necesidades económicas, psicológicas y sociales. Contribuye, sin lugar a dudas, a la creación de la propia identidad social.

El empleo, en permanente transformación, se erige como el gran reto impulsor del crecimiento económico. Nuestras sociedades, todas, necesitan modelos que favorezcan y revitalicen dicho crecimiento, la generación de empleo y la innovación empresarial. Se hace necesario poder incrementar los índices de empleabilidad para mejorar la calidad de vida de la población, y un mecanismo válido para conseguirlo es el autoempleo. Por tanto, las iniciativas emprendedoras cobran un papel muy importante en las sociedades actuales. No es de extrañar que ante semejante panorama, muchos visualicen al emprendedor como alternativa posible que, a un mismo tiempo, permita alcanzar la consecución de todos estos objetivos.

El emprendimiento alude al proceso de creación de valor que se genera por la aplicación de una serie de recursos que permiten aprovechar una oportunidad, que comprende desde las acciones destinadas a identificar oportunidades, a asumir riesgos, hasta implementar un nuevo negocio o a dirigirlo (Hurtado, N.E., Cordon, E., Sennise, M.E. ( 2007), de modo que englobaría todos aquellos actos de innovación, renovación o creación organizacional que puedan darse tanto dentro como fuera de una organización ya existente (Sharma, P., y Chrisman, J.J.,1999). En relación a ello, se considera al emprendedor como un agente que trata de descubrir nuevas oportunidades a través de la innovación y la creatividad (Schumpeter, J., 1934). Asumimos la innovación, la flexibilidad competitiva y la generación de empleo como los elementos clave de desarrollo económico, por lo que el emprendimiento se configura como un eje del crecimiento y una solución a estos tres problemas (Gómez, S., Delgado, J. y Vidal, M.D., 2010). 
El estudio del emprendimiento ha sido abordado desde muchas perspectivas, todas diferentes y complementarias entre sí, que recogeremos en el primer capítulo, tratando de centrar nuestro objeto de investigación en una definición propia del emprendedor. Ciencias como la economía, la sociología o la psicología, principalmente, han dedicado las últimas décadas a su estudio, al intento de delimitar conceptos y diseñar herramientas específicas que contribuyan a dar luz a este amplio campo de estudio.

Desde la Piscología, el interés se centra, básicamente, en el estudio del individuo emprendedor, en sus dimensiones conductuales, de personalidad o cognitivas, tratando de identificarlo y de predecir su conducta, relacionándole siempre con la acción de crear negocios (Baron, R.A., 2008; Stewart, A., 2001; Carland, J.K. Noulton, W.R., y Carland, J.A.C., 1984; Shane, S., 2000; Vecchio, R.P., 2003; León Moriano, 2005; Sánchez, J.C., 2010).

La Sociología pone el acento en los factores sociales que influyen en la acción de emprender, y en las consecuencias que del emprendimiento se derivan para la sociedad, (Albertos, P., 2003; Butler, 2002; Kennedy et al., 2003, Bretones, F. y Silva, M. (2009). Los economistas, principalmente, se interesan por el papel que juega en el crecimiento económico (Fillion, L.J., 2003; Baumol, W.J., 1990; Hisrich, R.D., 2008; Schmidt y Bohnenberger, L., 2008, Cárdenas, G., 2008).

En el presente trabajo y al objeto de dar una definición marco que guíe nuestro estudio, revisaré la literatura escrita sobre el emprendedor, centrándome en la que trata de delimitar la llamada personalidad emprendedora, identificando aquellos rasgos de personalidad que le caracterizan y diferencian. El primer capítulo, también, abordará este análisis.

Tras describir y analizar las variables de personalidad, consideraremos los principales factores culturales que influyen en el emprendizaje, a lo largo del segundo capítulo. Para ello, introduciremos los significados de cultura y emprendimiento, así como su importancia en el desarrollo económico, para después analizar los valores culturales que inciden en la intención de emprender. El objetivo básico de esta investigación será tratar de identificar qué tiene más peso en la intención emprendedora 
los rasgos de personalidad, o los valores culturales adquiridos, socialmente por el emprendedor.

Para nuestro análisis, tercer y cuarto capítulo, contaremos con una muestra de emprendedores, empresarios en activo que abrieron su propio negocio, es decir, partiremos del análisis de la conducta emprendedora ya ejecutada. Compararemos a estos emprendedores, subdividiéndolos en base a la zona geográfica donde abrieron su negocio, al objeto de tratar de identificar si lo que mantiene, a día de hoy, su intención emprendedora es la tenencia de ciertos rasgos de personalidad ó variables de tipo sociodemográficas (sexo, edad, nivel de estudios) y culturales (zona geográfica y valores).

Partimos, por lo tanto, de la premisa de que los rasgos psicológicos del emprendedor, siendo decisivos, no son suficientes para emprender. Intentaremos explicar y fijar cómo otros elementos sociales, los valores, como componente básico de la cultura, median en la intención de emprender. 
CAPITULO I-

LA FIGURA DEL EMPRENDEDOR 


\section{1.- EMPRENDEDOR Y EMPRENDEDORISMO}

En los últimos años, se ha despertado socialmente un creciente interés por todo lo que tiene que ver con el mundo del emprendedor y su vinculación con el papel que éste puede jugar en la vida socioeconómica como agente activador de la misma.

Este interés se ha traducido en multitud de estudios, todos complementarios entre sí, sobre quién es o puede ser emprendedor, qué aspectos median en su actitud hacia el emprendizaje, qué criterios fomentan o abortan su acción emprendedora, y el influjo real o papel que juegan los llamados emprendedores como actores socioeconómicos en sus entornos más o menos inmediatos.

Muchos son, pues, los aspectos a analizar en la persona llamada emprendedora, en sus motivaciones e ideas, en los comportamientos y en las dificultades que encuentra en su quehacer. No lo es menos el papel que cumple socialmente, las consecuencias de sus actos y por lo tanto, el interés que genera como agente básico del desarrollo socioeconómico, lo que explica el creciente interés de las distintas instituciones sociales y políticas en su fomento.

A través de estas líneas, trataremos de clarificar algunos de los elementos reseñados; aquellos que nos ayuden a entender quién y cómo es el llamado emprendedor, perfil psicosocial del emprendedor, y cómo operan esos rasgos en la acción de emprender.

\subsection{1.-ETIMOLOGÍA Y ORIGEN DEL TÉRMINO EMPRENDEDOR}

En el diccionario de la Real Academia de la Lengua Española, se define emprender, en su primera acepción, como "acometer y comenzar una obra, un negocio, un empeño o empresa”. Se usa más comúnmente hablando de “...los negocios que encierran dificultad o peligro" (RAE, 1992 p. 571). 
Sinónimos de emprender son acometer, intentar, comprometerse, abordar y comenzar, definiciones, todas ellas, que formarán parte del objeto de estudio de este trabajo.

Por su parte, Moliner dice de la persona emprendedora, que es aquella que tiene iniciativas y decisión para emprender negocios o acometer una empresa (Moliner, M., 1975).

El término castellano emprendedor parece tener su origen en el francés "entrepreneur", que aparece originariamente en la lengua francesa del Siglo XVI para designar a los conductores de hombres, en términos militares. Sin embargo, en el devenir de la historia, se hizo extensivo a todo tipo de aventureros.

Cochran, T., (1985) advierte que, a finales del Siglo XVII y principios del XVIII, el término "entrepreneur" pasó a designar en la lengua de Moliere a determinados contratistas de rutas, constructores y arquitectos de caminos y puertos, con fines militares o religiosos.

Todas estas acepciones del concepto, nos permiten afirmar que el término emprendedor ha sido causa de ciertos equívocos con otros términos concurrentes, que, sin embargo, tienen su propio y preciso significado. Confusión que, de igual modo, se ha producido en otras lenguas europeas, como la francesa e inglesa.

El siguiente cuadro puede ilustrarnos sobre el intrínseco significado de algunos de estos términos equívocos:

\section{Cuadro 1.1: Acepciones idiomáticas del término emprendedor}

\begin{tabular}{|l|l|l|}
\hline \multicolumn{1}{|c|}{ FRANCÉS } & \multicolumn{1}{|c|}{ INGLÉS } & \multicolumn{1}{c|}{ ESPAÑOL } \\
\hline Entrepreneur & $\begin{array}{l}\text { Entrepreneur } \\
\text { Person who sets up } \\
\text { business } \\
\text { deals in order to make a } \\
\text { profit. }\end{array}$ & Emprendedor \\
\hline $\begin{array}{l}\text { Employeur } \\
\text { Patron }\end{array}$ & $\begin{array}{l}\text { Employer } \\
\text { Owner }\end{array}$ & $\begin{array}{l}\text { Patrón } \\
\text { Empleador } \\
\text { Persona que tiene obreros } \\
\text { trabajando a su cuenta. }\end{array}$ \\
\hline
\end{tabular}

continua 


\begin{tabular}{|l|l|l|}
\hline FRANCÉS & INGLÉS & ESPAÑOL \\
\hline \multirow{5}{*}{ Entreprenant } & $\begin{array}{l}\text { Enterprising/ } \\
\text { Entrepreneurial } \\
\text { Someone who shows the } \\
\text { ability to do and has an } \\
\text { eagerness to do them } \\
\text { (Sinónimo de Entrepreneur). }\end{array}$ & $\begin{array}{l}\text { Emprendedor } \\
\text { Se aplica a la persona que } \\
\text { tiene iniciativa y decisión } \\
\text { para emprender negocios o } \\
\text { acometer empresas. }\end{array}$ \\
\hline \multirow{3}{*}{ Entreprise } & $\begin{array}{l}\text { Company / Enterprise } \\
\text { A business organization that } \\
\text { exists in order to make } \\
\text { money } \\
\text { by selling goods or services. }\end{array}$ & $\begin{array}{l}\text { Cosa que se emprende o } \\
\text { acción en la que hay trabajo } \\
\text { o implica dificultades. } \\
\text { Organización mercantil o } \\
\text { industrial que se dedica a la } \\
\text { explotación que se expresa. }\end{array}$ \\
\hline
\end{tabular}

Andrés Ciurana, B. y Montesa Andrés, (1994, p. 23)

Dicho esto, en el lenguaje coloquial, y aún en los medios de comunicación, con el término emprendedor suele aludirse al creador de empresas, entendido este desde un punto de vista económico y empresarial, por lo que, no es de extrañar, que el término fuera acuñado, originalmente, por la ciencia económica ${ }^{1}$. En la actualidad, ha adquirido un mayor alcance, dado que integra también a los llamados intraemprendedores; quienes conciben, desarrollan, impulsan nuevas ideas, tecnologías, proyectos,..., dentro de organizaciones ya creadas.

Genéricamente, se aplica el término emprendedor a las personas que tienen la capacidad y sensibilidad para detectar y reflexionar sobre necesidades sociales, de mercado o tecnológicas, emergentes o futuras y convertirlas en una oportunidad para aportar una solución en forma de producto, servicio o sistemas que aporten valor y soluciones, produciendo un impacto social y económico. El término "emprendedor" también implica que esta misma persona tiene la capacidad para captar o movilizar recursos, normalmente externos, que tienden a hacer viable y tangible una idea motriz y explotar la necesidad detectada, (Ilundain J.M, Sánchez, J.C., Yurrebaso, A., 2007).

\footnotetext{
${ }^{1}$ No debemos, sin embargo, confundir emprendedor con empresario. Si bien podemos identificar como emprendedor a quien percibe una oportunidad y crea una organización para conseguirla, empresario sería aquel que es capaz de convertir dicha organización en una empresa rentable. Asumido esto, no todos los empresarios son emprendedores ni todos los emprendedores llegan a ser empresarios.
} 
Se trata de identificar al emprendedor como un agente económico y social, que tiene una actitud propensa a emprender, sea cual sea el ámbito en el que actúa, por cuenta propia, ajena, en una ONG o en la administración pública.

Sin embargo, el término se extendió a otras disciplinas científicas distintas de la economía, unas conexas con la ciencia económica y otras no tanto. Aportando cada una, los puntos de vista que le son propios, y perfilando el sustrato conceptual del término.

Desde el ámbito de la psicología, se ha incidido sobre los aspectos de personalidad, conocimiento y conducta del emprendedor. Los sociólogos se han interesado por los factores sociales que propiciarán la acción emprendedora. Nada desdeñables son las aportaciones desde la antropología social, que han resaltado el impacto de los factores culturales; y desde la ciencia económica, que ha indagado sobre el papel que el emprendedor ha jugado en el crecimiento económico y la creación de riqueza.

Así pues, el estudio sobre el emprendedor es multidisciplinar. Esto es consecuencia de las relaciones de complementariedad entre las distintas disciplinas científicas, lo que enriquece las posibles conclusiones, con contribuciones a su entendimiento por las aportaciones conceptuales de cada una de ellas.

Encontraremos también diversas orientaciones metodológicas, patrocinadas por las diferentes corrientes de pensamiento, en cada una de las disciplinas que se han interesado por esta temática. Nuestro estudio, por tanto, aun teniendo en cuenta todas estas aportaciones, se desarrollará al amparo de premisas psicológicas: qué rasgos diferenciales de personalidad poseen los emprendedores, y sociológicas: en qué medida la intención de emprender, el deseo de seguir siendo emprendedor, es resultado de unos determinados valores culturales.

\subsection{2.- EL CONCEPTO DE EMPRENDEDOR}

Siendo conscientes de la dificultad que entraña la respuesta, abordaremos las distintas definiciones que se han aportado desde las diversas parcelas académicas. 
Si revisamos la literatura científica sobre el concepto, es forzoso concluir que no hay una definición de emprendedor universalmente aceptada. Varias Investigaciones (Palmer, 1971; Druker, 1985; Cromie, S. ,2000; Chell, E., 2000; Haworrth, 1982; Hisrich R.D., Peters M. P., Shepherd, D. A., 2005; Izquierdo, E., y Buelens, M., 2008), concluyen con una afirmación desalentadora: no hay una respuesta aceptable a esta pregunta. La única coincidencia entre los distintos tratadistas es que no hay acuerdo, excepto en un único punto, que desde el mismo instante en que alguien decide hacerse emprendedor tiene que poner a trabajar la imaginación y el esfuerzo por descubrir una oportunidad y transformarla en un proyecto. Éste hecho, que para algunos es un problema que dificulta su estudio, es visto por otros como una oportunidad de abrir nuevos campos en su investigación.

Así, la proliferación de estudios sobre el emprendedor, más de cien trabajos científicos distintos se han publicado en los últimos diez años relacionadas con el tema (Acs, Z., Braunerhjelm, P., Audretsch, D., y Carlsson, B. 2009), y, desde los distintos campos científicos, ha dado lugar a diferentes corrientes que pueden clasificarse de forma distinta.

Para un economista un emprendedor es aquel que transforma recursos, medios humanos y materiales, y otros bienes, para aumentar su valor, y del mismo modo quien introduce cambios, innova y crea un nuevo orden, como consecuencia de la combinación de todos estos elementos dispares.

Para un hombre de negocios, emprendedor es, pura y simplemente, una amenaza, un competidor, mientras que para otro hombre de negocios el mismo competidor es un aliado, un proveedor, un cliente, o un socio capitalista.

Para un filósofo capitalista, la misma persona la ve como alguien que crea riqueza, que encuentra mejores vías para utilizar los recursos, reducir los costes, o crear trabajo (Vesper, K.H., 1982). 
Algunos estudios analizan e investigan lo que ocurre cuando el emprendedor actúa, otros analizan por qué actúa, y por último, están los que se preocupan por estudiar cómo actúan (Stevenson, H.H. y Jarrillo, J.C., 1990).

Cada autor acuña su propia definición teniendo presente la época, el lugar, o país donde opera. En consecuencia, estas definiciones se pueden agrupar desde diferentes perspectivas. Según Kyrö, P. y Carrier, C., (2005), la forma tradicional para clasificar los distintos estudios del emprendimiento sería bajo estas tres categorías; la económica, la sociológica y la psicológica. Krueger, N. (2004), añadirá una corriente más, la gerencial, y una interesante reflexión, al indicar cómo el estudio del emprendedor deberá hacerse combinando las principales corrientes identificadas por Chu Ch.W. (2008).

\section{Cuadro 1.2: Principales corrientes de investigación sobre el emprendimiento según} Chu (1998)

\begin{tabular}{|l|l|l|}
\hline Corrientes principales & Temas de investigación & Líneas de preguntas \\
\hline Psicológicas; rasgos y conducta & $\begin{array}{l}\text { Características de los } \\
\text { emprendedores y del proceso } \\
\text { emprendedor }\end{array}$ & Causas (por qué) \\
\hline Sociológica; social y cultura & $\begin{array}{l}\text { Emprendedores de diferentes } \\
\text { fondos culturales y sociales }\end{array}$ & Causas (por qué) \\
\hline Económica & $\begin{array}{l}\text { Relación entre el entorno } \\
\text { económico y el emprendimiento }\end{array}$ & Efectos (qué) \\
\hline Gerencial & $\begin{array}{l}\text { Habilidades de los } \\
\text { emprendedores, gerencia y } \\
\text { crecimiento }\end{array}$ & Conducta (cómo) \\
\hline & Fuente Kruguer (2004, p. 15) \\
\hline
\end{tabular}

Kruguer, N. (2004) entiende que hay dos tendencias distintas en el estudio del emprendimiento: la que lo concibe como la persona que crea y desarrolla nuevos negocios, desarrollada por Say, J.B., (1803), y la que lo considera un innovador, más propia de Cantillon, R. (1755) y Schumpeter, J.A., (1934).

Durante largo tiempo, la iniciativa emprendedora se estudió, únicamente, desde una perspectiva económica; sin embargo, incluso las definiciones adoptadas por los economistas, están imbuidas de elementos procedentes de otras perspectivas, lo que responde a una realidad más compleja, a la que se ve avocado, conceptualmente, cada autor. 
Una de las clasificaciones sobre los estudios del emprendedor más difundidas, es la de Fillion, L.J., (2003). Indagando sobre los distintos estudios hechos sobre el emprendedor descubre que son los economistas los primeros en abordarlo y siempre vinculándolos a la innovación. Le siguen los psicológicos, en concreto los conductistas, que tratan de comprender la conducta emprendedora, alejándose de modelos de cuantificación estricta, insuficientes para explicar el surgimiento de los emprendedores.

\section{Cuadro 1.3: Líneas de investigación en el campo del emprendimiento}

\begin{tabular}{|l|l|}
\hline$>$ & Características del comportamiento de los emprendedores. \\
\hline$>$ & Características económicas y demográficas de las PYME. \\
\hline$>$ & Emprendimiento y PYME en los países en desarrollo. \\
\hline$>$ & Características directivas de los emprendedores. \\
\hline$>$ & Proceso emprendedor. \\
\hline$>$ & Creación de empresas. \\
\hline$>$ & Desarrollo de empresas. \\
\hline$>$ Capitales de riesgo y financiamiento de la PYME. \\
\hline$>$ Gestión de empernas, revitalizaciones, adquisiciones. \\
\hline$>$ Empresas de alta tecnología. \\
\hline$>$ Estrategia y crecimiento de la empresas emprendedora. \\
\hline$>$ Alianza estratégica. \\
\hline$>$ Emprendedor corporativo o intra-emprendedor. \\
\hline$>$ Empresas familiares. \\
\hline$>$ Trabajo autónomo. \\
\hline$>$ Incubadoras y sistemas de apoyo al emprendedor. \\
\hline$>$ Redes. \\
\hline$>$ Factores que influyen en la creación y el desarrollo de empresas. \\
\hline$>$ Políticas gubernamentales y creación de empresas. \\
\hline$>$ Mujeres, grupos minoritarios, étnica y empresariado. \\
\hline$>$ Educación emprendedora. \\
\hline$>$ Investigación en emprendimiento. \\
\hline$>$ Estudios culturales comparativos. \\
\hline$>$ Empresariado y sociedad. \\
\hline & \\
\hline & Franquicias. \\
\hline
\end{tabular}

La visión económica se basa en cálculos matemáticos para optimizar el beneficio, lo que conduce a que el emprendedor no quepa en ninguno de ellos, dado que la iniciativa no es una variable que se pueda cuantificar (Baumol, W.J., 1968). Este autor critica esta concepción, pues entiende que la verdadera esencia del emprendedor debe explicarse por la concurrencia de factores tales como las motivaciones, aptitudes y cultura del mismo, ya que se trata de una persona y no de una cifra o un porcentaje en un balance o estadística. 
Yamada, G., (2004), defiende que el estudio del emprendedor debe hacerse desde tres niveles que varían en base al énfasis otorgado a los distintos factores internos y externos vinculados al crecimiento de las organizaciones: el micro, medio y macro.

En el nivel macro incluye todos los estudios que tratan de identificar los factores del entorno y que inciden en el surgimiento de los emprendedores. Identifica características culturales de los distintos grupos locales que contribuyen al crecimiento económico.

En el nivel medio engloba todos los estudios basados en el crecimiento organizacional, a través de la adquisición, acumulación y distribución de recursos, vinculando el éxito o fracaso de las empresas a las estrategias de combinación de recursos internos y externos. Asume que el dominio de los recursos es un prerrequisito para el nacimiento y desarrollo empresarial, siendo clave, en este sentido, el papel tanto del fundador- emprendedor como del gestor empresarial en la optimización y utilización innovadora de los mismos,

El nivel micro aborda el estudio del emprendedor desde un prisma psicológico y sociológico.

Hébert, R. y Link, A. (1988) concluyen en la existencia de dos concepciones sobre el término emprendedor, una estática y otra dinámica. La concepción estática, hace referencia al concepto que tienen algunos economistas al considerar que la función principal del empresario es la aportación de capital, junto con la supervisión de los medios de producción, relegando a un segundo plano la función organizativa y de control, amén de la asunción de riesgo que conlleva la creación de una empresa.

Veciana, J.M., (2007) establece que, conforme a esta visión estática, cabría pensar que las empresas funcionan, por sí solas, ya que la única función del empresario emprendedor sería, única y exclusivamente, la aportación de capital, suministrando a los trabajadores maquinaria, herramientas, materias primas y salarios, para, en justa compensación a la aportación de capital, recibir los beneficios que genera el proceso productivo. No faltan autores que consideran que estas teorías de la concepción estática son incapaces de explicar la evidente paradoja de que existiendo un vacío en el 
mercado, no todas las personas decidan convertirse en empresarios, abandonando la seguridad de un trabajo, las oficinas de desempleo, o un seguro puesto de funcionario.

A mayor abundamiento, en diferentes culturas los empresarios actúan movidos por diferentes motivaciones: es más, dichas diferencias no pueden atribuirse necesariamente a factores económicos, tales como los recursos naturales, el capital, etc., pues estos elementos son idénticos en la mayoría de países y culturas, (Palmer, M., 1971).

Para entender tales diferencias, algunos autores estiman que deben tenerse en cuenta otros elementos como la ideología, las normas y las recompensas a un comportamiento adecuado, las aspiraciones colectivas e individuales, las aspiraciones religiosas, etc.

Desde esta visión estática, la consideración del empresario se reduce a algo que ya ha hecho. En consecuencia, no conciben la aparición de nuevos empresarios, ni el modo de incentivar dicha aparición.

Stevenson, H., Grousbeck, M. J. Roberts, and A. V. Bhide., (1999) tratan de definir al emprendedor y distinguirlo de los otros empresarios, analizando únicamente las funciones de carácter económico que desarrolla, haciendo más un ejercicio semántico que una dedicación práctica.

La concepción dinámica admite, sin lugar a dudas, la intervención de factores demográficos, psicológicos y sociológicos en la actitud emprendedora.

Siguiendo otro enfoque, Cunningham, B. Lischeron, J. (1991) clasificaron el estudio del emprendedor en seis escuelas de pensamiento, en las que analizan las diferentes fases del emprendimiento, a las que relacionaron determinadas conductas propias del emprendedor. Es un enfoque muy psicológico, centrado en la conducta, que deja al margen lo sociológico y económico. 


\section{Cuadro 1.4: Los acercamientos en el estudio del emprendedor según Cunnigham y Lischeron (1991).}

\begin{tabular}{|c|c|c|c|c|}
\hline $\begin{array}{c}\text { Modelo } \\
\text { emprendedor }\end{array}$ & Modelo emprendedor & Asunción & $\begin{array}{l}\text { Conductas y } \\
\text { habilidades }\end{array}$ & Situación \\
\hline $\begin{array}{l}\text { Escuela de la } \\
\text { "Gran Persona" }\end{array}$ & $\begin{array}{l}\text { El emprendedor posee una } \\
\text { habilidad intuitiva- un } \\
\text { sexto sentido- y rasgos e } \\
\text { instintos que nacen con } \\
\text { él/ella. }\end{array}$ & $\begin{array}{l}\text { Sin esta intuición } \\
\text { innata el individuo } \\
\text { sería como el resto } \\
\text { de los mortales. }\end{array}$ & $\begin{array}{l}\text { Intuición, vigor, } \\
\text { energía, persistencia } \\
\text { y autoestima. }\end{array}$ & $\begin{array}{ll}\text { Inicio del } \\
\text { negocio. }\end{array}$ \\
\hline $\begin{array}{l}\text { Escuela de las } \\
\text { características } \\
\text { psicológicas }\end{array}$ & $\begin{array}{l}\text { El emprendedor posee } \\
\text { valores únicos, actitudes y } \\
\text { necesidades que le } \\
\text { orientan. }\end{array}$ & $\begin{array}{l}\text { Las personas se } \\
\text { comportan de } \\
\text { acuerdo con sus } \\
\text { valores; la conducta } \\
\text { es el resultado de los } \\
\text { intentos de satisfacer } \\
\text { las necesidades. }\end{array}$ & $\begin{array}{l}\text { Valores personales, } \\
\text { propensión al riesgo, } \\
\text { necesidad re de } \\
\text { realización, entre } \\
\text { otros. }\end{array}$ & $\begin{array}{l}\text { Inicio } \\
\text { negocio. }\end{array}$ \\
\hline Escuela Clásica & $\begin{array}{l}\text { La característica central de } \\
\text { la conducta emprendedora } \\
\text { es la innovación. }\end{array}$ & $\begin{array}{l}\text { El aspecto crítico el } \\
\text { emprendimiento está } \\
\text { en el proceso de } \\
\text { hacer en lugar de } \\
\text { poseer. }\end{array}$ & $\begin{array}{l}\text { Innovación, } \\
\text { creatividad } \\
\text { descubrimiento. }\end{array}$ & $\begin{array}{l}\text { Inicio } \quad y \\
\text { crecimiento del } \\
\text { negocio. }\end{array}$ \\
\hline Escuela gerencial & $\begin{array}{l}\text { Los emprendedores son } \\
\text { organizadores de un } \\
\text { emprendimiento } \\
\text { económico, son du3ños, } \\
\text { quienes organizan, } \\
\text { gerentes y asumen el } \\
\text { riesgo. }\end{array}$ & $\begin{array}{l}\text { O emprendedores } \\
\text { pueden } \\
\text { desarrollados ser } \\
\text { entrenados } y \\
\text { funciones técnicas y } \\
\text { gerenciales. }\end{array}$ & $\begin{array}{l}\text { Planteamiento y } \\
\text { organización de } \\
\text { producción, } \\
\text { personas capital y } \\
\text { presupuesto. }\end{array}$ & $\begin{array}{l}\text { Crecimiento y } \\
\text { madurez del } \\
\text { negocio. }\end{array}$ \\
\hline $\begin{array}{l}\text { Escuela del } \\
\text { liderazgo }\end{array}$ & $\begin{array}{l}\text { Los emprendedores so } \\
\text { líderes, poseen la habilidad } \\
\text { de adaptar su estilo a las } \\
\text { necesidades de las } \\
\text { personas. }\end{array}$ & $\begin{array}{l}\text { Los emprenderos no } \\
\text { pueden conseguir sus } \\
\text { metas sin las demás } \\
\text { personas. }\end{array}$ & $\begin{array}{l}\text { Motivación, } \\
\text { dirección y lidera }\end{array}$ & $\begin{array}{l}\text { Crecimiento y } \\
\text { madurez del } \\
\text { negocio. }\end{array}$ \\
\hline \multicolumn{5}{|c|}{ Fuente Rao (2004, p. 62) } \\
\hline
\end{tabular}

Haciendo una clara referencia a la necesidad de abordar el estudio del emprendedor desde enfoque más sociocultural, encontramos a Putman, R. (1995) cuando afirma que "La viabilidad económica y política de una sociedad no es posible sin la asunción práctica, por parte de una mayoría de sus ciudadanos, de unos valores éticos fundamentales”, Lo que le lleva a afirmar que, “... no podemos entender el desarrollo de una sociedad sólo en términos económicos, aunque a menudo únicamente se aplique este criterio de medida, porque la misma viabilidad económica sólo es posible si está asociada (por parte de los actores sociales) al cultivo de valores sociales, culturales, medioambientales y éticos" (Putman, R., 1995) 
Pero ésta, no es una visión nueva. Ya a finales del siglo XIX, otros autores ajenos al campo económico, abordaron esa idea del emprendedor. El primero fue el sociólogo Max Weber (1985). En La Ética Protestante y el Espíritu del Capitalismo intentó demostrar la relación causal entre el ascetismo calvinista y la empresa capitalista moderna. Entendía por empresa una acción que persigue fines de una determinada clase de un modo continuo. Incluyendo en ella actividades de toda índole (políticas, privadas y públicas, mercantiles...) siempre que se le de continuidad en sus fines.

Identificó el espíritu del capitalismo en el ascetismo calvinista de los siglos XVI y XVII surgido en los piases Bajos, Francia, Inglaterra y Estados Unidos en el que centró su atención. El ascetismo intramundano del protestantismo actuaba con la máxima pujanza contra el goce despreocupado de la riqueza, contra su uso irracional. El tipo ideal del empresario capitalista de Weber, nada tiene que ver con el ricachón vulgar, al que aborrece, la ostentación, el lujo inútil, ni tampoco con el capitalismo medieval que se nutre del préstamo usurario para realizar el comercio colonial y esclavista, o el comercio bursátil especulativo. Lo que caracteriza al capitalismo moderno es la empresa duradera y racional, la técnica racional, el cálculo, el derecho racional y la ética protestante.

Weber distingue entre el empresario "tradicional" ubicado en el modelo tradicional de vida de las empresas tradicionales, con el empresario industrial, educado en la dura escuela de la vida, prudentes y arriesgados a la vez, sobrios y perseverantes, entregados de lleno y con devoción a su causa, con concepciones y principios éticos. Este tipo de empresario se encuentra ligado al concepto luterano de profesión, aquella que el hombre acepta por providencia, como misión impuesta por Dios. El calvinismo plantea la idea de que el hombre es sólo administrador de los bienes que Dios le ha otorgado. De este criterio deriva la palabra "profesión" en el sentido de vocación, de predestinación.

Según Weber una de las realizaciones específicas del protestantismo consiste en haber puesto la ciencia al servicio de la técnica y de la economía. Otro elemento del capitalismo moderno, lo constituye la empresa mercantil, que tiene elementos constitutivos en actos contractuales establecidos en la ley del negocio jurídico de que se trate, y por otra, la pertenencia objetiva a la profesión mercantil, y no como ocurría en el 
pasado, con la pertenencia a un estamento social constituido jurídicamente por unión o privilegio. Defiende la administración burocrática como más racional en precisión, continuidad, disciplina, rigor, confianza, y calculabilidad. A pesar de ello, el empresario capitalista, es realmente la única instancia inmune, al menos relativamente, a la ineludibilidad de la dominación científico-racional de la burocracia (weber, M., 1985).

Weber identificó el sistema de valores sociales como clave a la hora de explicar el comportamiento. Veía a los emprendedores como innovadores, personas independientes que poseían una fuente de autoridad formal debido al rol que ejercían como dirigentes de sus empresas.

Este razonamiento sociológico es revisado posteriormente por autores como Schumpeter, J., (1961), quien al cuestionar la teoría de la explotación de Marx subraya que, en una economía de competencia perfecta, los beneficios de la explotación inducirían a los capitalistas a expandir la producción. $\mathrm{Su}$ principal aporte es la concepción cíclica e irregular del crecimiento económico. Desarrolla, también, su teoría del Unternehmergeist o espíritu emprendedor, derivada de los empresarios, que crean innovaciones técnicas y financieras en un medio competitivo en el que deben asumir continuos riesgos y beneficios que no siempre se mantienen. Lo que le lleva, en otro momento a afirmar que, "... el héroe de este fenómeno es el emprendedor" (Schumpeter, J., 1961),

Estos pensadores resaltan la influencia que tiene en el emprendedor tanto la situación de desarrollo social como la situación económica, en un determinado contexto, llevando al mismo Schumpeter, J.A., (1961), a afirmar que "La estabilidad económica no implica ni las garantías del sistema político ni la estabilidad social, por lo que una situación económicamente estable puede darse en un marco políticamente inestable”.

Desarrollando estos conceptos. Donaldson, T. y Dunfee, T.W., (1985), depositarán en los valores éticos de la población la viabilidad económica y política de toda comunidad. Así la integridad, la responsabilidad, el respeto a las leyes y reglamentos, el respeto por los derechos de los demás ciudadanos, el amor al trabajo, el esfuerzo por la inversión, el deseo de recuperación, e incluso la puntualidad, son claves para activar el desarrollo socioeconómico de toda sociedad. 
Ahondando en este pensamiento, Fukuyama, F., (1995) defiende que la confianza en la economía es la expectativa que surge en una comunidad con un comportamiento ordenado, honrado y de cooperación, basándose en normas compartidas por todos los miembros que la integran.

Estas normas pueden referirse a cuestiones de valor profundo, como la naturaleza de la justicia, pero engloban también las normas deontológicas y profesionales y códigos de comportamiento, incluso llega a afirmar que para que un país pueda adaptarse correctamente a un mundo globalizado, es fundamental que su gente tenga confianza en las instituciones. Entiende que la economía debe funcionar sobre valores éticos y debe abrírsele paso al capital social para que la fuerza laboral participe en forma más completa y adecuada en el proceso productivo. "Aquellas sociedades de abundante capital social tienen una gran ventaja para adoptar estas nuevas formas y estructuras empresariales, que requieren de un alto grado de confianza en una economía que funcione sobre valores éticos." (Fukuyama, F., 1995).

Vemos pues, interpretaciones, modelos y clasificaciones muy distintas en el estudio del emprendedor, que responden a las diferentes líneas de pensamiento u objetivos específicos de investigación perseguidos por cada autor. Esta multidisciplinariedad en este campo de estudio es reconocida por diferentes autores (Chell, E., 2000; Mitchell, R. K., Busenitz, L. W., Bird, B., Marie Gaglio, C., McMullen, J. S., Morse, E. A., y Smith, J.B., 2007; Gutiérrez, P. et al., 2009). Chell, (2000) entiende, de hecho, el desarrollo de la interdisciplinariedad del conocimiento del comportamiento emprendedor, en el que centra sus investigaciones, como un nuevo enfoque para la investigación.

No estaría completo nuestro análisis, si solamente al referirnos al emprendedor la actividad de éste concluyera, necesariamente, en un proyecto empresarial, que acabaría o no gestionando. Si asumimos que emprendedor es también aquella persona que innova, que investiga, desarrolla sistemas, herramientas o participa en el desarrollo creativo de proyectos, nos vemos obligados a incluir en nuestra definición al llamado intraemprendedor, llamado por otros emprendedor cooperativo, que al tiempo que contribuye a la mejora y desarrollo de organizaciones ya existentes, da origen, por 
ejemplo, a fenómenos como los Spin -off, tomando como referencia la espiral de la innovación frente al modelo lineal tradicional, estableciendo relaciones recíprocas entre universidad y empresa. Las empresas Spin -off surgen de los emprendedores de las universidades, y ayudan a transferir el conocimiento y la investigación científica al mundo empresarial, buscando su aplicación directa en los procesos productivos, incluso en su comercialización.

Estas reflexiones justifican nuestro interés por esta línea de investigación, los valores y la personalidad emprendedora, tanto para abordar nuevos proyectos (emprendimiento) como para impulsar y desarrollar los ya existentes (intraemprendimiento).

\section{El concepto de emprendedorismo}

$\mathrm{Al}$ igual que al término emprendedor, al de emprendedurismo se le han atribuido diferentes definiciones; ello debido a las mismas razones exhibidas para el término emprendedor. Con lo cual, corresponde idéntico desafío darle una definición.

Podemos encontrar en la literatura científica autores que definen el concepto cono una conducta (Kyrö, P. y Carrier, C., 2005; Ajzen, I. y Fishbein, M. ,1980; Minniti, M., y Lévesque, M. ,2008). Quienes lo entienden como un proceso (Cromie, S. y Johns, S, 1983; Yamada, G. 2008), e, incluso, como una manera de pensar (West, G. P., 2007; Zhao, H., Hills, G. E. y Seibert, S. E., 2005).

La primera de las líneas de definición aparece en Kyrö, P. y Carrier, C. (2005). Un examen pormenorizado de sus argumentos nos lleva a concluir que relaciona el emprendedorismo con acciones innovadoras, y de modo más concreto, a nuevas formas de conducta; en todo caso, referidas al ámbito empresarial. En opinión de esta autora, hay varias y diferentes formas de emprender. La primera se refiere al emprendedurismo fuera de las organizaciones, y la segunda dentro de las mismas. Lo que parece aludir a la conducta individual y a la colectiva. Aunque suele ser una persona quien asume la acción de emprender, tratándose, por tanto, de un fenómeno individual, la organización 
es siempre colectiva. Así, identifica diferentes formas de emprendimiento que pasamos recoger;

\title{
Cuadro 1.5. Formas de emprendimientos identificadas por Kyrö
}

\author{
El emprendimiento tradicional \\ (Se refiere al individuo tradicional y a la empresa). \\ El intra-emprendimiento \\ (Se refiere a la conducta colectiva dentro de las organizaciones. \\ El emprendimiento auto-orientado, individual \\ (Se refiere a la conducta auto -orientada del individuo).
}

Fuente; Kyrö , 2005

Fundamenta su análisis en los cambios en el entorno cultural y económico en los diferentes momentos históricos y cómo éstos han provocado significativos cambios de conducta, también, en los emprendedores, pasando de acometer viejos hábitos y jerárquicas instituciones a conductas más arriesgadas e innovadoras. Pone de manifiesto cómo el emprendimiento ha generado nuevos conceptos en cada momento histórico, por entrar en conflicto con formas de actuar y modelos pasados. Cuando hay necesidad de cambios en la conducta de los emprendedores, motivados por los cambios del entorno en el que operan, el emprendimiento, la forma concreta de emprender, pasa a tener un nuevo significado (Kyrö, P. y Carrier, C., 2005).

La idea del emprendedorismo siempre vinculada a la función empresarial es defendida por autores como Yamada, G., (2004), quien propone, a su vez, una visión multidimensional del término. Enfatiza en la necesidad de que concurran variables individuales y contextuales para que surja el emprendimiento. Afirma que la actividad emprendedora o "el acto de crear negocio" es un proceso diacrónico basado en diferentes decisiones y acciones, donde hay innovación, asunción de riesgo, explotación de oportunidades de negocio, proactividad, participación en redes sociales amplias y la creación de un equipo que participe en la puesta en marcha del negocio.

Muchos autores hablan del llamado emprendimiento, aludiendo al proceso de creación de valor generado al aplicar una serie de recursos que permiten aprovechar una oportunidad. Comprendería desde las acciones destinadas a identificar oportunidades, a asumir riesgos, a implementar nuevos negocios y/o dirigirlos (Hurtado, N.E., Cordón E., Senise, M.E., 2007; Acs, Z., Braunerhjelm, P., Audretsch, D., y Carlsson, B., 2009), 
de modo que englobaría aquellos actos de innovación, renovación o creación organizacional que puedan darse tanto fuera como dentro de una organización ya existente (Sharma, P., Chrisman, J.J., 1999). Así, podemos considerar al emprendedor como un agente que busca identificar nuevas oportunidades a través de la innovación y la creatividad (Schumpeter, J. 1934).

Cromie, S. y Johns, S. (1983), dan un paso más defiendo al emprendedurismo como un proceso que habitualmente se orienta a la creación de nuevos negocios, desde una óptica claramente economicista.

Vesalainen, J. Y Pihkala, T. (1999), definen el emprendedurismo como un proceso de creación de negocios que incluye varias etapas: anterior al inicio o de percepción de oportunidades de mercado por parte del emprendedor, etapa de crecimiento y etapa de madurez.

Korunka, C., Frank, H., Lueger, M. Y Mugler, J. (2003), identifican el emprendimiento con el acto de crear nuevos negocios, un ejercicio complejo y dinámico que conlleva numerosas decisiones y actividades preparatorias. En la misma línea se define Wood, J. S., (2005), quien argumenta que el "emprendimiento consiste en la creación de una oportunidad anteriormente no percibida y la realización de la acción para tornarla realidad", aludiendo al objeto que el emprendedor pretende alcanzar, a la generación de una situación futura alternativa.

Hills, G., Lumpkin, T., y Singh, R. (1997), no dejan de señalar que el emprendedurismo debe considerarse como un proceso, cuyos elementos fundamentales son: el emprendedor, su búsqueda incesante de oportunidades, habitualmente relacionadas con el mercado, y un esfuerzo determinante para ordenar los recursos destinados a aprovechar esas oportunidades. Respondería a una consecución de esfuerzos que tiene el objetivo básico de formar una nueva empresa, identificando, así, el emprendedorismo con conducta emprendedora: son las acciones del emprendedor las que conducen a la creación del nuevo negocio. 
Por su parte, Shane, S. y Venkataraman, S., (2000), definen el concepto como el proceso mediante el cual las oportunidades de crear futuros productos y servicios, son descubiertas, evaluadas y aprovechadas.

Definir el emprendimiento es todo un desafío para los investigadores, pues son muchas las perspectivas de análisis que encontramos, aunque la mayoría acaban relacionando el acto de emprender con la creación, fundación y/o adaptación del negocio para que éste tenga éxito, tal como manifiesta Krueger, N. ,(2004). La autora, afirma que el emprendimiento empieza antes de crearlo, incluyendo en dicha acción otras, como la búsqueda de oportunidades, o la viabilidad en el entorno de la idea. Entiende el emprendimiento como un proceso con diferentes etapas, que vincula a la estrategia empresarial, en el que el emprendedor tiene que ejecutar conductas que le exigen determinadas capacidades. Resume dicho proceso señalando una primera etapa de desarrollo, donde se define la idea de negocio, una de búsqueda y configuración de recursos necesarios para ponerla en marcha, la implementación y, finalmente, la supervivencia y crecimiento del negocio. La siguiente figura ilustra el proceso;

Figura 1.1: El proceso emprendedor según Krueger

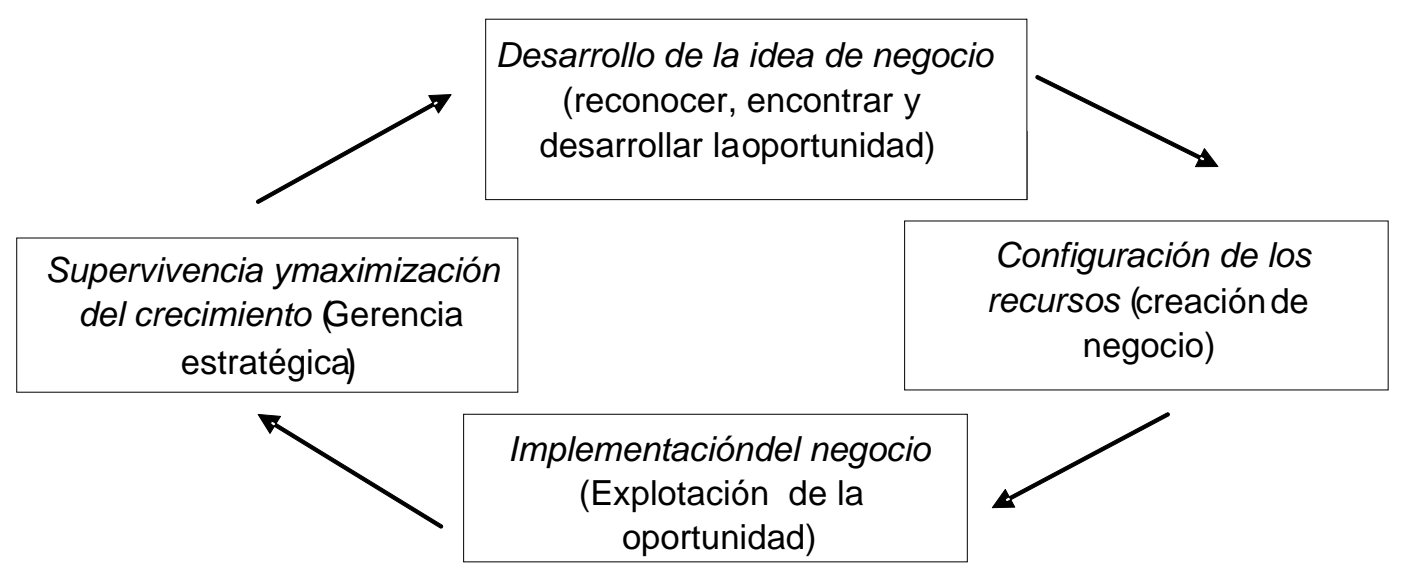

Fuente: Krueger (2004, p. 46)

Para la autora, el principal elemento del emprendimiento es el emprendedor. De hecho, asume que la función del emprendedor es, precisamente, emprender. Es la predisposición del individuo a actuar quien activa la acción de emprender, constituyendo ésta, un proceso a realizar en diferentes etapas. 
Otros autores consideran la acción de emprender y lo que ello conlleva, como un modo de pensar. Así opinan, esta es la concreta opinión de Bouckenooghe, D., Van den Broeck, H., Cools, E. y Vanderheyden, K., (2005), para quienes el emprendedurismo no es únicamente un tipo especial de actividad económica, también, y por añadidura, un cierto modo de pensar. Un estilo y tipo de conducta.

En este mismo plano cognitivo situamos a Mitchell, quien entiende el emprendimiento como las oportunidades de mercado creadas por individuos, que se diferencian de quienes no las crean. Asumen el reto de buscar y organizar recursos para montar organizaciones donde explotar estas oportunidades (Mitchell, R. K., et al., 2007).

Por otra parte no faltan en la literatura científica autores con una postura ecléctica que admiten un concepto mixto, conducta-proceso, tales como Palich, L. y Bagby, D. (1995). Concluyen que el emprendedurismo sería una conducta compartida en diferentes etapas de un proceso.

Cierto es que este campo de investigación ha crecido notablemente. Continuamente encontramos nuevas teorías y definiciones que se solapan, e incluso contradicen, produciendo cierta confusión sobre lo que es y no es el emprendedor, y el propio emprendizaje. En este sentido, Parker, S.C., (2006) propone clasificar los modelos teóricos explicativos del emprendizaje, en base a si éstos cuentan o no con suficiente apoyo empírico. Así distingue diferentes teorías en su estudio, aunque no aclara los criterios en su elección;

\section{Cuadro 1.6: Contenidos del emprendimiento según la investigación de Parker.}

\begin{tabular}{|c|l|}
\hline 1 & $\begin{array}{l}\text { Ejercicio de liderazgo, motivación y habilidad para resolver crisis (Leibenstein, } \\
\text { 1968). }\end{array}$ \\
\hline 2 & $\begin{array}{l}\text { Enfrentar las incertidumbres y obtener ganancias (Cantillon, 1755); y comercializar } \\
\text { para obtener ingresos sin riesgo (Knight, 19821). }\end{array}$ \\
\hline 3 & Empezar, mantener y desarrollar un negocio orientado a la ganancia (Cole, 1968). \\
\hline & $\begin{array}{l}\text { Explotación y juicio de oportunidades para abastecer el mercado de los recursos } \\
\text { que faltan (Kirzner, 1985) - posiblemente en una dimensión geográfica (Reynolds, } \\
\text { Storey y Westhead, 1994), y posiblemente involucrando la explotación de capital } \\
\text { financiero, social y humano (Parker, 2000; Gómez y Santor, 2001; Cressy, 1996). }\end{array}$ \\
\hline 5 & Innovación (Schumpeter, 1934). \\
\hline
\end{tabular}


6 Creación de una nueva empresa (Low y MacMillan, 1988).

Combinar factores de producción, incluyendo labor contratada (Say, 1828;

7 Schumpeter, 1934).

Fuente: Parker, 2006

La aportación más significativa que podemos destacar en él es su visión multidimensional del fenómeno, no ciñéndolo, estrictamente, como hacen la mayoría de los autores, a la propia creación de negocios.

En definitiva, la innovación, la flexibilidad competitiva y la generación de empleo son considerados elementos clave del desarrollo económico, por lo que el emprendimiento queda configurado como un eje básico de dicho crecimiento, (Gómez, S., Delgado, J. y Vidal M.D., 2010).

\subsection{3.- CONCLUSIONES}

El emprendedor y el emprendimiento son objeto de estudio en diferentes campos científicos y desde prismas muy distintos. En su estudio encontramos resultados dispares, sin consenso suficiente para perfilar definitivamente un concepto unívoco, de común aceptación. Independientemente de si es concebido como un proceso, una conducta o una forma específica de pensar, no podemos ceñir su estudio al individuo o colectivo que ejecuta la acción de emprender, pues a éste le influyen, a su vez, factores socioculturales y de entorno como estructuras económicas, aspectos tecnológicos, redes y alianzas, valores culturales, etc.

Es un fenómeno multidimensional en el que actúan multitud de aspectos, pero todos ellos giran en torno a quien ejecuta la acción; al emprendedor.

Hay diferentes tipos de emprendimiento, pero lo que básicamente les caracteriza es la acción de crear negocios, por lo que se trata de un fenómeno vinculado a la innovación y al desarrollo económico. Se trata, pues, de un fenómeno de importante relevancia social y económica, y como tal debe ser abordado. 
Son muchas los enfoques que encontramos en su estudio, pero todas las clasificaciones pueden ser agrupadas en tres grandes corrientes: la psicológica, la sociológica y la económica, donde incluimos la función gerencial del emprendedor.

Sobre estas premisas, y teniendo presentes todos las aportaciones, resumen de la revisión bibliográfica desentrañada en las precedentes páginas, abordamos nuestro estudio del emprendedor, tratando de encontrar enfoques teóricos que nos ayuden a delimitar una definición propia del mismo, así como una delimitación clara del emprendedorismo.

De todas estas perspectivas de estudio que se postulan como explicación de la actividad emprendedora, la psicosocial es la que, entendemos más nos ayuda a comprender este fenómeno. Ésta afirma que en la configuración de la personalidad emprendedora, el emprendedor tiene rasgos diferenciales de personalidad, algunos innatos y otros socialmente aprendidos, juega un papel decisivo la sociedad a través de la incidencia de pautas sociales y factores culturales sobre la persona. Aparece así la cultura como potenciadora de la intención de emprender. Centraremos nuestro análisis, por tanto, en delimitar el influjo de algunas variables individuales y culturales (los valores) en la intención de llevar a cabo y mantener actividades innovadoras y de emprendizaje.

\section{2.- EL ESTUDIO DEL EMPRENDEDOR}

Abordaremos el estudio del emprendedor siguiendo la clasificación de Kyrö, P. y Carrier, C. (2005), y sus tres grandes categorías de análisis: la económica, la sociológica y la psicológica, por ser ésta la más aceptada en el mundo académico (Djankov et al. 2006; Soriano Montero, 2008), y lo haremos siguiendo este mismo orden.

Así, ya hemos visto cómo la perspectiva económica centra el estudio del emprendedorismo basándolo en la racionalidad económica. Este enfoque englobaba, tradicionalmente, tres grandes orientaciones: el de la llamada Teoría del Desarrollo 
Económico de Schumpeter, el de la Teoría de la Elección Ocupacional bajo Incertidumbre y el de la Teoría de los Costes de Transacción.

Nuevos enfoques en el estudio del emprendedor, otorgan también, un peso significativo al influjo de aspectos ambientales y espaciales en la actividad económica (Economía Geográfica), e incluso a aspectos culturales, sociales e institucionales (Giro cultural). Expondremos, brevemente, sus contenidos básicos.

La perspectiva sociológica, por su parte, apunta que la decisión de emprender está mediada por factores del entorno social. Elementos socioculturales y el propio marco institucional, en cada lugar y momento, influyen en la acción de emprender. Son cinco las orientaciones teóricas más significativas en este enfoque; La Teoría del Desarrollo Económico de Weber, la Teoría de la Marginación, la Teoría del Rol, la Teoría de Redes y la Teoría Institucional, sin desdeñar quienes establecen en los factores demográficos la clave explicativa de la acción emprendedora.

La perspectiva psicológica, finalmente, será abordada a través de sus tres grandes orientaciones de estudio: La de la Teoría de los Rasgos de Personalidad, la Teoría Cognitiva y el Enfoque de la Conducta.

\subsection{1.- LA PERSPECTIVA ECONOMICA}

Tradicionalmente, desde la perspectiva económica, el trato que recibía el emprendedor (empresario) respondía más a una visión estática e incluso superficial, pues se consideraba que éste sólo debía dar respuestas de orden macroeconómico; es decir, aportar capital sin tener en cuenta cuestiones de funcionamiento interno de la empresa, ni el papel configurador que ejerce el empresario dentro de ésta. Esta visión estática del emprendedor ha cambiado hacia una visión más dinámica e integradora, recogida por la perspectiva psicosocial, que se centra más en las características globales del individuo y la naturaleza y los factores que condicionan la actividad emprendedora, en la interacción entre individuos y entre individuos y medio. 
Es justo reconocer a Cantillón, R., (1755) el mérito de ser el primer autor en introducir el concepto de emprendedor en la literatura económica; bien es verdad que en compañía de Say. Entendía al emprendedor-empresario como aquel que trabaja por su cuenta y riesgo. En este sentido los emprendedores jugaban un importante papel en el funcionamiento de la economía, como suministradores de productos y servicios, incluso interactuando en la fijación de los precios y la regulación del mercado. Muestra al emprendedor como un individuo enfrascado en la búsqueda de oportunidades de negocio, combinando una gestión eficaz y racionalizada con la minimización del riesgo.

Say, J.B., (1803), entiende al emprendedor como agente económico que actúa en los más diversos sectores productivos, para generar productos y servicios destinados al mercado. Mediante un proceso que comienza con el análisis de lo que va a producir, para continuar con el arbitraje de los medios necesarios para crear el producto, y finalizar con la gerencia de la producción. No sería, pues, el emprendedor, más que el que trabaja por cuenta propia.

Filion, L. J., (2003), considera que para Say, el emprendedor no era más que un innovador, un agente de cambio en definitiva, y por lo tanto algo diferente a un capitalista.

No sólo los economistas clásicos se preocuparon por el emprendedorismo. Para algunos, como Peacock, R. (2000), fue el economista alemán Joseph Schumpeter el verdadero creador de la figura del emprendedor. Recoge cómo Schumpeter definió el emprendedor como un innovador que introducía cambios en los sistemas económicos. En la asociación emprendedor-innovación, la columna vertebral de la teoría del emprendedor, Schumpeter estima que el emprendedor maneja recursos de una manera innovadora, para crear algo nuevo, original. Distinguiendo meridianamente entre invención e innovación. El emprendedor toma invenciones elementales y las transforma en invenciones económicas. Crea nuevos recursos, en forma de nuevos productos, nuevos métodos de producción, abre nuevos mercados, crea nuevas organizaciones. Es una especie de motor de los cambios en el ámbito económico. Ésta, la teoría de Schumpeter, es conocida como la Teoría del desarrollo económico. Entiende que el desarrollo económico se basa en la creación de empresas, donde el emprendedor - 
innovador es el protagonista de tal acción provocando continuos cambios y ajustes en el sistema económico.

Schumpeter concibe el emprendedor como un aventurero, el constructor de un imperio, el líder que asume riesgos, "The hero of his story is the entrepreneur." (Schumpeter, J., 1961, p.96).

Baumol, W. J. (1990), entiende el emprendedor como un creador de negocios innovadores, una persona ingeniosa y creativa que encuentra la manera de añadir a su propia riqueza poder y prestigio.

Por su parte Kirzner, I. M. (1997) centra su concepto de emprendedor en la creación de oportunidades de beneficio, un creador de negocios, esencialmente, un tomador de decisiones. De la importancia de estas aseveraciones, dice mucho, la consideración que ha alcanzado Kirnzer, en la ciencia económica. Algunos Wood, J. S. (2005) lo consideran como el más grande teórico del emprendedorismo en los últimos 40 años.

Es Wood, J. S. (2005) el que formula un de las definiciones más completas, desde el campo económico:

"El emprendedor, más que asumir riesgos, es un visionario, un individuo que cree firmemente en sus posibilidades, en su habilidad para prever el futuro, confiando ciegamente en sus previsiones, sin pensar ni por asomo en el riesgo, aunque si en las oportunidades de negocio que tiene ante si”, (Wood, J. S., 2005, p.168).

En definitiva, el emprendedor diseña mentalmente la oportunidad, apuesta fuertemente porque su previsión es la correcta, sin pensar en que esté arriesgándose.

La Teoría de la Elección Ocupacional bajo Incertidumbre, por su parte, defiende que la decisión de convertirse en emprendedor la hace el individuo en base a la propensión y/o aversión al riesgo que éste posee. Defiende que todos los individuos 
son iguales aptitudinalmente hablando, y que el hecho de convertirse en emprendedores o trabajadores por cuenta ajena depende, básicamente, de la capacidad que posean para asumir riesgos.

Ésta, que parece una afirmación poco fundamentada, es matizada por Bygrave, W. y Hofer, C. (1991) quienes afirman que la elección de emprender está basada en la percepción de obtención de beneficios superiores pro parte del sujeto, en relación a otras actividades alternativas. Sobre la base de esta percepción subjetiva el individuo tomaría la decisión de emprender o no.

Picot, A., Laub, U. D., y Schneider, D., (1989) explican la acción emprendedora en base a los costes de transacción. Las empresas que tienen en cuenta estos costes a la hora de tomar decisiones sobre si integrar o no determinadas actividades o recursos suelen tener mejores resultados. Se trataría de una acción básica en el emprendedor que se erige como fundamento de la llamada Teoría de los Costes de Transacción.

Al margen de estos enfoques teóricos, el hecho de que el emprendedorismo tenga mayor o menor presencia en diferentes zonas, regiones, países,..., subraya la necesidad, dentro del ámbito económico, de abordar este hecho, intentado encontrar causas explicativas. Encontrar factores convincentes en este sentido ayudaría, notablemente, a trabajar en su fomento, por el papel fundamental que juega como activador básico de los sistemas económicos.

En este sentido, dentro de la economía ha adquirido mucho relieve el estudio de la llamada Economía Geográfica ${ }^{2}$, que incide en la necesidad de abordar de forma

\footnotetext{
${ }^{2}$ Rama de la ciencia económica que analiza las influencias ambientales y espaciales en el estudio de la actividad económica. Pretende descubrir la naturaleza no determinista de los procesos económicos, y el peso de la cognición del individuo y de su percepción ambiental en las decisiones que conforman el espacio económico. Asumen que hay diferentes geografías económicas fruto y/o resultado de diferentes colectivos humanos (en base a diferencias culturales, históricas, religiosas...). Sánchez Calderón (2009). Sus diferentes estudiosos, asumen, mayoritariamente que existen interferencias entre los distintos espacios económicos, que no están aislados unos de otros, por tanto, y que, básicamente, la geografía económica está integrada por las siguientes ramas de estudio;
} 
específica los entornos concretos, lo local, asumiendo que en él se dan factores diferenciales que inciden de forma directa en la estructura económica de cada región. Los enfoques posmodernistas y el realismo crítico, entre otros postulan la necesidad de volver al estudio de los casos regionales (Albertos, J.M, 2002). Este enfoque, según Cárdenas, G., (2008), recogería, en síntesis, las principales ideas de la teoría de la estructuración, el realismo y la recuperación de la escala de trabajo local y regional, que entiende que la especialización se puede restaurar y adaptar a los nuevos tiempos, tomando como referencia las características y recursos de cada región (Cárdenas, G., 2008).

Este enfoque asume que nada se repite de forma idéntica, que los entornos concretos tienen características específicas y su evolución histórica introduce elementos de diversidad significativos Estos elementos, aparentemente aleatorios, generan regularidades de base a sus sistemas que podrían ser estudiados a la luz de procesos generales de funcionamiento. Así, "Lo único debería ser entendido como la forma particular que a escala local adoptan procesos comunes globales" (Albertos, J.M. 2002, p.230).

Estos estudios completan sus análisis, de corte estrictamente económico, con aspectos culturales, sociales e institucionales, lo que han generado el llamado Giro Cultural, (Jamenson, F. ,1999; Barnes, J.H., 2001; Galindo, P., 2003). Tal como defiende Barnes (1995), en el estudio de las economías locales, crece el interés por descubrir el papel la cultura como resultado de la influencia del pensamiento posmoderno.

Cuadro 1.7. Contenidos de la Economía Geográfica

\begin{tabular}{|c|c|c|c|c|}
\hline Economía & Historia & Demografía & $\begin{array}{c}\text { Ciencias } \\
\text { de la Tierra }\end{array}$ & Política \\
\hline $\begin{array}{l}\text { Identifica y analiza } \\
\text { el proceso } \\
\text { productivo de bienes } \\
\text { y servicio destinados } \\
\text { a la satisfacción de } \\
\text { las necesidades } \\
\text { humanas. }\end{array}$ & $\begin{array}{l}\text { Facilita la } \\
\text { comprensión de los } \\
\text { procesos temporales } \\
\text { que configuran las } \\
\text { dinámicas } \\
\text { socioeconómicas. }\end{array}$ & $\begin{array}{l}\text { Aporta el análisis de } \\
\text { la dinámica } \\
\text { poblacional, en sus } \\
\text { dimensiones } \\
\text { individual y } \\
\text { colectiva. }\end{array}$ & $\begin{array}{l}\text { Permite conocer las } \\
\text { características de los } \\
\text { recursos naturaleza } \\
\text { y sus posibilidades } \\
\text { de uso por parte dela } \\
\text { sociedad. }\end{array}$ & $\begin{array}{l}\text { Analiza las } \\
\text { relaciones de poder } \\
\text { que giran alrededor } \\
\text { de la distribución y } \\
\text { acceso a los } \\
\text { recursos, bienes y } \\
\text { servicios. }\end{array}$ \\
\hline
\end{tabular}

Fuente elaboración propia, basado en Sánchez Calderón (2009) 
No todos los estudiosos de la llamada Economía Geográfica avalan estas ideas, Sayer, A., (1994) entiende que analizar los factores culturales nos separa de nuestro objeto básico de estudio en el campo económico, debiendo centrarnos en aspectos básicos de producción distribución y consumo. Otros como Rodríguez P. (2001) llegan incluso a afirmar que al tiempo que nos separan del estudio básico de la economía el llamado giro cultural podría incluso empobrecer empíricamente los estudios económicos relegando a segundo puesto la geografía económica dentro de las ciencias sociales.

Subraya Pinillos Costa, M.J. (2011) que el comportamiento económico, socialmente reconocido como racional, es fruto de unas condiciones económicas y sociales determinadas, y sólo relacionándolo con su génesis individual y colectiva cabe comprender las condiciones económicas y sociales de posibilidad de dicho comportamiento y, con ello, a la vez, la necesidad y los límites sociológicos de la razón económica y de unas nociones, aparentemente incondicionadas, (necesidades, cálculo, preferencias, ...) (Shapero, A., y Sokol, L.,1982).

En nuestro estudio, el Giro cultural, es una referencia conceptual. El papel que los factores culturales pueden tener en la promoción local de la innovación, el nexo entre cultura e innovación establecido a través de los procesos de aprendizaje colectivo, asumiendo que en la cultura local el conocimiento es generado, compartido y/o transmitido socialmente, constituye un punto de partida básico en el estudio del emprendedorismo.

"En la nueva economía de la información el aprendizaje es, probablemente, el proceso social más importante y el conocimiento se convierte en el recurso clave. Por eso, para entender la dinámica de crecimiento basado en la innovación, es preciso prestar una mayor atención a los factores del medio local que condicionan el aprendizaje y la gestión del conocimiento: esto es, la cultura." (Mariussen, A., 2001).

No muy alejado de este enfoque teórico podemos situar a Galindo, P. (2003) quien afirma que el crecimiento sostenido de un país se base, fundamentalmente, en la 
creación de riqueza que supone la acción emprendedora. La decisión de emprender no está únicamente mediada por las capacidades psicológicas del individuo, sino que las circunstancias socioeconómicas y culturales, así como la evolución del propio país, afectan a su capacidad emprendedora, y, por ende, comprometen su crecimiento económico.

Señala este autor, como significativamente importantes, una serie de factores de carácter socioeconómico, que a continuación enumeramos;

- La existencia de un clima favorable hacia el emprendedor, haciendo referencia al hecho de que este no sea percibido socialmente de forma negativa: acaparador, explotador, excesivo afán de lucro...;

- El entorno familiar y social en el que ha crecido y desarrollado su vida, y la existencia o no de otros emprendedores en ella, tendrá una especial significación a la hora de percibir el emprendizaje como opción.

- Vinculada a las dos anteriores, la cultura existente en el país: ésta es proclive o no a incorporar y asimilar avances tecnológicos, es abierta a nuevos mercados y adaptable a nuevos y cambiantes entornos. Si existe en ella una importante presencia de actividad empresarial.

- Los procesos de expectativas sobre la actividad económica del país. En contextos donde los resultados económicos son favorables y hay perspectivas de crecimiento, es previsible que aumenten los niveles de emprendizaje, tratando de aprovechar los emprendedores, oportunidades de mercado no explotadas. Destaca Galindo, P., (2003) la labor institucional como básica a la hora de facilitar la actividad empresarial, generando una percepción positiva hacia el emprendizaje.

- En un plano positivo y negativo, a la vez, por lo que supone la supresión de barreras de entrada y salida a los mercados, que posibilitan la libre circulación de personas y mercancías, competencia directa para el 
emprendedor, el sector exterior sería un elemento clave que afectaría, directamente, a la actividad emprendedora.

- Finalmente, señala, cómo la concurrencia de todos estos factores favorece la concentración empresarial en una zona concreta, facilitando la agrupación y coalianzas para la investigación, el desarrollo y la innovación empresarial. También puede provocar un efecto llamada a la inversión de compañías extranjeras, normalmente de gran tamaño, que pueden poner en serias dificultades o incluso provocar la desaparición de la pequeña y mediana empresa ligada al emprendedor.

La siguiente figura recoge su planteamiento, de forma resumida:

\section{Figura 1.2. Factores socioeconómicos y culturales que influyen en el emprendimiento}

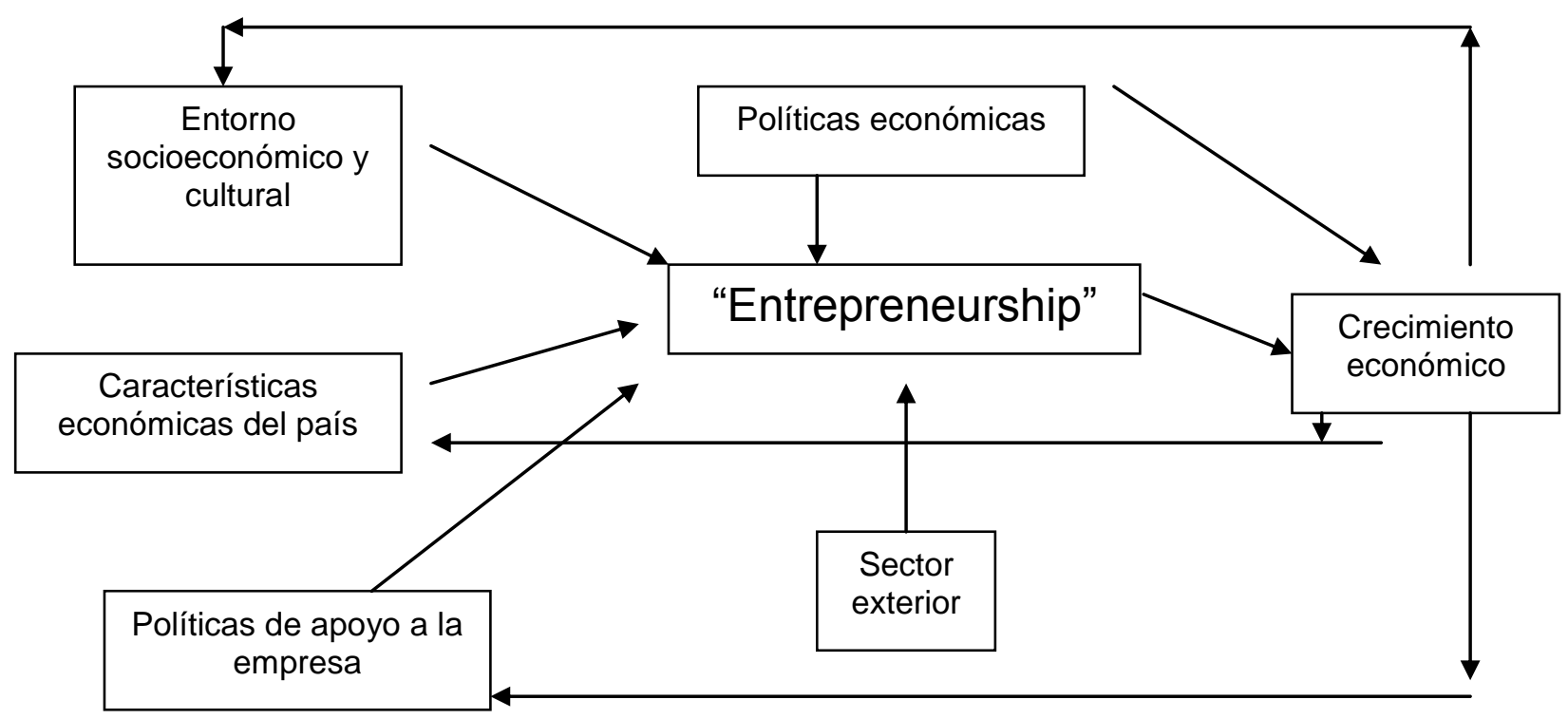

Fuente: Galindo, P., (2003)

Cierto es que todo crecimiento económico supone cambios en el propio sistema económico, cambios culturales y cambios en la propia sociedad.

Abordaré estos conceptos en las siguientes páginas del trabajo al objeto de identificar esos nexos de influjo entre los llamados factores culturales y la acción emprendedora. 


\subsection{2.- LA PERSPECTIVA SOCIOLOGICA}

El enfoque que desde la sociología se da al concepto de emprendedor, se cifra en reseñar que la conducta emprendedora se ve influenciada por el entorno social y los aspectos personales que están relacionados con él. Se aborda como un hecho social, centrando su interés, más que en el propio individuo (emprendedor), en todo lo que se mueve y gira en torno a él (emprendedorismo).

Max Weber, M., (1985), a través de su Teoría del Desarrollo económico fue el primer autor que, desde la óptica sociológica, aborda su estudio introduciendo la religión como una variable digna de ser tenida en cuenta para explicar el emprendedorismo. Considera que la influencia del contexto social, y más concretamente los valores sociales imperantes, condicionan el espíritu emprendedor.

Kyrö, P., y Carrier, C., (2005) defiende que, desde la óptica de Weber, el emprendedor es el que realiza una organización libre del capital, mediante un proceso guiado por la acción personal y la dedicación. Le atribuye a Weber la inclusión del factor colectivo para entender el concepto de emprendedor.

En estos primeros pasos, a Weber le siguieron autores como Simmuel y Sombart, quienes intentaron de algún modo explicar cómo emergieron los emprendedores en la evolución del sistema capitalista, aludiendo a factores de carácter social y a valores sociales. Dorasammy, R., (2004) considera a Weber como pionero en la identificación del "espíritu del capitalismo" y la "ética protestante" del trabajo, atribuyendo el éxito de los emprendedores a valores propios de la ética protestante como la frugalidad, la satisfacción y el ascetismo.

Shapero, A, (1982), se aplica en sus indagaciones sobre lo que denomina "El evento empresarial", considerando al emprendedor como una variable dependiente, dejando independiente al individuo o grupo empresarial, a los factores sociales, económicos, políticos, cultuales o situacionales. Identifica además, cuatro variables imprescindibles en la acción emprendedora: 
- Variable Psico-sociológica: es la probabilidad de iniciar la creación de una empresa, y el deseo de conseguirlo.

- Variable Situacional: es el conjunto de fuerzas desencadenantes que impulsan al empresario a la creación de su empresa (decisión de cambiar su vida, su carrera, los estudios que ha de cursar, o la experiencia que ha adquirido).

- Variable Económica: necesidad de proveerse de medios físicos, financieros, económicos y humanos para concluir su aventura empresarial.

- Variable Psicológica: conjunto de características de origen sociocultural que predisponen al emprendedor a actuar.

Otros autores clásicos de la corriente psicológica como David McClellan, incluyen aspectos sociales en el estudio del emprendedorismo, tales como la influencia familiar o los valores sociales, que acentúan la propensión al logro del individuo.

Dorasammy, R. (2004) estudió la relación Cultura-emprendedorismo en las Islas Fiji y define al emprendedor como la persona que enseña creatividad práctica, combinando recursos y oportunidades para beneficio propio, de la familia y de la sociedad. El espíritu del emprendedor, por tanto, se ve afectado por el contexto social del individuo, por los intereses personales, los de la familia y la comunidad. Adapta una perspectiva ecológica, para enfatizar la importancia de las influencias externas y estructurales en la creación y supervivencia de los negocios. Define el emprendedor, como el que desarrolla una idea, y la crea, teniendo en cuenta las influencias externas de la colectividad.

Valencia, P., y García, P. (2009), adoptan, también una perspectiva sociológica a la hora de acercarse al concepto de emprendedor, como aquel que posee y gestiona, por su propia cuenta y riesgo, un negocio. En la misma línea, como el que crea empresas y asume riesgos lo definen Minniti, M., y Lévesque, M. (2008) y Chen, C. P., Greene y A. 
Crick (1998) que se trata de quien crea una empresa, la gestiona y dirige y además posee el cincuenta por ciento de su propiedad.

Concluyen Ruiz, M., Fuentes, M., Rodríguez, L. y Rodríguez, S. (2009) que emprendedor como individuo, es producto del entorno. Asumen que la formación y posterior desenvolvimiento de un negocio dependen del entorno social del emprendedor, así como de las condicionantes subjetivas asociados al entorno social.

Kyrö, P., y Carrier, C., (2005), por su parte, entiende que el emprendedorismo es el fruto de determinados aspectos culturales y de contexto. Si bien, las clásicas postulaciones de los psicólogos para explicar la conducta emprendedora se centran fundamentalmente en determinados aspectos del entorno, las más modernas corrientes científicas se aúnan con las sociológicas, proponiendo un modelo interactivo, utilizando variables tanto de carácter personal como del entorno. Explican la conducta emprendedora, teniendo en cuenta tanto al individuo, como las condiciones ambientales en las que este se desenvuelve. Sin olvidar tampoco los valores ideológicos Vesalainen, J. y Pihkala, T. (1999).

Revisando la bibliografía sociológica sobre el emprendedorismo destacamos, además del enfoque teórico de Weber, otras cuatro tendencias teóricas significativas; El de la teoría del rol, la Teoría de la marginación, el de las redes sociales, y el que aporta la teoría sociológica institucional. Todas rechazan cualquier visión teórica de corte individualista sobre el emprendizaje, por tratarse, a su entender, de un hecho claramente social inmerso en las estructuras sociales. Resumamos sus postulados básicos.

Diferentes investigadores sitúan las redes sociales como elemento determinante en el nacimiento de una un emprendedor (Coque, J.; López, N. y Loredo, E. J. ,2007; Fuentes, M.M. Albacete, S. Bojica, A. Fernández, V. Ruiz, M., 2008; Díaz, F., García, E., Ruiz, C., Jaimez, M. y Hernández, M.J., 2009). Este enfoque, más conocido como la Teoría de redes, entiende que el emprendedorismo nace y se desarrolla en una red de relaciones sociales.

Tal como apunta Kilby, P. (1971) la visión de un emprendedor inmerso en sus relaciones sociales, redes sociales, para progresar en la planificación y coordinación de 
sus actividades en un sistema económico adverso, es defendida o al menos tratada, por numerosos autores, al margen de que luego siguieran otras sus líneas de investigación; Cantillón, R., (1755); Say, J., (1803); Weber, M.,(1904); Schumpeter, J.,(1931); Kilby, P. (1971); Kirzner, I., (1997); ); Swedlberg, R., (2000); Cassis, y Papelasis, I., 2005.

Entienden que las redes facilitan el acceso al poder, a la información al conocimiento y a todo tipo de recursos, constituyendo una auténtica palanca hacia el éxito de la actividad emprendedora, en función de las características (más menos desarrollada y estructurada) y tamaño (más menos lazos creados) de la red y del uso que haga de la misma, (Herrera, H., 2008).

Las redes sociales pueden ser definidas como estructuras sociales, constituidas por individuos u otras redes, donde las relaciones que entre los integrantes se mantienen, pudiendo ser de índole diversa, se basan en operaciones de intercambio. Casson, M.C., (1982) las distingue de las físicas, donde las conexiones se dan entre objetos (edificios, equipos, sistemas de información...) y no individuos. Afirma que aun siendo diferentes, ambas están muy relacionadas, pues al final, suelen ser los individuos, integrantes de redes sociales, quienes explotan la red física.

Autores como Hung, H., (2006) diferencian las redes interpersonales de las interorganizacionales. Mientras que las primeras serían las redes personales que posee el emprendedor: sistemas sociales en los que está inmerso como la familia, los amigos, los colegas, contactos de negocios, afiliaciones a asociaciones de todo tipo, las segundas serían redes extendidas, en las que se relacionan el nuevo emprendedor, una vez creada su idea de negocio. Estas últimas ayudan a mejorar la ventaja competitiva de las empresas. Hansen, E., (1995) las define como redes de colaboración informales, y suponen una alternativa de coordinación interorganizacionales frente a los mercados. A veces, si son duraderas en el tiempo, pueden generar, incluso redes de dependencia, como apunta Williamson, O.E., (1991), formando redes de cooperación que regulan las transacciones inter-firmas, ayudan a desarrollar una visión compartida de futuro y proveen de una infraestructura de coordinación.

Ambas son fundamentales, como explica Casson, M.C., (1982), pues si bien las de tipo interorganizacional constituyen la base del crecimiento emprendedor, éstas se 
mantienen por los contactos interpersonales entre los representantes de las organizaciones. De hecho, en la práctica, se ha demostrado que el cambio de interlocutor en las organizaciones puede suponer el fin de las relaciones y por tanto de parte de esa red. Las redes organizacionales suelen ser redes interpersonales formalizadas.

En esta línea de pensamiento, Yamada, G., (2003) explica el emprendedorismo, con un enfoque multidimensional, desde la actividad de las "redes sociales, indispensables en el momento de crear una empresa. Dividiendo estas redes en dos tipos, las formales; inversores, abogados, contables, e informales; familia, amigos y contactos empresariales)".

La actividad emprendedora es el resultado de la interacción de mecanismos sociales, características de la personalidad y condiciones económicas. Este autor propone que las redes personales y de negocio, así como el entorno social e institucional deben tenerse en consideración para el entendimiento del fenómeno emprendedor.

Estos autores, atribuyen al entorno social y económico el afloramiento de la actividad emprendedora. Constata que en países con estructuras institucionales flexibles, con un marco jurídico estable y redes de apoyo económico y social, se dan las condiciones oportunas para que se propicien las iniciativas empresariales. Sin embargo en otras naciones con estructuras institucionales rígidas, con pesadas administraciones burocratizadas donde se cuestiona el derecho a la propiedad e impera la inseguridad jurídica, y las infraestructuras son precarias, suponen un impedimento para el seguimiento de las iniciativas emprendedoras.

Son otras muchas, las clasificaciones que se hacen de las redes sociales de emprendimiento, en función de si estas están estructuradas a través de organizaciones establecidas o no, es decir formales o informales, (Malewicki, R.J.,1995), de los factores claves que constituyen la misma red; nivel de diversidad, heterogeneidad de la red y nivel de fortaleza en las relaciones inmersas (Aldrich, U., y Ruef, TH.,2006), o de la etapa en la que ésta se encuentre, donde la confianza entre los diferentes actores surge en base a la periodicidad de las relaciones, la duración y frecuencia de las mismas (Larson, A. y Starr, J., 1993; Butler, J., y Hansen, G., 1991). 
Herrera, H., (2008), haciendo una revisión bibliográfica sobre el tema, concluye que la naturaleza de las redes de emprendimiento suele analizarse desde tres perspectivas diferentes, que reflejamos en la siguiente tabla; La estructuralista, la relacional y cognitiva;

\section{Cuadro 1. 8. Enfoques teóricos en el estudio de las redes de emprendimiento}

\begin{tabular}{|c|c|c|}
\hline Es & Relacional & $\overline{\mathrm{Co}}$ \\
\hline Smith & $\begin{array}{l}\text { Rowley, Bhrens y Krackhardt, } \\
\text { (2000), Saparito (2006), } \\
\text { Adler y Kwon, (2002) y Burt } \\
(2000)\end{array}$ & $\begin{array}{l}\text { Anderson y Jack (2002), Nahapiet } \\
\text { y Ghoshal (1998) y Nonaka } \\
(1994)\end{array}$ \\
\hline $\begin{array}{l}\text { La configuración de la red } \\
\text { de intercambio afecta al } \\
\text { desempeño de la actividad } \\
\text { económica. La estructura en } \\
\text { la que provee de las } \\
\text { condiciones para transferir } \\
\text { información y recursos. }\end{array}$ & $\begin{array}{l}\text { Son el contenido y naturaleza de } \\
\text { las relaciones personales } \\
\text { directas, a través del tiempo, lo } \\
\text { que posibilita el éxito } \\
\text { emprendedor. La confianza y el } \\
\text { flujo de información dependen } \\
\text { directamente de factores como } \\
\text { tiempo de relación, intensada } \\
\text { emocional intimidad y } \\
\text { reciprocidad,...). }\end{array}$ & $\begin{array}{l}\text { Los valores y paradigmas } \\
\text { compartidos que permiten la } \\
\text { construcción común de } \\
\text { significados y firmas apropiadas } \\
\text { de actuar, son la clave del éxito } \\
\text { emprendedor. } \\
\text { institucionalista de las redes que } \\
\text { apunta a cómo éstas proveen un } \\
\text { conjunto de normas para el } \\
\text { comportamiento aceptable del } \\
\text { emprendedor; conducta } \\
\text { socializada del emprendedor. }\end{array}$ \\
\hline
\end{tabular}

Fuente propia, basada en el artículo de Herrera H., 20089.

En definitiva, sí parece demostrado, que la interacción repetida de encuentros formales o informales entre diferentes emprendedores, genera lazos de confianza que favorecen las relaciones de cooperación, generando un capital social que aporta significativos beneficios al emprendedor, (Adler, P., y Kwon, S., 2002; Burt, R., 1992).

Las redes sociales de emprendimiento pueden tener un importante valor instrumental, en la medida en que proporcionan legitimidad social a sus integrantes. Cuanto mayor sea la innovación que uno plantea mayor reconocimiento y aceptación social requerirá, pudiendo el emprendedor usar su posición en la red para ganarla (Baum, J. R. y Locke, E. A. , 2004).Vemos pues, cómo la red repercute de forma directa sobre la acción emprendedora, como también lo hace cuando es utilizada por sus integrantes para acceder a diferentes recursos (Premaratne, S.P. (2001). ${ }^{3}$

\footnotetext{
${ }^{3}$ Diferentes estudios ponen de manifiesto esta idea; Proveen de información relevante (Bygrave, W. y Minniti, M., 2000). Fuente de competitividad, (Malecki J. y Velhdoen, M., 1993). Favorecen el crecimiento y desarrollo de los emprendimientos (Johannisson, B.2000; Hansen, E., 1995). Permiten la entrada a mercados internacionales Wood, J. S., 2005. Son una fuente de legitimidad (Elfrinh, T. y
} 
Este enfoque también tiene detractores. Para una revisión crítica, véase Hoang. H. y Antoncic B. (2003).

Siguiendo con el enfoque de diferenciación local, la Teoría del rol encuentra un significativo marco de estudio. Entiende que es el ejemplo de otros empresarios emprendedores, anteriores en el tiempo, lo que anima a emprender. La existencia de ejemplos o pruebas similares dan credibilidad a la posibilidad de iniciar una actividad empresarial, convirtiendo este hecho en un factor externo clave que permite explicar por qué surgen más empresarios, y por tanto más actividad empresarial en unas zonas geográficas que en otras.

Sus defensores ponen el acento en la verosimilitud que genera a un individuo el ver como otros, en circunstancias similares a las suyas, han credo una empresa con éxito, generando en el individuo una reacción interna que impulsa a la acción de emprender, confiando en que él puede tener el mismo éxito que tuvieron los anteriores. Son los "hechos", el tejido empresarial, el entorno familiar, los que hacen verosímil la posibilidad de emprender. Añaden cómo la presencia de otros empresarios en el entorno familiar, rol empresario, condiciona de manera clara la inclinación de los hijos hacia esta salida profesional y no hacia otras. Esto ayudaría a entender cómo la mayor parte de los empresarios se caracterizan por tener progenitores o parientes cercanos empresarios quienes, a su vez, proporcionan estímulo y apoyo social, a los nuevos, (Vázquez. A., 1999; Veciana, J.M., 2007; Díaz, J.C., 2002).

La teoría de la marginación, explica cómo el proceso de creación de una nueva actividad empresarial surge motivado por la ruptura con el estilo o modo de vida previo. Convierte el cambio en el modelo de vida en factor explicativo de la actividad emprendedora, por entender que, cuando éste se produce, muchos de los individuos no se adaptan a las nuevas circunstancias y formas de vida. La propia marginación social a la que llegan individuos en base a diferencias socioculturales de todo tipo (grupos étnicos diferentes, inmigrantes, religión o desempleados) hace que algunos individuos encuentren en la creación de su propia empresa una salida profesional e incluso un

Hulsink, W., (2003). Son reconocidos como espacios para la innovación y el reconocimiento de oportunidades (Hills, G., Lumpkin, T., y Singh, R. (1997), entre otros. 
reconocimiento e integración social, (Vázquez. A., 1999; Veciana, J.M., 2007; Díaz, J.C., 2002).

Según esta hipótesis, para convertirse en empresarios es necesario que se den dos condiciones claras; haber barajado y madurado previamente la idea, es decir, tener una estrategia en incubación, y un suceso desencadenante o catalizador, como el desempleo, despido, falta de seguridad en el empleo, situaciones de imposibilidad de acceso a la promoción en la empresa actual, situaciones de rechazo de ideas, de nuevos productos, o propuestas de cambio por parte de la dirección de la empresa donde se trabaja, o incluso la huida de la pobreza.

No sólo la obtención de beneficios justifica la iniciación de actividades empresariales, situaciones críticas explican y justifican la decisión de emprender, (Veciana, J.M., 2007).

Desde la llamada Teoría Sociológica Institucional, son crecientes los estudios que abordan el fenómeno emprendedor, donde éste es, básicamente, colectivo. Es un marco teórico interesante, especialmente centrado en analizar los factores que lo condicionan, y desde donde, los distintos autores, tratan de explicar cómo son las relaciones existentes entre las distintas dimensiones que componen el entorno institucional, regulador, normativo y cognitivo y el emprendimiento. Representa un marco teórico adecuado en el estudio de las acciones emprendedoras por parte de las organizaciones (Bruton, G.D., Ahlstrom, D. y Li, H-L., 2010), ya que clarifica las distintas formas que tienen de interaccionar, formales e informales, los elementos intervinientes en el desarrollo económico, centrándose, principalmente, en el papel que juegan las organizaciones, o lo que ellos llaman, emprendimiento corporativo; El emprendimiento "abarca o engloba actos de innovación, renovación o creación organizacional que ocurren dentro o fuera de una organización ya existente" (Sharma, P., Chrisman, J.J., 1999, p. 17). Este emprendimiento surge de la creación de una empresa o en nuevas actividades dentro de las organizaciones ya existentes, denominando emprendimiento corporativo.

De las distintas perspectivas de la teoría institucional, la sociológica es la que mejor ayuda a entender el influjo que ejercen las diferentes instituciones en los 
comportamientos organizacionales y su postura hacia el emprendimiento (Gómez, S., Delgado, J. y Vidal M.D. ,2010).

Esta línea de investigación significa, notablemente, el papel del contexto cultural e histórico para entender el marco institucional, y por tanto el de las organizaciones en los entornos concretos (Busenitz, L. W., 1999; Ruiz, M., Fuentes, M., Rodríguez, L. y Rodríguez, S., 2009).

A pesar de las diferencias entre las dos corrientes, no opuestas, por otro lado, del enfoque institucional $^{4}$, éste se relaciona con áreas como la economía, las ciencias políticas y la sociología. Mientras los economistas defienden que es en las estructuras de gobierno, donde se negocian y ejecutan las transacciones y en las organizaciones de todo tipo, donde debemos centrar nuestra atención, (Groenewegen, J, Pitelis, C. y Sjöstrand, S. ,1995; Williamson, O.E., 1989). Los politólogos analizan el papel de las instituciones en la vida política, sus rasgos distintivos y el influjo que ejercen en el comportamiento de los individuos.

La sociología enfatiza el papel de los procesos culturales, el papel del contexto cultural e histórico a la hora de entender el marco institucional. Entienden que, a pesar de que las instituciones restrinjan el comportamiento individual, existen criterios donde los individuos descubren y se decantan por preferencias entre diferentes alternativas

No está exenta de críticas, la teoría institucional, por no prestar atención, fundamentalmente, a los procesos de cambio que se generan, continuamente, en las organizaciones. Cambios que surgen de las modificaciones en su dinámica interna, y/o externamente, del entorno institucional, introduciendo en la organización estrategias, procesos y praxis nuevas, (Groenewegen, J, Pitelis, C. y Sjöstrand, S. ,1995).

Cada organización interpreta su entorno para entender las respuestas dadas ante las presiones institucionales, recibiendo el nombre de emprendedores institucionales. Éstos, crean normas y patrones de comportamiento consistentes con su identidad y sus

\footnotetext{
${ }^{4}$ El Viejo institucionalismo (se centra en la organización individual) frente al nuevo institucionalismo (destaca el concepto de campo organizativo o conjunto de organizaciones e instituciones que comparten vida institucional)
} 
intereses, y los establecen como estándares de legitimación. Los emprendedores serían sujetos organizados que visualizan nuevas instituciones, y que, por tanto acaban creando o modificando las ya existentes (Veciana, J.M., y Urbano, D. (2008).

Dentro de este emprendimiento corporativo al amparo de la teoría institucional del emprendizaje, se distinguen tres corrientes en el análisis de la actividad emprendedora: la económica, que define a emprendedor como agente que intenta descubrir nuevas oportunidades en el mercado, mediante la innovación y la creatividad (Schumpeter, J., 1934), y el emprendimiento como el proceso a través del cual éste, en un entorno incierto rompe el equilibrio del mercado generando nuevos procesos económicos (Cantillón, R., 1755): la sociopsicológica, que pone énfasis en las características personales del sujeto emprendedor, buscando lo que le diferencia, y, por tanto, identifica, como la creatividad, la asunción del riesgo, el locus control, la necesidad de logro...(McClelland, D.C.,1961), donde el eje de atención es el individuo; y la corriente comportamental, en la que son las acciones y no los rasgos individuales, los que explican la actividad emprendedora. "qué hace," y no "cómo son” (Covin, J.G. y Slevin, D.P. ,1991) ó, como apuntan Antoncic y Hisrich (2001), los factores que facilitan su éxito.

Siendo necesarios los recursos para emprender, la cultura, el marco legal en el que se mueve la actividad empresarial, la tradición y la historia, el marco normativo y cognitivo, así como los incentivos de toda índole, pueden tener un impacto en el nivel y potencial éxito de la actividad emprendedora (Baumol, W.J., Litan, R.E. y Schramm, C.J. ,2009).

Adquiere aquí especial relevancia identificar y analizar las más significativas variables, que repercutan en la acción emprendedora.

En este mismo sentido, algunos autores afirman que un elemento clave que regula la actividad emprendedora en los entornos socioeconómicos concretos, es la percepción de corrupción (Fukuyama, F., 1995). Añade este autor que, la desconfianza ampliamente difundida, en una sociedad impone una especie de impuesto a todas las formas de actividad económica, un impuesto que no tienen que pagar las sociedades con un alto nivel de confianza interna. Defiende que las sociedades de abundante 
capital social y ausencia de corrupción, tienen una gran ventaja para adoptar estas nuevas formas y estructuras empresariales, que requieren de un alto grado de confianza en una economía que funcione sobre valores éticos.

Comesañas, C. (2011) ha llegado a afirmar, parafraseando a Adam Smith, que la economía es una ciencia con un profundo sentido moral, pero la existencia, añade, de un nuevo tipo de corrupción, que él denomina "corrupción inocente" sin ser ilegal, pero éticamente censurable, está detrás de las crisis actuales, ..." que es potencialmente más dañina que la corrupción pura y dura que se practica con nocturnidad y alevosia", у..." Al ser pretendidamente inocente, se transforma en un virus contagioso, capaz de penetrar en el ADN ético de la sociedad y de mutarse como una verdadera cultura de corrupción, difícil entonces de erradicar”. Concluye, que esta situación genera un daño irreparable en las sociedades por cuanto que disuade a los emprendedores de la idea de llevar a cabo su idea de negocio por la inseguridad añadida que les produce la falta de ética (Comesañas, C., 2011).

Minniti, M., y Lévesque, M., (2008) proponen que la creación de nuevos negocios es el resultado principalmente de las normas sociales y las necesidades económicas, además de las condiciones contextuales del país; tales como la disponibilidad de capital, educación, mercado laboral y calidad de las infraestructuras. Además de factores intrínsecos del individuo.

Otros autores propugnan que el emprendedorismo está influenciado por factores sociodemográficos, tales como la base familiar, edad, sexo, experiencia en el trabajo, formación educativa, orden de nacimiento y hábitos de trabajo (Dorasammy, R., 2004).

Analicemos algunos de estos importantes factores, tratando de determinar si tienen, o no, peso específico en la intención emprendedora.

- Edad; Peacock, R., (2000). es uno de los primeros autores en vincular la edad a la capacidad emprendedora. Afirma que hay un promedio de edad, entre los 25 y 35 años, en que los individuos perciben oportunidades de negocio, al margen e que las pongan en marcha o no, pues en ello, afirma, influyen otras variables de corte sociológico como la insatisfacción en el 
trabajo, la pérdida de empleo, etc. Habilidad ésta que va reduciéndose a partir de esa edad y, progresivamente, a medida que el sujeto avanza en edad.

Son numerosas las investigaciones que ponen de manifiesto que los individuos jóvenes son más propensos a crear un negocio que los de mayor edad (Minniti, M., y Lévesque, M., 2008; Rodríguez, Andrés, Elia García, Carmen Ruíz y María Jesús Hernández., 2009). Incuso existe un umbral de edad, afirman, crítico en la decisión del sujeto de si emprender o trabajar por cuenta ajena.

En su modelo tienen en cuenta la edad, la propensión al riesgo y el beneficio medido a largo plazo como variables determinantes de la conducta emprendedora (Minniti, M., y Lévesque, M., 2008).

- Genero; Analizando la bibliografía al respecto, encontramos autores que abordan el género tanto como una variable de corte individual, como de tipo contextual. Será a partir de los años ochenta, coincidiendo con la incorporación y progresivo aumento de la mujer al mercado laboral, cuando se suceden los estudios del emprendedorismo en mujeres. Todos ellos ponen de manifiesto, lo mismo que los datos que arrojan todos los proyectos GEM realizados hasta ahora, que las tasas de emprendizaje en todos los países y regiones son muy superiores en hombres. Sólo en los países con altas rentas disminuyen las diferencias, siendo siempre mayores en los varones (Acs, Arenius, Hay y Minniti, 2004; Gutiérrez, P., Fuentes, Mª.M.; Lázaro, A., 2009).

- Valores culturales; Hay discrepancias entre los autores sobre la influencia de los valores culturales sobre el emprendedor. Mientras aluden a que los emprendedores comparten un conjunto de valores, independientemente de la cultura a la que pertenecen, otros postulan que la cultura influye en el emprendedorismo.

Rao, D. R., (2004) estima que los valores son atributo del individuo y de la cultura; hay valores originarios de una cultura determinada, pero no todos los 
valores que posee el individuo se originan en la cultura. Afirma este autor que las dimensiones culturales tienen un importante papel en la formación de las percepciones del individuo y, por consiguiente, en su conducta y en los resultados de ésta. Siguiendo el modelo cultural de Hofstede, G. (2001), donde la cultura es aprendida y no inherente, es originada en el entorno social de las personas y no en sus genes, entiende que hay dos tipos de valores que influyen en la cultura; el individualismo y el colectivismo. Valores que todos los individuos poseen y manifiestan según las circunstancias. Ambos valores tienen efectos en el emprendedorismo. A nivel micro, normalmente se asocia el individualismo con el emprendimiento y a nivel macro, donde ambos valores se asocian a la innovación y al crecimiento.

En un plano distinto encontramos autores como Dorasammy, R., (2004). quién estima que el emprendedorismo está asociado a una cultura individualista, mientras que el colectivismo supone un obstáculo para el emprendimiento.

En el segundo capítulo de esta tesis, tendremos oportunidad de profundizar en el impacto real que los valores tienen sobre la acción e intención emprendedora.

- Situación laboral; son muchos los estudios de emprendedorismo donde se aborda la variable situación laboral como determinante. Algunos autores, como Peacock, R., (2000), hablan de la necesidad de que surja un detonante que active la intención de emprender, cuando previamente se ha percibido una oportunidad de negocio y el individuo no se atreve a dar el paso definitivo. Así, la insatisfacción en el empleo o la propia pérdida del mismo pueden ser clave en este sentido Otros autores, por el contrario, creen que los efectos del desempleo en la creación de nuevos negocios no son concluyentes (Kennedy, J., Drennan, J., Renfrow, P., Watson, B., 2003). Los resultados en las diferentes investigaciones no son clarificadores. Distinguen dos tipos de factores contradictorios: los relacionados con la situación de oportunidad, llamados de estimulo o "pull”, y los de necesidad, u obligación 
llamados "push". Cuando el mercado presenta una situación boyante, en la que se identifican oportunidades de negocio, los individuos en mala situación laboral pueden verse atraídos a crear un negocio. Cuando las condiciones de mercado son inversas, con altas tasas de desempleo, pueden llegar a sentirse obligados a emprender, como medio de subsistencia.

Experiencia Laboral es señalada como un aspecto influyente en la elección de la carrera profesional hacia el autoempleo (Kolvereid, L., 1996; Oliveira, M. F., Garrido, E.,y Sánchez, J. C., 2005; Martínez-Rodríguez, F. M. , 2009).

Krueger, N. y Dickson, P. R., (1994) aplicando el modelo de "evento emprendedor" de Shapero, llegan a la misma conclusión, la experiencia laboral previa incide positivamente en la viabilidad percibida (autoeficacia emprendedora, pero en el atractivo percibido para iniciar un nuevo negocio (componente actitudinal del modelo).

Como propone Azjen, I., (1991) la conducta pasada no puede considerarse un factor causal ponderado, las actitudes, la norma subjetiva y la percepción de autoeficacia, son también de alguna forma, fruto de la experiencia pasada.

Diferentes estudios señalan esta relación directa entre el hecho de que el individuo haya tenido experiencias laborales previas en pequeña empresa y la decisión de abrir un negocio (Díaz, J.C., Hernández, R. y Barata, M., 2007).

- Capital social y humano; Para Carolis, D. y Saparito, P., (2006) el capital social está representado, generalmente, por la familia y la comunidad inmediata al individuo; llegan incluso a considerarlo vital para la formación del capital humano. Ambos son, a su entender, recursos intangibles, considerados esenciales en los negocios, pues proveen al emprendedor de nuevas fuentes de capital. 
El capital social se definiría a través de las relaciones sociales. Son las redes sociales las que proporcionan los medios para transformar recursos en informaciones valiosas.

Davidsson, P., y Honig, B. (2003) lo entinen, como la habilidad que tienen los individuos para extraer recursos de la estructuras sociales, redes y asociaciones. Lo completan la educación, la experiencia y el capital financiero.

Todos estos autores defienden que el capital social provee de redes que facilitan al emprendedor el descubrimiento de las oportunidades de negocio, así como la identificación, localización y obtención de recursos escasos y necesarios para ponerlo en marcha. El capital social es eficaz para la provisión y difusión de informaciones y otros recursos esenciales.

- El capital humano se refiere a los conocimientos y habilidades de los individuos que permiten el cambio en las acciones y el crecimiento económico. Se puede desarrollar a través de la educación y el entrenamiento. Davidsson, P., y Honig, B. (2003) defienden que el conocimiento proporciona al individuo mayores habilidades de cognición, que le permitirían acceder a actividades más productivas y eficaces, llegando a percibir, en mayor medida, las oportunidades rentables existentes en la economía. Estos autores consideran la educación formal como uno de los componentes esenciales del capital humano, llegando, incluso, a afirmar a existencia de una relación positiva entre educación, emprendimiento y éxito.

- La familia; El seno familiar, proporciona importantes modelos sociales que inciden favorablemente en la acción emprendedora (Hoselitz, B.F., 1960; Eckhardt, J. y Shane, S., 2003; Jackson, W., Gaster, W., y Gaulden, C., 2001; Hisrich R.D., Peters M. P., Shepherd D. A., 2005; Saporta, B., 2002; Katz, J.A., 1992; Shapero, A., 1982; Sánchez Almagro, M.L., 2003). 
Los individuos que provienen de familias con vinculación empresarial, desde la infancia ven un ambiente empresarial en el hogar Es más fácil seguir el ejemplo de los progenitores, percibiendo la ocupación como atractiva por el alto grado de independencia y flexibilidad que tiene. Además de la familia, en sentido estricto, otro miembro con significativo peso, en este sentido es el cónyuge. En el estudio de Sánchez Almagro, M.L., (2003), el $31 \%$ de los emprendedores encuestados, manifestaron que su cónyuge también trabajaba por cuenta propia, descendiendo este porcentaje hasta un (13\%) entre los no emprendedores. En el mismo estudio, concluye que en los emprendedores casados, el cónyuge desarrollaba un papel clave, proporcionando estima, seguridad financiera, y la estabilidad necesarias para equilibrar el estrés de su vida empresarial (Sánchez Almagro, M.L., 2003).

Desde la teoría social cognitiva de Bandura, encontramos un posible modelo explicativo del influjo de los modelos sociales en la conducta emprendedora, desde el proceso de aprendizaje vicario, como fuente de desarrollo de las creencias personales de autoeficacia (Bandura, A., 1997). La persona emprendedora observa su entorno inmediato (padres cónyuges o amigos) y ve como éstos han conseguido el éxito tras denodados esfuerzos (perseverancia). Lo cual puede aumentar su creencia respecto a sus propias capacidades para emprender.

Los modelos sociales, ejercerán mayor influencia si la circunstancia personal de potencial emprendedor es similar al modelo observado, pues los individuos buscan modelos que posean competencias similares a las que aspiran, De esta forma, padres, madres, cónyuge, y /o amigos pueden ser idóneos candidatos para servir de modelo social, para excitar la autoeficacia emprendedora a través del aprendizaje vicario.

También el modelo que prepone la Teoría de la Acción Planificada ha sido utilizado para tratar de medir el impacto que tienen la familia y otros modelos sociales en la intención emprendedora. Kolvereid, L. (1996) en su estudio a través del programa LISREL, y utilizando ecuaciones estructurales para validar dicho modelo, puso de manifiesto que, el hecho de tener una familia 
cercana al emprendimiento, únicamente, supone un efecto indirecto en la intención emprendedora influyendo en las actitudes, normas subjetivas y el control percibido.

- La educación: Tradicionalmente, no sólo en España, también en el resto de Europa, se ha tenido la percepción de que el ejercicio de cualquier tipo de actividad empresarial es arriesgado Así, socialmente, las referencias en la búsqueda de empleo; han estado más orientadas a profesiones tradicionales o a la administración pública. Esta idea, inmersa en nuestra cultura, ha acarreado consecuencias importantes a nivel educativo, como, por ejemplo, que fueran únicamente los estudiantes de ciencias económicas o empresariales quienes abordaran en sus planes el mundo del empresario y la creación de empresas Fayolle, A. ,(2005). El punto de inflexión que rompe esta dinámica, podemos situarlo en el año 2000, cuando el Consejo Europeo de Lisboa, y, especialmente la Carta Europea de Pequeña Empresa, ponen el acento en este asunto, demandando la urgente necesidad de estrechar lazos entre la empresa y los sistemas educativos, proponiendo el desarrollo del espíritu emprendedor, como uno de los objetivos estratégicos cumplir ${ }^{5}$ antes del 2010.

A lo largo de estos años, numerosos estudios han tratado de ver en qué medida los sistemas educativos o la educación concreta que poseía un individuo podían ser un factor determinante en la intención de emprender (Fayolle, A., 2005; Formichella, M., 2004; Gutierrez Ortega, M., 2005; Bretones, F. y Silva, M., 2009). La mayoría de estos estudios concluyen que el nivel y el tipo de educación están directamente relacionados con el tipo de empresas que crean los emprendedores. Así los emprendedores innovadores que crean empresas de alta tecnología suelen tener el título de doctor (MartínezRodríguez, F. M., 2009).

\footnotetext{
${ }^{5}$ En idéntico sentido, en Abril de 2005, se publica el Programa Marco para la Innovación y la Competitividad (2007-2013), entre cuyos objetivos está el fomento de la iniciativa empresarial y la cultura innovadora.
} 
Las investigaciones realizadas por Veciana, J.M. (2007), ponen de manifiesto que, los estudiantes universitarios de Ciencias Empresariales e Ingenierías manifiestan mayores índices de emprendizaje, como orientación profesional. por el tipo de formación básica que reciben.

Por otra parte, se ha constatado que los rasgos personales, motivación al logro, locus de control interno, autoeficacia, y las habilidades del emprendedor, pueden desarrollarse por medio de la educación (Baron, R. ,1998; De Noble, A. F., Jung, J. y Ehrlich, S. B., 1999; Hansen, E., 1995; Wu, S, Sizong; Wu, S., Lingfei, 2008).

A pesar de ello, la educación puede estimular la conducta emprendedora de muy diversas formas.

Sin duda, todos esto factores deben ser tenidos en cuenta en ele estudio del emprendedor.

\subsection{3- LA PERSPECTIVA PISCOLOGICA}

La Psicología comienza a interesarse por la figura del emprendedor de la mano de David Clarence McClelland, profesor de la Universidad de Boston a mediados del siglo XX. En este momento, y desarrollando las teorías de Abraham Maslow (fundador de la psicología humanista y Frederick Herberg (Utah) sobre la teoría bifactorial de las necesidades, McClelland, D.C., (1961) desarrolla su propia teoría motivacional ${ }^{6}$, en un contexto, los años sesenta, en el que se percibe al emprendedor como a alguien que

\footnotetext{
${ }^{6}$ La teoría de McClelland establece las siguientes necesidades básicas:

Necesidad de Realización; el individuo tiene interés por desarrollarse, por destacar aceptando responsabilidades personales distinguirse de los demás por intentar hacer bien las cosas, tener éxito, incluso por encima de los premios, buscando el enfrentamiento con problemas y la retroalimentación para saber sus resultados y afrontar el triunfo o el fracaso. .

Necesidad de poder; cuyo rasgo principal es el de tener influencia y control sobre los demás afanándose en ello. Prefieren la lucha, la competencia y se preocupan por su prestigio y por influir sobre las otras personas incluso más que por sus resultados.

Necesidades de afiliación, cuyo rasgo esencial es ser solicitados y aceptados por otros persiguiendo la amistad y la cooperación en lugar de la lucha y buscando comprensión y buenas relaciones.
} 
persigue, fundamentalmente, la búsqueda del beneficio económico. Para la consecución de este fin primordial se requería un comportamiento de liderazgo, con una gran capacidad de convencimiento e iniciativa, para aprovechar las necesidades que fueran surgiendo. Siendo las características más sobresalientes del emprendedor: la necesidad de logro, el locus de control interno, la aceptación a la incertidumbre y la tolerancia hacia la ambigüedad.

Junto con McClelland, los estudios de Collins, O.F. y Moore, D.G., (1970) y de Smith, N. B., (1967), configuran lo que podríamos llamar los comienzos de la teoría del emprendedor.

En los setenta, sigue viéndose al empresario emprendedor como un líder con grandes dotes de persuasión, siendo necesario, si pretende gestionar con éxito su empresa, tener un gran conocimiento del negocio y ser hábil para obtener los recursos que en él necesite, asumiendo los riesgos estrictamente necesarios, para no poner verse comprometida la actividad empresarial. El enfoque en este momento es el del análisis del emprendedor en comparación al gerente, ó a los líderes de la población en general. Destacan los estudios de autores como Collins, O.F. y Moore, D.G., 1970; Hornaday, J. y Aboud, J. ,1971; y Shapero, A., 1982.

Shapero, A., (1982) se aplica en sus indagaciones sobre lo que denomina " $E l$ evento empresarial", considerando al emprendedor como una variable dependiente, dejando independiente al individuo o grupo empresarial, los factores sociales, económicos, políticos, culturales y situacionales. Asume que el emprendimiento es un proceso interrelacionado donde, como vimos anteriormente, las variables psicosociológica, situacional, económica y psicológica, se suceden, siendo claves para la acción emprendedora. Atribuye, las siguientes características, al proceso emprendedor:

La toma de iniciativa, entendida como la decisión del emprendedor para identificar y llevar a cabo la oportunidad de negocio.

La acumulación de recursos, entendida como el proceso de determinar las necesidades, conseguir y asignar los recursos físicos, humanos, financieros y tecnológicos necesarios. 
La gestión administrativa, entendida como la capacidad de estructurar una organización y una dirección al nuevo emprendimiento y llevarlo a cabo.

Autonomía, entendida como la libertad del emprendedor para tomar decisiones sobre el funcionamiento de la organización, de su proyecto.

Asunción de riesgos, entendida como la disposición a asumir las recompensas o las pérdidas que su proyecto genere.

Según Shapero, A., (1982), el proceso de generación de nuevos emprendedores es el resultante de la interacción de factores situacionales, sociales, psicológicos culturales y económicos y que cada nacimiento de un nuevo emprendedor ocurre en un momento dado, como resultado de un proceso dinámico que provee situaciones que impactan sobre las personas cuyos valores y percepciones están condicionados por sus experiencias y herencias culturales y sociales.

En la década de los ochenta, se incrementa notablemente el número de estudios en el campo emprendedor. Este se define, como el sujeto que motivado por la consecución del beneficio, asume una elevada motivación de logro, le atrae el riesgo, aunque moderado, mantiene elevados niveles de autoconfianza, autocontrol, y autoestima. En definitiva, se le atribuyen creatividad, imaginación, e innovación.

Diferentes autores (Hebert, R. y Ling, A., 1989; Hisrich, Robert D., Peters, Michael P., Shepherd, Dean A., 2009), definen al emprendedor en función de su relación con la administración: función directiva.

Casson, M.C., 1982 y Stevenson, H. H. H. I. Grousbeck, M. J. Roberts, and A. V. Bhide., 1999, por su parte, destacan las cualidades más sobresalientes del emprendedor, su pericia para detectar y analizar las oportunidades, tomar decisiones, y la habilidad para buscar los recursos necesarios a fin de crear una empresa (Veciana, J. M.,1999; Picot, A., Laub, U. D., y Schneider, D., 1989; Ribeiro-Soriano, D. y Urbano, 2009). Se fijan en los valores, las habilidades y las motivaciones del emprendedor. 
Coque, J.; López, N. y Loredo, E. J., (2007) ponen el acento diferenciador del emprendedor en la asunción del riesgo, y centrándose en la inversión y en el emprendimiento innovador, como cualidad diferencial: es el llamado proceso Schumpeteriano. García-Egocheaga, (1984) y Drucher, P. (1986). Drucher, en sus investigaciones sobre el liderazgo, desarrollan, técnicamente, los conceptos de privatización, emprendimiento, dirección por objetivos y sociedad del conocimiento. (Drucher, P., 1986). Términos hoy en día, globalmente, aceptados Presentan la innovación y el emprendimiento como disciplina determinada y sistemática, que analiza los retos y oportunidades de una nueva economía emprendedora

Posteriormente, en la década de los Noventa, se aprecia más la personalidad del emprendedor; los estudios toman un enfoque multidimensional, buscando la interacción entre el individuo, las funciones sociales y económicas que influyen en la conducta del emprendedor. Es decir, a la perspectiva psicológica, se le añaden las variables personales y circunstanciales. Ponen el énfasis en la innovación y el cambio, para transformar la sociedad y la empresa, como características diferenciales del emprendedor. El emprendedor ya no debe aceptar las circunstancias según le vienen sino que debe luchar contra la inercia y la parálisis. Autores como Robinson, P. B. y Sexton, E. A., (1994) se centran en la organización de recursos que facilitan la fabricación o producción de un bien, el establecimiento de un proceso o de un servicio totalmente nuevo o la utilización de un producto que responda a las necesidades del mercado.

Desde otro punto de vista, Brockhaus, R.H. y Nord, W.R., (1979) y Brown, R., (1988), estudian el sistema de toma de decisiones como factor que debe anticiparse a los futuros cambios que puedan producirse en los mercados, actitud que define la figura del emprendedor como factor determinante de la coordinación e impulso creativo de los recursos de un proyecto empresarial.

Le Bras, H., (1995), establece como rasgos de carácter indispensables, independiente de las cualidades personales para el éxito: la autodisciplina, la autonomía, la exactitud, la perseverancia, el rigor, la independencia, la eficacia, la ambición, el espíritu práctico, el dinamismo, la confianza en sí mismo y la resistencia física. 
En el emprendedor del Siglo XXI, se destacan como elementos fundamentales, además de la personalidad, el entorno y sus funciones dentro de la empresa:

- El entorno: ha de tenerse en cuenta la influencia de los valores religiosos, culturales y sociales que existen en el país, la tecnología, el medio escolar, el régimen político y el cuerpo normativo.

- Características personales: se han de considerar la motivación, la confianza en uno mismo, la capacidad de compromiso, la constancia, la iniciativa, la creatividad y la competitividad.

- Funciones del emprendedor: la innovación, la eficacia, los planteamientos estratégicos, son elementos imprescindibles para que su negocio sea competitivo.

March, I., (1998) define al emprendedor como una persona que inicia su aventura empresarial, en sectores novedosos, en relación con las actividades cotidianas de su entorno y siguiendo, aunque con matices diferenciales, eta línea destacan Lucas, W. A. y Cooper, S. Y. ,(2005).

A la luz de este breve recorrido histórico, los diferentes autores, poniendo cada uno de ellos el acento en aspectos diferentes, han tratado de identificar y definir al emprendedor con más o menos éxito. Será necesario, por tanto, tener en cuenta todos estos análisis y estudios si no queremos desviarnos del objetivo en este trabajo. En este cometido, habremos de tener en cuenta las diferentes orientaciones teóricas, y es, en base a ellas, como observamos que puede establecerse una clasificación de los diferentes estudios que de la conducta emprendedora se han hecho y se están haciendo, en el campo de la psicología;

- Encontramos autores que estudian la conducta emprendedora en base a la personalidad. Las teorías de la personalidad basadas en los rasgos, entendienden estos, como características personales, que diferencian a esas personas de las demás, es lo que las hace únicas e irrepetibles. 
Cromie, S. y Johns, S. (1983) entienden que los rasgos de la personalidad que poseen los individuos son determinantes para que aflore la conducta emprendedora, es decir, los emprendedores poseen unos rasgos peculiares que les predisponen para la acción emprendedora.

- Los que englobamos en la llamada orientación cognitiva, que surge como una perspectiva diferencial o desgajada de la orientación de los rasgos, al producir ésta, resultados contradictorios. Los autores que siguen este nuevo enfoque, creen que lo que diferencia a los emprendedores de otros individuos, son los factores cognitivos, por decirlo de otro modo, los procesos mentales, que van desde las creencias hasta los valores, y concluyen en la acción de emprender. Y,

- La orientación de la conducta, donde los diferentes autores se esfuerzan por definir al emprendedor desde la óptica de las conductas que presentan (tipos de comportamiento) y no en función de sus rasgos u otros aspectos psicológicos.

Los dos últimos serán reseñados brevemente, pues nuestro objeto de investigación básico se centra en explicar cuál es y, en qué medida hay diferencias en la personalidad del emprendedor, con respecto a quien no lo es.

\subsubsection{EL ENFOQUE DE LA PERSONALIDAD; LA ORIENTACION DE LOS RASGOS}

Tratándose el emprendedorismo de un fenómeno de vital importancia en la revitalización socioeconómica de las regiones, ha habido especial interés en multitud de campos científicos por tratar de generar una cultura que fomente la creación empresarial como alternativa de empleabilidad. La psicología no ha sido ajena a este propósito, por lo que ha tratado de identificar, a través de multitud de estudios, las diferentes competencias y capacidades personales necesarias para emprender con éxito. El estudio de las características personales o rasgos de personalidad del emprendedor recibe especial atención en la literatura científica, en los últimos años, al objeto de 
encontrar en estos rasgos modelos explicativos de la conducta emprendedora, dirigiendo sus esfuerzos en la identificación y diferenciación de los emprendedores, con respecto quienes no lo son.

Definen y analizan al emprendedor desde la personalidad, siendo éstos, individuos que poseen una serie de atributos personales que despiertan su intención de emprender, diferenciándolos así resto de la población (Krueger, N. F., Reilly, M. D., y Carsrud, A. L., 2000) y que están predispuestos al emprendizaje, con independencia de la influencia del entorno (Vesalainen, J. y Pihkala, T., 1999).

Incluso hacen depender la puesta en marcha y el éxito del negocio de estas características de personalidad (Baum, J. R. y Locke, E. A., 2004; Rodermund, E. S., 2004; Miner, J. B., 1996).

En las siguientes líneas haremos un recorrido por los diferentes enfoques teóricos que aglutina esta particular visión, extrayendo sus aportaciones más significativas, pudiendo, así, examinar los rasgos más, comúnmente, aceptados que se atribuyen a los emprendedores.

Como ya apuntáramos anteriormente, es McClelland, D.C. (1961) el primer autor que desde la psicología intenta descubrir si existes rasgos diferenciales de personalidad en los llamados emprendedores y el efecto que éstos pueden tener en la conducta emprendedora. Reflexionó sobre las cualidades o capacidades que tenían los emprendedores de éxito, si eran o no compartidas, al fin de poder extraer un perfil más o menos común. En este estudio (1961) concluye que, al margen de la actividad o lugar donde se desarrollada, independientemente de variables como nivel socioeconómico, religión, cultura sexo o raza, todos ellos poseían una serie de características personales que diferenciaban a los triunfadores de quienes no lo eran.

El análisis, en base a los comportamientos comunes observados, concluye en la detección de diferentes pautas de comportamiento emprendedor, que podían ser analizadas de forma aislada o interrelacionándolas entre sí. Estas pautas aparecían en diferente grado en las personas que fueron objeto de estudio y son las que presentamos agrupadas en tres grandes grupos; 
$\underline{\text { Pautas de logro: }}$

- Búsqueda de oportunidades e Iniciativa: actuar por uno mismo, independientemente de las circunstancias, buscar líneas nuevas de negocio; aprovechar todo tipo de oportunidades en los negocios y obtener recursos.

- Correr riesgos calculados: calcular concienzudamente los riesgos y evaluar todas las alternativas de acción. Atracción por situaciones que conllevan retos, riesgos moderados y actuar para reducir estos riesgos o tener controlados los resultados.

- Exigir eficacia y calidad: esforzarse por hacer mejor las cosas, en menos tiempo o de forma más barata. Asegurar los requisitos de calidad y actuar siempre siguiendo los requisitos (normativos) establecidos.

- Persistencia: Asumir toda la responsabilidad en la consecución de las propias metas y objetivos y reaccionar ante los desafíos, ante lo desconocido, ideando estrategias hasta superarlos.

- Cumplimiento: empeñarse en el esfuerzo y sacrificarse para realizar el trabajo, asumiendo cualquier papel dentro de la organización y teniendo siempre presente al cliente y su satisfacción (fidelizar a los clientes, al margen de los beneficios a corto).

Pautas de planificación:

- Búsqueda de información: Estar al día sobre los últimos avances vinculados el negocio (competencia, proveedores, investigaciones de todo tipo, clientes...). 
- Fijar metas: Fijar objetivos que impliquen un reto personal. Tener una visión clara de lo que se pretende alcanzar a largo plazo y fijar metas y objetivos para conseguir a corto.

- Planificación sistemática y seguimiento: Estructurar los planes y objetivos en subtareas y fijar plazos de realización, haciendo seguimiento continuo de su consecución. Revisar continuamente los cambios en el entorno y registrar nuestras actividades para utilizaras como apoyo en la futura toma de decisiones.

\section{$\underline{\text { Pautas de poder: }}$}

- Persuasión y redes de apoyo: Usar nuestras estrategias para influir en otros, buscar apoyos para la consecución de nuestros objetivos (desarrollar y mantener redes de contactos para el negocio).

- Autoconfianza e independencia: Creer en los objetivos fijados aunque sean difíciles y confiar en uno mismo para alcanzar metas y concluir positivamente las tareas. Mantener el control del negocio, al margen de las otras personas.

En base a estos comportamientos observables, McClelland, D.C. (1961) define el concepto de competencia ${ }^{7}$, como aquellas características personales que se manifiestan a través del comportamiento y determinan un desempeño excelente en una determinada actividad, englobando no sólo los conocimientos adquiridos, también una serie de aptitudes y actitudes. En este mismo sentido se encuentra la denominada inteligencia emocional, parte de la cual es inherente e innata a la persona, y parte puede ser desarrollada por el individuo a lo largo de su vida.

\footnotetext{
${ }^{7}$ El concepto de competencia responde a todas aquellas habilidades y conocimientos del emprendedor, resultado de la evolución de las aptitudes desarrolladas a lo largo de su vida, gracias al aprendizaje y la experiencia. Se traducen en comportamientos observables, siendo la Innovación y Creatividad, la Capacidad de Análisis y la Capacidad de Influencia, las más consensuadas competencias que la bibliografía académica atribuye al emprendedor (McClelland, 1961)
} 
Son las aportaciones de McClelland, D.C.,(1961, 1962 y 1965) con el citado análisis de la motivación del logro, las preferencias por el desafío y la innovación; así como las de Collins, O.F. y Moore, D.G., (1970) y las de Smith, N.R., (1967) las que suponen el principio de la configuración teórica del emprendedor. Cromie, S. y Johns, S., (1983) añaden que los rasgos de personalidad que poseen los individuos son determinantes para que aflore la conducta emprendedora, es decir, los emprendedores poseen unos rasgos peculiares que les predisponen para la acción emprendedora. Otros estudios, se centran en, identificar como rasgos de personalidad del individuo, los factores que tienen que ver con las motivaciones que éste tiene y que le llevan a iniciar su proyecto, y con factores que tienen que ver con sus capacidades y competencias personales (De Carolis, D. y Saparito, P., 2006).

Muchas investigaciones, realizadas en los últimos 20 años, han tratado de profundizar en la figura del emprendedor, como elemento determinante del proceso de emprender, sin embargo cuestiones sobre la forma en que un individuo que dirige su propio negocio difiere de los directivos de grandes compañías o de la población general, son cuestiones todavía difíciles de responder. En los estudios publicados por Gartner, W.B., (1989) y Ginsberg, A., y Buchholtz, A. (1989) se presentan resultados poco consistentes, pero a pesar de ello, existen razones suficientes para pensar que las conductas emprendedoras son lo sobradamente relevantes para diferenciar a los emprendedores de la población general.

Stewart, A. ,(1990) comparó, empíricamente, tres características clásicas en el emprendedor-propietario de pequeños negocios y el directivo de grandes compañías, concluyendo que el emprendedor puntuaba significativamente más alto que los directivos en motivación de logro, preferencia por la innovación y propensión al riesgo. Por otro lado, en la investigación emprendedora se acepta, con rotundidad, que los factores culturales, situacionales y la función social son componentes integrantes del proceso de emprender (Herron, L., Sapienza, H.J., 1992; Van de Ven, A.H., 1993). Pero también se apunta a que no todas las personas se convierten en emprendedores, bajo circunstancias parecidas, lo que lleva a pensar que las características individuales pueden ser determinantes (Cromie, S. y Johns, S. 1983). Por tanto los atributos o características del individuo deben formar parte integrante en la investigación, como un elemento significativo en la comprensión del proceso de emprender (Carland J.W. 
Boulton, W.R. y Carland, J.A.C., 1984; Herro y Robinson, P. B. y Sexton, E. A., 1994; Johnson, S. and Loveman, G., 1995).

Resumiendo, encontramos diferentes enfoques de estudio; investigaciones que se centran en distinguir a los emprendedores de otros grupos como los gerentes, procurando determinar las causas por las cuales unos individuos resultan emprendedores y otros no (Hansemark, O. C. (2003), y aquellas que pretenden relacionar la personalidad con el éxito de los emprendedores (Miner, J. B., 1996; Baum, J. R. y Locke, E. A., 2004; Rodermund, E. S., 2004). Sin olvidarnos de las últimas tendencias en la investigación que dirigen sus esfuerzos a intentar dar una explicación, satisfactoria, a la conducta emprendedora, mediante la aplicación de la teoría del comportamiento planeado.

Algunos de los autores señalados estiman que el emprendedor es un tipo ideal de persona para el ejercicio empresarial; otros, en cambio, creen que el emprendedor es un fundador de negocios, un propietario de negocios, astuto, que busca expandir sus empresas.

Rodermund, E. S., (2004) define al emprendedor como una persona oportunista, innovadora, creativa, imaginativa, con ideas, activa, inquieta, aventurera y prometedora de cambios. Afirma que los emprendedores poseen rasgos comunes, que han sido puestos de manifiesto en multitud de estudios. Así los emprendedores poseen una alta necesidad de logro, creatividad, iniciativa, locus interno de control, independencia, autonomía, asumen riegos, seguros de sí mismos. Además, realizan sus funciones con energía y responsabilidad, y son persistentes en la consecución de sus objetivos.

El punto débil de estas definiciones, centradas en la personalidad, consiste en considerar un único tipo de personalidad emprendedora, siempre de éxito. Miner, J. B., (1996), al respecto, identifica cuatro tipos de personalidad emprendedora, diferentes entre sí:

- La realizadora: Se caracteriza por una intensa necesidad de realización, deseo por el feedback, un gran compromiso personal con el negocio, y gran iniciativa. 
- El Vendedor por excelencia: Creen firmemente en los procesos sociales y asumen como fundamental la fuerza de las ventas para la estrategia de la compañía.

- El Gerente real: Un emprendedor sumamente interesado en el liderazgo corporativo, con un principio de autoridad acentuado, y gusto por la competitividad y el poder.

- El Especialista en la generación de ideas: Posee una personalidad innovadora, con gran intensidad en la generación de ideas, el desarrollo de nuevas líneas de producción y nuevos productos. Inteligente y cauteloso con los riesgos que asume, es crucial para la empresa.

Otro problema básico, al respecto de los rasgos de personalidad, que debe dilucidad la Piscología, es determinar si estos rasgos emprendedores son innatos o adquiridos. Actualmente, los diferentes esfuerzos realizados a tal fin, no han sido capaces de encontrar ninguna evidencia empírica al respecto. Cada autor, decantándose por lo que más conviene a sus fines de investigación, diluye esta cuestión con una definición propia. En este estudio, sin duda, se cree en la posibilidad de adquirir los rasgos emprendedores, siendo la educación en todas sus facetas, decisoria, (Ilundain J.M, Sánchez, J.C., Yurrebaso, A., 2007; Sánchez, J. C., Lanero, A., Yurrebaso, A., Villanueva, J. J., 2006).

Debemos concluir que, investigaciones más recientes, proporcionan evidencias de la validez predictiva de los rasgos de personalidad (Steward, W., y Roth, P., 2001; Collins, C. J., Hanges P. J. y Locke E. A., 2004; Sánchez, J. C., Lanero, A., y Yurrebaso, A., 2005; Zhao, H., Seibert, S.E y Hills G.E., 2005). Por lo que asumo, en este estudio, el carácter predictivo y/o explicativo del modelo de los rasgos o atributos de personalidad en la intención emprendedor.

Llegados a este punto debemos intentar enumerar las características definitorias que distinguen al emprendedor. El análisis se complica cuando intentamos determinar los rasgos concretos que definen o diferencian su perfil, sobre los que, prácticamente, 
cada autor hace su propia clasificación Desde la literatura científica se cita una gran multiplicidad de atributos que intentan explicar las características del emprendedor. Por ejemplo, Hornaday, J. y Aboud, J., (1971) presentan una lista de hasta 42 rasgos considerados importantes. Ante esta dispersión de características resulta difícil llegar a un acuerdo para determinar qué rasgos son los esenciales y comprobar su relevancia (Chell, E., Haworth, J. y Brearley, S., 1991; Sánchez García, J.C. (2010).

\subsubsection{1 -LOS RASGOS DE LA PERSONALIDAD EMPRENDEDORA}

Peacock, R., (2000) afirma que, aun siendo complejas las características de los emprendedores, algunos rasgos pueden ser más importantes que otros, e incluso, factores tan personales como la educación o la influencia familiar pueden incidir positivamente en la acción emprendedora, por el influjo que tienen, a su vez, en la personalidad.

Desde el constructivismo social, Chell, E. (2000) define el rasgo de la personalidad como "una categoría descriptiva, usada por un observador de la realidad social, para descubrir los comportamientos de otras personas". Asume que algunas conductas son el exponente de algún rasgo e incluso de varios.

Por medio de los rasgos de la personalidad se pretenden explicar los comportamientos continuados de las personas, al objeto de determinar por qué personas diferentes, reaccionan de modo distinto ante la misma contingencia.

Se afirma que los emprendedores son propensos al riesgo, que analizan las informaciones, positivamente, que son optimistas, eficaces, y que poseen mayores niveles de locus interno de control. Que sienten una mayor necesidad de éxito. Estas características del emprendedor, más compendiadas, son esgrimidas por Korunka, C., Frank, H., Lueger, M. Y Mugler, J., (2003). En concreto, afirma que las tres más, comúnmente, identificadas por la amplia bibliografía sobre el emprendedor serían:

1. Alta necesidad de logro.

2. Locus interno de control. 
3. Propensión al riesgo.

A las que añade, de su cosecha, dos más:

4. Iniciativa personal.

5. Motivaciones personales: seguridad y confianza.

Para Vesalainen, J. y Pihkala, T. (1999) los rasgos que, con mayor frecuencia, se suceden entre los emprendedores son la necesidad de logro, y el locus de control. Aunque la tolerancia a la ambigüedad y la creatividad se hallan frecuentemente relacionadas con el emprendedorismo.

Para Vecchio, R. P., (2003) son cinco los atributos que con mayor frecuencia aparecen en los estudios doctrinales, como definidores del espíritu emprendedor: Asunción de riesgo, necesidad de logro, necesidad de autonomía, auto-eficacia y locus de control.

Por el contrario Filion, L. J., (2003) considera que tras multitud de elaboraciones, no se ha llegado a un patrón científico absoluto que pueda identificar el perfil del emprendedor. Estima que una muestra que incluya a empresarios que han puesto en marcha sus empresas en los dos últimos dos años, en modo alguno establecería el mismo perfil que otra, que incluya a emprendedores que lo hayan hecho hace 20 años. Ello es debido a la educación, empleos anteriores, los valores religiosos, el miedo o la cultura familia, que habrán de influir necesariamente en el perfil, factores externos que, a su juicio, tienen un peso significativo en este asunto. De todos modos, si se utilizan definiciones diferentes de emprendedor para componer las muestras, éstas, lógicamente, llegarán a conclusiones distintas. El análisis de los rasgos personales de un individuo, en ningún caso podrá llevarnos a concluir si un emprendedor triunfará o no en su empeño (Filion, L. J., 2003). Aun así, hace una clasificación de los rasgos emprendedores revisando toda la bibliografía sobre el tema. Obtuvo 24 características que según afirma, atribuyen estos estudios al emprendedor; 


\section{Cuadro 1.9 Características más comunes atribuidas a los emprendedores por los especialistas en el comportamiento según Filion.}

\begin{tabular}{|c|c|}
\hline 1-Innovación. & 13- Necesidad de logro. \\
\hline 2- Liderazgo. & 14- Locus de control interno. \\
\hline 3- Toma de riesgos moderados. & 15-Auto-confianza. \\
\hline 4- Independencia. & 16- Compromiso a largo plazo. \\
\hline 5- Creatividad. & $\begin{array}{lllll}\begin{array}{l}\text { 17-Tolerancia } \\
\text { incertidumbre. }\end{array} & \text { a la } & & & \text { ambigüedad } \\
\end{array}$ \\
\hline 6- Energía. & 18- Iniciativa. \\
\hline 7- Perseverancia. & 19- Capacidad de aprendizaje. \\
\hline 8- Originalidad. & $\begin{array}{l}\text { 20- Capacidad de utilización eficiente de los } \\
\text { recursos. }\end{array}$ \\
\hline 9-Optimismo. & 21- Sensibilidad hacia los otros. \\
\hline 10-Orientación hacia resultados. & 22- Agresividad. \\
\hline 11- Flexibilidad. & 23-Tendencia a inspirar confianza. \\
\hline 12- Desenvoltura. & $\begin{array}{l}\text { 24- Capacidad de usar el dinero como medida } \\
\text { de resultados. }\end{array}$ \\
\hline
\end{tabular}

Fuente: Filion, L.J., 2003

La clasificación de Filion, no implica un perfil típico de emprendedor, sería prácticamente imposible que alguien asumiera todas estas características pero ilustra sobre los rasgos que, normalmente, encontramos en los emprendedores.

Vemos cómo cada autor genera su propia lista de rasgos, llegando cada cual a conclusiones discordantes. Incluso, podríamos afirmar que no se han perfilado suficientemente en la doctrina los conceptos de rasgo, conducta, e incluso cognición, entremezclándose caracteres de dichos conceptos.

Cromie, S. y Johns, S., (1983) después de analizar gran parte de la bibliografía publicada sobre la identificación de los rasgos del emprendedor, concluye que estos son siete: necesidad de logro, locus interno de control, asunción de riesgo, tolerancia a la ambigüedad, creatividad, necesidad de autonomía y autoconfianza.

Esto nos permite concluir sobre la complejidad de nuestro estudio. Pues es difícil analizar la personalidad individual. Es difícil establecer cuáles son los rasgos que diferencian a un sujeto de otro. Se hace complicado establecer qué rasgo es más significativo o esencial en su personalidad. Muchos de estos rasgos, a su vez, pueden estar influenciados por otros de tipo ambiental o sociocultural. Son muchos los rasgos 
que se atribuyen al emprendedor, y es inusual encontrar todos en un mismo sujeto (Peacock, R., (2000).

Pasaremos a analizar los rasgos que más se repiten en los diferentes estudios y que han sido comprobados empíricamente ${ }^{8}$ : Locus de control, Autoeficacia, Riesgo y Proactividad (Covin, J. G. y Slevin, D. P., 1997,Koh, H., 1996; Filion, L. J.,, 2003; Cromie, S. y Johns, S., 1983; Vecchio, R. P., 2003; Sánchez, J.C., 2010).

\subsection{1- LOCUS DE CONTROL}

El término de "Locus Control" se ha usado para referirse al concepto de control interno vs. Control externo desarrollado por Rotter, J. B., (1966), y alude al grado con que un individuo cree controlar su vida y los acontecimientos que influyen en ella. Sería la atribución que realizan las personas sobre el resultado de sus acciones y puede hacer referencia a factores ajenos a ella misma (factores externos como el azar, o los otros) o a factores controlables por la propia persona (factores internos como las habilidades o el trabajo personal).

Rotter, J. B., (1966), distingue entre personas con locus de control externo, que son aquellas que son conscientes que su destino está controlado por otras personas, situaciones, la suerte, u oportunidades que ocupan su control. Este tipo de individuos no serán tendentes a abrir un negocio porque considerarán que no controlan todos los riesgos que ello comporta.

Por el contrario, las personas con locus de control interno son más proclives a buscar el logro. Lo definiríamos como la capacidad interna de un individuo para controlar el ambiente, mediante las acciones que realiza. Estos individuos que poseen un alto nivel del control interno creen tener el control de su mundo, del ambiente en el que se mueven y estiman que la suerte y el destino no determinan los acontecimientos. Los individuos con locus de control interno son más positivos, tienen más confianza en sí mismos, afrontan los desafíos y tienden a resolver los problemas mediante soluciones

\footnotetext{
${ }^{8}$ Rasgos que mediremos con el COE en nuestra muestra.
} 
creativas, aguantan la presión, y tienden a la innovación. En definitiva, únicamente, los que ejercen un cierto control sobre sus objetivos, pueden crear negocios con éxito.

Hansemark, O. C., (2003) entiende que el locus de control está relacionado con otros aspectos de la personalidad, tales como la necesidad de logro y la iniciativa personal. Lo define como las expectativas de éxito o fracaso en el juicio de los objetivos. Las personas atribuyen los resultados a sí mismas o a factores externos: sin embargo, las personas que tienen control sobre los resultados poseen locus de control interno. El locus de control es una característica de la personalidad que puede ser aprendida, muta con el tiempo al mudar el contexto social, con lo cual es preciso establecer si esta característica personal existía antes de producirse la acción emprendedora, o si tal rasgo fue desarrollado ante los retos planteados por la propia actividad empresarial. Los hallazgos de Hansemark, O. C., (2003) concluyen que los fundadores de nuevos negocios poseen un nivel mayor de locus de control interno, que los no fundadores.

Defiende este autor que le locus de control interno puede aprenderse y desarrollarse a lo largo del tiempo. Las expectativas pasadas de un individuo irán cambiando el tipo de atribuciones hacia factores internos y externos que éste haga. Los existo contribuirán a generar una sensación de control sobre la situación experimentada y los fracasos a factores externos que no puede controlar (Hansemark, 2003; Korunka, C., Frank, H., Lueger, M. Y Mugler, J., 2003).

Por el contrario, Chen, C. P., Greene y A. Crick, (1998) no encuentran diferencias significativas de locus de control entre emprendedores y no emprendedores.

Podemos inferir una relación entre el locus de control y la teoría del control conductual de Ajzen, I. (1991), puesto que un locus de control más interno llevaría a que el sujeto considerara, en general, a la conducta propia como más controlable, ya que si las consecuencia de la conducta dependen de él, también los factores que la generan dependerán de su persona. De esta forma, para que el individuo formase la intención de emprender sería necesaria una atribución interna del esfuerzo, concediendo al locus de control interno un valor importante en las predicciones de la intención de conducta. El deseo y la percepción de control estarían unidos a la intención y el mantenimiento de la 
conducta dirigida a metas (autoeficacia) y significativamente asociado a la intención de emprender.

Cromie, S. y Johns, S., (1983) creen que el locus de control está sometido a influencias externas, entendidas como factores situacionales temporales y encuentra más eficaz el factor de la auto-eficacia empresarial, que el locus de control, para distinguir entre emprendedores y gerentes.

Esta teoría del locus de control, ha sido determinante en la teoría de los rasgos desde los años sesenta del pasado siglo. El locus de control interno ha sido uno de los rasgos psicológicos más frecuentemente mencionados como predictor del emprendimiento. Así se ha confirmado como rasgo existente tanto en emprendedores como entre otros cargos directivos y empresarios. Sin embargo, algunos estudios apoyan una mayor puntuación en este rasgo entre los emprendedores fundadores de empresas con respecto a otros cargos no fundadores en población general (Bonnett, C. y Furnham, A., 1991). Igualmente, se ha encontrado, en compañías existentes, que la habilidad exitosa y el rendimiento financiero están relacionados con el locus de control interno.

\subsection{2- AUTOEFICACIA}

Cromie, S. y Johns, S., (1983) establecen que los emprendedores buscan crear negocios, y esto no sería posible si no tuvieran confianza en sí mismos. Este rasgo es imprescindible para abordar tareas difíciles. Estima que una persona para emprender necesita un mínimo de confianza en sí mismo. Esto, requiere un sentimiento de dominio sobre las diferentes tareas y problemas que pudieran presentarse para gestionar con éxito una empresa. Con los cual podría entenderse que las motivaciones psicológicas son previas a la conducta.

La autoeficacia, cobra así, un significativo peso explicativo en el emprendizaje. Entendida como la convicción de que uno puede organizar y ejecutar acciones para producir unos resultados deseables y que ejercen influencias sobre situaciones que afectan a sus vidas (Bandura, A., 1986). 
Defiende Bandura, A., (1997), que en la acción humana ningún mecanismo es más importante que la creencia de cada cual en su eficacia personal, ya que está regida por procesos cognitivos, motivacionales, afectivos y selectivos. Un individuo que posee esta característica, persistirá en el esfuerzo durante un período de tiempo prolongado, resistirá las dificultades que encuentre en su quehacer y desarrollará mejor los planes y estrategias, obteniendo, así, mejores resultados.

Podemos entender, por tanto, la autoeficacia como una atribución de competencia personal y control en una determinada situación. Pone de manifiesto la percepción que tiene un individuo sobre su propia capacidad personal para llevar a cabo una acción concreta. La autoeficacia afectaría a la elección de la acción y a la cantidad de esfuerzo que tiene que realizar el individuo, siendo éste el predictor básico que tiene el sujeto en la elección de carrera Bandura, A., (1997),

Relaciona elevados niveles de autoeficacia con la persistencia, con conductas innovadoras, y con el reconocimiento de las oportunidades emprendedoras.

Vecchio, R. P., (2003) estima que los emprendedores, es decir, lo que presentan altos niveles de autoeficacia, son propensos a crear nuevos negocios. Estos individuos perciben con mayor claridad las oportunidades, y están mejor preparados para superar las dificultades. La autoeficacia es percibida por Bruger (2004) como capital para entender los caracteres fundamentales de la conducta emprendedora, que cifra en la innovación, la propensión al riesgo y la proactividad.

Otros autores como Shane, S., Lochey, E., y Collins, C, J., (2003) consideran que la autoeficacia es imprescindible para identificar las causas últimas de por qué personas con iguales actividades actúan de modo diferente. Chen, C. P., Greene y A. Crick, (1998) entienden la autoeficacia como la creencia de cada uno en su capacidad para realizar con éxito las tareas emprendedoras. Prospectando entre grupos de estudiantes, gerentes y dueños de pequeños negocios, Chen demostró que los emprendedores, dueños de pequeños negocios poseen esta cualidad de la autoeficacia y propensión al riesgo, en mayor medida que los no emprendedores. En suma, son los componentes cognitivos, más que los técnicos, funcionales o generacionales, los que 
inciden en la autoeficacia. Este autor demostró que la autoeficacia es decisiva para conformar la intención de emprender. Esta característica es más importante para predecir la intención de emprender, que el locus control.

La autoeficacia permite entender porque razón algunos individuos eluden la acción emprendedora, no por falta de habilidad, sino porque no creen poseer tales habilidades.

De Noble, A. F., De Noble, A. F., Jung, J. y Ehrlich, S. B., (1999) definen la autoeficacia como una estructura que mide las creencias de las personas en sus propias habilidades para realizar las labores necesarias que conduzcan a aprovechar nuevas oportunidades de negocio. En su estudio, este autor, refiere las creencias de autoeficacia emprendedora a otros factores, como el desarrollo de oportunidades, creación de un entorno innovador, afrontar desafíos inesperados que caracterizan la conducta emprendedora. Otra conclusión a considerar en su trabajo, es el hecho de que las intenciones emprendedoras, se relacionan positivamente con la acción emprendedora propiamente dicha. Las creencias de autoeficacia emprendedora se refieren a la capacidad de afrontar desafíos y ejecutar acciones. Sin embargo la revelación entre la autoeficacia y el desarrollo de oportunidades y la innovación, no parece tan clara en los resultados de este estudio trabajo (De Noble, A. F., De Noble, A. F., Jung, J. y Ehrlich, S. B., 1999).

Reciente Oliveira, M. F., Garrido, E., y Sánchez, J. C., (2005) intentaron cuantificar el impacto del entorno social en las creencias de la autoeficacia de los emprendedores, resultando que aquellos que tienen un entorno microsocial (familia, amigos o un pariente emprendedor) en el momento de emprender, presentan mayores niveles de autoeficacia, que los que se mueven en un entorno macrosocial.

Apoya esta argumentación Krueger, N. F. Jr., (2003) cuando afirma que las variables externas afectan a la conducta, en la medida que influyen en sus intenciones y sus antecedentes. Así pues, un entorno favorable que haga sentir apoyo, aumenta la autoeficacia emprendedora, puesto que el individuo evalúa sus posibilidades con referencia a las percepciones, oportunidades y obstáculos que aprecia en el entorno. 
El estudio de Baron, R. A., y Markman, G. D., (1999), sobre autoeficacia y comportamiento emprendedor, realizado con una muestra de inventores de patentes, concluyó que los emprendedores poseen mayores niveles de autoeficacia que los no emprendedores. Únicamente la Autoeficacia se mostró como elemento vertebrador de la conducta emprendedora. Los inventores de patentes mostraron mayores niveles de autoeficacia que lo no emprendedor.

La relación entre autoeficacia y emprendimiento está, suficientemente, justificada. Son numerosos los estudios que ponen de manifiesto que las personas evitan carreras y ambientes que perciben que exceden a sus propias capacidades, y acaban emprendiendo otras donde se perciben capaces de llevarlas a cabo. La autoeficacia predice la elección de carrera, las preferencias ocupacionales, la perseverancia ante las dificultades y la efectividad personal (Bandura, A., 1997; Krueger, N. F. Jr., 2003).

Si asumimos que la iniciativa empresarial implica afrontar muchos riesgos y dificultades, es lógico pensar que los emprendedores requerirán niveles elevados de autoeficacia. Además, cuando se tiene confianza en poder alcanzar un resultado deseable, el incentivo para llevarlo a cabo es mayor, convirtiéndose la autoeficacia en un determinante del comportamiento emprendedor exitoso (Sánchez, J. C., Lanero, A., y Yurrebaso, A., 2005).

\subsection{3- PROPENSION AL RIESGO $Y$ TOLEREANCIA A LA AMBIGÚEDAD}

El primer autor en atribuir esta característica a los emprendedores fue Cantillon, en la segunda mitad del Siglo XVIII (Carland J.W. Boulton, W.R. y Carland, J.A.C., 1984).

Es obvio que la actividad emprendedora implica, por definición, asumir riesgos de algún tipo. Siguiendo a Covin, J.G., Slevin, D.P., (1989) la propensión al riesgo es, junto con la proactividad y la innovación, una de las tres dimensiones de la llamada orientación emprendedora. En este marco, la propensión al riesgo se refiere a la disposición del sujeto a comprometerse con fuentes de oportunidades bajo posibilidades 
de fracaso. Es un rasgo de personalidad que pone de manifestó la disposición del individuo a asumir riesgos. Altas puntuaciones en asunción de riesgo implican que el individuo tiene en cuenta alternativas cuyas consecuencias pueden estar alejadas de su marco de expectativas de resultados. Bajos nivel en la dimensión, implican que el sujeto no está dispuesto asumir riesgos, evitando alternativas que puedan concluir en resultados alejados de sus expectativas.

La conducta emprendedora generalmente se ha relacionado con niveles moderados de propensión al riesgo en el individuo. Sin embargo, los resultados son bastante contradictorios cuando se trata de confirmar dicha dimensión de personalidad como rasgo distintivo del sujeto emprendedor. Así, algunos estudios han evidenciado que las personas que crean una nueva empresa y luchan porque salga adelante pueden percibir y reaccionar al riesgo de forma diferente (Busenitz, L., y Barney, J., 1997; Busenitz, L. W., 1999). En la misma línea algunos estudios confirman una mayor propensión al riesgo en emprendedores fundadores de su propia empresa que en directivos de empresas ya creadas. La propensión al riesgo se convierte pues desde esta perspectiva en un predictor de la elección de carrera. Por ejemplo, Kolvereid, L., (1996) encontró que el argumento "evitar asumir riesgos" es mencionado frecuentemente como un factor impulsor en la elección de empleo en organizaciones ya existentes.

Frente a esta evidencia, otros estudios indican que los emprendedores no tienen una mayor propensión al riesgo que los directivos y la población general, incluso cuando, objetivamente, aceptan mayores niveles de riesgo en sus elecciones de carrera y decisiones de negocio. Desde esta postura se defiende que la diferencia clave entre emprendedores y no emprendedores puede ser la tolerancia al riesgo, y cómo procesan información sobre el éxito potencial de una nueva oportunidad de empresa. En esta línea diferentes estudios apoyan que los emprendedores tienden a categorizar las situaciones de negocio como menos arriesgadas que los no emprendedores (Busenitz, L., y Barney, J., 1997; Busenitz, L. W., 1999). En otras palabras, los emprendedores pueden no pensar en ellos mismos como más propensos a asumir riesgos que los no emprendedores, pero están más predispuestos a categorizar las situaciones de riesgo como positivas. 
Este rasgo es entendido por Cromie, S. y Johns, S., (1983) como la capacidad de las personas emprendedoras para buscar y emprender oportunidades productivas y moverse con soltura en un ambiente incierto. Son personas, según este autor, que no se intimidan ante situaciones arriesgadas. Afirma que existen evidencias empíricas de que los emprendedores son más propensos a arriesgarse que otros colectivos, Cromie, S. y Johns, S., (1983). Considera que la propensión al riesgo varía proporcionalmente al nivel de desarrollo del negocio. Lo que él llama Asunción de Riesgo, Vecchio, R. P., (2003) lo define como propensión al riesgo y lo identifica como la capacidad de tomar decisiones, teniendo en cuenta la capacidad de pérdidas, a cambio de una mayor recompensa potencial.

A parte de esta polémica, lo que sí parece claro es que el proceso de emprendimiento podría paliar la propensión al riesgo. Así, Brockhaus, R. y Horwitz, P., (1986) propone que los empresarios de mayor reputación pueden tener un perfil de riesgo diferente y Timmons, J. A. (1989), predice que la disposición al riesgo puede reducirse cuando hay fondos que proteger. De forma similar, Miner, J. B., (1996) observa que la evasión del riesgo es mayor entre empresarios de firmas de crecimiento rápido que de crecimiento lento.

Dorasammy, R., (2004) establece que multitud de investigadores han identificado la toma de riesgo financiera, social y psicológica como una porción de la conducta emprendedora. Tal vez el motivo del resultado fallido de esta investigación, se deba a que los experimentos de toma de riesgos empleados son parte de la propensión al riesgo en general y no circunscritos a los emprendedores.

Stewart W., Carland J. C., Carland J. W., (1998), estiman que entre los diversos instrumentos utilizados en los estudios empíricos, para medir este rasgo de los emprendedores, es la escala de toma de riesgo del cuestionario de personalidad de Jackson, T., Weiss, K.E., Ludquist, J.J., Soderlind, A., (2002) y el cuestionario del dilema de la elección de Bogan, B. y Wallach, L. (1964), los más asiduamente utilizados.

A la vista de los resultados el CDQ no parece el más idóneo para medir la propensión al riego, y tal vez esta sea la causa de la disparidad de los resultados 
obtenidos. Se cita cono paradigma el estudio de Brockhaus, R. y Horwitz, P., (1986), el cual no encontró diferencias significativas entre la propensión al riesgo de los emprendedores en relación con los gerentes, lo que tal vez provenga de utilizar este instrumento de análisis.

Rohrmann, B., (2004) en sus prospecciones prácticas sobre la actitud, propensión o aversión al riesgo aporta algunas investigaciones metodológicas interesantes de cómo el concepto ha de ser tratado adecuadamente. Aunque sus estudios no se han ceñido estrictamente a la propensión del riesgo como rasgo definitorio de la personalidad de los emprendedores, en sus conclusiones afloran algunas pautas no tenidas en cuenta por los estudiosos de la personalidad emprendedora. Afirma que aunque haya gran cantidad de estudios sobre la percepción del riesgo, es escasa la labor investigadora en cuanto a los esquemas mentales previos a la asunción de riesgo y actitudes para el riesgo, tales como propensión y aversión al riesgo.

Rohrmann, B., (2004) estima que las personas tienen distintas actitudes frente al riesgo, que van desde la cautela hasta el placer. La conclusión de su estudio establece que las actitudes frente al riesgo son dimensiones diferentes, que las orientaciones individuales frente al riesgo únicamente son sólidas en determinadas situaciones coyunturales, y que las motivaciones para asumir el riesgo son variables, dependiendo del tipo de riesgo.

Para él, las categorías aludidas (propensión, búsqueda y aversión al riesgo) son definidas en la literatura científica de modo oscuro, a veces ilógico. Esta ambigüedad terminológica la resuelve aportando nuevas definiciones, que tratan de obviar los inconvenientes apuntados.

a) Riesgo: Posibilidad de que se produzca un daño, detrimento o pérdida física, social o financiera. Amén de esta definición negativa, en la definición del riesgo cabe una definición neutral, los riesgos de una decisión pueden ser buenos o malos; y una definición positiva, el riesgo como emoción, los riesgos producen sentimientos de excitación. 
b) Magnitud del riesgo: El juicio (creencia, opinión) de una persona sobre el volumen del riesgo asociado al peligro (orientación negativa).

c) Actitud ante el riesgo: se trata del esquema mental del individuo para evitar o encarar el riesgo, cuando los resultados son inciertos. Esta actitud puede ser de dos tipos: propensión al riesgo y aversión al riesgo (actitud tendente a evitar el riesgo).

d) Aceptación o excusa del riesgo: alude a una decisión para determinar que volumen de riesgo es aceptable en términos individuales o sociales.

e) Conducta de riesgo: Conducta de las personas al afrontar una situación de riesgo.

Estas definiciones de propensión y aversión al riesgo, afirma el autor, han de ser entendidas como actitudes y deben ser evaluadas adecuadamente.

Los términos propensión y aversión al riesgo, han sido entendidos como un rasgo, un estado o una actitud. Entre las categorías de riesgo distingue el riesgo físico, accidentes o enfermedades; Riesgo financiero, inversión, juego, apuestas; Y riesgo social, concurrir a las elecciones, descubrir la homosexualidad Rohrmann, B., (2004).

El autor concluye que puede afirmarse, con cierta probabilidad, que la actitud hacia el riesgo tal vez no sea un rasgo de la personalidad dimensional. Si no que puede ser influenciada por otras características de la personalidad, tales como la búsqueda de sensaciones o la impulsividad.

Lumpkin, G. T. and Dess, G. G., (1996) relacionan la propensión al riesgo con los procesos de innovación, lo que no impide que entiendan este riesgo como válido para la predicción de la orientación emprendedora.

Estudios recientes han encontrado que la tolerancia y las actitudes positivas hacia el riesgo predicen la formación de intenciones emprendedoras Sánchez García, J.C. (2010). Igualmente, se ha encontrado que la propensión al riesgo está 
positivamente asociada con las intenciones de autoempleo, a través de su influencia sobre ciertos predictores de éstas, como la autoeficacia Zhao, H., Seibert, S.E y Hills G.E. (2005).

Son muchos los autores que relacionan las dimensiones de asunción de riesgo y tolerancia a la ambigüedad o incertidumbre.

Scherer, R. F., Brodzinski, J. D., y Wiebe, F. A., (1991) afirman que la tolerancia a la ambigüedad es un rasgo a tener en cuenta en la acción emprendedora, puesto que los desafíos y el potencial de éxito derivado de la creación de un negocio, son imprevisibles. Sin embargo tales juicios son contradictorios, lo que puede derivarse, posiblemente, de la metodología utilizada en las investigaciones. Segal, G., Borgia, D. y Schoenfeld, J., (2005 entienden que desde el campo de la Psicología, es más estricto hablar de ambigüedad que de incertidumbre, pues ésta primera se circunscribiría a disyuntivas conocidas mientras que incertidumbre afectaría a alternativas desconocidas.

Shane, S., Lochey, E., y Collins, C, J., (2003) definen la tolerancia a la ambigüedad como la capacidad para vislumbrar situaciones sin resultados, como atrayentes en vez de amenazadoras.

Cromie, S. y Johns, S., (1983) entienden la tolerancia a la ambigüedad como la capacidad de los emprendedores para tomar decisiones careciendo de determinadas informaciones necesarias para ello, es decir, en una situación de incertidumbre. Incluso, afirma, que este atributo es definitivo para distinguir entre emprendedores y no emprendedores.

Los individuos más conservadores, suelen ser menos tolerantes a la ambigüedad o la incertidumbre. Tienden a ser dogmáticos, se inclinan más frecuentemente a recibir información de apoyo y menos de tipo objetiva. Buscan, como un fin evitar, el conflicto y la ansiedad, tratan de huir de las cuestiones complejas y novedosas.

Hofstede, G., (1998) considera que la tolerancia a la incertidumbre puede estar influenciada por diferentes normas de origen social, ritual, educativo, religioso o tecnológico, lo que parece conducir a procesos cognitivos. También hace referencia a la 
distinción entre creatividad e innovación. En este sentido, considera la innovación como la piedra angular del emprendedorismo, siguiendo el mismo pensamiento que Drucker, P., (1986). Considera que la creatividad poco tiene que ver con la innovación, se refiere más que otra cosa a la búsqueda sistemática de modificaciones en el ambiente de trabajo o el entorno, búsqueda de nuevas oportunidades. Por tanto la innovación, a su entender, no sería un rasgo de la personalidad sino un esfuerzo sistemático.

Por el contrario Krueger, N., (2004) establece una estrecha relación entre creatividad e innovación, cuando afirma que la creatividad es el punto de partida de la innovación, lo que conduciría al proceso emprendedor. Este autor considera que la creatividad es fundamental para identificar la oportunidad de negocio. Concluye que creatividad es más un proceso, mediante el cual las innovaciones son desarrolladas.

\subsubsection{1-4- PROACTIVIDAD}

La literatura científica identifica la proactividad como un importante propulsor de la intención emprendedora (Krueger, N. Y Brazeal, D., 1994; Shapero, A., 1982; Crant J., 1996).

Podemos definirla como el rasgo que poseen algunas personas para identificar diferentes oportunidades, y actuar sobre ellas. Implicaría iniciativa, realizar acciones directas y perseverar hasta conseguir un cambio significativo. La proactividad pone el acento en la anticipación, en ser capaz de prevenir los problemas antes de que ocurran y tener una clara orientación a la acción. (Sánchez, J. C., Lanero, A., y Yurrebaso, A., (2005).

Asumida por Covin, J.G. y Slevin, D.P., (1991) como dimensión básica en la llamada orientación emprendedora, implica perseverancia, capacidad de adaptación y alta disposición a asumir la responsabilidad ante el fracaso en la acción de emprender. Los individuos proactivos buscan, continuamente oportunidades de negocio, lo mismo que las organizaciones en los mercados (Stevenson, H. H., y Jarillo, J. C., 1990; Lumpkin, G. T. and Dess, G. G., 1996). 
Encontramos estudios que relacionan proactividad con comportamiento emprendedor, tanto en empresas ya creadas como en la población en general (Jennings, R., Cox, C. y Cooper, C.L., 1994). Otros evidencian la relación de proactividad en el contexto de orientación emprendedora y el desarrollo empresarial (Davidsson, P., 2006; Brown, R., 1988).

Afirma Shapero, A. (1982) que la propensión personal a actuar sobre las oportunidades es uno de los factores que más pueden influir sobre la realización intención - comportamiento, precipitando o facilitando la realización de intenciones.

\subsection{5,- LA NECESIDAD DE LOGRO}

Podría definirse como el esfuerzo denodado de una persona para obtener el éxito. Apunta Cromie (2000) que este rasgo es el atributo más importante del emprendedor, hasta el punto que McClelland, ${ }^{9}$ D. C., Atkinson, J. W., Clark, R. A. y Lovell, E. L. (1953), lo conciben como una forma de vida más que una actitud. Este tipo de personas que sienten la necesidad de superarse a sí mismos para obtener una meta, son autoexigentes, activos, osados, en el cumplimiento de sus objetivos.

El primero en asociar este rasgo con el emprendedor fue McClelland, D.C., (1953). Sin embargo Filion, L. J. (2003) confirma que aunque McClelland atribuyó esta característica al emprendedor, en su producción científica no establece una relación clara entre la necesidad de logro y la puesta en marcha de una empresa, e incluso, con el hecho de ser propietario o administrador de la misma. Otros autores admiten que McClelland argumenta que personas con una intensa necesidad de logro son más propensas a actividades innovadoras, que requieren una amplia planificación y un plus de responsabilidad en los resultados (Collins, C. J., Hanges P. J. y Locke E. A., (2004).

Las conclusiones del estudio pragmático de (Collins, C. J., Hanges P. J. y Locke E. A., (2004).ponen de manifiesto que los individuos que realizan actividades

\footnotetext{
${ }^{9} \mathrm{La}$ define como (nAnch), considerando que los individuos con alta motivación de éxito y triunfo, muestran en sus comportamientos más iniciativa. Buscan en sus entornos, continuamente, desafíos y retos que les permitan ponerse a prueba y demostrarse a sí mismos si son capaces de triunfar. Los emprendedores son personas con un elevado (nAnch).
} 
emprendedoras presentan niveles más elevados de necesidad de logro que otros que se dedican a otro tipo de actividades. Admitiendo, además, que la necesidad tiene efectos no sólo en el inicio de la actividad emprendedora, sino también en su desarrollo.

La medida de ese éxito puede ser el dinero u otro género de ganancias. Este tipo de personas con una fuerte necesidad de logro, poseen un mayor nivel de autoconfianza, moderación al riesgo, investigan el entorno, tienen iniciativa y están interesados en controlar y plantear concienzudamente los procesos. Sin embargo Cromie (2000) concluye que los estudios científicos que han tratado de medir este rasgo en los emprendedores, han llegado a resultados poco claros y concluyentes, sin llegar a establecer con claridad la relación entre la necesidad de logro y la propensión de iniciar negocios.

Hansemark, O. C., (2003), por el contrario, confirma que entre los atributos psicológicos del emprendedor estudiados empíricamente, únicamente dos: la necesidad de logro y el locus de control, ofrecen resultados significativos.

El estudio de Steward, W., y Roth, P. (2001), usando el método de revisión meta-analítica, ha confirmado que los emprendedores poseen un nivel de necesidad de logro, ligeramente más elevado que los gerentes, lo que confirma la aseveración clásica de que el emprendedor está más orientado al logro, que aquellos que realizan funciones gerenciales.

\subsubsection{2.- NUEVAS ORIENTACIONES EN EL ENFOQUE DE LA PERSONALIDAD}

A tenor de los inconsistentes, imprecisos y a veces contradictorios resultados en numerosos estudios, existe un consenso generalizado, entre los investigadores, de la insuficiencia de utilizar el llamado enfoque de la personalidad como único predictor de la conducta emprendedora.

Ya en los años 80 surge esta desazón ante la teoría de los rasgos de la personalidad, y aunque es innegable la utilidad de los estudios sobre los rasgos de 
personalidad, no se consideran determinantes para explicar la definición de emprendedor, ni la conducta emprendedora, lo cual abre nuevos horizontes en la literatura científica, (Mitchell, R. K., Busenitz, L., Lant, T., McDougall, P. P., Morse, E. A., y Smith, B., 2002).

Aunque la literatura científica es amplia en el campo de los rasgos, no hay consenso en cuáles son los elementos nucleares que distinguen al emprendedor del no emprendedor (Dorasammy, R. , 2004). Ello es debido a la naturaleza inestable de los rasgos, la subjetividad de los juicios y la escasa atención a los factores culturales y de medio ambiente, sin tener en cuenta otros elementos como el género, la clase social, o la educación, que lógicamente influirán en el emprendedor.

Chell, E., Haworth, J. y Brearley, S. (1991) proponen el constructivismo social como nuevo enfoque. Afirma que el concepto de personalidad no es determinante; aunque una persona perciba situaciones de negocio, las percibe como oportunidades, por tanto la conducta se producirá como consecuencia de una acción, el perseguir o no las oportunidades.

Se atribuyen tres errores importantes en las investigaciones fundamentadas en la personalidad: El hecho de que muchos estudios investigan rasgos globales, dejando de lado las específicas habilidades del emprendedor. Otros relacionan personalidad y éxito del emprendedor, ignorando el papel de la conducta emprendedora, y, el hecho de que, frecuentemente se utilizan métodos estadísticos inadecuados. Tras investigar los efectos positivos de los rasgos, los consideran importantes cuando se ciñen a las situaciones específicas del trabajador emprendedor. Estos autores, han estudiado los efectos positivos de algunos rasgos (necesidad de logro, auto-eficacia, alta necesidad de orientación) en la conducta innovadora y de iniciativa, concluyendo que las variables de personalidad son de interés cuando tienen en cuenta las situaciones específicas del trabajo del emprendedor, Davidsson, P., y Wiklund, J., (2001).

Hay estudios que, incluso, reconocen que no hay característica, predisposición o conjunto de rasgos en el nivel de análisis individual del emprendedor que prediga el emprendizaje con cierta consistencia, (Lumpkin G. T., Dess G.G., 2001). 
Filion, L.J., (2003) considera que los estudios centrados en la conducta son mejores predictores del éxito emprendedor que los de los rasgos de personalidad, por lo que, éstos últimos, acabarán desapareciendo.

Ante este panorama, no es de extrañar que nuevas variantes de la teoría de los rasgos se abran camino en la literatura científica. A saber: el modelo de los cinco grandes para predecir la conducta emprendedora, aplicado conjuntamente, con el modelo de intenciones de Azjen, una vez que las investigaciones de Krueger, N. F., Reilly, M. D., y Carsrud, A. L., (2000), sobre este modelo, y el del Evento Emprendedor de Shapero, eran óptimas para predecir estas conductas, y fundamentalmente, modelos que relacionan los rasgos con otras variables socioculturales del entorno.

Superando limitaciones, estos nuevos enfoques han provocado un renovado interés en el estudio de los rasgos de personalidad emprendedora como predictores del éxito, relacionándolos con las competencias, motivaciones, la cognición y la conducta, Baum, J. R. y Locke, E. A., (2004).

\section{El modelo de los cinco grandes;}

Surge como la gran teoría de la personalidad en los últimos años. Sus defensores creen que el modelo se basa en la personalidad individual de cada ser humano, sin interferencia de la cultura o el ambiente. Incluye cinco grandes rasgos o parámetros, más genéricos que específicos, sin que exista un claro acuerdo sobre el contenido conceptual de los mismos:

- Ajuste, también denominado estabilidad emocional: mide en un continuo, del estable al neurótico.

- Sociabilidad: de lo extrovertido al introvertido.

- Franqueza intelectual: de imaginativo e interesado en muchas cosas a práctico y estrechamente enfocado 
- Conformismo: de benévolo a beligerante

- Racionalidad: de fidedigno y meta-orientado a independiente e impulsivo.

En su primera aplicación compara hombres y mujeres emprendedoras, no encontrando diferencias significativas entre ambos sexos, en cuanto a estabilidad emocional, sociabilidad, y conformismo. Sin embargo, son más abiertas que los hombres, pues presentan altos niveles de franqueza intelectual. Sin embargo los hombres son más racionales.

Surgen numerosos estudios al amparo de este enfoque. Rodermund, E. S., (2004) entiende que la personalidad emprendedora se caracteriza por altos niveles de extroversión, la sociabilidad en el modelo anterior, así como bajos niveles de conformismo y descontrol emocional, lo que, por otra parte, les garantiza el éxito. La orientación al logro, la ambición y la persistencia son características de la personalidad emprendedora que estarían relacionadas con la dimensión racionalidad. Sugiere, en base a sus resultados, que los individuos abiertos, racionales y no acomodado son los más compatibles con la creación de un negocio. Teniendo gran peso las características personales del emprendedor, no sirven para explicar todos los determinantes de su conducta.

Brice, J., (2004) aplica en sus investigaciones al modelo de intenciones de Ajzen, I. y Fishbein, M., (1980) y el formulario de los cinco factores de la personalidad como instrumento de medida, concluyendo que la racionalidad y la mente abierta a las experiencias, son caracteres positivos en cuanto a la acción emprendedora; mientras que el conformismo se considera una actitud negativa. Abunda en que la orientación al logro, la ambición y la perspectiva caracterizan el afán emprendedor.

Por su parte, Baron, R. A., y Markman, G. D., (1999), que estudian el emprendedorismo como un proceso, usando la teoría de los cinco grandes, junto con otras variantes de carácter demográfico, cognoscitivo y de motivación, llegan a la conclusión que el talante extrovertido incide positivamente en la resolución de crear un negocio. 


\section{El modelo de las configuraciones;}

Se trata sin duda, de una de las más modernas corrientes doctrinales que analiza la personalidad emprendedora. Propuesto por Korunka, C., (2001), el modelo de las configuraciones entiende que la personalidad emprendedora debe ser considerada en relación con otras variables y con el entorno. Define La configuración como entidades multidimensionales, en las que atributos claves se interrelacionan y se refuerzan mutuamente. La personalidad emprendedora se define como un área de configuración en relación con otras áreas: recursos personales (educación, experiencia, posición financiera, renta y apoyo bancario). Entorno macrosocial y microsocial, y actividades de organización (planificación, decisiones, fracaso, acción), (Korunka, C., 2001).

Para muchos autores, el hecho de que las personas lleguen a emprender, no va a depender sólo de los rasgos de personalidad que estos posean; la influencia de factores culturales, económicos y psicológicos será determinante (Landström, H., 2005; Ripollés, M., 1995; Ribeiro-Soriano, D. y Urbano, 2009). Otros resaltan las tradiciones sociales y culturales como elementos significativos a la hora de fijar que personas puede llegar a ser emprendedoras, señalándolos como elementos claves del entorno que pueden regular la capacidad emprendedora de los individuos (Staley, E. y Morse, R., 1971).

Todas estas variables, además de otras dimensiones importantes ya contrastadas por similares herramientas, están recogidas en el COE; Cuestionario de Orientación Emprendedora del profesor José Carlos Sánchez de la Universidad de Salamanca (2010), que utilizaremos en la parte empírica de nuestra investigación. Definiremos los parámetros y variables que fueron soporte para su elaboración, por contener los ítems necesarios que nos permitirán corroborar si la persona encuestada tiene o no perfil emprendedor.

\subsubsection{2- LA ORIENTACIÓN DE LA CONDUCTA}

Este enfoque aborda al emprendedor desde lo que éste hace, o ha hecho, ciñendo su estudio a la conducta que desarrolla. Trata de abordar diferentes aspectos vinculados 
al comportamiento, estudiando todas aquellas características que se utilizan para definirlo.

Es curioso como en la literatura científica podemos encontrar numerosos autores que tratan de deslindarse el enfoque tradicional de los rasgos, por entenderlo insuficiente como modelo explicativo del emprendizaje, asumiendo que la conducta emprendedora explica mejor el concepto de emprendedor como el individuo que asume riesgos, que es un creador de negocios, donde además de los factores de personalidad, el emprendedor debe desarrollar ciertas habilidades y capacidades para poder emprender (Peacock, R.,2000), afirmando, incluso, que el estudio de los rasgos es importante, únicamente, si va dirigido a explicar su conducta.

La mayoría de estudios que encontramos en la orientación de la conducta identifican la conducta emprendedora con la acción de crear negocios o gestionarlos. Enfoques, igualmente importantes, serán el de la innovación como característica distintiva de la conducta emprendedora, y el de los factores motivacionales como responsables de la misma. Especial significación ha adquirido, a tenor los resultados que brinda, el modelo de intenciones aplicado a la conducta emprendedora (Ajzen, I. (1991) en su intento de predecir este comportamiento, por lo que abordaremos este modelo en profundidad.

Es la creación de negocio lo que identifica al emprendedor, así no todos los dueños o gerentes de empresa son emprendedores, ya que muchos adquirieron las empresas que otros crearon, sin aportar cambios significativos; por tanto, no han desarrollado una conducta emprendedora, entendida como la conducta de creación de negocios Filion, J.L., (2003). El emprendedor sería la persona que inicia un negocio con prácticamente nada, excepto lo que ella aporta, sea un concepto, unos pocos contactos, acaso algún capital. Todas esas cualidades intangibles son importantes para el éxito de un nuevo negocio (Brodsky, M.A., 1993). Es emprendedor quien produce y explota nuevos productos, nuevos procesos de producción y novedosos modos de organización. Quien se ocupa de dirigirlo a la expansión (Allinson, CH.W, Chell, E. y Hayes, J. (2000). 
Son muy pocos los investigadores que no relacionan al emprendedor con la conducta de creación de negocios, si bien es cierto que cuando dirigen su atención hacia otro tipo de conductas no relacionadas con la actividad empresarial, vuelven la mirada a los estudios de las características de personalidad. Gelderen, M., Bosma, N., Thurik, R, (2001) entienden que si el concepto de emprendimiento se concibe en base a la posesión de ciertas cualidades psicológicas (autonomía, asunción del riesgo, proactividad, competitividad, agresividad e innovación). El individuo que las posea puede mostrarlas en cualquier situación, en cualquier contexto, al margen de la creación de negocios. El emprendimiento sería la cualidad que un individuo posee para producir alguna ventaja, Gelderen (2000). En este mismo sentido se pronuncian Schultz, W., (1980) y Baumol, W.J., Litan, R.E. y Schramm, C.J., (2009).

\subsubsection{1- LA CONDUCTA EMPRENDEDORA}

La principal conducta que se atribuye a los emprendedores es la de crear negocios, aunque no es la única, pues es necesario tener en cuenta otras, como la identificación de las oportunidades de negocio, la apertura y gerencia, o el mantenimiento del mismo. Todas esas acciones que el individuo lleva a cabo para crear y poner en marcha el negocio hacen referencia a la conducta o actividad emprendedora. Diferentes autores, aportan su particular clasificación en este sentido:

Chell, E., (2000) desde el constructivismo social, afirma que la conducta emprendedora es secuencial, ya que el emprendedorismo es un proceso. La conciencia emprendedora se mantiene a lo largo de la vida del negocio, en tanto que siga produciendo beneficios. Destaca las siguientes conductas atribuidas al emprendedor;

- Propensión a crear negocios.

- Búsqueda de nuevas oportunidades de negocio.

- Buscar soluciones innovadoras a los problemas. 
- Tener autonomía, planeamiento estratégico en la organización de los recursos para transformar las oportunidades en ventas.

- Esforzarse en la obtención de beneficios y en la expansión del negocio.

- Asumir riesgos.

La identificación de oportunidades es avalada como conducta distintiva del emprendedor por muchos autores (Minniti, M., y Lévesque, M., 2008; Filion, J.L., 2003). Este último afirma, a su vez, que la independencia, es una de sus señas de identidad. El individuo emprendedor usa sus propios juicios para tomar las decisiones referidas al negocio, (Filion, J.L., 2003).

Estos autores coinciden al afirmar que son cinco las acciones integrantes de la conducta emprendedora:

- Encontrar y perfilar las oportunidades.

- Adquirir los recursos necesarios para la puesta en marcha del negocio.

- Gestionar el negocio en el día a día.

- Identificar a los clientes y vender el producto.

- Aislar el negocio de los problemas de otra índole, sean personales, familiares, amistades, etc.

Del análisis pormenorizado de la doctrina científica, y resumiendo las aportaciones más significativas, podemos destacar seis conductas características del emprendedorismo:

1.- Desarrollo de nuevas oportunidades de negocio y nuevos productos.

Probablemente se trate de la conducta más analizada en la doctrina, constituye la 
esencia del emprendizaje; no podemos hablar de emprendedorismo sin abordar esta conducta, (Minniti, M., y Lévesque, M., 2008; Filion, J.L., 2003; Fillion, 2003; Chell, E., Haworth, J. y Brearley, S., 1991).

Los emprendedores buscan nuevas oportunidades introduciendo nuevos productos o mejorando los ya existentes; lo cual presume ciertos desafíos; incluso las oportunidades pueden influir la conciencia emprendedora, debido a los costes económicos que pudiera tener cada una de ellas.

Krueger, N. (2004) define la oportunidad como la búsqueda de posibilidades de explotación comercial de nuevos productos, procesos, mercados, o modos de organización, la aceptación del riesgo de pérdidas, e incluso el fracasar de la propia oportunidad a cambio de realizar altos niveles de crecimiento. A su vez, relaciona esta conducta con la creatividad; o dicho de otro modo, asume la identificación de oportunidades de negocio como la clave de la actividad creativa del emprendedor. En el mismo sentido opinan De Noble, A. F., Jung, J. y Ehrlich, S. B. (1999); Shane, S. y Venkataraman, S., (2000), quienes definen las oportunidades como situaciones en las que mediante la introducción de nuevos bienes, servicios y materias primas en el mercado, arbitrando nuevos métodos de organización, se producen ventas en mayor medida que los costes de producción, generando, así, el esperado beneficio.

Apuntan la diferencia entre el emprendedor y el gerente, precisamente en esta capacidad para descubrir y aprovechar las oportunidades de negocio. El emprendedor es hábil en identificar las oportunidades, el gerente en mantener la rentabilidad del gerente (De Noble, A. F., Jung, J. y Ehrlich, S. B., 1999).

2.- Desarrollar un ambiente innovador; Se trata de la capacidad de un individuo para impulsar a otras personas con las que trabaja a hacer cosas nuevas, nuevas ideas, nuevos alicientes, asumiendo la responsabilidad de los resultados. Un emprendedor debe ser capaz de establecer un ambiente innovador donde antes no existía nada. (De Noble, A. F., Jung, J. y Ehrlich, S. B., 1999).

3.- Iniciar relaciones con Inversores; Serían las acciones dirigidas a la obtención de fondos para capitalizar la empresa, estableciendo contactos con posibles inversores 
(De Noble, A. F., Jung, J. y Ehrlich, S. B., 1999). Esta conducta está relacionada con la capacidad emprendedora de allegar los recursos necesarios para la implantación del negocio. Sería lo que Chell, E. (2000) refirió como que la conducta emprendedora no está limitada a los dueños del capital.

4.- Precisar los objetivos del negocio; Consistiría en propiciar los incentivos necesarios para atraer al personal decisivo: gerencia, empleados, inversiones. El individuo que no posee niveles ponderados de autoeficacia, es improbable que se sienta motivado para iniciar un negocio, (De Noble, A. F., Jung, J. y Ehrlich, S. B., 1999).

5.- Saber como actuar ante desafíos inesperados; Tener la suficiente capacidad para neutralizar la ambigüedad y la incertidumbre. De Noble (1999) considera que los desafíos procederán de los inversores, las fluctuaciones del mercado y otros factores.

\section{6.- Allegar los Recursos Humanos necesarios para la implantación del} negocio; La selección del personal adecuado a las específicas necesidades del negocio, es importante para la consecución de los objetivos y el éxito de la actividad (De Noble, A. F., Jung, J. y Ehrlich, S. B., 1999).

Si bien es cierto que existe cierto consenso entre los diferentes autores a la hora de considerar éstas como las más importantes conductas identificativas del emprendedor, quiero referenciar la conducta innovadora, vinculada a la creación y crecimiento de todo negocio, como distintiva de la conducta emprendedora. Introducida por Schumpeter ha sido avalada por numerosas investigaciones (Butler, J. y Hansen, G., 1991; Peacock, R., 2000; Filion, L.J., 2003; Rao, D. R., 2004).

Otro enfoque, igualmente importante, es el que vincula conducta emprendedora y motivaciones del emprendedor, (Shane, S., Lochey, E., y Collins, C, J., 2003; Segal, G., Borgia, D. y Schoenfeld, J., 2005).

Aun asumiendo que el emprendizaje depende de factores externos, tales como la situación de la economía, la viabilidad de capital necesario del negocio o las leyes de un país, y que todo ello influyen, finalmente en la acción de emprender, afirman que las 
motivaciones humanas influyen en las decisiones de emprender, por tanto cualquier variación sobre la motivación de la persona, mediará en quien descubre la oportunidad de negocio, en quien localiza y aglutina los recursos necesarios, y en el modo concreto como acabe emprendiendo, (Shane, S., Lochey, E., y Collins, C, J., 2003

\subsection{1.- EL MODELO DE INTENCIONES APLICADO A LA CONDUCTA EMPRENDEDORA}

Las investigaciones basadas en la intención ponen de manifiesto la contribución de la intención como predictor individual de la conducta planificada. Constituyen un marco coherente y sólido que ayuda a comprender los procesos de emprendizaje (Sánchez J.C., 2005 y 2010).

Bird, B. (1988) define la intencionalidad como un estado mental que conduce al individuo a un objetivo concreto. Otros autores, (Chen, C. P., Greene y A. Crick, 1998; De Noble, A. F., Jung, J. y Ehrlich, S. B., 1999; Kickul, J. y Zaper, J.A., 2000) entienden que la intención depende de otras variables (independientes) que pueden ser de tipo personal, del entorno social, económico o incluso organizativo. Vesalainen, J. Y Pihkala, T., (1999) afirman que las intenciones emprendedoras van dirigidas a la creación de nuevos negocios, o a aumentar los valores de los ya existentes. La intencionalidad, según afirman, incluiría pensamientos racionales y analíticos y pensamientos globales intuitivos. La intención emprendedora dependería de la personalidad, pero también de la situación vital de la persona, de los cambios de objetivos, preferencias, o contingencias. Estos autores atribuyen a la autoeficacia un papel preponderante sobre la intencionalidad, ya que la autoeficacia puede incentivar, $\mathrm{u}$ obstaculizar tal intención.

Kickul, J. y Krueger, N. A., (2004), utilizando un modelo de ecuaciones estructuradas, han podido demostrar que los factores personales y cognitivos, tienen un efecto directo en la autoeficacia emprendedora, así como en los antecedentes de la acción de emprender (posibilidad de viabilidad y conveniencia) y en la propia intención. En suma la viabilidad se relaciona con la conveniencia y ambas con la intención. Además observaron una relación directa entre la intención de emprender y las creencias 
de autoeficacia, relación con los inversores, definición del objetivo de negocio, la posibilidad de afrontar desafíos inesperados.

Kickul, J. y Zaper, J.A., (2000) investigaron en un grupo de empleados, la influencia de factores personales y del contexto organizacional en la intención del emprendedor. Tales son la personalidad proactiva, caracterizada por la presencia de rasgos de necesidad de logro, locus de control, tolerancia a la ambigüedad, propensión al riesgo, persistencia y dominio, y compromiso organizacional. Los resultados pusieron de manifiesto una interacción entre los factores individuales y organizacionales, en la acción emprendedora. Los individuos que no se sentían obligados a permanecer en la organización y que poseían una personalidad proactiva, eran más propensos a la acción emprendedora, a crear su propio negocio. La ausencia de lealtad y de compromiso del empleado, respecto a la organización, en individuos proactivos, generaba una fuerte inclinación a crear un negocio propio.

El modelo conceptual del proceso emprendedor considera que la acción emprendedora es el resultado de un complejo proceso, en el que intervienen intenciones, actitudes, así como variables del entorno y otros factores. Las variables personales incluyen rasgos de la personalidad; mientras que los factores externos incluyen variables relacionadas con el Marketing, las finanzas, y otros aspectos sociales. Los rasgos de la personalidad son eficaces y se relacionan con factores situacionales.

Vemos como, de entre todos estos diferentes estudios, en la Psicología Social, dominan los basados en la propuesta de Ajzen, I. y Fishbein, M., (1980), junto con los elementos principales de la Teoría del Aprendizaje Social y Autoeficacia de Bandura, A (1986), e incluso el Modelo del Evento emprendedor de Shapero, A. (1982).

En su modelo inicial, conocido como Teoría de la Acción Razonada, demuestran cómo la intención dependía de la actitud y de la norma subjetiva Más tarde Azjen, en sus esfuerzos por comprender la conducta humana, entiende que pueden enfocarse desde diferentes puntos de vista, teniendo en cuenta los procesos psicológicos o considerándolo desde las instituciones sociales, o bien de las actitudes sociales o los rasgos de la personalidad. Ahondando en sus investigaciones sobre el comportamiento humano surge, un nuevo marco conceptual, La teoría de la conducta 
planeada, en un intento de predecir y explicar la conducta humana en contextos específicos, (Azjen, I., 1999).

La principal premisa de esta teoría es que las intenciones que conducen a realizar determinadas conductas, pueden ser predichas en función de determinadas variables. Azjen llama a estas variables subjetivas de determinantes o antecedentes de intenciones, conceptualmente independientes. Estas variables son las siguientes:

La actitud para la acción: referida a la valoración que uno hace sobre determinada conducta, sea favorable o no. Se relaciona con la percepción de la persona sobre el resultado de una conducta. Si uno percibe como favorable el resultado de una conducta, es más probable que la realice.

Las normas subjetivas: alude a la presión social que un individuo percibe respecto a la realización o no de una determinada conducta. Es una influencia externa que condiciona la toma de decisiones. Si las personas del entorno de un individuo esperan que este realice una conducta es más probable que este la ponga en práctica, que si la actitud de las personas que le rodean fuere negativa.

El control percibido de la conducta: es la percepción del individuo en orden a la dificultad o facilidad de ejecutar una determinada conducta. Si el individuo percibe una conducta como factible, hay mayor probabilidad de que se realice. Este control percibido es un concepto cercano al de la autoeficacia de Bandura. Este control percibido de la conducta incide más sobre las intenciones que sobre la conducta real, según Azjen, (Azjen, I., 1999).

La teoría de la conducta planeada postula que cuanto más favorable sea la actitud, las normas subjetivas, y el control percibido hacia una conducta, aumentará la intención de un individuo hacia la realización de esa conducta, (Azjen, I., 1991). Ahora bien, el propio Azjen relativiza el impacto de cada uno de esos antecedentes de intenciones, como motivante de una conducta variando al compás de las diferentes situaciones. En ocasiones, únicamente las actitudes ejercen un influjo suficiente sobre las intenciones. En otros casos, las actitudes y el control percibido de la conducta 
justificarán el aumento de las intenciones. Para otros supuestos, cada una de las tres variables contribuye independientemente a la ejecución de la conducta

El modelo diferencia, claramente, dos dimensiones de análisis; la intención (previa a la conducta, en este caso la intención de abrir un negocio o emprender) y la conducta final, a la que, se supone, conduce la intención (abrir el negocio). Este estudio se centrará en la segunda dimensión, por tomar como muestra a un colectivo de empresarios emprendedores que han materializado su idea de negocio.

Krueger, N. F., Reilly, M. D., y Carsrud, A. L., (2000), tras comprobar en su investigaciones que las variables situacionales (pérdida de empleo) e individuales (rasgos de la personalidad) ofrecían resultados empíricos parciales e inconsistentes para las predicciones de la conducta emprendedora, optó por la Teoría de la Conducta Planeada de Azjen y el Modelo del Evento Empresarial del economista Shapero, A. (1982). Los resultados de su investigación, le llevan a concluir, que las intenciones son los elementos más importantes de la conducta al emprendedorismo antes que las variables situacionales e individuales que ejercen una influencia indirecta en el emprendedor. La intención ejerce una función mediadora entre la acción emprendedora y las potenciales influencias externas. La intención es el estado cognitivo inmediatamente anterior a la ejecución de una conducta. Las actitudes influyen en la conducta, por su impacto en las intenciones, del mismo modo que las intenciones y actitudes dependen de la situación (Krueger). En el modelo de las intenciones además de las variables aludidas, influyen otros factores variables del individuo, tales como su nivel de educación, estado civil y experiencia vicaria.

La $\mathrm{TpB}^{10}$ está gráficamente representada en la figura presentada a continuación.

${ }^{10} \mathrm{TpB}$; Teoría de la Conducta Planeada (Azjen, 1999) 
Fig. 1.3. Teoría de la Conducta Planeada.

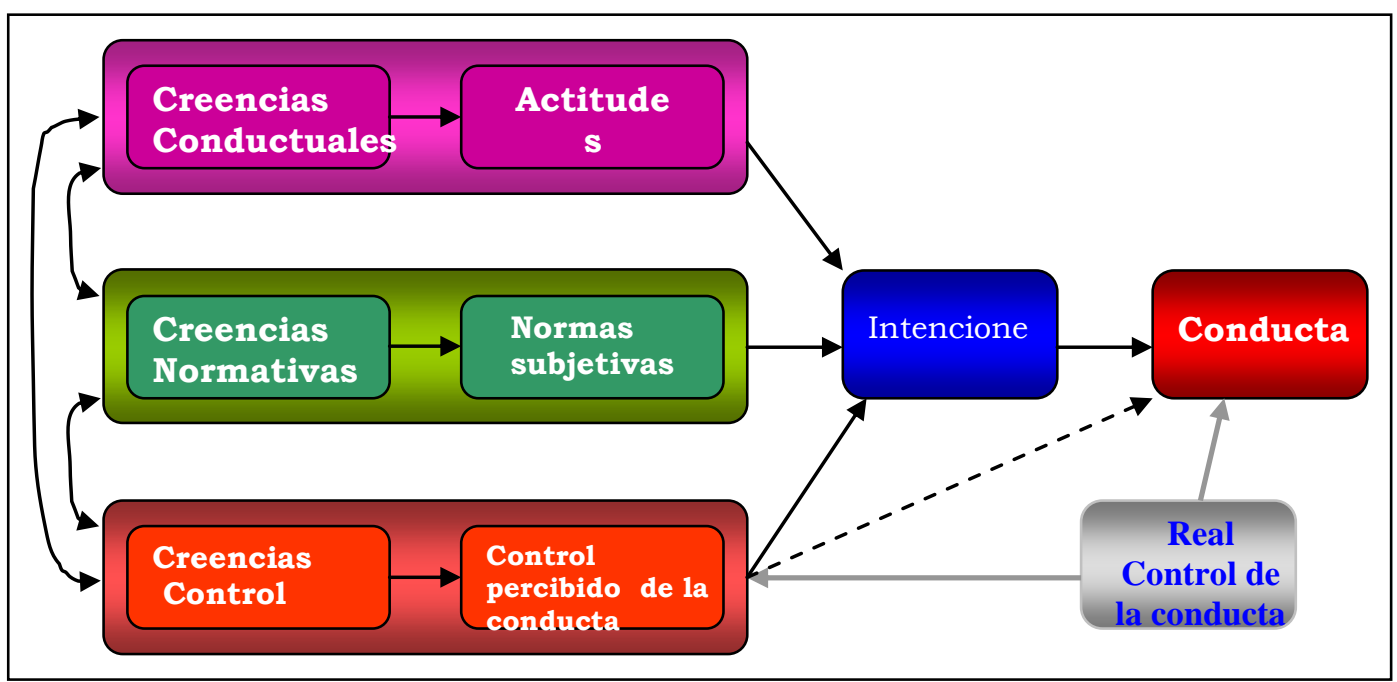

Fuente Azjen I, 1999

Scholten, V., Kemp, R. y Omta, S. W. F., (2004) aplica la TpB a la conducta emprendedora. Primero definieron los antecedentes de la intención; La actitud para el emprendimiento, se referiría a las creencias sobre los posibles resultados que obtendrían al crear un negocio y la evaluación que harían de estos resultados; La norma subjetiva, que incluye las creencias sobre las expectativas de los demás referentes a la conducta emprendedora y las motivaciones para cumplir con estas expectativas, sería la imagen del emprendimiento; y, finalmente, el control percibido de la conducta, que incluye las creencias sobre la presencia de factores que pueden facilitar o impedir la creación del negocio, y el poder percibido de controlar estos factores (creencias de control).

Concluyen, tras su investigación que la intención de emprender será mayor cuanto más favorable sea la actitud y las normas subjetivas y mayor el control percibido por el sujeto, (Scholten, V., Kemp, R. y Omta, S. W. F., 2004).

Defienden además, que otras variables al margen de las que integra el modelo de intenciones, como los factores personales individuales (educación, estado civil y experiencia vicaria), pueden influir en la intención de emprender, y aunque no lo incluyen en su estudio, afirman que la propensión al riesgo y la autoeficacia, tienen una influencia indirecta en la intención, estando mediatizados por la actitud, las normas 
subjetivas y el control percibido del comportamiento, (Scholten, V., Kemp, R. y Omta, S. W. F.,2004).

Figura 1.4. Modelo de intenciones de la conducta emprendedora

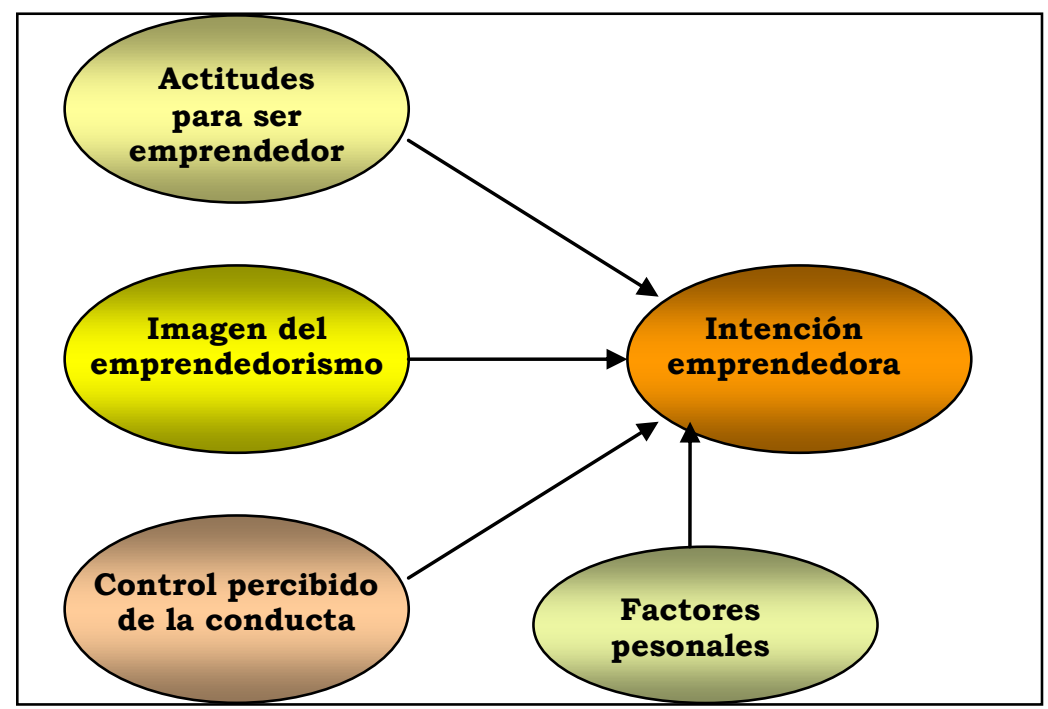

Fuente: Scholten, Kemp y Omtta (2004)

La conducta emprendedora, por lo que implica en cuanto creación y puesta en marcha de una idea o negocio, puede definirse como una conducta planeada . Asumiendo que la simple intención de ejecutar una conducta no garantiza su ejecución, y que la intención es uno de los mejores predictores de determinados tipos de conducta, podemos justificar el modelo de intenciones al campo del emprendedorismo, (Krueger, N. F., Reilly, M. D., y Carsrud, A. L., 2000).

\subsubsection{3- LA ORIENTACION COGNITIVA}

Dentro de la orientación psicológica, la corriente cognitiva, relativamente nueva, trata de dar luz sobre los aspectos cognitivos del emprendedor. Surge, en la mitad de los noventa del siglo pasado, como una nueva corriente en la orientación de los rasgos, que si bien había obtenido importantes resultados, estos eran contradictorios, desplazando el interés de los investigadores hacia otros aspectos personales del individuo. Sus seguidores consideran que, a diferencia del enfoque de los rasgos, lo que distingue a los emprendedores de otros grupos de individuos son sus aspectos cognitivos, desde sus 
creencias y valores hasta sus aspectos mentales. Centra el estudio de la conducta emprendedora en los aspectos cognitivos, tales como la creencia de autoeficacia y/o el uso del modelo de intenciones, (Chen, C. P., Greene y A. Crick, 1998; De Noble, A. F., Jung, J. y Ehrlich, S. B., 1999; Vesalainen, J. Y Pihkala, T., 1999; Mitchell, R. K., Busenitz, L. W., Bird, B., Marie Gaglio, C., McMullen, J. S., Morse, E. A., y Smith, J.B., 2007).

Lo decisivo de este nuevo enfoque es la identificación de estructuras de conocimiento, que los emprendedores usan para hacer valoraciones, juicios $\mathrm{o}$ decisiones.

Baron, R. A., (2006) incide en los procesos mentales de los emprendedores. Todo lo que un individuo piensa, dice o hace, está influido por el proceso mental, por los mecanismos cognitivos a través de los cuales, el individuo transfiere, transforma y usa la información. La perspectiva cognitiva se ha revelado útil para determinar quiénes son propensos a crear empresas y quiénes no; dado que las personas procesan las informaciones, de manera diferente unas de otras.

Mitchell, R. K., Busenitz, L. W., Bird, B., Marie Gaglio, C., McMullen, J. S., Morse, E. A., y Smith, J.B., (2007) atribuyen a este enfoque el mérito de determinar cómo piensan los emprendedores y porque hacen lo que hacen; todo ello mediante el rigor y la demostración empírica y sistemática. Afirma que es la Psicología cognitiva la única disciplina capaz de establecer el proceso mental de los individuos, tanto el propio, como el que generan cuando interactúan con otros individuos y con el entorno. Este autor, propone la Teoría de la Cognición Emprendedora, en la que define cognición como un proceso mediante el cual las percepciones sensoriales son transformadas, acotadas y elaboradas, guardadas, recuperadas y usadas. De este modo, las cogniciones emprendedoras serían una estructura de conocimiento usada por las personas para hacer valoraciones, juicios o decisiones que conducen a la evaluación de oportunidades.

Pretende establecer los procesos mentales que usa el emprendedor para procesar y sistematizar la información previamente inconexa, que le sirva para crear nuevos productos o servicios, conseguir los recursos necesarios para poner en marcha un negocio o ampliarlo. Mitchell, R. K., Busenitz, L. W., Bird, B., Marie Gaglio, C., 
McMullen, J. S., Morse, E. A., y Smith, J.B., (2007) afirman que otras investigaciones precedentes, no han conseguido explicar, satisfactoriamente, por qué algunas personas son capaces de identificar las oportunidades de negocio y desarrollarlas. Entiende que hay dos tipos de factores que informan de la posibilidad de que una persona identifique las oportunidades; la posesión de información que permite identificarlas, y ciertas habilidades cognitivas que posee el individuo.

Steward, W., y Roth, P., (2001) estiman que los emprendedores poseen un sistema cognoscitivo diferente al resto de los individuos, que les permite interpretar las circunstancias y aprovechar las oportunidades. Explica el emprendedor, como alguien dotado de una serie de caracteres; desde un punto de vista cognitivo, serían personas que tienen preferencia por un determinado tipo de aprendizaje, de obtención de conocimiento y aprovechamiento de la información, que le lleva a tomar de decisiones, elementos clave para el emprendedor. Su manera de pensar es condición indispensable para la obtención de recursos. Son individuos que se enfrentan diariamente a la incertidumbre, debido, fundamentalmente a la competitividad y el cambio tecnológico (Steward, W., y Roth, P., 2001).

El enfoque cognitivo, en definitiva, considera a los emprendedores como individuos que identifican y aprovechan las oportunidades de negocio, entendiendo que estas son habilidades de carácter cognitivo. El emprendedor sería el dueño gerente de un negocio que pretende identificar y conseguir oportunidades, dirigidas al aumento de capital. Los emprendedores de éxito se diferencian de todos los demás individuos, precisamente por su especial forma de pensar y procesar las informaciones relacionadas con la toma de decisiones, ya que el entorno ofrece informaciones incompletas, ambigüedad e incertidumbre, (Chell, E., 2000; Zhang, et, al., 2005).

Identifican, por tanto al emprendedor como el creador de una nueva empresa, algo que pueden hacer, porque perciben los cambios del entorno como oportunidades para explorar lo desconocido, e identifican estas oportunidades obrando en consecuencia. Para Baron, R. A., y Markman, G. D., (1999) y Neck, H.M., Manz, C.C., y Godwin, J., (1999), la conducta emprendedora es aquella que busca la identificación de oportunidades de negocio. 


\subsection{CONCLUSIONES}

Sin lugar a dudas han sido los economistas los precursores del estudio del emprendedor, vinculándolo de forma directa a la creación de empresas. Le atribuyen la gran cualidad de la innovación, y le responsabilizan de los cambios en los sistemas y estructuras económicas. La generación de ideas novedosas, la identificación de nuevas oportunidades en los mercados, y su posterior explotación, son los ejes centrales de su análisis.

Para todo ello, se ven obligados a tomar decisiones difíciles, de consecuencias no siempre esperadas, asumiendo continuos retos y riesgos, en base todas ellas, a la información que obtienen, o la forma personal de interpretarla, de los entornos concretos donde deciden emprender. El contexto social, político, cultural y económico es básico a la hora de comprender al individuo que emprende y el tipo de emprendizaje que aborda, proporcionándonos pautas explicativas de su forma de ser, de interpretar la realidad y posicionarse ante ella, y de su comportamiento final.

$\mathrm{Su}$ propia realidad sociodemográfica, los ascendentes familiares, así como el entramado de relaciones que posee, redes sociales de las que forma parte, ayudarán a entender su orientación hacia el emprendizaje.

Desde la psicología, el enfoque de la personalidad, trata de definir e identificar las características intrínsecas de estos individuos, como agentes vinculados a la creación de empresas. Un enfoque distinto y complementario, a la vez, del tradicional economicista y del social.

El estudio de los rasgos de personalidad del emprendedor pretende identificar y clasificar a los emprendedores, en base a la posesión de determinados atributos, que, en principio, servirán como predictores de la conducta emprendedora, siendo la principal conducta que a ellos se les atribuye, también, la de crear negocios. Son muchas y diferentes las clasificaciones de características que se han aportado, prácticamente cada autor ha proporcionado la suya propia, aunque no todas cuentan con la misma solvencia empírica. Tampoco hay acuerdo la hora de entender si ciertos rasgos efectivamente lo 
son, o por el contrario serían actitudes (propensión al riesgo), procesos (creatividad), o cogniciones (locus de control, motivación, necesidad de autonomía, necesidad de logro), ó o conducta (iniciativa, innovación y creatividad).

Llegados a este punto, podemos concluir que no existe un perfil consensuado de personalidad emprendedora, ni tan siquiera consenso en lo que significa rasgo, lo que predispone a interpretaciones diferentes, contradictorias incluso, que dificultan la utilización del enfoque como referente conceptual. Hasta la relación rasgos y emprendedor ha sido cuestionada por la propia investigación (Chell, Haworth y Brealey, 1991; Cooper, A.C., Gimeno-Gascon, F.J., Woo, C.Y., 1994; Hurtado, N.E., Cordón E., Senise, M.E., 2007).

En nuestro estudio, consideraremos los rasgos del emprendedor en conjunto con otras variables de carácter personal y de contexto, pues de forma aislada, no proporcionan resultados significativos a la hora de explicar la creación de negocios. Serán utilizados conjuntamente con otras variables de ámbito personal, cogniciones, recursos personales, además de variables de entorno, donde los factores culturales tendrán un peso significativo.

Asumiremos que los rasgos son cambiantes, varían con el paso del tiempo y que son una disposición hacia el comportamiento y no una determinación, pues el individuo puede decidir actuar contra su disposición.

Como respuesta a las limitaciones apuntadas desde el enfoque de los rasgos, se abren paso la orientación cognitiva y la de la conducta en el estudio del emprendimiento.

Los cognitivitas explican el emprendedor y sus acciones, básicamente identificadas con la creación de negocios, desde sus estructuras cognitivas, sus creencias, mecanismos de procesamiento de la información, etc. El comportamiento final del emprendedor dependerá de cómo sean estas estructuras, atribuyéndoles la explicación básica de la conducta emprendedora, caracterizada por buscar e identificar nuevas ideas de negocio y conseguir los recursos necesarios para llevarlas a cabo. 
Al igual que el enfoque de los rasgos, ven al emprendedor como alguien diferente, poseedor de capacidades distintas al resto de la población, y estrictamente individuales, olvidando variable externas a la hora de explicar su distinción y su conducta, lo que supone una gran limitación.

Desde el enfoque de la conducta, y, partiendo del análisis de los comportamientos concretos que desarrolla el emprendedor, pretenden identificarlos y definirlos, para acabar concluyendo que la principal conducta que podemos atribuirle es la de crear negocios. El resto de aspectos vinculados a su estudio, características de personalidad, modelos cognitivos, factores del entorno económico o social, etc., se analizan bajo la premisa de la creación de negocios. Se convierte pues, en un hilo conductor perfectamente válido para abordar el emprendedorismo desde un enfoque pluridimensional.

Cuando se refieren a la creación de negocio como actividad central, no hay acuerdo al delimitarla, Así para unos la creación sería el punto de partida, para otros cualquier actividad vinculada al propio negocio; la gerencia, asunción de la responsabilidad por los riesgos que acarrea, el crecimiento del negocio, las relaciones con otras redes, etc., Para otros la innovación o introducción de nuevos productos o servicios en el mercado (entienden la fundación de un nuevo negocio como un acto de innovación).

Afirman que el emprendizaje es factible parara cualquier individuo, cualquiera puede llegar a ser emprendedor, al margen de la tenencia o no de determinados rasgos de personalidad.

Un aspecto importante a tener en cuenta en la conducta emprendedora es el conjunto de motivaciones que la impulsa; los diferentes estudios demuestran que tanto los rasgos de personalidad, las cogniciones o modelos de pensamiento, como las situaciones concretas por las que atraviesa el individuo pueden despertar la motivación a crear negocios. Bien por necesidad, bien por oportunidad, estos aspectos motivacionales, pueden influir en las diferentes etapas de conducta que comprende el proceso emprendedor. 
Con respecto a si podemos o no predecir la conducta emprendedora, diferentes modelos ponen de manifiesto que si, en situaciones concretas. El modelo de intenciones de Azjen, es el de mayor predicamento. La Autoeficacia de Bandura relacionada con la capacidad de afrontar desafíos inesperados, trabaja en el mismo sentido. Hay estudios se usan variables de rasgos, cognitivos y de entorno para predecir la conducta emprendedora utilizando el modelo de intenciones. Oros analizan la actitud hacia la conducta como variable predictora de conductas emprendedoras.

El enfoque de la conducta pone encima de la mesa nuevos desafíos en la investigación emprendedora, que deberán ser abordados en relación a los numerosos campos de estudio del emprendimiento.

A tenor de lo expuesto, entendemos que sólo un enfoque multidimensional y multidisciplinar abordará con éxito el estudio del emprendedor. Ni los rasgos, ni las cogniciones, ni su conducta pueden aislarse del influjo de su entorno más inmediato, donde otros protagonistas, factores socioculturales y estructuras económicas median en él y en su quehacer.

Podemos definir al emprendedor "Individual entrepreneurship", como la persona capaz de generar ideas, de poner en marcha iniciativas con potencial de desarrollo, en casi todos los casos innovadoras, distintas, con un valor útil añadido para la sociedad o el mercado diferenciado, que merced a su actuación emprendedora pueden sobrevivir y transformarse por sí mismas, adaptándose a la evolución del entorno (Ilundain J.M, Sánchez, J.C., Yurrebaso, A., (2007).

El emprendedor es aquel que pone en marcha su imaginación y esfuerzo para descubrir una oportunidad y transformarla en un negocio o en una actividad social o política que pueda sobrevivir y crecer sin su concurso posterior. Esta acción emprendedora aparece en las circunstancias más adversas y en épocas de cambio, (Ilundain J.M, Sánchez, J.C., Yurrebaso, A., (2007). 


\section{LA CULTURA EMPRENDEDORA}




\section{1.- LA CULTURA}

Este capítulo se aproxima al universo de la cultura emprendedora, al objeto de analizar el influjo que los llamados factores culturales puedan tener en el desarrollo de las actividades de emprendizaje. Para ello, revisaremos bibliográficamente las principales investigaciones y estudios en torno a la cultura y al emprendimiento, por estar considerado, este último, eje estratégico del desarrollo económico.

Tras definir la Cultura ${ }^{11}$, su transmisión y componentes más significativos, analizaremos, por un lado, la influencia de los valores culturales en el emprendimiento, y por otro, aquellos factores resultado de la propia cultura, cuyo efecto repercute decisivamente en la cultura emprendedora; las instituciones, las políticas de empleo y las redes sociales.

Las principales conclusiones extraídas parten de la detección de determinados valores culturales como la autonomía, la creatividad, el individualismo, la competencia, la orientación al logro, la gestión del riesgo o el dinamismo entre otros, como favorecedores de la iniciativa, la innovación y el cambio, y con ello, del emprendimiento.

\subsection{1.- DEFINICION DE CULTURA}

Hasta el Siglo XVIII, en Alemania, no encontraremos una definición de la misma vinculada a la idea de progreso de la sociedad. Será entonces, cuando los historiadores de la época afirmen que "las malas sociedades vienen de la incultura", (Adelung, J.C., 1782). Es la primera connotación colectiva que encontramos del término.

En el siglo XIX, la etnografía y antropología más próxima al estudio de los grupos primitivos, dará las primeras nociones del término. En este contexto y hasta la

\footnotetext{
${ }^{11}$ Habrá enfoques diversos y complementarios; básicamente, los que analizan la cultura como hecho externo o social, y hecho como interno, en la medida en que el individuo la interioriza en su estructura menta; los que ponen el acento en las funciones básicas que desempeña; y los que acentúan los contenidos que tiene.
} 
primera mitad del siglo XX, es entendida, básicamente como un conjunto de presiones y acondicionamientos, que aprendidas en la infancia, acaban fijando patrones de conducta cuando uno es adulto.

Este cuadro resumen, pone de manifiesto cómo en cada época, en cada momento histórico, se ha entendido la cultura de forma diferente.

\section{Cuadro 2.1. Características de los estudios tradicionales de cultura}

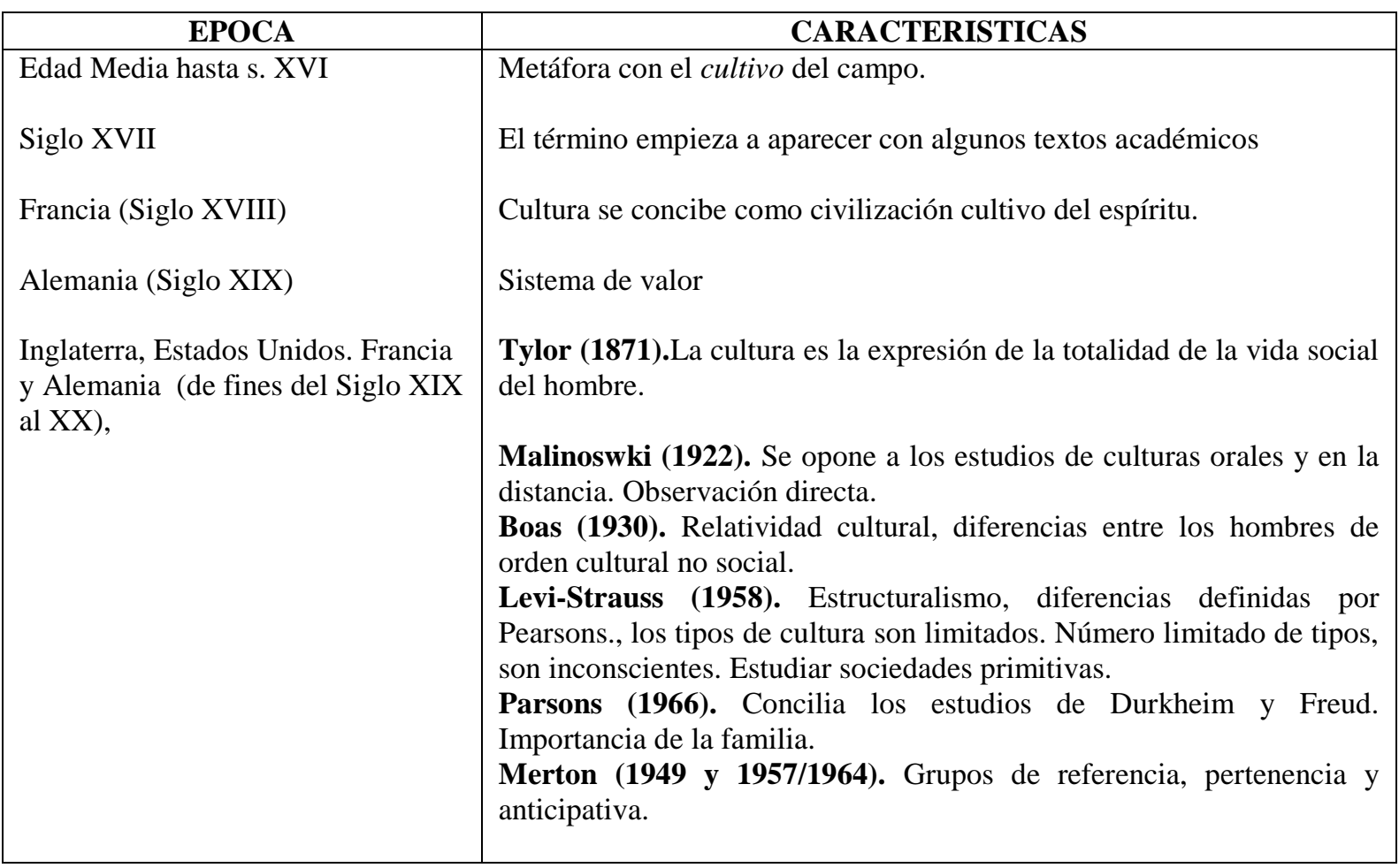

\section{Fuente; Rodríguez M}

Todos ellos entendían la cultura como un determinante del comportamiento, poniendo el acento en el control social que ejercen las normas, donde los miembros de un grupo o comunidad, cultura, de forma inconsciente, adaptan su forma de proceder a la tradición socialmente aprendida, (Buxíó i Rey, 1984).

Esta visión, que nos permite explicar lo que nos une y lo que nos hace comunes como seres humanos, encuentra su máximo exponente en la que, quizás sea, la definición más universalmente utilizada del término; la dada por Edward Taylor en 1871; “Cultura o civilización, tomada en su amplio sentido etnográfico, es ese 
complejo de conocimientos, creencias, arte, moral, derecho, costumbres y cualesquiera otras actitudes y hábitos que el hombre adquiere como miembro de la sociedad", (Taylor, E.,1871).

A pesar de las críticas por la imprecisión de la misma, pues deja abierta la posibilidad de incluir otros elementos, sigue siendo un referente en las ciencias sociales. Baztan, A. (2004) destaca en la definición de Taylor, tres partes, significativamente diferentes. La totalidad compleja, la producida por el hombre, y el hombre como miembro de una sociedad. Explicaría todo aquello que es el hombre y lo hace desde sus productos o resultados sociales, desde la cultura material y formal. Desde este punto de vista no cabría hablar de cultura individual, ésta sería siempre social, de la colectividad.

Este enfoque asume la cultura como hecho externo, social. Taylor pone el acento en lo socialmente aprendido y compartido por los miembros de la sociedad. Otros autores, seguirán la misma orientación. Rocher, G (2004), basándose en él, dará una noción de cultura como hecho social (definirá cultura como "el conjunto trabado de maneras de pensar, de sentir y obrar, más o menos formalizadas, que, aprendidas y compartidas por una pluralidad de personas sirven de un modo objetivo y simbólico a la vez, para constituir a esas personas en una colectividad particular y distinta" (Rocher, G, 2004, p 36). Se enfatiza la relación o sentido colectivista de la cultura. Afirma que afecta a toda actividad humana. Que es acción y realidad vivida, al mismo tiempo. Son maneras más o menos formalizadas, compartidas por un colectivo. Es aprendida, no innata, objetiva y simbólica al mismo tiempo y, que como conjunto trabado, es un sistema social.

De igual forma, como un hecho social interiorizado que guía la conducta individual en el grupo, facilitando la convivencia, se manifiestan Durerger, M. (1975) y Béjar, H. (1979).

Durerger define cultura, desde un punto de vista más dinámico, como “aquel conjunto coordinado de maneras de pensar, actuar y sentir que constituyen los roles que definen los comportamientos esperados de una colectividad de personas" (Durerger, M., 1975, p 63). 
Para Béjar sería aquel el "conjunto de patrones explícitos e implícitos, manifestados en la forma de vida, que son aprendidos y transmitidos mediante símbolos que constituyen los logros distintivos de los grupos humanos, tanto materiales como espirituales”, (Béjar, H., 1979, p. 44).

Desde la sociocultura, o perspectiva más sociológica de la cultura se hace hincapié en los aspectos socio-ambientales de la misma. La conciben como un elemento que da lugar a los distintos procesos sociales, que integra a las distintas sociedades. La cultura sería la forma de vida de la sociedad, añade Touraine y cómo "ningún análisis sociológico puede dispensarse de aprender el carácter más fundamental de la acción social, a saber su orientación normativa. Se puede considerar este aspecto, afirmando que los hombres se guian por valores, ideas, principios...)”, Touraine, R. (1969, p. 56).

Podemos concluir que son muchos los autores, además de Taylor (1875) los que circunscriben la cultura al ámbito estrictamente social; (Boas, F., 2008; Durerger, M., 1975; Schein, E., 1990; Giner, S. 1982; Brunet, A., Alarcón, A., 2002).

Boas afirmará, que toda manifestación de los hábitos sociales de una comunidad es cultura, como lo son las reacciones que tienen sus individuos en la medida en que están condicionados por las costumbres del grupo. (Boas, F.,1930).

Schein, E., (1990), por su parte, entiende la cultura como "Un patrón de supuestos básicos compartido que el grupo aprende en la medida que resuelve sus problemas de adaptación externa e integración interna, que los ha trabajado lo suficiente para ser considerados como válidos y, por lo tanto, dignos de ser enseñados a los nuevos miembros como la forma correcta de percibir, pensar y sentir en relación con esos problemas" (Schein, E., 1990, p 12). Para analizar la cultura propones tres dimensiones o niveles de análisis, refiriéndose, cada uno de ellos, al grado en que el fenómeno cultural es visible al observador; los artefactos, los valores adoptados y declarados y los supuestos básicos (Schein, E., 1990, 16-27). 
- Los artefactos serían las estructuras y procesos de organización que por ser observables, permiten estudiar la propia cultura. Son los resultados tangibles de los actos desarrollados en el grupo y se apoyan en los valores y en los supuestos.

- Los valores, tienen valor intrínseco considerados por el mismo autor como principios sociales, filosofías y metas, ayudan a predecir el comportamiento de los miembros del grupo. Incluirían los objetivos, del grupo.

- Los supuestos básicos, son las representaciones de las creencias que tiene el grupo sobre la naturaleza humana y la realidad. Sirven para facilitar la adaptación externa e integración interna. Son asumidos, por repetición, por los miembros del grupo convirtiéndose en creencias percepciones, pensamientos y sentimientos, asumidos inconscientemente, y tomados como verdaderos por el grupo. Serían la fuente de la que beben los valores y los artefactos. Acudiríamos a los supuestos básicos para poder entender y explicar algunos comportamientos del grupo cuando los valores no los explican, pues al ser compartidos cualquier comportamiento alejado del mismo será considerado no aceptable para el grupo. Son la clave para entender y cambiar la cultura del grupo. (Schein, E., 1992, 1627).

"La cultura del grupo puede ser estudiada por estos tres niveles, el nivel de sus artefactos, el nivel de sus valores y el nivel de sus supuestos básicos. Si uno no descifra el patrón de supuestos básicos que pueden estar operando, no se sabrá cómo interpretar los artefactos correctamente o cuanta credibilidad dar a los valores adoptados y declarados. En otras palabras la esencia de la cultura radica en el patrón de supuestos básicos subyacentes, y una vez que se comprende éste se puede comprender fácilmente los otros niveles que son más superficiales y tratar apropiadamente con ellos" (Schein, E., 1990, p.26).

González Ferrer, G. (1998) recoge, de forma muy ilustrativa, el modelo de Schein referenciando los Niveles de Cultura y su intervención. 
Figura 2.1. Niveles de Cultura y su intervención según Schein
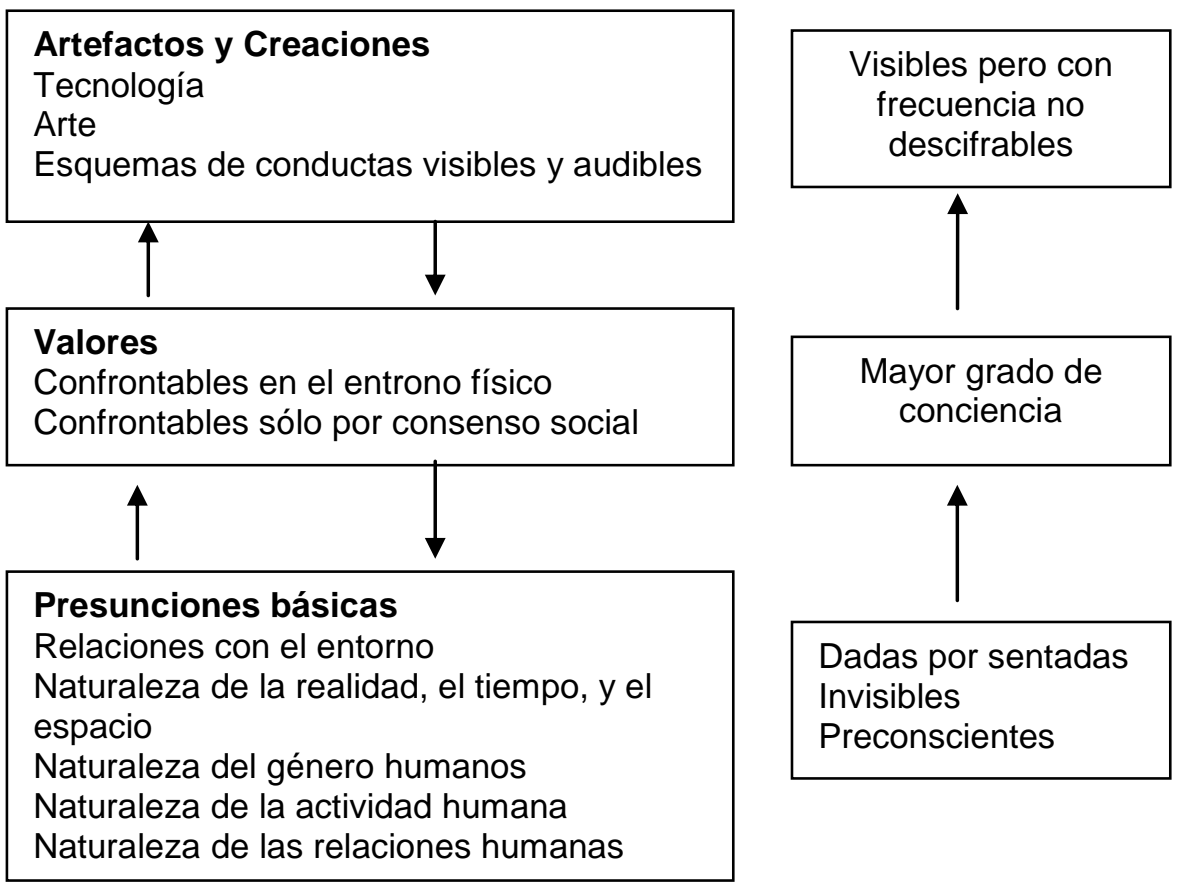

Fuente: González Ferrer, G. (1998) p. 70

Méndez J., S., Zorrilla, S., y Monroy F., (1992). definen la cultura como "la expresión dinámica, en transformación constante, de los elementos en interacción que conforman los códigos y formas de vida, resultado de la relación del hombre en sociedad".

Alanís, H., y Díaz Mendoza, R. (1992-93) la definen como “un producto social, creada o transformada por el hombre, para dar sustento a sus interacciones, para consolidar y transformar sus patrones axiológicos; la cultura es lo que la norma a la actividad humana, pero también es lo que facilita su transformación”.

Haciendo hincapié en cómo se interioriza mentalmente la cultura como hecho social encontramos las aportación de Goodenough, quien la define como "lo que uno debe conocer (saber o creer) para comportase aceptablemente de acuerdo a las normas de los demás”, (Goodenough, W.H., 1971). Traslada la cultura al interior de la mente, siendo esa representación simbólica la que los individuos aprenden con el paso del 
tiempo, para adaptarse a un entorno concreto. Es un enfoque que trata de entrever los principios organizativos que subyacen a la cultura y los códigos cognoscitivos que tienen los individuos y desde los que actúan, por pertenecer a ella. Esta visión, muy aceptada y desarrollada en los Estados Unidos de América, ha recibido fuertes críticas, también, que la acusan de excesivamente psicologista, y de no tener una base estadística, además de prescindir del contexto.

En el mismo sentido, y definiendo la identidad cultural como una construcción mental, se manifiesta la antropóloga española María Jesús Buxó i Rey, quien define la cultura como "el sistema de conocimientos a partir de cuyos significados el humano tamiza y selecciona su comprensión de la realidad en sentido amplio, así como interpreta y regula el hecho y los datos del comportamiento social”, (Buxíó i Rey, 1984, p.7).

La antropología hermenéutica, tiene en Geertz, C., (1987) a uno de sus máximos representantes, quién se manifestaba así sobre el término,...” el concepto de cultura que propugno, es esencialmente un concepto semiótico. Creyendo con Max Weber que el hombre es un animal inserto en tramas de significación que él mismo ha tejido, considero que la cultura es urdimbre y que el análisis de la cultura ha de ser por lo tanto, no una ciencia experimental en busca de leyes, sino una ciencia interpretativa en busca de significaciones. $\quad$....la cultura se comprende mejor no como complejos de esquemas de conducta -costumbres, usanzas, tradiciones, conjuntos de hábitos- como ha ocurrido en general hasta ahora, sino como una serie de mecanismos de controlplanes, recetas, fórmulas, reglas, instrucciones (lo que los ingenieros de comunicación llaman "programas"- que gobiernan la conducta”. (Geertz, C., 1987).

Entiende la cultura como un proceso, como una red de sentidos que usamos para dar significado, para entender los fenómenos que encontramos en la vida cotidiana, y que nos permiten interactuar con los demás en el ámbito social. La cultura produce sentidos o significados; aquellos que tenga cada fenómeno o acontecimiento que surge en la vida cotidiana de un colectivo o grupo humano concreto, porque éste así se lo ha dado. De ese sentido que se da a las cosas, surge la importancia del contexto. Se erige éste, como un elemento importante en el estudio de cada cultura particular. 
Si bien es cierto que, como parte de una herencia social, el individuo recibe cultura también lo es que éste puede contribuir, y de hecho contribuye, a su conformación, introduciendo nuevos caminos, herencia también para las próximas generaciones.

Sería un sistema que ordena el pensamiento, y también la acción e interacción de quienes de ella participan, y los valores que los justifican (Gómez, A. 2008, p. 38), "La cultura se reproduce por medios propios, culturales. El principal medio cultural de reproducción es la transmisión de significados culturales, no solo de generación en generación, también en el espacio de una misma generación, en lo cotidiano. Esta trasmisión se efectúa a través del lenguaje y del comportamiento enseñado, emulado y aprendido por los pueblos de la colectividad. Al tiempo, al transmitir los significados que la caracterizan, la cultura se mantiene) (Gomes, 2008, p. 38, traducción propia). Añade el autor, que toda cultura es única y singular y proporciona a sus miembros el sentido de ser y estar en el mundo, (Gomes, A., 2008).

"Esta herencia social, es el concepto clave en la antropología cultural, incluiría los artefactos, bienes, procedimientos técnicos, ideas, hábitos y valores heredados. La organización social no puede comprenderse verdaderamente excepto como una parte de la cultura" (Malinoswki, B., 1975, p. 76).

La visión de guía o pauta de comportamiento en la vida, conducta aprendida y sus resultados, un todo que orienta a los miembros de una sociedad en cada momento, es defendida por autores como Linton, E. (1936).

Otras definiciones ponen el acento en la función que desempeña. Giner incluye en la noción de cultura la creación de símbolos, valores, normas, y creencias definiéndola como "un orden significativo de lenguajes, objetos, y seres humanos" (Giner, S., 1982. La cultura sería un hecho específicamente humano, un mecanismo a través del cual el hombre crea y satisface necesidades. Un sistema complejo, integrado por ideas, valores, aptitudes, formas de vivir, etc..., que dispuestos en patrones, más o menos estables, en una sociedad concreta, influyen en su forma de estructurarse y en su conducta. Consistiría en pautas de comportamiento socialmente aprendidas, y, aun siendo algo abstracto, se manifestaría en conductas y resultados concretos. Cumpliría 
una triple función; la de adaptación del individuo a su entorno, la de permitirle considerarse individual y colectivamente miembro de una comunidad, y la de moldear su personalidad individual dotándole de ciertos rasgos comunes; preferencias por comidas, objetos, productos culturales, en definitiva, de la propia cultura.

La cultura, según Marcuse, H., (1979) tendría la función de transformar la parte más biológica e instintiva del ser humano, en una persona madura, que abandona sus placeres para someterse al principio de la realidad sociológica, aceptando así, las restricciones y sacrificios que implica la convivencia en el seno de una sociedad.

El carácter duradero de estos, sus componentes, es enfatizado por Zahara, S.A.M y George, G., (2002), al afirmar en su investigación sobre la Cultura y sus consecuencias para un espíritu emprendedor, que el término cultura se usa para referirse al conjunto duradero de valores de una nación, una región o una organización

Ante tal cantidad y diversidad de definiciones del término, éste puede presentarse como algo complejo. Se hace necesario una definición amplia que incluya los rasgos existenciales, las características de la población, sus formas de manifestarse, de vivir y producir, sus sistemas de valores, creencias, opiniones..., pues la cultura incluye todos los ámbitos de la vida de un pueblo; el espiritual y/o religioso, el sociológico, el político, el económico, el tecnológico y científico, etc. y afecta a toda actividad humana. Es un término global que incluirá todo aquello que la persona obtiene por ser miembro de una sociedad, hábitos, tradiciones, valores, un modelo educativo, ideas y creencias...;. Es algo vivo que, aun siendo más o menos estable, cambia continuamente por no ser un hecho acabado, sino en continua transformación, fruto de la participación activa de la comunidad.

Se trata pues de un concepto abierto. Referirnos a las instituciones a las que da lugar, a las conductas que reproduce, a los valores y modelos culturales que encierra.

La cultura, como algo aprendido, transmitido de una generación a otra por el lenguaje o a través de la imitación está formado por diferentes componentes, Normas, habilidades, conceptos, percepciones, etc., y será aquí donde situemos el acento a la hora de estudiar o analizar cada cultura concreta, Estamos por tanto asumiendo que se 
trata de un fenómeno sociológico que puede ser estudiado, según las reglas del método sociológico.

Por otra parte, la cultura, englobaría a un importante número de individuos en un territorio más o menos amplio (Názar ,V., 2004). Será frecuente encontrar en su seno, variaciones significativas atendiendo a criterios nacionales, locales, de clase, o de cualquier otro tipo. Estas variaciones son las que nos permiten distinguir distintos segmentos poblacionales que coexisten con total armonía o no, pues también pueden incorpora valores no aceptados en la sociedad global en una cultural más general. Estos segmentos forman las llamadas subculturas, que coexisten con entendimiento en el marco de una cultura general. ${ }^{12}$

A pesar de este complejo entramado de subculturas y de la diversidad de elementos que puedan coexistir en el interior de una cultura todas sus partes, y de forma interdependiente, han de estar mínimamente integradas (Názar, V., 2004). Es esta mínima interdependencia, este sistema mínimamente ordenado, lo que posibilita la supervivencia cultural.

Toda cultura es un sistema dinámico, que está vivo, en continua evolución, pero también es un sistema ordenado que actúa como referente, y por tanto es conocido y predecible. El cambio cultural implica adaptarse al medio físico y social y a las innovaciones que en ellos se producen. $\mathrm{Y}$ es esta adaptación la que posibilita su supervivencia, aunque provoque, también la perdida, en ocasiones, de ciertas características propias o la asunción de otras procedentes de culturas distintas.

"A medida que una sociedad responde a las necesidades individuales y colectivas de sus miembros, elabora y reelabora de manera permanente su cultura $Y$ como expresión de esa convivencia humana, la cultura puede ser considerada simultáneamente proceso (o conjunto de procesos) y resultado de los mismo" (Infestas, 2001, p 168).

\footnotetext{
${ }^{12}$ Nos referimos a las subculturas de una misma cultura, pues puede haberlas de otras culturas fácil y comprensible la aparición de conflictos.
} 
Dentro de toda cultura, vamos a encontrar unidades pequeñas que pueden ser identificables, lo cual tiene un importante valor epistemológico, pues al poder ser aisladas y definidas, es útil de cara a la propia investigación científica del fenómeno. Se las denomina Rasgos culturales. Carecen de valor por sí mismas, y para abordarlas necesitamos integrarlas en configuraciones o patrones más amplios, que son conocidos en las ciencias sociales como Complejos Culturales. Los complejos culturales estarían formados por todos los rasgos culturales de una cultura y, aunque también evolucionan y cambian, fruto del dinamismo cultural, tienden a ser duraderos en espacio y tiempo. Los complejos culturales se manifiestan físicamente, como formas concretas de hacer las cosas. Suelen ser diferentes en cada lugar, lo que permite identificar distintas áreas culturales, pues esas formas distintas de hacer (las distintas formas de construcción de un edificio y los diferentes tipos de equipamiento, o los usos distintos que a ellos se dan por ejemplo). Pone el acento en los distintos usos que las diferentes culturas dan a las mismas cosas. Estos rasgos culturales pueden trasladarse a otras poblaciones y ser integrados, originando el fenómeno que conocemos como Difusión cultural.

Giner, S., (1982) reivindica continuamente este cambio y evolución constante en la cultura ${ }^{13}$. Llega a hablar, incluso, de "la necesidad cultural de evolucionar", como una característica propia de la misma cultura.

En toda cultura encontramos fenómenos, significativamente importantes, que propician estos cambios; La difusión cultural, en forma de modas y usos culturales distintos propios de otras culturas, que llegan a la nuestras y se adoptan, produciendo un cambió en nuestra cultura. La aculturación, que se produce por una síntesis (fusión, suma) al entrar en contacto dos culturas distintas. Y, el último, y quizás más importantes elemento generador de cambios culturales, la trasmisión cultural. Es la garante de la evolución pues integra los cambios más innovadores culturalmente hablando.

La interrelación de estos elementos permite entender mejor a aquellos autores que definen la cultura como una forma de ver el mundo en un lugar y tiempo concreto, una forma concreta que prevalece para un grupo de personas. "La cultura en una

\footnotetext{
${ }^{13}$ El ritmo, es propio en cada cultura y mientras para unas es continuo y rápido, otras manifiestan más resistencias al cambio, siendo más lento.
} 
sociedad consiste en todo aquello que se conoce o crea con el fin de operar de una manera aceptable sobre sus miembros. La cultura no es un fenómeno material: no consiste en cosas, gente, conductas o emociones. Es más bien una organización de todo eso. Es la forma de las cosas que la gente tiene en su mente, sus modelos de percibirlas, de relacionarlas o de interpretarlas” (Goodenough, W.H., 1971, p. 112).

Cuando Geertz, C., (1987) habla de la estructura social afirma que "la cultura es la trama de significados en función de la cual los seres humanos interpretan su existencia y experiencia, así mismo como conducen sus acciones; la estructura social (sociedad) es la forma que asume la acción, la red de relaciones sociales realmente existentes. La cultura y la estructura social (sociedad), no son entonces, sino diferentes abstracciones de los mismos fenómenos” (American Anthropologist, vol. 59, 1957).

Desempeña, según Infestas, A., (2001) diversas funciones; la simbólica, en cuanto que representa la vida social del grupo o comunidad, las formas de convivencia social. La identificadora, convirtiéndose en referente de pertenencia al grupo. A través del comportamiento concreto de sus integrantes, podemos deducir, por su carácter simbólico, a qué grupo o cultura pertenecen. La integradora, al ser el comportamiento el propio del grupo, hace que seno presente quien lo ejecuta como miembro integrado del propio grupo. Y, finalmente, la instrumental, en cuanto que los grupos la utilizan para conseguir todos estos fines anteriores, (Infestas, A., 2001).

Si asumimos que no existe un concepto universalmente aceptado del término cultura, cierto es que en la mayoría de definiciones analizadas, encontramos un sustrato común. Toda cultura incorpora un conjunto de conocimientos compartidos por un grupo de personas que comparten una misma historia y estructura social común (Hosfstede, G., 1980; Kottak, C., 1994; Triandis, H.C., 1996; Bauman, Z., 2002; Bourdieey, P., 2010).

A lo largo de este trabajo, asumiremos la cultura como un conjunto de códigos simbólicos compartidos por quienes de ella participan. Está compuesta por categorías que nos ayudan a clasificar la realidad. Establece diferencias entre los distintos grupos sociales. No es innata, se aprende y es a través del proceso de socialización, por el que la convertimos en algo compartido. Esto unifica a sus integrantes y nos lleva a la idea 
de continuidad. La cultura se adaptará y cambiará en base a las necesidades de sus integrantes y formará parte de un sistema integrado, donde cada componente está relacionado con los demás. Estos fenómenos sociales son integrados todos, en la estructura personal del sujeto. Si asumimos que la sociedad es una suma de individuos, el perfil individual se forjará en el entorno social. Al mismo tiempo, y en mayor medida, la suma del promedio de los perfiles individuales será lo que forje y determine el perfil cultural de una comunidad, región, país...; (Ilundain J.M, Sánchez, J.C., Yurrebaso, A., 2007).

Insistimos en la cultura como orientación de la acción individual. La cultura nos ofrece un abanico de posibilidades de comportamiento, con más o menos 'varillas', donde podemos elegir las formas de pensar, sentir y obrar aceptadas en nuestra sociedad. Las sociedades son más cerradas o más abiertas en función del número de opciones socialmente aceptables que la cultura ofrece a sus miembros. La cultura es el marco externo donde el individuo estructura y desarrolla su personalidad, incluido el ámbito profesional (Infestas, A., 2001).

Resumiendo

1. Es un hecho social;

2. Que tiene su origen en la vida del grupo/sociedad, a medida que éste va solucionando sus problemas de cohesión interna y de adaptación externa;

3. Que define las formas de sentir, pensar y obrar, socialmente correctas, es decir, admitidas como socialmente válidas en una sociedad;

4. Que esa definición de lo 'socialmente correcto' impone límites al comportamiento de sus miembros, de modo que hay sociedades más abiertas/cerradas que otras;

5. Que la sociedad espera que los individuos definan su personalidad dentro de esos límites (pautas culturales) que le ofrece; 
6. Para ello cada sociedad trasmite su cultura a los individuos mediante el proceso de socialización;

7. Aún en las culturas más monolíticas, menos permisivas, más cerradas..., existe un grado de diferenciación cultural interna según los grupos sociales existentes (familias, clases sociales, grupos de base local...) y esa diferenciación puede manifestarse también a través de los distintos agentes de socialización.

\subsection{2- LA TRASMISION SOCIAL DE LA CULTURA; EL PROCESO DE SOCIALIZACIÓN}

Un elemento significativo de evolución y cambio en toda cultura es su trasmisión social. Aquel que permitía adaptarse a los cambios tras incorporarlos y aprenderlos, haciéndolos suyos, y evolucionando desde ellos. En este sentido es de vital importancia analizar y conocer los mecanismos de que se vale una sociedad para adquirir y trasmitir, de generación en generación, sus elementos - contenidos culturales.

Un proceso básico en este sentido es el proceso de socialización, que podemos entender como un vínculo, un puente entre la persona (cada persona concreta) y la sociedad, su sociedad. Según Dowse, R., y Hughes, J.,(1982), sería un proceso de aprendizaje social perenne, que se desarrolla a lo largo de toda la vida del individuo, pues estamos inmersos en un mundo continuamente cambiante (dinámica cultural). La "Socialización es el proceso por el que los individuos adquieren el conocimiento, las capacidades y disposiciones para participar en los grupos sociales y en la sociedad" (Dowse, R., y Hughes, J.,1982).

A través de la socialización las personas aprendemos a interiorizar, en nuestra vida, los elementos socioculturales del entorno en el que vivimos y nos movemos. Estos elementos los integramos en la estructura de nuestra personalidad a través de cada experiencia vivida, y de la influencia de agentes sociales relevantes para nosotros, en definitiva, de nuestro aprendizaje vital. 
Podemos señalar, entonces, dos niveles distintos o puntos de vista con respecto a la socialización: El primero, vinculado a la colectividad, nos apunta los mecanismos por los que se transmiten y mantienen la relativa permanencia de la cultura. Es a través del proceso de socialización como adquiríos la cultura, aprendemos nuestra propia cultura, siendo un periodo clave en la vida de cada persona la infancia. Así nos adaptamos al entorno social. Y lo hacemos nuestro. Lo asumimos y lo compartimos con nuestra comunidad.

El segundo, en el plano individual, donde la socialización se refiere a qué es lo que aprendemos, cómo lo aprendemos y cuando lo aprendednos. Cómo nos conformamos a nuestra propia cultura de forma natural y espontánea, pues la integramos en nuestra propia estructura personal, sin esfuerzo alguno.

El proceso de socialización nos permite aprender y participar, de nuestra propia cultura, pues nos permite compartirla con el grupo social al que pertenecemos. Así aprendemos cuál debe ser nuestra actitud y nuestra conducta en la sociedad; la que responda a las normas socialmente aprendidas que, si acatamos, nos convertirá en seres "normales" por haber aprendido a comportarnos como de nosotros espera nuestra colectividad y, si no, seremos unos inadaptados y nuestras actitudes no estarán de acuerdo con nuestra cultura.

Schein, E. (1990) concede una importancia capital al proceso de socialización, como forma de preservar la cultura e indica cómo las respuestas de los individuos en los grupos ante este proceso pueden variar significativamente, pudiendo encontrar lo que él denomina orientación de custodia (donde los nuevos miembros se conforman y completan su aprendizaje en la cultura mediante técnicas de socialización formales y auto constructivas), individualismo creativo, (donde los miembros desempeñan un rol de innovación y creatividad al aceptar solo los más significativos valores y suposiciones básicas de la cultura inicial, rechazando aspectos menos importantes. Las técnicas de socialización aquí empleadas serán menos formales) y/o rebelión (implicaría un rechazo total a los supuestos básicos de la cultura existente, orientando los métodos de socialización del grupo a la formación de valores y supuestos básicos contrarios a la cultura inicial (Schein, E.,1990). 
Dowse, R., y Hughes, J.,( 1982), analizan el proceso de socialización y destacan diferentes orientaciones en su estudio; La antropológica, la psicológica y la sociológica.

Desde la antropológica, apuntan dos importantes fenómenos sociales que intervienen en la socialización; el de la Aculturación- Inculturación- Enculturación (proceso por el que una persona llega a integrarse a un medio cultural nuevo y extraño al de su origen).Se refiere al encuentro entre diversas culturas. Y cómo el individuo se adapta a ellas. Y, el de la trasmisión intergeneracional de cultura; en el que son los ancianos, los padres quienes trasmiten la cultura a las nuevas generaciones en las sociedades primitivas, en las cuales, entre ambos grupos, suelen ser pocas las variables intervinientes.

Desde la Orientación Psicológica; destacan a Freud y el psicoanálisis, quien estudia el proceso de adquisición de controles socialmente aceptables a impulsos básicos (Freud, S., 1985)

En la orientación sociológica; se trata la socialización como enseñanza y aprendizaje de roles para la participación social. Subraya el objetivo social de la socialización, el de conseguir la conformidad, la integración de los individuos en la estructura normativa de la sociedad. En aproximaciones más recientes, hoy, se enfatiza la capacidad de resistencia del individuo (relativamente).Hay una tensión entre la personalidad individual y la estructura social, y el proceso de socialización trataría, en principio, de adecuar, de compatibilizar estos dos polos.

Dowse, R., y Hughes, J.,(1982), privilegian la orientación sociológica, por propiciar ciertas ventajas; pues juega un papel importante como conformadora del comportamiento. Está abierta a la posibilidad de conflicto (inadaptación a la norma, ir contra lo establecido), lo que alberga margen de libertad individual, y pone especial atención a un elemento clave en el proceso, cual son los agentes de socialización.

El sistema social, en palabras de Dowse, R., y Hughes, J.,(1982) es complejo y para entender su comportamiento y funcionamiento, debemos estudiar cómo las personas estructuran su mundo social cognoscitiva y afectivamente. Debemos comparar esos conocimientos y afectos tanto dentro del mismo sistema social como con otros 
diferentes sistemas sociales, y diferenciar así lo que es la cultura local. Debemos considerar los diferentes agentes de socialización implicados en el proceso y en el cambio social, atendiendo especialmente a los efectos de los agentes y procesos de socialización política, así como diferenciar las culturas de dominación y de subordinación que puedan estar o estén latentes en los procesos de socialización

Dowse, R., y Hughes, J.,(1982), añaden la importancia de analizar las distintas etapas $^{14}$ de socialización, distinguiendo, como más importantes .la familia, la escuela y la edad adulta Lo que para ellos son etapas, otros autores las identifican como los más importantes agentes básicos de socialización; la familia, la educación, el grupo de iguales y los medios de comunicación. Analicemos brevemente el papel que juegan en este proceso de aprendizaje vital.

La familia es el agente de socialización más importante en cualquier tipo de sociedad (recordemos que en las primitivas, en las no avanzadas tecnológicamente no hay instituciones como la escuela). Desde la infancia en el seno familiar se trasmiten al niño valores, normas y prejuicios culturales. Es una socialización ésta temprana y que se desarrolla sin programa establecido pero de forma continua. Desde niños imitamos los modelos que visualizamos en el seno familiar con padres, hermanos y el resto de la familiar (familia extensa). La familia transmite capital cultural, haciendo que los hijos tiendan a seguir, a imitar los pasos de sus progenitores, (tendencia a repetir los comportamientos, valores, creencias. aprendidos e interiorizados en el seno familiar).En esta etapa de la vida, el mundo se circunscribe a los límites de la propia familia, será al entrar en contacto con personas distintas, de distinto origen y condición cuando descubramos que hay "otros mundos distintos". Esto suele ocurrir con la escolarización.

En la escuela empezamos a conocer y actuar desde otras valoraciones de la vida, de la sociedad y de todas aquellas cuestiones que le son importantes. Además de los contenidos reglados en los itinerarios formativos marcados institucionalmente, se

- ${ }^{14}$ Familia; El aprendizaje familiar puede tener sus consecuencias emprendedoras en el futuro (trabajo de padres, roles que asumen, actitud ante el trabajo...) Hay muchas variables intervinientes.

- Escuela; se pasa de una educación más personal a una menos personal, de más informal a más formal, más adquisitiva, empieza a haber roles más diferenciados (estudio europeo).

- Edad adulta (parte del proceso de socialización de toda la vida). 
adquieren otras competencias. Nos formamos en todo tipo de valores, mensajes explícitos e implícitos que tienden a reforzar el sistema de valores sociales. La escuela es el primer lugar donde debemos actuar según reglas formales y rígidas, En ella aprendemos valores de disciplina, autocontrol, y obediencia, necesarios y exigibles en los diferentes grupos y organizaciones en que se estructura la sociedad y a los que tenderemos a pertenecer a lo largo de la vida. Un foro en el que se nos evalúa y acepta por nuestros resultados, por lo que hacemos y no por quienes somos, como ocurría en la familia

El grupo de iguales está compuesto por personas de la misma edad y posición social, con intereses comunes y que elegimos por proximidad. Estamos cerca de ellos, podemos acceder a ellos fácilmente y nos relacionamos con ellos. Están en nuestro entorno próximo. Independientemente de la edad o momento de la vida, este grupo permite, por estar fuera del control de los padres, compartir y explorar nuevas inquietudes e intereses ajenos a los propios de la familia, a veces incluso éstos son el origen de las primeras fricciones y/o problemas de relación con los progenitores ${ }^{15}$ Éste, es un conflicto más ficticio que real, pues los padres son siempre un referente y ejercen gran influencia en los hijos, a lo largo de toda la vida.

Los medios de comunicación, son también un importante agente de socialización. Los nuevos avances tecnológicos permiten que puedan dirigirse y transmitir todo tipo de información a gran cantidad de individuos, de grupos, de colectivos, simultáneamente. Los diferentes medios, la televisión especialmente, forman y generan opinión, pudiendo manipular las decisiones de quienes los siguen.

\subsubsection{1.- SOCIALIZACIÓN Y PERSONALIDAD BASICA}

Siguiendo a Dowse, R., y Hughes, J.,(1982), podemos explicar el comportamiento de los individuos concretos, a través de una variable clave; la personalidad.

\footnotetext{
${ }^{15}$ En la adolescencia se hace esta separación más factible, por ser el momento en el que el adolescente empieza a descubrirse a sí mismo, como persona independiente y diferente de sus padres y es con el grupo de iguales con el que más identificación tiene (mismas inquietudes, mismos problemas....).
} 
Se trata de un fenómeno, no observable directamente. Una entidad inferida a la que se acude para dar cuenta de las regularidades del comportamiento de un individuo en respuesta a diversos estímulos externos.

Adorno, T.W., (1986) explica los comportamientos antisemitas relacionando una rígida disciplina familiar, que crea personalidades autoritarias.

Estudios sobre el autoritarismo obrero relacionan la socialización en un entorno de inseguridad económica y psicológica y simplismo cognoscitivo, y esto lo correlacionan con personalidad autoritaria y la militancia en partidos duros poco democráticos.

La antropología cognitiva ${ }^{16}$ se ha preocupado por estudiar la relación entre lo etnográfico y la transculturalidad de la cognición. Explican como el sujeto se construye psicológicamente en un contexto sociocultural, ya que el sistema cognitivo recibe y procesa la información que recibe del medio, y programa y regula patrones de conducta para adaptarse a ese medio. Conciben el sistema cognitivo como un mecanismo biológico de adaptación al entorno. Esta rama de la antropología ha desarrollado la llamada Teoría de los Esquemas, que utilizan, sus defensores, para explicar la vinculación entre individuo y cultura. Defiende, dicha teoría, que los individuos construyen en su mente diferentes esquemas, desde los que filtran la información que les llega y las experiencias que viven, de forma que cuando un cierto número de experiencias vinculadas se relacionan entre sí, como un todo, se forma un esquema mental. Con el paso del tiempo las nuevas informaciones y experiencias van encajándose en esa red de asociaciones mentales, sin modificarse el esquema, que suele ser compartido por gran número de miembros de la comunidad.

Otros autores, desde la antropología, han intentado explicar cómo se configura la personalidad del individuo en la cultura. Boas, F., (2008), pone el acento en las actitudes individuales, y afirma que "la cultura incluye todas las manifestaciones de los hábitos sociales de una comunidad, las reacciones del individuo en la medida en que se

${ }^{16}$ Área de la antropología psicológica que se inicia con la corriente de Cultura y Personalidad. 
ven afectadas por las costumbres del grupo en que vive y los productos de las actividades humanas en la medida en que se ven determinadas por dichas costumbres".

Mead, M., (1927) se interesa por el influjo de la forma cultural educativa en la diversidad del comportamiento, siendo, a su juicio estas formas, pautas o valores en que se educan las personas de cada cultura, los que configura la vida de estas personas. Defensor de la universalidad de la dimensión biológica de los individuos, entiende que la diversidad de los mismos surge por las respuestas particulares que tienen éstos a sus necesidades biológicas

Benedict, R. , (1948) da mucha importancia al proceso de adquisición cultural del individuo en sociedad, sobre todo en la infancia. Hablan de la existencia de una Personalidad Modal, o "conjunto de comportamientos aprendidos y de rasgos de personalidad de los que participan los miembros de un grupo o comunidad cultural"

La personalidad de base, afirma Benedict, R., (1948) R. debe diferenciarse del carácter, que sería la disposición individual del yo. Se formaría por la influencia de las instituciones primarias, siendo la más importante la familia. "Éstas instituciones primarias dan lugar a las instituciones secundarias (creencias, instituciones jurídicas...), que satisfacen necesidades y mitigan las tensiones creadas por aquellas". Benedict, R. , (1948)

El modo en que nos adaptamos al medio sociocultural y la forma en que influye la cultura sobre nuestro pensamiento y acción ha sido estudiado también por Spindler, G., y Spindler, L., (1992), a través de su conocida técnica Inventario de Actividades Instrumentales (IAI). Ésta, presenta, a través de un conjunto de dibujos, la representación de diferentes estilos de vida de la comunidad, de forma, que las respuestas al estímulo visual del sujeto, dan información concreta sobre las orientaciones cognitivas que influyen en cómo percibimos y cómo nos enfrentamos a la realidad social. Centrado más en la personalidad, que en la misma transmisión de la cultura, defiende la diferenciación individual (cada individuo en único) aunque se apoye en las normas socioculturales. 
Podemos afirmar que la asimilación de valores, creencias, y pautas de comportamiento por parte de los individuos, grupos y demás entes sociales, se produce en tanto que estamos inmersos en un proceso de comunicación social y transmisión de los mismos, el cual se caracteriza por la situación en que se encuentran los elementos que lo constituyen: códigos, emisores, receptores, canales y mensaje.

Las definiciones y características de la cultura implican la relación de un individuo (un ser único, específico) con la cultura (fenómeno relacionado con el grupo, entidad colectiva). La cultura le ofrece al individuo un complejo de creencias, de estándares de pensamiento y comportamiento y diferentes modelos para solucionar los problemas a los que puede enfrentarse. Todo ello es compartido por el grupo social al que el individuo pertenece.

Para establecer la relación entre el individuo y la cultura y explicar lo común y lo diferente entre los individuos y los grupos sociales, Hofstede, G., (1998) introduce el modelo de mental programs o mental programming. En este concepto Hofstede define la cultura como "programación colectiva de la mente".

Entre los años 1967 y 1973, Hofstede, G., (1998) realiza un estudio entre los empleados de la $\mathrm{IBM}^{17}$ en más de 60 países. Pretendía, y logró, establecer diferentes dimensiones culturales que explican las relaciones intergrupales en las organizaciones, permitiendo demostrar la importancia de la cultura nacional propia de cada colectivo en las diferentes actitudes y valores de los grupos. En su investigación Hosfstede presenta cuatro dimensiones de la cultura en los países estudiados; distancia de poder, individualismo - colectivismo, masculinidad y aversión a la incertidumbre., intentando traducir la cultura al ambiente social de la persona (Hofstede, G., 1998)

Mental Programs es un modelo Psico-social que permite la abstracción y simplificación de un total tan complicado como es la estructura social y la inserción del individuo en ella. Permite también explicar lo común en el comportamiento compartido por todos los seres humanos, lo diferente que identifica a los grupos sociales, y lo específico de cada ser humano. Mental programs, contiene un nivel universal, pero tiene niveles

\footnotetext{
${ }^{17}$ Empresa International Business Machiness Corporations.
} 
particulares que permiten explicar cierta homogeneidad en el comportamiento humano y su predictibilidad con base a la pertenencia a cierto grupo social.

Los tres niveles de Mental programs son:

1. Nivel universal, compartido prácticamente por toda la sociedad. Es de base biológica y por tanto heredada de las funciones del cuerpo humano. Contiene también los comportamientos como risa, llanto, comportamiento asociativo y comportamiento agresivo que el ser humano comparte con otros animales.

2. Nivel colectivo, que ya no es compartido por toda la humanidad, sino por ciertos individuos que pertenecen a cierto grupo o categoría social diferente de los demás grupo o categorías sociales. A este nivel pertenecen los elementos como idioma, relación hacia los miembros mayores del grupo, distancia física que suele mantener el individuo de los demás de la interacción, percepción de actividades humanas en general como es comida, amor, ceremonias, etc. Mental programming a nivel colectivo es la base cultural del comportamiento humano y es aprendida.

3. Nivel individual, es la parte única y específica de cada individuo, parcialmente heredada, parcialmente aprendida, entonces influenciada por ambos niveles inferiores.

Estos niveles de identificación de Hofstede, los hemos tomado como premisas para identificar lo común y lo diferente, si bien se trata de una relación mecánica, el concepto de mental programming nos sirve para identificar otras clasificaciones de la cultura y su percepción por el individuo. 


\section{Figura 2.2. Los tres niveles de programación mental}

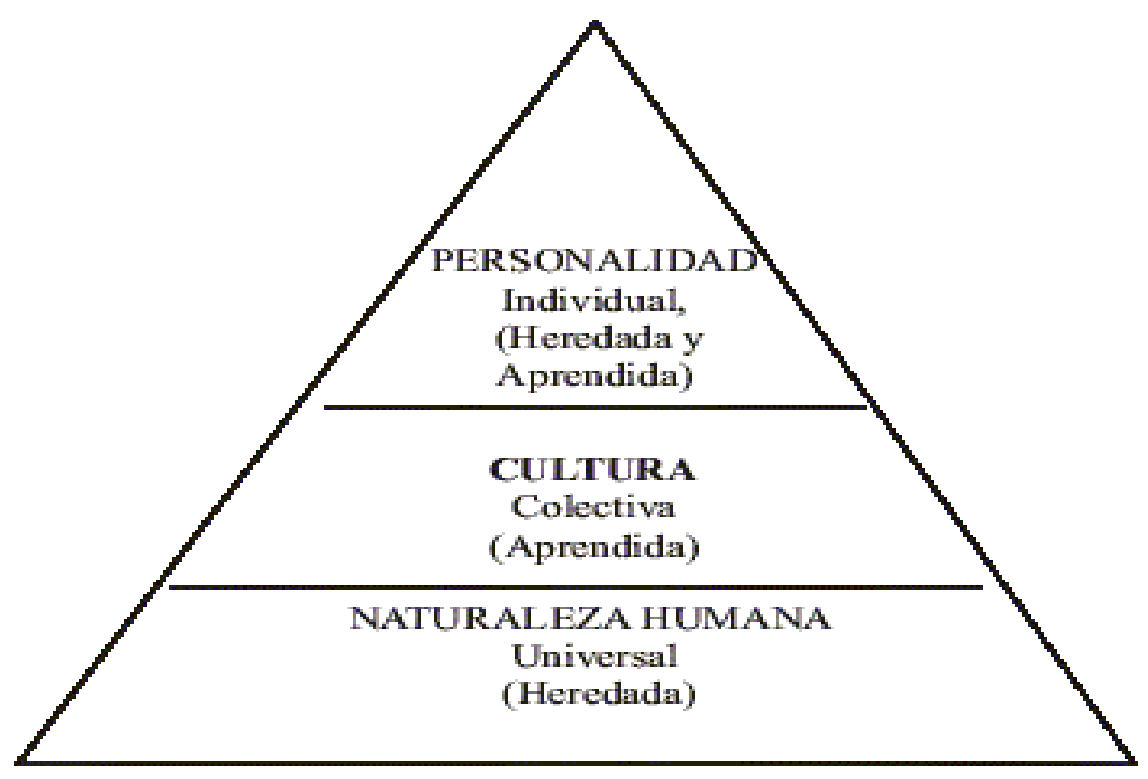

Fuente; Hofstede, G., 2001

Entiende la cultura como algo que proviene de la convivencia social y no de la genética, de forma que ni se aprende ni es heredada .Debe distinguirse de la naturaleza humana y de la personalidad individual. "La naturaleza humana es lo que todos los seres humanos, desde un profesor ruso a un aborigen australiano tienen en común, representa el nivel universal del software mental de cada uno. Se hereda en genética, es como el sistema operativo que determina con analogía al ordenador, el funcionamiento físico y psicológico básico. ;... la personalidad de un individuo es el conjunto exclusivo de programas mentales que no se comparten con ningún otro ser humano, basándose en rasgos que en parte se heredan en el conjunto genético exclusivo del individuo y en parte se aprenden”. (Hosfstede, G., 1998, p.35).

"Los símbolos son las palabras, gestos, imágenes u objetos que poseen un significado concreto, que solamente es reconocido por quien comparte esa cultura. Los símbolos tienen significados y valores particulares para las personas que comparten una misma cultura. Los héroes son las personas vivas o muertas, reales o imaginarias, que poseen características bastante apreciadas en una cultura, sirviendo de modelo de conducta. Los rituales son actividades colectivas, teóricamente superfluas, para la obtención del fin deseado, pero que dentro de una cultura se consideran fundamentales a nivel social y se efectúan por su propio valor. Los valores, son considerados el núcleo de 
la cultura, son tendencias amplias para preferir ciertos estados de las cosas a otros (Hofstede, 1999, p. 37-39).

Otros autores (Cateora, P., y Graham, J.L., 2001), bajo el nombre de criterio de auto referencia, intentan relacionar los conceptos abordados por Hofstede, identificando los siguientes círculos de identificación:

1. Círculo de religión. Está definido por la macrocultura religiosa y más fácil de identificar. Religión como sistema de símbolos, normas, convicciones, comunicaciones, comportamiento y expectativas tiene el período más largo de influencia en todas las naciones. Desde el punto de vista histórico y filosófico se puede polemizar sobre el papel de las religiones, pero desde un punto de vista intercultural es evidente, que toda persona está influenciada por el círculo religioso. Por ejemplo, los diez mandamientos se convirtieron en muchos aspectos en el sistema de normas básicas morales, éticas y legales del comportamiento del hombre occidental.

2. Círculo de la nación. Es algo más estrecho, surge de un marco específico, histórico-cultural de identificación, algunas naciones son muy antiguas, otras de reciente surgimiento.

3. Círculo de los sujetos sociales. Como la familia, la empresa, las clases sociales, el grupo profesional, etc. Que a menudo establecen sus culturas específicas las llamadas subculturas. Los rasgos específicos de estas subculturas se derivan de los dos círculos arriba mencionados.

De manera que existen tres círculos de identificación del individuo con la cultura; es decir, la religión, la nación, y los sujetos sociales. Los tres están interconectados y hasta cierto grado existe entre ellos una jerarquía. Estas manifestaciones culturales se dividen a su vez en manifestaciones concretas materiales e inmateriales de una cultura.

Las manifestaciones concretas de una cultura son la forma como se muestra en la vida cotidiana de una sociedad y es lo que para un observador externo resulta más 
evidente. Sin embargo, si este desconoce las bases de la cultura, no podrá entender correctamente sus manifestaciones concretas.

A las dimensiones arriba descritas, Ferraro, C., (2003) agrega cinco elementos principales:

1. Sistema económico que asegura producción y distribución de los miembros producidos entre los miembros de la sociedad.

2. Sistema matrimonial y familiar que establece reglamentos para las relaciones conyugales, crianza y educación de niños y condiciones para la existencia del matrimonio y relaciones interfamiliares.

3. Sistema educacional que asegura la continuidad de la cultura mediante la entrega de los conocimientos históricamente acumulados y mediante enseñanza de cómo vivir en la sociedad.

4. Sistema de control social que segura que la mayoría de la gente va a respetar por mayoría o no las leyes y reglamentos existentes.

5. Sistema de fe y creencias supernaturales, que representa la forma como se ajusta la sociedad con los elementos del medio ambiente que se encuentran fuera de su control. Comprende religión, magia, brujería, hechicería y astrología.

Las dimensiones de la cultura y sus efectos en la sociedad, han sido objeto de estudio por todos estos autores. Algunos distinguen dos grandes dimensiones: lo macroculturas y lo microcultural. (Lo macrocultural que se relaciona con grandes conjuntos geográficos, cultura europea, asiática, latinoamericana, etc... Las macroculturas, especialmente culturas nacionales, son las más relevantes, y se definen siempre contra las demás culturas nacionales, pero se dividen, a su vez, en gran cantidad de culturas de los grupos sociales (subculturas), y y lo microcultural, sería sinónimo de subcultura). 
Afirma Kottak, C.P., (1997, p.2) que las culturas "son tradiciones y costumbres transmitidas mediante el aprendizaje, que rigen las creencias y el comportamiento de las personas que les están expuestas". Maximiano, A., (2006), la define como "el repertorio de experiencias, conocimientos y valores que se maduran y que son transmitidos a sus integrantes a lo largo del tiempo". Sirven para aprender el comportamiento grupal, ayudando a los individuos a sobrevivir y a ser aceptados por su comunidad. Los individuos que constituyen una cultura se comportan en base a los conocimientos y patrones adquiridos en ella, transmitidos de generación en generación.

Queda claro que la transmisión y adquisición de cultura se produce en sociedad, en un contexto humano en el que sus integrantes interactúan socialmente, dando como resultado la construcción sociocultural del individuo. La cultura se transmite a través de símbolos que otorgan al individuo diferentes significados y valores, a través de los cuales no sólo aprende su cultura, también se convierte en un ser social.

Nos interesa, por tanto, analizar aquello que se transmite o adquiere de la cultura, los llamados contenidos culturales, lo que aprendemos socialmente en interacción con los otros.

\subsection{3.- CONTENIDOS DE LA CULTURA}

$\mathrm{Si}$ numerosas han sido las diferentes definiciones de cultura que hemos analizado, no lo son menos las distintas clasificaciones de su contenido.

Desde la antropología se diferencian dos elementos básicos de la cultura; el Ethos y el Eidos.

El Ethos cultural se concibe como el carácter y calidad de vida de un pueblo, su estilo moral y estético. Se correspondería con su escala de valores, (Fernández Martorell, M., 1984). 
El Eidos, por el contrario se corresponde con los estilos de pensamiento. Vendría a ser la normalización de los aspectos intelectuales de la personalidad de sus miembros. Algo así como la expresión de su comportamiento, en palabras de la misma autora.

El Ethos cultural nos conduce a los valores y creencias, propios de todo proceso cultural, que siendo transcendentales para una cultura, pueden carecer de todo sentido para otra. El Eidos, a las normas y modos de conducta culturales. Las normas sociales serían las maneras de percibir un hecho social, un marco de referencia compartido que describen la uniformidad de conducta y se traducen en obligaciones de rol (presiones sociales), (Fernández Martorell, M., 1984).

La Sociología, no sin controversia, pues son varias las clasificaciones que podemos encontrar, diferencia los siguientes contenidos culturales: Los elementos cognitivos o conocimientos, los signos, las normas, las formas no normativas de conducta, las creencias, y los valores.

Estas dos últimas, creencias y valores, junto con las actitudes, son el contenido básico que suele atribuírsele a la cultura desde la psicología social. Analizaremos, brevemente, las primeras, para centrar nuestra explicación en estas últimas, ya que constituyen el je básico de nuestra investigación.

Los elementos cognitivos hacen referencia a los conocimientos objetivos que toda cultura posee sobre la naturaleza, sobre el mundo que la circunscribe y la sociedad en general, sin él, se vería comprometida la supervivencia de cualquier grupo humano (Giner, S., 1982). Todo grupo, independientemente del nivel de progreso o evolución que haya sufrido como colectividad, mantiene una estrecha relación con la naturaleza que le rodea. Sabe cómo enfrentarse a ella, como satisfacer en ella sus necesidades, cómo obtener lo que necesita para sobrevivir, al margen de sus creencias, o valores.

Los signos, que pueden ser de dos tipos; Señales, que indican hechos concretos y sólo tienen significado en una cultura concreta, pasando del todo desapercibida, careciendo de todo significado en las demás. Y, los símbolos, con significado más complejo están enraizados en los sistemas de comunicación propios de cada cultura, 
generando su propia red simbólica, clave para el orden social; su lenguaje específico. (Giner, S., 1982).

Las normas son reglas explícitas, o no, que pueden ser asumidas a nivel personal (norma personal) o social (norma social), sobre los modos de comportamiento que se consideran válidos o no, aceptables o no en el marco social. Serían un conjunto de reglas y expectativas sociales que generan una expectativa de cumplimiento, y regulan el comportamiento colectivo. Por tanto las habrá con carácter prohibitivo ó proscriptivas, o indicadoras del comportamiento socialmente aceptable, del deber hacer, o prescriptivas.

Las formas no normativas de conducta, representan la llamada idiosincrasia de todo pueblo o comunidad. Son formas específicas de conducta que los identifican como diferentes (rasgos específicos de diferentes regiones dentro de una misma nación, por ejemplo). (Giner, S., 1982).

Como afirmáramos, anteriormente, desde la psicología social, suelen tres los elementos que componen la cultura; las creencias, los valores y las actitudes. En ellas basaremos nuestra investigación, por ser las más estrechamente relacionadas con la personalidad individual. .

\section{Las creencias}

Tradicionalmente, han relacionado las creencias con la naturaleza del conocimiento humano. Podríamos definirlas, formalmente, como "un juicio psicológico que pone en relación dos proposiciones sin que esa relación esté completamente verificada; es una inferencia o juicio psicológico con cierto nivel de incertidumbre”. (Garzón, A, 1996).

Esa es la razón, según explica esta profesora de la Universidad de Valencia, por la que muchos autores se refieren a las creencias como una actitud mental de aceptación, visión, ya defendida, en el siglo XVIII, por David Hume, uno de los primeros autores en abordar su estudio. 
Las diferentes definiciones que, desde entonces, podemos encontrar sobre las creencias son muy variadas. Rockeach, M., (1979), las analiza desde el marco del procesamiento de la información, en un plano cognitivista. Intenta desarrollar una estructura lógica, formal y sistemática de la estructura o sistema cognitivo, relacionando las opiniones, las creencias, las actitudes y los valores.

Rockeach, M., (1979), define las creencias como la adhesión a una idea, como la persuasión de que la idea es verdadera, como algo opuesto al saber, pero al mismo tiempo como algo que puede fundamentar el mismo saber. Alude a la verdad o falsedad de algo, objeto o situación, a su valoración de si es bueno o malo. Siendo enunciados específicos, no demostrables empíricamente, inducirían al comportamiento, por ser considerados ciertos por las personas (Rockeach, M., 1979).

Las creencias se configurarían en base a tres componentes básicos; el cognitivo, el afectivo y el valorativo.

- El componente cognitivo representa el conocimiento que una persona tiene sobre lo que es verdad o mentira, bueno o malo...

- El componente afectivo, explica como la creencia es capaz de despertar afectos de diferente intensidad, en determinadas condiciones, que pueden estar centradas en el mismo objeto de la creencia, en otros objetos (situación, individuo, grupo...) que se manifiestan a favor o en contra del objeto de la creencia, ó, de la misma creencia. En definitiva cuando se cuestiona su validez. Cuando la creencia no es cuestionada, el componente afectivo queda desdibujado, aunque no desaparece.

- El componente valorativo o conductual, habla de la conducta en un sentido amplio (cualquier respuesta que da el sujeto a un estímulo, siendo ésta del tipo que fuere; fisiológica, motriz mental o cualquier combinación de ellas). Al tratarse la creencia de una predisposición, deberá coincidir con algún tipo de acción, cuando ésta se activa adecuadamente, (Rockeach, M.,1979). 
En palabras de la profesora Garzón, las creencias son de gran utilidad para los individuos. A través de ellas intentan ordenar y dar sentido a sus propias experiencias, desarrollando explicaciones sobre los hechos, objetos, situaciones.... Así, simplificando la información que tienen, pueden enfrentarse a su propia realidad, al mundo concreto y momento histórico en que viven. (Garzón, A., 2005).

Las creencias se relacionan con el mundo del conocimiento, pero éste no está libre de valores, de ahí la necesidad de incorporar a las creencias una dimensión evaluativa y otra afectiva. (Garzón A., 2005).

Son un componente esencial de la cultura, pues soportan la estructura del pensamiento racional. Se erigen como un referente orientador del comportamiento. Las creencias dotan de contenido a las actitudes y a los valores.

Estas formas de interpretación de la realidad son compartidas por la comunidad, de ahí su carácter social. Sería la forma que tiene la colectividad de entender el mundo, “... relacionadas con la ideología, no en su sentido marxista, sino como sistema ordenado de ideas y concepciones del mundo físico y social, compartido y desarrollado por un colectivo o sociedad. (Garzón, A. 2005).

Tradicionalmente, se ha estudiado ese sistema general de creencias, y se afirma que está compuesto por tres grandes dimensiones relacionadas entre sí, las, tradicionalmente, recurrentes para analizar y comparar las diferentes sociedades; La política, la social y la cultural.

La dimensión política hace referencia a la forma concreta que tiene una sociedad de estructurarse y organizarse socialmente La dimensión cultural es la forma de entender el tiempo, la historia y el conocimiento, y la dimensión social, o psicosocial, en palabras de Garzón, que incluye las formas de interacción social concretas que predominan en esa sociedad. (Garzón, A., 2005).

Esto implicaría que, en cada momento histórico, cada colectividad crea y desarrolla su propio sistema de creencias, socialmente compartidas, que integraría de diferente forma, según sus propias características y evolución, estas tres grandes dimensiones. 
Por consiguiente, podemos agrupar las diferentes creencias de una colectividad en dichas dimensiones. (Garzón A., 2005).

\section{Figura 2.3. Modelo General del Sistema de Creencias}

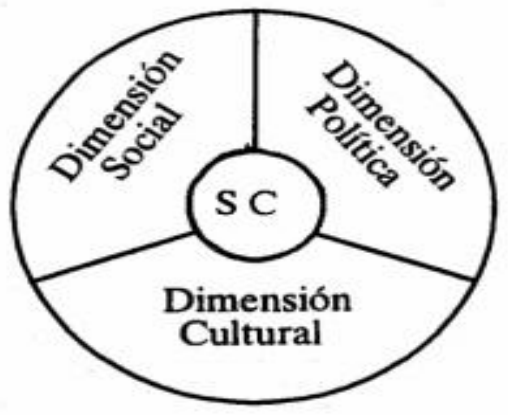

Fuente; Garzón, A. 2005

La creencia, socialmente compartida y aceptada por cada individuo, sobrevivirá en el tiempo siempre que existan razones sociales para mantenerla viva. Continuamente se desarrollan creencias nuevas que conviven con la herencia social recibida. Las nuevas creencias se aceptan total o parcialmente, o pueden entrar en conflicto con las anteriores. En función de 'como se articulen podemos encontrar diferentes ritmos y modelos de evolución social.

Las creencias, como componente básico de la cultura que son, se relacionan con las actitudes, los valores, las opiniones....

\section{Las actitudes}

El término actitud es versátil y puede generar cierta incertidumbre.

"Por desgracia el término actitud tiene dos significados, uno amplio y otro estrecho. Fue usado primero en sentido bastante limitado, para indicar una predisposición motriz y metal a la acción. Después se empleó con un alcance mayor, para señalar tendencias reactivas específicas o generalizadas, que influyen sobre la interpretación de nuevas situaciones y la respuesta frente a éstas”. (Kimball Young,, 1963). 
Mientras muchos autores consideran que la actitud es una predisposición a responder, otros afirman que es una respuesta en sí misma. (Dicotomía entre pensamiento y comportamiento). La respuesta es algo que podemos analizar en el ámbito del comportamiento, La predisposición sería una orientación cognitiva o afectiva que proporciona una creencia central o dominante en ese sistema organizado que solo se da en el intelecto y que nos lleva a asumir decisiones y respuestas espontáneas. Entendida así, la actitud sería un concepto virtual; un conjunto indeterminado de creencias y comportamientos que definen nuestro posicionamiento ante algún tema o situación.

Krech, D., y Crutchfield, E.S., (1948), distinguen las actitudes de las creencias de la siguiente forma; "La creencia es una organización durable de las percepciones y de los conocimientos relativos a ciertos aspectos del mundo de un individuo, mientras que la actitud es una organización durable de los procesos emocionales, motivacionales, perceptivos y cognoscitivos referentes a ciertos aspectos del mundo de un individuo". Es decir, que la actitud es una creencia adicionada de carga afectiva.

Allport, g: W., (1935) definía la actitud como "la disposición mental y neurológica que se organiza a partir de la experiencia que ejerce una influencia directriz o dinámica sobre las reacciones del individuo respecto de todos los objetos y a todas las situaciones que les corresponden".

La actitud, según, (Kimball Young, 1963, p- 523), sería “la tendencia o predisposición aprendida, más o menos generalizada y de tono afectivo, a responder de un modo persistente y característico, por lo común positiva o negativamente, con referencia a una situación, idea, valor, objeto o clase de objetos materiales, o a una persona o grupo de personas".

"Las actitudes son predisposiciones a obrar, percibir, pensar y sentir en relación a los objetos y personas “(Jack H. Curtis, 1960, p.38).

Como la tendencia del individuo a reaccionar, positiva o negativamente, ante cierto valor social, la definían Thomas, W., y Znaniecki, F., (1918) y como disposiciones duraderas formadas en base a la experiencia anterior, Asch, S., (1956). 
Para Milton Rockeach la actitud sería una organización de creencias interrelacionadas, relativamente duradera, que describe, evalúa y recomienda una determinada acción con respecto a un objeto o situación, un "conjunto de predisposiciones para la acción relacionadas entre sí y organizadas en torno a un objetivo o situación”. (Rockeach, M., (1979).

Podemos afirmar que las actitudes son el vinculo entre el conocimiento que hemos adquirido a lo largo de la vida y las acciones que desarrollaremos ahora y en el futuro. Llevamos en nuestra memora el pasado y las acciones que acometimos. Éstas influirán en las acciones futuras.

Si ambiguo es el término, como las distintas definiciones que diferentes expertos de la sociología y psicología social han dado, no lo son menos las explicaciones sobre su desarrollo o cambio.

Aun pudiendo asumir que existen algunas actitudes básicas innatas, como el miedo a lo desconocido, prácticamente ninguna teoría cuestiona que es a través del proceso de aprendizaje como se adquieren y desarrollan las actitudes.

Nuestras actitudes cambiarán si también lo hace la información que tenemos grabada en la memoria (opiniones y creencias), que es de donde éstas surgieron antes. Entonces, si podemos hablar del sistema de creencias sociales, podremos hablar de la actitud asociada al grupo.

Podemos encontrar factores determinantes en las actitudes, como es el hecho de que éstas se expresen como reacciones de afecto ante los objetos, personas o situaciones. Cómo es la impresión que produce a un individuo un objeto lo que determina el significado que el individuo le otorgue, y no los datos objetivos, que de él se desprendan. Las actitudes son creadas por las actitudes de los demás a través de las interacciones sociales y se pueden modificar y desarrollarse. 
En esta misma línea se manifiestan Eiser, y W. Strobe, (1962, p.12) al afirmar que la actitud "es una predisposición aprendida a responder de un modo consistente a un objeto social". (Eiser, y W. Strobe, 1962).

Al margen del concepto en sí mismo, lo cierto es que las actitudes son importantes parámetros de análisis desde los que inferir el comportamiento, para la piscología social.

\section{Los valores}

La psicología, en palabras de Cayón A. y Pérez, E., (2008), entiende los valores como las formas concretas que tienen las personas de concebir lo que desean. Estas formas influirían en las evaluaciones que estos individuos hacen los acontecimientos de la vida y dirigirían sus formas de acción. Serían la base tanto de las actitudes, en cuanto que las orientan, como del comportamiento de individuos y grupos. (Cayón A. y Pérez, E. 2008).

La sociología, en general, entiende el valor como un sistema representativo de interpretación y valoración de las condiciones sociales (Giner, S., 1982). Sería las diferentes formas de actuar ante un hecho o situación que puede tener un individuo en base a una concepción del mundo concreta aprendida y mantenida por la comunidad.

Rockeach los define como "aquel objeto de conocimiento que se convierte en término orientador de la conducta social”. ”. (Rockeach, M., 1979).

Esta concepción de los valores, a nivel práctico genera cierta confusión e incertidumbre. Las ciencias sociales nos los presentan como los principios orientadores y configuradores de la conducta social global, siendo el término principio orientador el que genera confusión, porque podemos traducirlo por ese sistema de creencias organizadas en torno a un tema o situación en el que determinadas creencias centrales y dominantes prevalecen al ejercer su influencia de cara a la orientación y rumbo de nuestro comportamiento”. (Rockeach, M., 1979). 
Hofstede, los define como "sentimientos con una flecha que los apunta: tienen un lado positivo y otro negativo” (Hofstede, G., 1998).

Baztan define los valores como "criterios estables de los deseable, que se constituyen en guía de conducta, con vista a la obtención de un fin”. (Baztan, A.,2004, p.223).

El concepto de valor prevalece en el terreno intelectual y del pensamiento, sin que su significado esté comprometido dentro del terreno del comportamiento. Linton añadirá cómo una vez interiorizados por los individuos, harán que éste actúe bajo su prisma, de forma inconsciente. (Linton, R., 1945).

Aceptamos pues que los valores son interiorizados individualmente por cada sujeto, orientando su propia conducta, y, que es en la interacción social, en sus distintos planos (familiar, grupal, social, etc.,...), donde se aprenden, sirviendo de reguladores del comportamiento social, en cuanto que posibilitan la convivencia en común. Esto nos lleva a poder afirmar que en todo grupo social existe un sistema de valores orientador de la conducta colectiva. Un sistema de valores sería aquel conjunto de principios orientadores y configuradores de la conducta de una sociedad global. Esos principios son los valores sociales, considerados, dentro del ámbito en el que se hallan vigentes, como correlato positivo de las necesidades sociales. Serían el marco en el que se regula la convivencia de sus miembros. Es, sin duda alguna, el foco común de la socialización (lo que se transmite culturalmente), y por tanto, pauta y término de sus conductas.

Se presenta ante los individuos en él integrados como una realidad objetiva poseedora de validez universal. Definidos en el seno de una cultura, a través de los cuales las personas evalúan lo bueno, lo bello, lo deseable. Sirven de guía para vivir en sociedad.

Las pautas de comportamiento que se manifiestan en el seno de una cultura se rigen por el sistema de valores y su jerarquía. Éste cristaliza en una serie de actitudes, consistentes en un conjunto organizando de creencias que predisponen a actuar de una determinada manera. 
Que los valores no son entendidos de forma unánime, es una evidencia. Se hace necesario dotarlos de contenido concreto en virtud del conjunto de creencias que se aglutinan en torno a él. El hecho de que todo sea valorable (todo se puede valorar), no implica que todo deba ser considerado como valor. Esto lo ejemplariza perfectamente la profesora Collazos cuando habla del valor económico que asignamos a cualquier objeto y cómo se incrementa o menosprecia, exclusivamente, en base al sentido subjetivo que le otorgamos, independientemente de su sentido económico.

\section{Cuadro 2.2: Definiciones de valor, según diversos autores}

\begin{tabular}{|c|c|}
\hline Autores & Definición de valor \\
\hline Kluckhohn (1951) & $\begin{array}{l}\text { Concepción, explícita o implícita, propia de un individuo o característica de un grupo, } \\
\text { acerca de lo deseable, lo que influye sobre la selección de los modos, medios y fines de } \\
\text { la acción accesibles. }\end{array}$ \\
\hline Allport (1961) & Una creencia a partir del cual el hombre actúa por preferencia \\
\hline Rokeach (1973) & $\begin{array}{l}\text { Una creencia duradera de que un modo de conducta o estado de existencia específico } \\
\text { es personal o socialmente preferible a un modo de conducta o estado de existencia } \\
\text { opuesto o alterno. }\end{array}$ \\
\hline Hofstede (1984) & Una tendencia general a preferir ciertos estados de cosas sobre otros. \\
\hline $\begin{array}{l}\text { Schwartz y Bilsky } \\
\text { (1992) }\end{array}$ & $\begin{array}{l}\text { El concepto de un individuo sobre una meta transituacional (terminal o instrumental) } \\
\text { que expresa intereses (individualistas, colectivistas o ambos) relacionados con un } \\
\text { dominio motivacional (disfrute... poder) y evaluado en rangos de importancia (de muy } \\
\text { importante a sin importancia) como principio guía en su vida }\end{array}$ \\
\hline Fisher (1993) & $\begin{array}{l}\text { Aprendizajes estratégicos, convicciones estables en el tiempo con relación a que un } \\
\text { determinado modo de conducta es preferible a su opuesto. }\end{array}$ \\
\hline García y Dolan (1997) & $\begin{array}{l}\text { Son estructuras del pensamiento que se mantienen preconfiguradas en el cerebro de } \\
\text { cara a nuestra supervivencia como especie humana. }\end{array}$ \\
\hline $\begin{array}{l}\text { Arciniega y González, } \\
(2000)\end{array}$ & $\begin{array}{l}\text { Representaciones cognitivas de necesidades universales expresadas por medio de } \\
\text { metas transituacionales que se organizan de forma jerárquica y que se manifiestan en } \\
\text { distintos contextos de la vida de las personas. }\end{array}$ \\
\hline
\end{tabular}

Fuente: García, Medina, Inbarb, y Dutschkec, (2010)

\section{Relación entre actitudes, creencias y valores}

Rokeach afirma que estos tres elementos (creencias, actitudes y valores) están interrelacionados y jerarquizados en base a un único sistema integral y global de creencias, del que forman parte, (Rockeach, M., 1979). 
Las actitudes serían las la representación de la orientación general que es persistente en el sujeto frente el medio en el que vive (Newcomb, T.M, 1943).

Dependen de los valores, que a su vez son creencias jerarquizadas sobre las formas de vivir o de existir que guían nuestras actitudes y comportamientos, (Rockeach, M., 1979).

Los valores forman parte de la estructura de la personalidad del sujeto, mientras que actitudes y comportamientos son elementos más periféricos (Ros, M., 2001).

Los valores son independientes de una situación concreta y representan las creencias que posee una persona, las formas ideales de comportamiento. Los valores son más estables y dirigen nuestras acciones, juicios y opiniones hacia el mantenimiento de la misma actitud, (Rockeach, M., 1979).

Los valores constituyen el sistema fundamental por el que orientamos y definimos nuestras relaciones y conductas con el medio en el que vivimos y con quienes en él se insertan. Son estructuras complejas y difíciles de cambiar. Las actitudes se situarían entre los valores y las conductas, derivándose de los primeros y orientando a las segundas. Son nuestro valores personales los que influyen en las elecciones y preferencias que diariamente hacemos, los que orientan nuestras relaciones y comportamientos en el medio en que vivimos (Ros, M., 2004).

\section{2.- MODELOS CONCEPTUALES SIGNIFICATIVOS EN EL ESTUDIO DE LOS VALORES}

Si asumimos que son los valores el núcleo esencial de toda cultura (Kroeber, Al. y Kluckhohn C., 1952) y que es a través de los procesos de socialización como los interiorizamos y los clasificamos en orden de importancia en base a nuestras prioridades y necesidades concretas, en cada momento, se hace necesario profundizar en el estudio de los valores, tratando de determinar el impacto real que éstos puedan tener, 
posteriormente, en la generación de una cultura emprendedora. Para ello, y tras la introducción del concepto, pasamos a referenciar algunos autores o teorías, dentro de las ciencias sociales, significativamente claves, por su línea de pensamiento o innovación en este campo.

Profundizando en el estudio de los valores, encontramos concepciones distintasAlgunos autores (Thomas, W., y Znaniecki, F., 1918; Parsons, T., 1960; Rokeach, m., 1973) entenderán los valores como guías que orientan el comportamiento y centrarán su énfasis en analizar el impacto que éstos tienen sobre las actitudes y comportamiento de los individuos. Otro enfoque, distinto pero complementario, pondrá el acento en analizar la relación que tienen los valores con otras variables de tipo social, político y económico, tratando de determinar en qué medida estas variables establecen o no un perfil concreto de valores (Hofstede, G., 1980; Triandis, H.C., 1996; Inglehart, R., 1991). Podemos hacer otra clasificación, relativa a aquellos estudios que abordan los valores como resultados de la influencia de variables de tipo social, económico o político (Hofstede, 1980; Triandis, 1996; Inglehart, 1990), y las de quienes entienden que los valores son variables independientes que pueden explicar las acciones de los sujetos y/o grupos (Schwartz, S.H., 1992; Ros, M. 2001; Ros, M., 2002; Pato, C., Ros, M., y Tamayo, A., 2005; Pereira , R., 2007; Gómez, A., Seyle, C. Huici, C. y Swann, el Banco Mundial, Jr., 2009).

Concluimos que la cultura, facilitadora de la adaptación de los individuos al grupo, se transmite socialmente, hemos podido mostrar como los valores son un componente esencial de la misma. Los valores, en cuanto guía de la conducta individual, son principios personales, pero también sociales, en la medida en que son compartidos por la colectividad, de forma que permiten conectar la vida de estos individuos con la sociedad donde interactúan. (Rokeach, M., 1975; Schwartz, S.H., 1992, 2001; Ros, M., 2002).

Desde esta dimensión no personal o colectiva, podemos utilizar los valores como concepto clave en la identificación de las diferencias entre culturales, centrando así como unidad de análisis la misma cultura y no a sus individuos integrantes, (Rokeach, M.,1982; Hofstede, G.1988). 
"La estructura de las culturas nacionales difiere de la estructura de las personalidades individuales (...) las culturas se forman por la interacción de personalidades diferentes (...) y que forman un todo, que es más que la suma de sus partes. La cultura de un país o de cualquier otra categoría de personas, no es una combinación de propiedades del ciudadano promedio (...). El confundir el nivel individual con el nivel de la sociedad se conoce en las ciencia sociales como falacia ecológica y se trata de una confusión entre la personalidad y la cultura" (Hofstede, G., 1980, p. 93).

Uno de las primeras y más importantes investigaciones hechas en este terreno fue la de Thomas y Znaniecki, dando lugar a su interesante y conocida obra El campesino Polaco en Europa y en América (1918-1920). Realizan un estudio profundo de los procesos de adaptación de los inmigrantes polacos en los Estados Unidos, a principio del Siglo XX, poniendo en relación los aspectos étnicos y culturales de estos inmigrantes, con la cultura, y las normas sociales de la nueva comunidad de acogida.

En este sentido introducen el concepto de actitud, entendida como el significado que tienen las cosas para las personas, y contribuyen, de forma decisiva, al estudio sociológico de los valores, lo que provoca la irrupción en la sociología de un área independiente de análisis, alejada de la corriente biologicista de los instintos, imperante en la psicología de aquella época (psicoanálisis), así como de la sociología de Giddens, de la escuela de Columbia (Ros, M., 2001)

Thomas y Znaniechi definen "la actitud como el proceso de la conciencia individual que determina la actitud real o posible del individuo en el mundo social", (el hambre que obliga al consumo de comida; la decisión del trabajador de usar una herramienta; la tendencia extravagante a gastar dinero; el sentimiento e ideas de un poeta expresadas en un poema y la simpatía y la admiración del lector; las necesidades que la institución trata de satisfacer y la respuesta que provoca; el miedo y la devoción que se manifiesta en el culto a la divinidad; el interés por crear, comprender o aplicar una teoría científica y las formas de pensar que están implícitas. Todo esto son actitudes (Thomas, W., y Znaniecki, F., 1918).

En suma, estos autores perciben la actitud como un proceso en el que alguien cognitivamente capta una situación y en consecuencia decide como debe actuar. Se 
trataría pues, de un concepto exclusivamente emocional y de comportamiento. Sin embargo al relacionarlo con la actividad introducen el concepto hegeliano de intencionalidad. Conectan las actitudes con la estructura social a través de los valores, entendiendo los valores "cualquier dato que tenga un contenido empírico accesible a los miembros de un grupo social y un significado con respecto a cual es o pueda ser objeto de actitud" (Thomas, W., y Znaniecki, F., 1918, p. 21-22).

Los valores se conciben en relación con las actividades o comportamientos concretos, siendo un antecedente importante en la Psicología Social (Schwartz, W., 1990). Si los valores están dirigidos a las metas, implica que hay una motivación para actuar. Así, presentan cinco motivaciones ínsitas en los valores: reconocimiento social, seguridad, respuesta, dominio o competencia y nuevas experiencias. El fundamento de la motivación de los valores es el deseo de relacionarse con los otros. (Thomas, W., y Znaniecki, F., 1918).

Esta visión concreta de los valores relacionados con la acción o comportamiento del hombre, es opuesta a la que defendían autores como Durkheim, E., 1967; Goffman, E., 1967) no volverá a ser tenida en cuenta, en la Sociología, hasta Parsons, T. 1960).

Parsons toma de Weber el concepto de acción social y en lugar de hablar de personas, habla de actores que realizan acciones, y las acciones no se realizan de forma aislada, sino que se integran en conjuntos o sistemas de acción: el sistema de la personalidad, el sistema social y el sistema cultural.

- El sistema de la personalidad alude a que el actor actúa a nivel personal, acuciado por sus necesidades, en busca de una gratificación, para cuya consecución ha de sopesar las alternativas de que dispone.

- En el sistema social, el actor se mueve motivado por la complementariedad de las expectativas entre el individuo y los demás con los que interactúa, la acción de cada uno será dirigida en relación con las expectativas de los demás. A la postre es la comunicación la condición previa de dicho proceso. Esta no podría existir sin el sistema cultural, ya que sólo puede ser asegurada por las convenciones respetadas por ambas partes. 
- El sistema cultural es, por tanto, el que hace el sistema interpersonal (social) y personal” (Parsons T., 1951, pág. 16).

La persona se motiva guiada por tres criterios, cognitivos, estéticos y evaluativos y también por los valores personales, que a su vez tienen tres aspectos: cognitivo, evaluativo y de responsabilidad personal, tanto para la persona que actúa como para el sistema social. Parsons patrocina un concepto de valor distinto del de Thomas y Znaniecki, "Un valor es una concepción explicita o implícita distinta de un individuo o característica de un grupo sobre lo deseable, que influye en la selección de las formas, medios y fines existentes de acción" (Parsons T., 1951, pág. 395).

Parsons habla de variables patrón para referirse a los valores, que están establecidos jerárquicamente, y los entiende como incitadores del comportamiento, asumidos interiormente por los individuos.

Aísla los valores de las normas: "eran tan generales que no eran específicos de una situación o de una función”. (Parsons, T., 1961, pág. 43). Los valores, como conceptos abstractos suponen únicamente un referente para la reflexión y la acción, mientras que las normas establecen lo que hay que hacer o no hacer en situaciones específicas. Ambos, valores y normas forman parte de la estructura del individuo y se adquieren en el proceso de socialización, ce forma que cuando el individuo actúa en base a sus normas y valores, está respondiendo a las exigencias del entorno inculcadas con anterioridad por el mismo orden social.

La contribución de Parsons al estudio de los valores, no está exenta de críticas (Levin, J., y Spates, J., 1970; Ros, M., 2001).

- El apoyo empírico; a pesar de la elegancia y la consistencia lógica de la teoría funcionalista de los valores, existen pocos datos que la apoyen.

- El problema de la imposición deductiva; los valores no se pueden inferir de las situaciones y de su contenido específico deducido por el teórico cuidadoso. 
- Finalmente, se plantea el problema de la abstracción. A medida que se desarrolla la teoría funcionalista, define los valores, cada vez, de forma más abstracta.

La demostración empírica a estas afirmaciones viene en los años 90 con los estudios sobre la estructura transcultural de los valores, donde diferentes autores procuran establecer dimensiones comunes para poder comparar sociedades. Surge la necesidad de diferenciar el nivel de análisis individual del cultural (Schwartz , S.H, y Smith, J., 2000; Ros, M., 2001).

Antes de abordar estos enfoques transculturales, en cuyo seno centraremos nuestro enfoque investigativo, haremos un repaso a las aportaciones al concepto de valor, que a desde la Psicología hizo Maslow, A., (1984). Desarrolla una teoría de la motivación, que él denomina holística (gestáltica) y dinámica por basarse en autores como Freud, Fromm, Horney, Reich, Jung y Adler. (Maslow, A., 1954). Esta teoría, derivada de su observación y experiencia clínica, y no sometida a pruebas de contraste, explica cómo las personas tienen varios tipos de necesidades, Fisiológicas (comida, bebida, deseo sexual); de seguridad (estabilidad, protección, estructura); de pertenencia y amor (intimidad, contacto, familia); de estima (autor espeto y autoestima); de actualización (realizar, desarrollar lo que la persona puede llegar a ser); de conocimiento (entender, explicar, tener iniciativas); estéticas (búsqueda activa de la belleza). Estas siete necesidades están organizadas "según un principio de jerarquía de prepotencia relativa" Lo que implica que solo se tiende a satisfacer necesidades superiores cuando hemos satisfecho las básicas.

Sin embrago, establece algunas excepciones a este orden fijo en la jerarquía:

1. Para algunas personas la autoestima es más importante que el amor.

2. Para otras el nivel de aspiración está saturado y no experimentan necesidades de orden superior. 
3. Las personas que han tenido satisfecha una necesidad durante largo tiempo tienden a infravalorarla. (Maslow, A., 1964)

Figura 2.4.- Teoría de la Jerarquía de Necesidades de Maslow

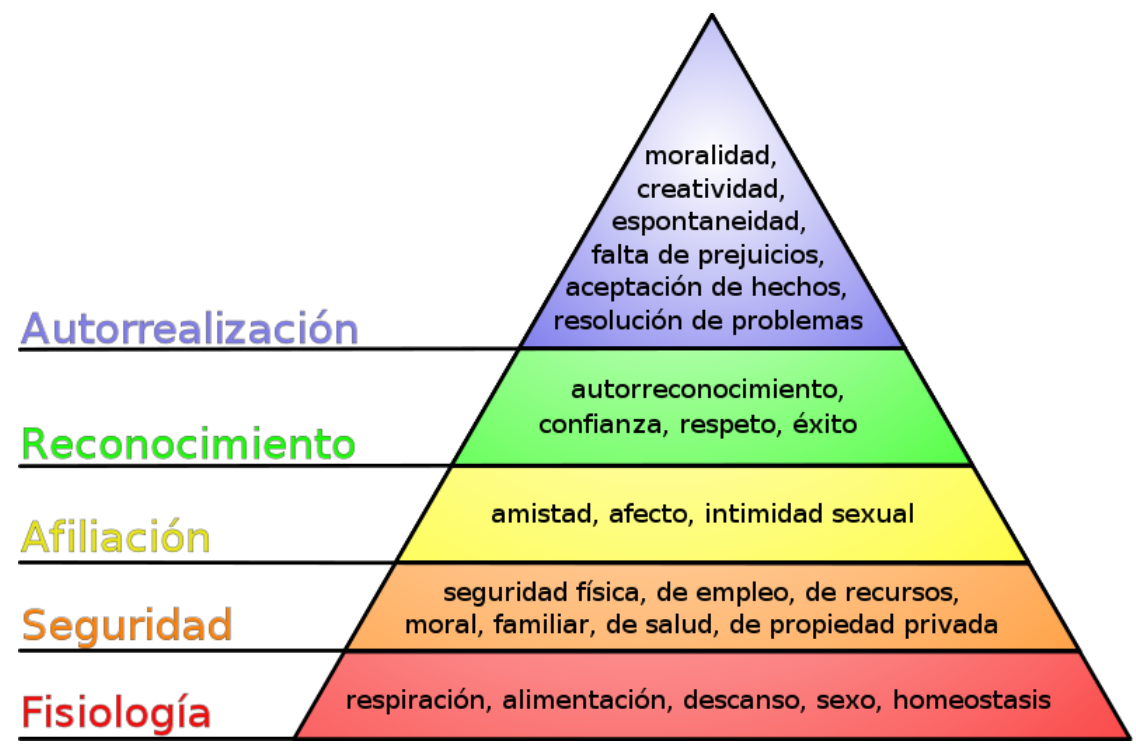

Fuente: Maslow, A., 1954)

Será Inglehart, R., (1977), en su teoría de los valores políticos del materialismo y posmaterialismo, ligada a la satisfacción de necesidades de bienestar económico y a la autorrealización, quien indirectamente evidencie la teoría de Maslow. Solo cuando los países han superado la escasez económica pasarán de valorar la seguridad, el orden y la prosperidad económica, a valorar las necesidades postmaterialistas de autorrealización, participación política y cuidado del medio ambiente, presenten en todo tipo de países. De aquí podemos deducir que algunos valores son metas deseables tanto cuando están satisfechos como cuando no lo están, y que el grado de satisfacción de una necesidad es relativo a las aspiraciones de cada persona o cada sociedad. (Ros, M., 2001).

Rokeach, M., (1973) define los valores como creencias de tipo general, que están ordenadas jerárquicamente, al margen de las situaciones concretas de los individuos, y que sirven de criterio para el comportamiento, pues los individuos los manifestadas a través de sus preferencias. En este concepto subyacen varios aspectos dignos de ser considerados: En primer lugar, los valores son creencias prescriptivas, que 
nos indican lo que es correcto o no lo es. Se organizan según criterios de importancia y, la mayoría de ellos, los que son estables, orientan nuestras decisiones. Distingue dos tipos de valores:

1- Terminales: que responden a las necesidades de la existencia humana. Que a su vez se dividen en personales, como la autorrealización, la felicidad o la armonía interna; y sociales, como la seguridad familiar, seguridad nacional e igualdad.

2- Instrumentales: son los valores que van dirigidos a alcanzar los fines de la existencia humana. Estos a su vez pueden ser: morales, como ser honesto, ser responsable; los cuales pueden ser interpersonales, cuyo incumplimiento provoca culpa; y de competencia como autorrealización, ser imaginativo, y su falta de realización provoca sentimiento de ineficacia personal.

Aunque no lo desarrolla, plantea la existencia de un conflicto entre valores, más específicamente, entre los valores morales y o de competencia. (Rokeach, M. 1973).

Al definir los valores, la mayoría de autores pone el acento en su carácter de guía, en cómo son principios que guían la vida de los individuos y cómo a través de ellos conectan con la sociedad. Así, podemos decir que en la medida de que los valores individuales son ampliamente compartidos por los miembros de una sociedad, éstos se convierten en valores sociales.

Ahora, bien, las aportaciones al campo de valores trabajadas hasta ahora, no nos son útiles, metodológicamente, a la hora de diferenciar distintos tipos de valores. Será Schwartz, S.H., (1992) el primer autor que supere esta deficiencia. Son varias las teorías que trabajan el concepto de estructura de valores culturales, al objeto de entender y poder comparar las características diferenciales de cada sociedad. Medir las diferencias entre culturas es un objetivo básico paran todas las ciencias sociales.

A continuación, y partiendo de la teoría de Schwartz, por ser la más idónea a nuestro objeto de estudio, abordaremos someramente, las más importantes teorías sobre valores culturales. 


\section{Cuadro 2.3. Teorías de los valores Culturales}

\begin{tabular}{|c|}
\hline Teorías de los Valores Culturales \\
\hline Schwartz $(1994,2000,2002)$ \\
\hline Hofstede $(1980,1991,2001)$ \\
\hline Inglehart $(1990,1998)$ \\
\hline Triandis $(1996)$ \\
\hline Bond $(1987)$ \\
\hline Trompenaars, $(1997,2000)$ \\
\hline
\end{tabular}

Fuente: Elaboración propia

\subsection{1- TEORIAS DE LOS VALORES CULTURALES}

Las teorías transculturales sobre los valores se desarrollan durante los años ochenta y noventa del pasado siglo y aluden a dos niveles: el nivel cultural y el nivel individual.

En el nivel individual, caracterizan las prioridades de las personas, las bases motivacionales en que se sustentan los valores, que a su vez tratan de explicar las diferencias interindividuales. Suelen estar conectados con las decisiones y las actitudes que observamos, y están en la base de los conflictos que padecemos a la hora de tomar decisiones.

En el nivel cultural, los valores caracterizan a las sociedades en su conjunto, representando los criterios comunes utilizados para resolver los problemas de la colectividad. (Tetloch, P.E., 1986).

\section{Teoría de la estructura de valores individuales de Schwartz}

Schwartz, concibe los valores como metas deseables, no iguales en orden de importancia, que estando al margen de la situación concreta de cada individuo, actúan como principios en la vida de una persona o un grupo social. Se adquieren, básicamente a través de la socialización y de la experiencia personal. No sólo justifican las acciones, sino que, en palabras del autor, puede motivar a las mismas. (Schwartz, S.H., 1992). Esta es la gran distinción, o el gran aporte de su teoría; el establecer una posible 
diferenciación de los valores en base al tipo de meta motivacional que expresan. Cada valor representa un objetivo perseguido por el sujeto. Este objetivo o meta, además, se corresponde con tres condiciones básicas del individuo; la de sus necesidades biológicas, la de sus necesidades de interacción social coordinada, y las de poder dar respuesta a requerimientos básicos que permitan un adecuado funcionamiento y supervivencia del grupo al que pertenecen. Los valores en forma de metas conscientes, representan las respuestas que los individuos y las sociedades dan a retos de tipo universal. (Schwartz, S.H., 1996).

El modelo permite comparar valores generales y universales, que son compartidos y entendidos de igual forma por los sujetos, entre diferentes países. La gran aportación radica en poder distinguir estos valores, en base a la meta motivacional que expresan. Schwartz, hace una revisión a las anteriores formulaciones teóricas sobre valores, y en base a ellas destaca cinco grandes características de los valores comunes a todas ellas (Schwartz, S.H., 2001)

\section{Cuadro 2.4- Características de los valores según Schwartz}

\begin{tabular}{|ll|}
\hline Características de los valores según Schwartz \\
\hline 1. & Son creencias vinculadas a las emociones \\
\hline 2. & $\begin{array}{l}\text { Son constructos motivacionales (se refieren a los objetivos } \\
\text { que las personas anhelan conseguir) }\end{array}$ \\
\hline 3. & $\begin{array}{l}\text { Son objetivos abstractos que trascienden de las acciones y } \\
\text { situaciones concretas. }\end{array}$ \\
\hline 4. & $\begin{array}{l}\text { Dirigen la selección de las acciones y cualquier tipo de } \\
\text { acontecimiento que vive la persona (normas o criterios de } \\
\text { actuación) }\end{array}$ \\
\hline 5. & $\begin{array}{l}\text { Se ordenan jerárquicamente, en base a la importancia que } \\
\text { tengan para el sujeto (lo distingue de normas y actitudes). }\end{array}$ \\
\hline
\end{tabular}

Fuente elaboración propia basado, en Schwartz, S.H., 2001.

Ahondando en el estudio de los valores humanos, Schwartz concluye que su estructura está formada por diez tipos motivacionales, relacionados entre sí; poder, logro hedonismo, estimulación, autodirección, universalismo, benevolencia, tradición, conformidad y seguridad. Explica la posibilidad de que entren en conflicto unos con otros, cuando el sujeto persigue varios valores a la vez. 


\section{Cuadro 2.5.- Características de los 10 tipos motivacionales de valores en Schwartz}

\begin{tabular}{|c|c|c|}
\hline $\begin{array}{l}\text { Tipo de } \\
\text { valor }\end{array}$ & Definición & Ejemplos del Valor \\
\hline $\begin{array}{l}\text { Poder } \\
\text { (PO) }\end{array}$ & $\begin{array}{l}\text { Posición y Prestigio social, control } \text { y/o } \\
\text { dominio sobre las personas y los } \\
\text { recursos. }\end{array}$ & $\begin{array}{l}\text { Poder social. Reconocimiento social. } \\
\text { Riqueza, Autoridad, Preservar la imagen } \\
\text { pública. }\end{array}$ \\
\hline $\begin{array}{l}\text { Logro } \\
(\mathbf{L O})\end{array}$ & $\begin{array}{l}\text { Éxito personal como resultado de } \\
\text { demostrar competencia según las normas } \\
\text { sociales y culturales }\end{array}$ & $\begin{array}{l}\text { Ambicioso, Capaz, Logro. Tiene } \\
\text { influencia }\end{array}$ \\
\hline $\begin{array}{l}\text { Hedonismo } \\
\text { (HE) }\end{array}$ & $\begin{array}{l}\text { Gratificación y placer sensual para la } \\
\text { persona }\end{array}$ & $\begin{array}{lllll}\begin{array}{l}\text { Placer. Disfrutar } \\
\text { indulgente }\end{array} & \text { la } & \text { vida. Auto } \\
\end{array}$ \\
\hline $\begin{array}{l}\text { Estimulación } \\
\text { (ES) }\end{array}$ & $\begin{array}{l}\text { Excitación, variedad, entusiasmo } \\
\text { retos/desafíos en la vida }\end{array}$ & Atrevido, Vida variada, Vida excitante \\
\hline $\begin{array}{l}\text { Autodirección } \\
\text { (AU) }\end{array}$ & $\begin{array}{l}\text { Independencia en las acciones y en los } \\
\text { pensamientos, creatividad, exploración. }\end{array}$ & $\begin{array}{l}\text { Creatividad, independiente, curioso, } \\
\text { libertad. Elegir las metas propias }\end{array}$ \\
\hline $\begin{array}{l}\text { Universalismo } \\
\text { (UN) }\end{array}$ & $\begin{array}{l}\text { Tolerancia, comprensión de las personas } \\
\text { y del medio ambiente }\end{array}$ & $\begin{array}{l}\text { Igualdad, Tolerancia. Justicia social, } \\
\text { sabiduría, un Mundo en paz. Abierto, } \\
\text { Protección del medioambiente. }\end{array}$ \\
\hline $\begin{array}{l}\text { Benevolencia } \\
\text { (BE) }\end{array}$ & $\begin{array}{l}\text { Preocupación por el bienestar de las } \\
\text { personas con las que uno está en contacto } \\
\text { de forma personal y frecuente. }\end{array}$ & $\begin{array}{l}\text { Ayuda, Honesto, No rencoroso, Leal, } \\
\text { Responsable. Ayuda y perdona a los } \\
\text { demás. }\end{array}$ \\
\hline $\begin{array}{l}\text { Tradición } \\
\text { (TR) }\end{array}$ & $\begin{array}{l}\text { Compromiso y aceptación de costumbres } \\
\text { ideas y tradiciones (que la cultura o } \\
\text { religión importen), respeto. }\end{array}$ & $\begin{array}{l}\text { Respeto a la Tradición, Humilde, Devoto, } \\
\text { Moderado. }\end{array}$ \\
\hline $\begin{array}{l}\text { Conformidad } \\
\text { (CO) }\end{array}$ & $\begin{array}{l}\text { Restricción a la acciones de los impulsos } \\
\text { e inclinaciones que pudiesen dañar o } \\
\text { molestar a otros o violar expectativas o } \\
\text { normas sociales. }\end{array}$ & $\begin{array}{l}\text { Educado, Buenos modales, Obediente, } \\
\text { Disciplinado, Honra a Padres y mayores. }\end{array}$ \\
\hline $\begin{array}{l}\text { Seguridad } \\
\text { (SE) }\end{array}$ & $\begin{array}{l}\text { Búsqueda de Armonía. Seguridad, } \\
\text { Estabilidad en la sociedad, en las } \\
\text { relaciones interpersonales y en uno } \\
\text { mismo. }\end{array}$ & $\begin{array}{l}\text { Seguridad de la familiar y nacional. } \\
\text { Limpio. Orden social. Reciprocidad de } \\
\text { favores }\end{array}$ \\
\hline
\end{tabular}

Fuente Schwartz, S.H. ,2004

Schwartz, propone, desde este esquema, su teoría de los valores culturales, que ayudaría a mostrar los problemas básicos a los que se enfrenta cada sociedad .Afirma que los valores que prevalecen en una sociedad, se pueden inferir a partir de los valores que manifiestan sus individuos (Schwartz, S.H., 1999).

Estos diez tipos motivacionales mantienen entre sí relaciones de compatibilidad y contradicción, lo que se refleja en dos posiciones bipolares: 
1. Autopromoción versus trascendencia.

2. Apertura al cambio versus conservación.

Los representa, gráficamente en un círculo, ubicando en dirección contraria los que son opuestos.

Figura 2.5-. Modelos teóricos de la relaciones entre los tipos de motivaciones de valores y dimensiones bipolares en Schwartz

\section{AUTO-TRASCENDENCIA}

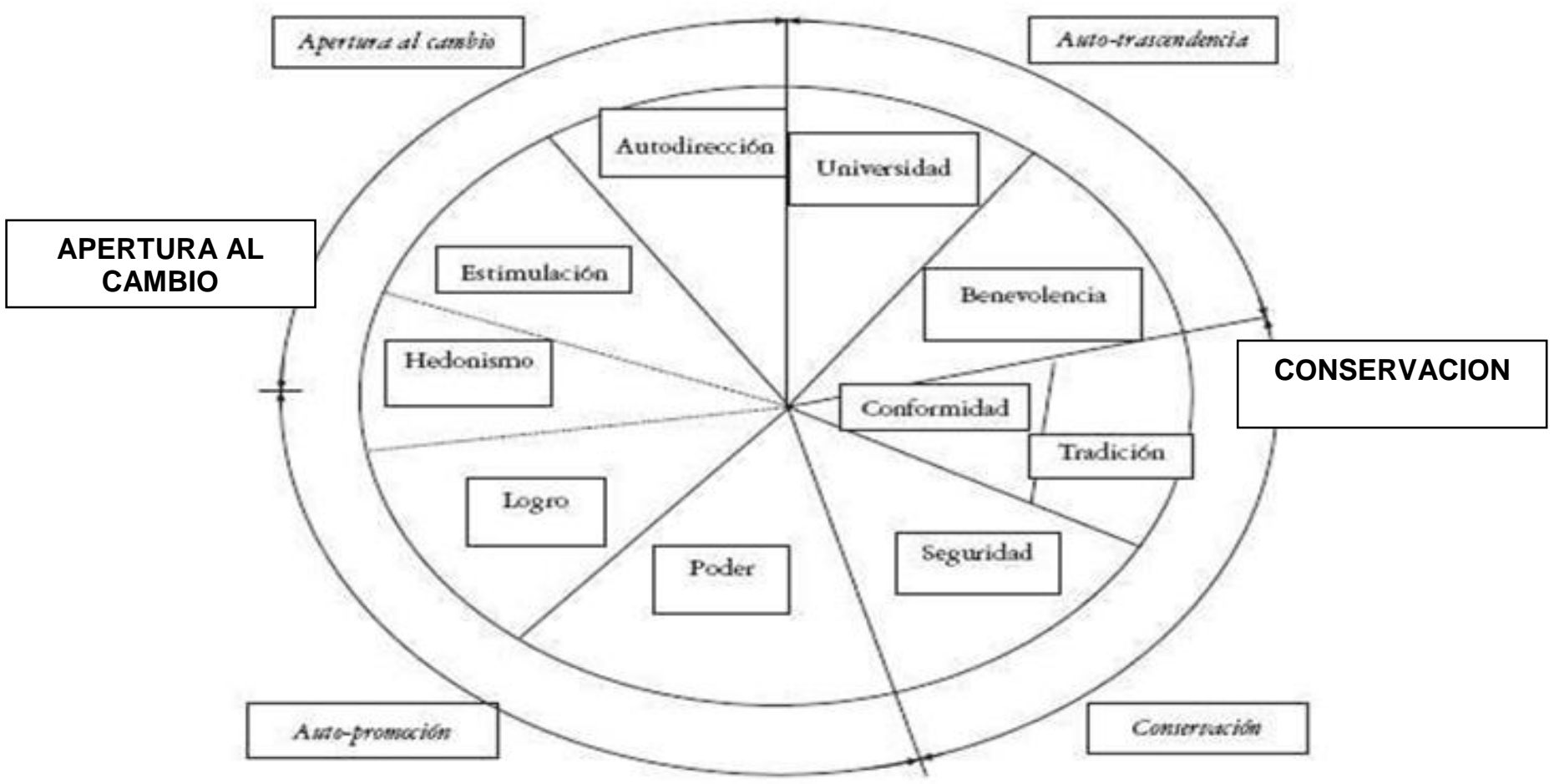

AUTO-PROMOCION

Fuente. Schwartz, S.H., 1992

La primera dimensión agrupa valores tipo de logro y poder, comportamientos dirigidos a promover la promoción personal, frente a universalismo y benevolencia, que se caracterizan por trasponer los intereses personales a favor de los demás. La segunda dimensión engloba valores de estimulación y autodirección, que apuntan a metas de cambio, frente a los valores de seguridad, tradición y conformidad, que aspiran al mantenimiento del Statu Quo, (Ros, M., 2001). 
El sistema de valores representa un todo cohesionado, integrado al comportamiento. Ello implica que toda variable externa al sistema de valores tienda a asociarse a aquellos valores adyacentes del propio sistema de valores. Por otra parte, la asociación del sistema de valores con cualquier variable externa desciende a medida que se mueve en la estructura circular de los tipos de valores en ambas direcciones, desde el tipo de valor más positivamente asociado, hasta el tipo de valor asociado en menor medida. Esto significa que las conductas estarán más intensamente relacionadas con unos tipos de valores que con otros. Es decir, una vez determinado qué valor tipo está asociado a una conducta, el resto de valores tipo irán descendiendo en la estructura circular hasta alcanzar el menor grado de asociación, y i de nuevo ascenderán en sentido inverso hasta llegar al tipo opuesto al inicialmente considerado (Schwartz, S.H., 2001).

Por ejemplo, si una persona tiene en gran estima el valor igualdad, tenderá a tratar a todas las personas de forma similar. En consecuencia, esta conducta estará más intensamente relacionada con el valor universalismo, ya que además de la igualdad esa persona comparte otros valores relacionados con el bienestar de los demás, incluso con los desconocidos Siguiendo el orden circular de la estructura de valores, la conducta de tratamiento igualitario estará relacionada con el valor tipo benevolencia. Con toda probabilidad irá perdiendo intensidad en relación con valores como tradición, conformidad, seguridad; e incluso no tenga relación alguna con los valores de autodirección o estimulación. Y aún más, esté negativamente relacionada con los valores de logro y poder, que en el modelo, son valores incompatibles con los de universalismo y benevolencia. (Ros, M., 2001).

Basándose en el $\left(\mathrm{SVS}^{18}\right)$, elabora su teoría de de valores culturales, donde encontró siete tipos de valores culturales agrupados en tres dimensiones bipolares; Conservación, Autonomía Intelectual, Autonomía Afectiva, Jerarquía, Compromiso Igualitario, Competencia y Armonía.

\footnotetext{
${ }^{18}$ Desarrolla un instrumento para medir los valores, el Schwartz Value Survey (SVS), con 45 valores trabajados y que hallaron equivalencia conceptual en 49 países (Cuadrado, 2006). Mostró, por la formulación de las preguntas, su no adecuación a todo tipo de poblaciones, por lo que desarrolla, como instrumento complementario, el Portrail Values Questionnaire PVQ), que mide los valores de forma indirecta (Ros 2001)
} 
Jerarquía y Conservación se relacionan positivamente, de igual forma que Compromiso Igualitario y Autonomía (más con la Afectiva que con la Intelectual). Competencia se relaciona positivamente con Autonomía Afectiva e Intelectual, de la misma forma, y se relaciona negativamente con Compromiso Igualitario. Armonía es compatible con Conservación y con Compromiso Igualitario (Schwartz, 1994).

Figura 2.6.- Estructura de los Valores Culturales den la teoría de Schwartz

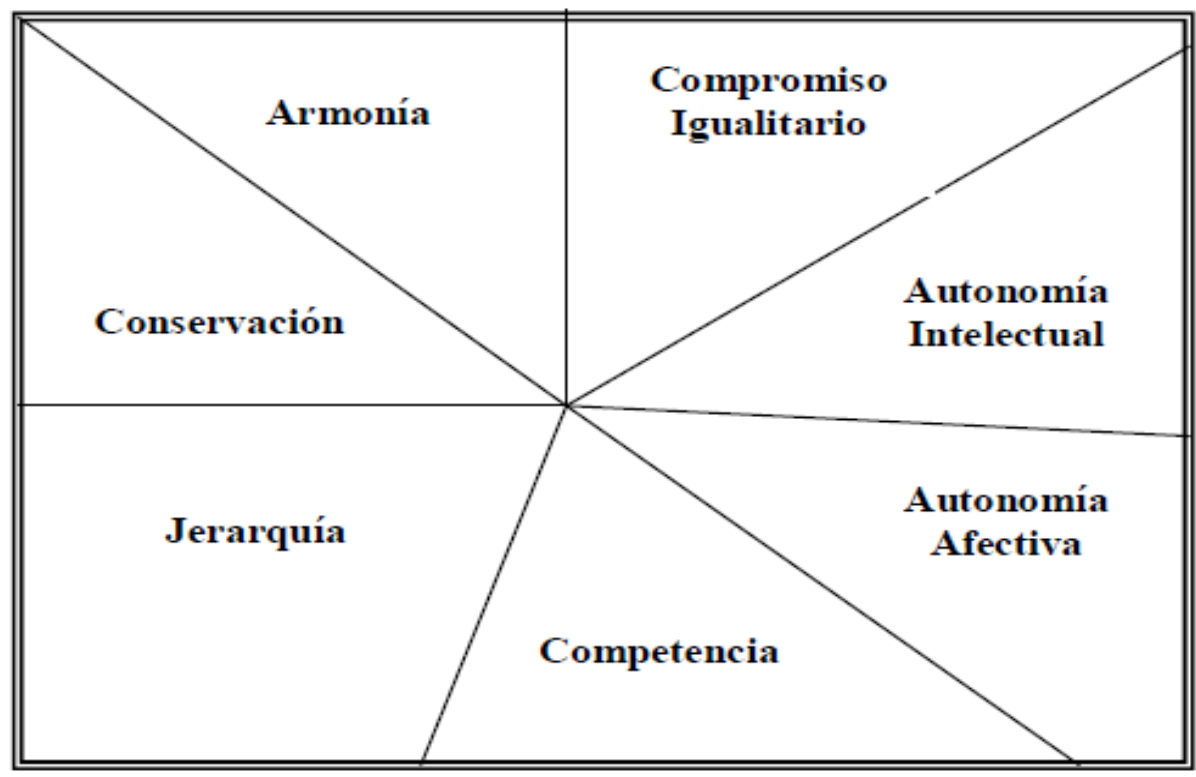

Fuente Schwartz, S.H., 1994

Los siete tipos de valores culturales, forman tres dimensiones bipolares:

- Conversación vs. Autonomía (Intelectual y afectiva). Manifiesta la vinculación entre el individuo y el grupo. En el extremo de Conservación encontramos las caluras que ven a las personas dentro del colectivo, donde mantener el orden y la tradición es lo más importante. En el polo de la Autonomía esta las culturas que ven al individuo como un ser autónomo, donde se valora la diferencia individual, independiente de lo establecido por el grupo o colectividad.

- Jerarquía vs. Compromiso Igualitario. La dimensión jerárquica entiende como legítimo que quien tiene el poder es a quien corresponde la responsabilidad y que es legítimo que el poder esté distribuido de forma 
desigual para asegurar la responsabilidad social. El compromiso igualitario entiende que los miembros de la sociedad son personas iguales que persiguen el bienestar común.

- Competencia vs. Armonía. Refleja la relación cultural de las sociedades con el medio ambiente. En la competencia, en un extremo, encontramos las culturas que explotan y dominan la naturaleza buscando el beneficio propio, mientras que en la Armonía, en el externo opuesto, encontramos las culturas que intentan adaptarse a la naturaleza tal como es.

Su sistema de valores responde a la función de adaptación y supervivencia del ser humano al medio, al contexto cultural en el vive. Es precisamente la forma concreta de adaptación a cada contexto, con sus diferencias y especificidades, lo que determina el que predominen unos y otros valores, (Schwartz, S.H., 1992).

En los valores culturales se fundamentan las normas que permiten entender a los individuos, en cada momento, qué es o no lo correcto (Schwartz, S.H., 1994). Así es a través de leyes, actuaciones políticas, el sistema educativo, como las distintas instituciones sociales seleccionan o priorizan uno u otro valor, haciendo que sean unos y no otros los que prevalezcan en una sociedad, indicando el comportamiento socialmente apropiado (Schwartz 1994). Los valores culturales son inherentes al funcionamiento y estructura de las instituciones sociales y se relacionan con comportamientos regulados normativamente. (Ros, M., y Schwartz, S.H., 1995).

Podemos concluir que la teoría de los valores desarrollada por Schwartz (Schwartz, S.H.,; Schwartz, S.H., y Bilsky, W., 1987; Schwartz, S.K., y Sagiv, L., 1995), supone un modelo consistente y adecuado para explicar desde una perspectiva de los valores la influencia de la cultura en algunos aspectos del comportamiento individual (Ros, M., 2001). 


\section{Teoría de las dimensiones culturales de Hofstede}

Hofstede, G. (2001) definió la cultura como la programación cultural de la mente, siendo, precisamente, la cultura lo que permitiría diferenciar a un grupo de personas de otro (Hofstede, G., 1980). En su trabajo sobre los valores identifica empíricamente, por medio del análisis factorial ecológico (con las naciones como unidad de análisis y las medias como puntuaciones) y con los datos de una encuesta hecha a más de 116.000 trabajadores de IBM, en 56 países, cuatro dimensiones a través de las cuales se pueden ordenar los valores dominantes de las diferentes culturas. Hofstede (2001) denomina a las cuatro dimensiones: Distancia de Poder, Individualismo-Colectivismo, Masculinidad-Feminidad y Evitación de la Incertidumbre, siguiendo el modelo de los cuatro problemas de Inkeles, A., y Levison, D.J., (1969). ${ }^{19}$.

\section{Figura 2.7.- Dimensiones culturales de Hofstede}

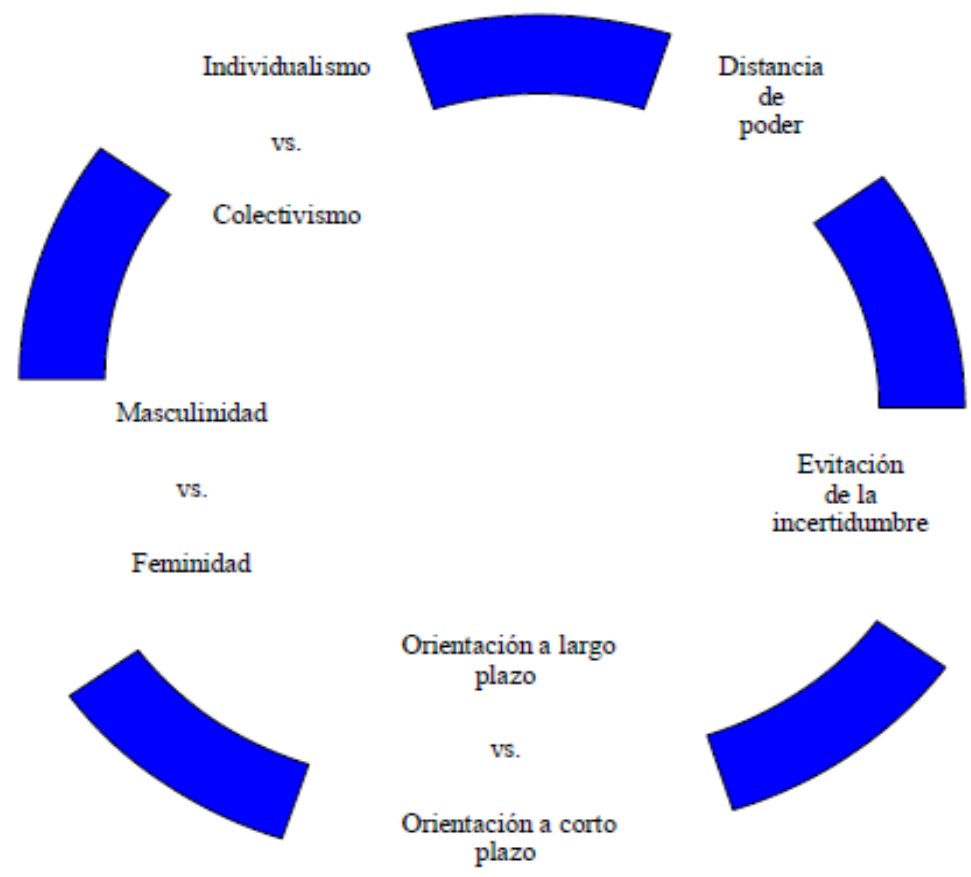

Fuente Rodríguez, (2222)

\footnotetext{
${ }^{19}$ Inkeles, A., y Levison, D.J., (1969) plantean que hay cuatro problemas básicos que todas las culturas han de afrontar: a) la relación con la autoridad; b) la concepción del yo o de la persona; lo que incluye la relación entre la persona y la sociedad y la concepción de la masculinidad y feminidad; y c) los conflictos y su resolución (expresión versus inhibición de las emociones, incluyendo el control de la agresión).
} 
Las puntuaciones medias o agregadas de muestras nacionales sobre valores del trabajo son un indicador macro-psicológico que representa el constructo colectivo cultura subjetiva y que Hofstede ha validado mediante su correlación con indicadores macrosociales objetivos, subjetivos y macro-psicológicos (Hofstede, G., 2001).

La distancia de poder plantea hasta qué punto los miembros menos poderosos de los grupos acepta las desigualdades de poder. Habla de desigualdad en sentido literal (económico, social, en relación al poder) Implicaría la aceptación de una sociedad ante un poder ejercido de forma desigual. (Hofstede, G., 2001). Las culturas que se posicionen en una alta distancia de poder, serán aquellas que valoren la norma, el respeto, la jerarquía, la obediencia y la conformidad. Propugnan una clara separación entre quienes ostentan el poder y estatus social, y quienes no lo tienen.

La dimensión de Individualismo-Colectivismo sería como una variable unidimensional, estando ambos, individualismo y colectivismo, cada uno en un extremo. Se referiría a la prioridad dada a la persona o al grupo o al colectivo (a menudo a la familia extensa). Sería el grado en que los miembros de una sociedad se ocupan más o menos de sí mismos o de los grupos a los que pertenecen. Diferentes investigaciones han mostrado su gran utilizad en la comparación entre culturas (Paéz D., Fernández, I., Basade, N., y Grad, H., 2003).

El individualismo incluiría el conjunto de creencias, valores, prácticas culturales que priorizan los individuos por encima de la colectividad. El colectivismo, en sentido inverso, agruparía aquellos componentes de carácter colectivo, del grupo, que se priorizan antes que los individuales. En culturas individualistas, esto se manifiesta, por ejemplo, en el cuidado de la familiar nuclear (tradición, norma, sentido del deber). En las colectivistas la cooperación entre personas y grupos, se reivindica como más importante. (Hofstede, G., 2001).

Individualismo y colectivismo harían referencia al grado en que los miembros de una sociedad buscan la satisfacción de necesidades personales (individualismo) o necesidades e intereses grupales (colectivismo). Las sociedades individualistas valoran 
la liberta personal, como forma de mejorar la calidad de vida, está más orientadas hacia alcanzar un objetivo y a la competición. Por ejemplo la sociedad americana, considerada en los estudios antropológicos como la más individualista.

Schwartz, criticó la dicotomía individualismo-colectivismo propuesta por Triandis y avalada por Hofstede, por varios motivos (León Moriano, J.A. ,2005).

1- Existen valores que, por su naturaleza, sirven tanto a intereses personales (individualismo) como grupales o sociales (colectivismo), como la búsqueda de seguridad, por ejemplo, tanto a nivel personal familiar o regional.

2- Existen valores que sirven para lograr metas colectivas, y no son propios del endogrupo, como la igualdad para todos, el amor y preservación de la naturaleza. Se trataría de valores universales.

3- La dicotomía individualismo -colectivismo implica una oposición polar, y pueden existir intereses individualistas y colectivistas que no están en conflicto. (León Moriano, J.A., 2005, p. 130-131).

Según la estructura bidimensional de los valores de Schwartz "las personas pueden tener un perfil mixto, () las personas pueden dar prioridad tanto a los valores individualistas como colectivistas" (León Moriano, J.A. ,2005). Esta posición ha sido reforzada por los estudios realizados en España por Ros y Gómez (1997).

La masculinidad-feminidad afecta al grado en que las culturas marcan la máxima distinción entre hombres y mujeres. (Distribución de los roles emocionales entre sexos).Las culturas masculinas enfatizan las conductas estereotípicas de género y los valores dominantes como el éxito, el dinero, la competición y la asertividad. Las culturas femeninas no enfatizan las diferencias de rol de género, no son competitivas y valoran la cooperación y el cuidado de los débiles. Utiliza las descripciones tradicionales de los roles de cada género para establecer esta dimensión, pero debemos tener en cuenta que desde los 80 en que se ideó, éstos han ido cambiando socialmente (Basabe, N., Páez, D., Valencia, J. González, J.L. Riné, B., y Diener, E. (2002). 
Las sociedades masculinas son aquellas en las que los comportamientos agresivos (masculinos) son vistos como más importantes para garantizar el éxito, la riqueza, los logros, la instrumentalizad, mientas que en las sociedades femeninas, la ayuda a los demás, la conservación y el amor por el medio ambiente, la igualdad de género son valores predominantes (Hofstede, G., 2001).

La evitación de la incertidumbre se define como el grado en que la gente se siente amenazada por las situaciones ambiguas, que intentan evitar por medio de códigos y creencias estrictas. Las naciones de alta evitación de la incertidumbre buscan la seguridad y son intolerantes ante la incertidumbre. Las naciones con baja evitación de la incertidumbre aceptan más los riesgos y son más tolerantes. (Hofstede, G., 1980, 2001).

Valoran más las normas claras y delimitadas que no tenerlas, no asumen bien la improvisación, por lo que en situaciones nuevas, no conocidas buscarán información estereotipada correcta o no, que les proporcione seguridad y conocimiento ante lo desconocido. En sociedades donde la evitación a la incertidumbre es baja se vive con curiosidad lo desconocido, sin miedo, y serán las personas concretas, de forma individual y específica, quienes busquen y gestionen la información para enfrentarse a cada nueva situación. (Hofstede, G., 1980).

\section{Cuadro 2.6.- Dimensiones de valores cultuales de Hofstede en base a los problemas sociales de Inkeles y Levinson}

\begin{tabular}{|l|l|}
\hline \multicolumn{2}{|c|}{ Dimensiones de Cultura } \\
\hline $\begin{array}{l}\text { Problemas básicos a todas las sociedades Inkeles } \\
\text { y Levinson }\end{array}$ & Valores de Hofstede \\
\hline 1. Relación ante la autoridad & Distancia al Poder \\
\hline $\begin{array}{c}\text { 2. Concepción de Sí mismo: } \\
\text { a) relación individuo-grupo }\end{array}$ & a)Individualismo/colectivismo \\
b) diferencias hombre/mujer & b) Masculinidad/femineidad \\
\hline $\begin{array}{c}\text { 3. ¿Cómo enfrentar el conflicto, controlar la } \\
\text { agresión y la expresión de las emociones? }\end{array}$ & Reducción de la incertidumbre \\
\hline
\end{tabular}


Fuente Hofstede, a partir de Inkeles y Levinson, 2001

A pesar del hecho de que las encuestas se realizaron hace ya más de 20 años y de que algunas naciones han ido cambiando su posición en estas dimensiones las puntuaciones de Hofstede muestran una alta validez concurrente con la investigación transcultural actual. (Paéz D., Fernández, I., Basade, N., y Grad, H., 2003).

El modelo, a pesar de tener un cierto relativismo cultural y un cierto grado de determinismo, contrario a la natural libertad de la naturaleza humana, es meticuloso y de gran utilidad. De ahí que haya sido usado en numerosas investigaciones en campos diversos, por no menos investigadores. Destacamos en este sentido, la realizada por Nakata, C., y Sivakumar, K., (1996.) que agregaron, a las cuatro dimensiones de Hofstede, una quinta: La Orientación a Largo Plazo vs. Orientación a Corto Plazo.

La Orientación a largo plazo, hace referencia a los valores orientados (ahorro, continuidad), mientras que la Orientación a Corto plazo, se orienta a los valores propios del pasado (respeto, tradición, normas sociales...). La orientación a largo plazo implica el grado en que una sociedad adopta o no valores tradicionales de largo plazo. Si esa cultura se adscribe a valores como el compromiso a largo plazo y el respeto por la tradición. La ética en el trabajo, donde se esperan compensaciones a largo plazo como premio por la actividad realizada en el presente.

\section{Teoría de las dimensiones culturales de Inglehart}

Será Inglehart, R., (1977), en su teoría de los valores políticos del materialismo y posmaterialismo, ligada a la satisfacción de necesidades de bienestar económico y a la autorrealización, quien indirectamente evidencie la teoría de las necesidades humanas de Maslow. Basándose en la teoría de la Jerarquía de Necesidades Humanas de Maslow, hace un estudio en el que compara los rasgos diferencias de 6 culturas.

Concluye que solo cuando los países han superado la escasez económica pasarán de valorar la seguridad, el orden y la prosperidad económica, a valorar las necesidades postmaterialistas de autorrealización, participación política y cuidado del medio 
ambiente, presenten en todo tipo de países. De aquí podemos deducir que algunos valores son metas deseables tanto cuando están satisfechos como cuando no lo están, y que el grado de satisfacción de una necesidad es relativo a las aspiraciones de cada persona o cada sociedad. (Ros, M. 2001).

Pretendía demostrar que algunas sociedades, suelen caracterizarse en base a sus rasgos culturales estables y duraderos y cómo estos, a veces, suelen tener consecuencias políticas y económicas importantes. Sigue en su planeamiento las tesis del gran Weber (Weber, M., 1985) quien estableció, sobre una base observacional, la posible influencia de los factores culturales en los procesos de crecimiento económico. En la misma línea, y con el mismo influjo de Weber, son los trabajos de los sociólogos americanos Inkeles, A., y Levison, D.J., (1969).

\section{Cuadro 2.7.- Dimensión de los Valores de Inglehart}

\begin{tabular}{|c|c|c|}
\hline Valores materialistas & Tipo de sociedad & Valores concretos \\
\hline $\begin{array}{l}\text { Valores } \\
\text { postmaterialistas }\end{array}$ & $\begin{array}{l}\text { Predominio de la inseguridad } \\
\text { Escasez económica } \\
\text { orden, poder militar y } \\
\text { económico seguridad y } \\
\text { estabilidad . } \\
\text { Predominio de la seguridad } \\
\text { Desarrollo económico y social } \\
\text { altos }\end{array}$ & 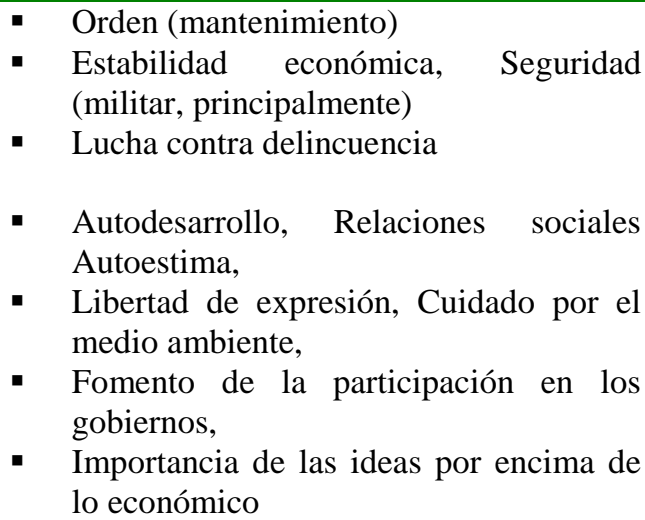 \\
\hline
\end{tabular}

Fuente propia a partir de Ros, M.,2002

El paso de una sociedad a otra solo puede producirse cuando las condiciones económicas son apropiadas, es decir, proporcionan seguridad a sus ciudadanos, incrementado así el bienestar económico. Una investigación posterior, además de la mencionada dimensión bipolar, agrega otra; la de Modernidad vs Postmodernidad, con ella explica cómo se desarrolla en una sociedad el paso de la tradición a la modernidad (el paso de sociedades representadas por la autoridad religiosa, a las representadas por autoridades estables) (Inkeles, A., y Levison, D.J., 1969). 


\section{Modelo de Triandis}

Interesado en las diferencias entre culturas, centra su objeto de investigación en la relación existente entre actitudes, normas, roles y valores. (Triadis, H.N., 1996). Vinculado a la noción de cultura subjetiva, desarrolla un modelo en el que a las nociones clásicas de individualismo y colectivismo debemos añadir dimensiones como igualdad y la desigualdad, obteniendo así dos dimensiones bipolares. En la dimensión individualista, los sujetos están motivados por preferencias propias y priorizan sus propios objetivos, en la colectivista, la personas están motivadas por las normas del grupo de pertenecía, y se priorizan las metas grupales, antes que las individuales (Triandis, H.C., 1995).

\section{Cuadro 2.8.- Dimensiones bipolares en Triandis}

\begin{tabular}{|c|c|c|}
\hline \hline \multicolumn{2}{|c|}{ Individualismo } \\
\hline Vertical & & Horizontal \\
$\begin{array}{c}\text { concepción del yo como } \\
\text { independiente y } \\
\text { diferente }\end{array}$ & Vs. & $\begin{array}{c}\text { concepción del yo como } \\
\text { independiente e igual }\end{array}$ \\
\hline \multicolumn{2}{|c|}{ Colectivismo } \\
\hline $\begin{array}{c}\text { concepción del yo como } \\
\text { interdependiente y } \\
\text { diferente }\end{array}$ & Vs. & $\begin{array}{c}\text { concepción del yo como } \\
\text { interdependiente e igual }\end{array}$ \\
\hline
\end{tabular}

Fuente Elaboración Propia a partir de Ros, 2002.

Este autor sugiere que en un nivel individual el individualismo-colectivismo se puede entender por separado, lo cual significaría que un bajo individualismo no implica, necesariamente, un alto colectivismo y viceversa, pudiendo existir personas que actúen de forma colectivista como individualista, en función de la situación que vivan. (Triandis, H.C, 1998).

Las culturas colectivistas, mantienen una mayor vinculación emocional al grupo, en ellas sus individuos se sienten más unidos al grupo. Cuando necesidades individuales y 
colectivas entran en conflicto, se espera del individuo que se incline a favor de las grupales (Triandis, H.C., 1996).

\section{3.- CULTURA Y EMPRENDIMIENTO}

El concepto de cultura es claramente pluridimensional y podemos encontrar formas distintas de abordar el estudio que la relaciona con el emprendedor, Podemos abordarla como expresión de identidad y pertenencia a un territorio ó como factor que influye en el comportamiento económico de un grupo. En la medida en que la cultura establece las pautas de comunicación y los mecanismos de interpretación de la información y el conocimiento que se transmite socialmente, en la medida en que de ella surgen normas, mayoritariamente aceptadas, que regulan las relaciones de convivencia, generando confianza entre los miembros, y sanciones para el incumplimiento, generando un clima de confianza colectiva por cuanto que hay un orden más o menos estable de regulación del comportamiento colectivo. Así entendida la cultura, desde la interculturalidad o cultura propia de cada grupo, debe poseer determinadas características si queremos que favorezca el dinamismo innovador y empresarial, el emprendizaje; debe estar viva y fuertemente asentada en la conciencia de la población. "Una cultura fuerte es aquella capaz de vertebrar la sociedad local, generar un fuerte sentido de identificación y pertenencia, y ofrecer pautas de relación y comunicación que puedan ser utilizadas por los agentes sociales, políticos y económicos” (Albertos, P., 2003).

Los estudios sobre la cultura como factor que influye en el comportamiento económico, pueden tener enfoques diferentes: Los que analizan el impacto de la cultura en el entorno económico en general o en el conjunto de medidas del entorno empresarial (producción, innovación nacional, creación de nuevos negocios...).

Cada vez que nos encontramos con la afirmación de que hay una mayor predisposición emprendedora en unas sociedades que en otras, estamos obligados a revisar el papel que la cultura puede ejercer en el proceso emprendedor. (Hurtado, N.E., Cordón E., Senise, M.E. (2007). 
Encontramos investigaciones que vinculan la relación entre las características de la cultura nacional y comportamiento emprendedor, como características individuales del emprendedor o aspectos del emprendedor corporativo (Zahara, S.A.M y George, G., (2002), las que analizan el impacto de la cultura nacional en dimensiones del emprendedor, como creación de negocios. Las que relacionan culturas nacionales y características del emprendedor, examinando los valores, creencias y motivaciones que posee y adquiere a través de la cultura. Hay estudios que relacionan el impacto de la cultura nacional en el emprendedor corporativo (asociación entre cultura y forma de entrar en los mercados extranjeros (Kogut, B., Y Singh, H. 1988; Shane, S., 1995; Albors G., Hervas, O., Hidalgo, J.L., y Nuchera, A., (2009).

En la relación de innovación algunas investigaciones demuestran como la innovación dentro de las organizaciones se ven fuertemente afectadas por el entorno cultural de la empresa (Schein, E., 1990; Shane, S., 1992; González G, 1998; Infestas, A., 2001) no habiendo sido analizado el efecto moderador de la relación entre orientación emprendedora y adaptación de innovaciones.

Destacamos los que relacionan la cultura nacional con las características de los emprendedores individuales (análisis de los valores creencias, motivaciones y cogniciones de los emprendedores a través de la cultura). "La cultura de un lugar afecta profundamente a la forma en que su población actúa y reacciona frente al cambio tecnológico en función de sus creencias, conocimientos, valores culturales y capacidades.” (Malecki, R.J., 1995, p. 106).

Toda cultura incluiría "el repertorio de experiencias, conocimientos y valores que se maduran y que son transmitidos a los nuevos integrantes, a lo largo del tiempo". Maximiano, A., (2006, p.30) Sirven para aprender el comportamiento del grupo, ayudan a sobrevivir, a lograr la acepción de los otros miembros de la colectividad. Formar parte de una cultura implica compartir conocimientos y patrones conductuales, ésos, tendentes al emprendizaje o no, nos los ha transmitido la generación que nos precede, y a ésta la anterior, y así sucesivamente. Maximiano, A., (2006), 
Interiorizamos nuestra propia cultura, en el proceso de socialización donde asumimos presunciones, creencias y todo aquello que como comunidad construimos en base a nuestra experiencia compartida. "En esencia un sistema de valores y símbolos compartidos que serán tanto más fuerte cuanto mayor sea su implantación social, cuantos más compartidos sean esos valores” (González, G, p. 8).

Interiorizamos nuestra cultura económica local, la de nuestro entorno y contexto concreto, independientemente de que esté o no orientada a la acción de emprender, bajo nuestras características de personalidad, (Hofstede, G., 1980; Triandis, H.C, 1989).

Nuestra cultura refuerza nuestras características personales y un determinado tipo de conductas, penalizando otras. El sustrato cultural desempeña un papel crítico en la determinación de nuestra conducta emprendedora, por cuanto que es el sistema del que subyacen nuestros valores normativos y los modelos de percibir la actividad emprendedora (Zahra, S.A., Jennings, D.F., Kuratlo, D.F. 1999).

Si la cultura determina la manera concreta de actuar de los individuos dentro de un grupo o comunidad, por extensión, también determinará la manera concreta de actuar del grupo como tal, de una región o del país de pertenencia, donde esos valores que se comparten incluirán creencias (económicas, religiosas, tradiciones heredadas, estilos y patrones de comportamientos, etc.). Así, podríamos enunciar una versión emprendedora que atendiendo a las formas de identidad y a los valores del grupo, moldee los patrones de preferencia hacia el comportamiento emprendedor (Throsby, D., 2001).

La percepción que en un contexto tenemos sobre el hecho de emprender está basada en las creencias que tenemos al respecto y en el valor concreto que como individuos le conferimos al hecho de emprender (Allen, HungNg, y Leiser, 2005).

Throsby, D. (2001) apunta que la cultura influye sobre la economía en tres grandes esferas; la de eficacia económica, donde lo valores culturales compartidos favorecen el que las decisiones sean eficaces, rápidas y de mejor adaptación al entorno; la equidad, donde la cultura local incluye principios morales de solidaridad, el interés 
general; y los objetivos económicos, que guiados por los valores, determinarían las preferencias de la población, sirviendo, al mismo tiempo, como criterio a la hora de juzgar el fracaso o éxito económico de esa sociedad (Throsby, D., 2001).

Analizando la eficacia económica vemos claramente el impacto que en ella tiene la cultura, a la hora de tomar decisiones, de innovar, en definitiva de adaptarse al entorno, y como, al mismo tiempo, podemos hablar de un tipo concreto de personalidad en quien toma esas decisiones, en quien innova o no. Otro aspecto clave, en este sentido, tiene que ver con la percepción que los individuos tienen sobre la económica en la que viven, por constituir un precedente clave ante la toma de decisiones, que a su vez están basadas en creencias y en el valor que estos individuos confieren a los fenómenos económicos que forman parte de su entorno (Allen, Hungng, y Leiser, 2005).

Esta inclusión de los factores culturales en la economía se aborda desde la economía del desarrollo, donde se los valores locales en los estudios del desarrollo económico tratando de explicar el hecho económico, los comportamientos desde su interpretación de las tradiciones e instituciones propias de cada región. Recurren, en su análisis, a la orientación de los valores como guías comportamentales para ver el impacto que tienen en los procesos de innovación y modernización. Esto implica hablar de diferencias culturales, juzgando a unas como más proclives a la hora de promover la prosperidad y el desarrollo, (Albertos, 2003). Esta línea de análisis sigue la clásica, aunque muy discutida también, línea de pensamiento de Max Weber, en La ética del Protestante y el Espíritu del Capitalismo (Weber, M. 1904).

Pero será en Economía y Sociedad, donde Weber realmente analice los efectos que se derivan de la ética protestante cuando se aplican a la empresa concreta. Aquí utiliza la racionalidad económica como base para explicar las relaciones sociales que se dan en toda organización (Infestas, A., 2001).

La racionalidad económica, afirma, puede ser estudiada a través de dos categorías sociológicas; La racionalidad formal y la racionalidad sustancial. Las unidades productivas tienen una racionalidad instrumental que se basa en la forma concreta de ordenarse los recursos naturales y humanos para la producción de bienes y servicios en condiciones de bienestar. Esta racionalidad instrumental persigue como objetivo 
prioritario, el beneficio que reporta la venta del producto o servicio, pues estos bienes y servicios, carecen de valor en sí mismos, sólo valen en la medida en que el mercado les atribuye un determinado valor Sitúa en el beneficio económico, traducido a fines monetarios el fin último de la empresa.

Se justifica así el creciente interés por estudiar las diferencias culturales entre los pueblos, para analizar el influjo que éstas puedan tener sobre el comportamiento emprendedor. Los valores compartidos actúan como roles clave para el funcionamiento psicológico de los individuos. Los valores culturales se reflejan en los textos y en las conductas colectivas (Inkeles, A., y Levinson, D.K., 1969; Schooler, S., 1996; Triandis, H.C., 1995; Markus, H.R., kitayama , S. 1996; Informe GEM, 2011))

El estudio de la cultura permite entender el motivo por el que los países presentan características emprendedoras distintas, hecho que puede estar relacionado con el mismo proceso de aculturación aprendido durante años. Cada cultura tiene su propio ritmo de reproducción, conservación y cambio. Su dinámica es particular. Ninguna cultura es superior, simplemente distinta de las demás (Cárdenas, G. 2008; Bretones, F. y Silva, M., 2009).

Las diferentes teorías sobre valores transculturales han sido aplicadas, al estudio del emprendedorismo, con más o menos éxito.

Morris, M.H., y Jones, F.F., (1999), siguiendo el modelo de Hofstede, G., (1999) estudia la relación entre individualismo y actitud emprendedora dentro de las organizaciones. Plantea cómo los valores de individualismo o colectivismo puedan estar relacionados con bajos niveles de comportamiento emprendedor. Obtiene, en este sentido, resultados positivos en EEUU y Sudáfrica pero no en culturas de alto colectivismo como Portugal. Sostiene, como hipótesis, que la actitud emprendedora esta favorecida por culturas con alto individualismo y baja evasión de incertidumbre, baja distancia de poder y alta masculinidad, y que cuanto mayor sea la distancia de ese ideal de altura más bajos serán los niveles de actitud emprendedora individuales y a nivel de empresa (Kogut, B., y Singh, H., 1998; Shane, S., 2004). Los países con alta evasión de la incertidumbre prefieren optar por la creación de Joint-ventures, frente a la adquisición o creación de filiales (Kogut, B., y Singh, H., 1998).Las empresas en 
países caracterizados pos baja distancia de poder no tienen interés en controlar las actividades del exterior prefiriendo optar por licencias y no inversiones directas.

Algunos autores afirman que podemos predecir el comportamiento emprendedor (iniciativa empresarial) de los individuos en base a su posesión de valores individualistas o colectivistas; "no se caracterizan por valores colectivistas, como por ejemplo la tradición o la conformidad, sino, por el contrario, sus valores estarían insertados dentro de la dimensión individualista (autonomía, estímulo, hedonismo, autoridad y logro)”, (León Moriano, J.A., 2005. P., 136).

La mayoría de estos autores relacionan la tenencia de valores individualistas como propios del individuo emprendedor, aunque también hay estudios que avalan la posición contraria, afirmando que son los valores colectivistas los que se relacionan con la actividad emprendedora de una región o país. Independientemente de la posición que adoptemos lo cierto es que la investigación transcultural avala el papel del individualismo en la configuración global de las culturas (Hofstede 1980) y sobre todo como elemento que influye en la determinación de la conducta. En consecuencia, la utilización de los valores individuales y colectivos resulta útil para una adecuada comprensión de la cultura emprendedora.

Desde el estricto punto de vista de la cultura, algunos autores manifiestan que una cultura donde priman los valores individualistas, es el caso de los Estados Unidos, fomenta la independencia a la responsabilidad personal, estimula nuevos conceptos, ideas e iniciativas individuales, dirigidas a la consecución de metas de carácter personal. (Hofstede, G., 1980; Fornas, J., 1995).). Lo que conduce a la posibilidad de que personas con una fuerte motivación de logro, se planteen alternativas de futuro (Triandis, H.C, 1995), y puedan llegar a crear su propio negocio.

Morris, M.H., y Jones, F.F., (1999), entienden que las culturas individualistas concitan una más intensa responsabilidad personal dirigida hacia la innovación y el beneficio. En otro sentido, una cultura colectivista podría conducir a un rechazo al proceso emprendedor, puesto que el colectivismo tiende a evitar el conflicto y a resistirse a transmisiones radicales, aunque sean necesarias para el desarrollo de ideas innovadoras. Por supuesto, Davidson, P., y Honh, B., (2003) encontraron alguna relación entre algunos 
valores individualistas, tales como la autonomía, la orientación al cambio o la competitividad; y la creación de nuevas empresas.

En idéntico sentido, De Noble, A. F., De Noble, A. F., Jung, J. y Ehrlich, S. B., 1999, pág. 50) afirman que "los valores culturales relacionados con el logro individual, la asunción de riesgo y la innovación (características fundamentales de la conducta emprendedora), tendrán un impacto en la percepción que el individuo tiene de sus propias capacidades para asumir complejas e inciertas actividades emprendedoras", con lo que concluyen estos autores, que las culturas individualistas poseen un mayor nivel de autoeficacia emprendedora, que las colectivistas. Multitud de estudios empíricos corroboran esta afirmación, los valores individualistas presentan una mayor tendencia a la conducta emprendedora. Así lo muestras estudios realizados por Moriano, J., Sanchez, M. y Palací, F. (2004) en España.

Queda, por tanto, demostrado, que los valores, como sustrato básico de toda cultura, serán también vitales en las interacciones emprendedoras de una sociedad (cultura), que según los valores que esta colectividad posea (habrá que identificarlos a través de sus sujetos integrantes) ésta mostrará mayor o menor comportamiento emprendedor.

Si bien es cierto que no hay un acuerdo unánime en todos estos estudios de cuáles son los valores específicos que posee el llamado emprendedor, aquellos que nos permitan identificarle de quien no lo es, todos estos estudios e investigaciones nos permiten resaltar alguna relación significativa. (Hisrich R.D., Peters M. P., Shepherd D. A., 2005) indican un estudio sobre las actitudes del emprendedor, en el que concluyen que los emprendedores tienen actitudes emprendedoras vinculadas al proceso cultural de la sociedad de la que el sujeto forma parte y como éstas son resultado de los valores concretos a que estos individuos están expuestos a lo largo de su vida (Hisrich R.D., Peters M. P., Shepherd D. A., 2005).

Los valores juegan un papel muy importante en lo que respecta a la predisposición de las personas a sumir determinadas acciones, por ser estándares que guían la conducta de la persona o concepciones que reflejan las características básicas de adaptación, a partir 
de los cuales se fabrican actitudes (Schwartz, S,H., 1999), por lo tanto se puede pensar que en función de la estructura de valores que posea un individuo, éste ejercerá su acción de emprender. (Cayón, A. y Pérez, E.,2008).

Así una cultura proclive al emprendedorismo debe tener identificados y socializados valores de los cuales dependerá el éxito de los emprendedores.

\section{4.- CONCLUSIONES}

En el presente trabajo se ha tratado de analizar la influencia de la cultura en el emprendimiento a través del análisis de los valores culturales y del papel de otros factores que inciden en la cultura y tienen peso específico sobre el emprendizaje, y, por tanto, en los procesos de desarrollo socioeconómico.

Existe una fuerte relación entre la cultura y los logros económicos, y vinculado a ello, entre la orientación al logro y la creación de empresas. Estas tres dimensiones, economía, cultura y sociedad, constituyen la base del desarrollo socioeconómico y laboral de una región. Esto nos lleva a afirmar que hay que dedicar tiempo y esfuerzo al fomento de una cultura emprendedora sólida y consistente. Hay que impulsar la proliferación de valores de carácter emprendedor que estimulen el desarrollo de iniciativas empresariales emprendedoras.

El desarrollo económico parte de la iniciativa empresarial, el cual genera empleo y riqueza para el país a través de la mejora en la eficacia económica, la rápida innovación y la adaptación flexible al entorno, por lo que hay que luchar por cambiar la cultura de aquellos países en los que los valores establecidos atenten contra la iniciativa en pro del status quo, al igual que hay que continuar fomentando el espíritu emprendedor en aquellos otros donde la cultura ya apueste por el emprendimiento. Y esta difícil labor, cumplen un papel muy importante las instituciones, las redes sociales y las políticas de empleo que se implementen.

Por cultura entenderíamos todos los hábitos y capacidades adquiridos por el hombre como miembro de la sociedad, desde los conocimientos, las creencias, el arte, la 
moral, la ley, o las costumbres, es decir, incluye todo el sistema de actitudes, valores y comportamientos que son compartidos ampliamente por la sociedad y que se trasmiten de generación en generación. La cultura es aprendida, lo que implica que varíe entre las sociedades, a diferencia de la naturaleza humana que es biológicamente innata y universal (Taylor, E., 1871; Inglehart, R.1998).

Dentro de la cultura, tienen un peso muy relevante los valores, los cuales son resultado del propio contexto, es decir, de las condiciones macroeconómicas y macrosociales. La orientación de los valores explica gran parte del desarrollo económico y humano de un país, ya que estos responden a una forma determinada de funcionamiento social (Ros. M., 2002), y vinculado a ello, también explican la percepción que se tiene de las iniciativas emprendedoras, así como su propio desarrollo.

La predisposición emprendedora de una sociedad está vinculada al papel de la cultura, por lo que de manera inversa, podemos afirmar que la cultura nacional, es decir, la cultura específica de cada país afecta a las características del emprendedor .En relación a ello, se presenta un repaso de las principales teorías acerca de la influencia de las características culturales sobre el emprendimiento.

La teoría de los valores culturales de Schwartz , S.H., (1992) estructura los tipos de valores culturales en relación a tres dimensiones bipolares: conservadurismo o colectivismo vs autonomía o individualismo, jerarquía vs igualitarismo y competencia vs armonía. Esta teoría ha sido relacionada con dimensiones del comportamiento laboral, de las normas sociales en el trabajo, con los valores asociados al trabajo, por lo que no resulta descabellado afirmar que se relaciona también con el espíritu emprendedor.

Las culturas favorecedoras del emprendimiento son aquellas en las que prevalecen los valores vinculados a la autonomía, al individualismo y a la competencia, frente a aquellas que fomentan el conservadurismo, el mantenimiento del status quo y la aceptación del entorno tal y como es. Se considera que una cultura favorece la autonomía y el individualismo cuando pone énfasis en el desarrollo de las ideas, del pensamiento individual, de la curiosidad, de la creatividad, de la apertura de mente y en general, considera al individuo como diferencia; y del mismo modo, se considera 
favorecedora de la competencia, entendida ésta como el énfasis por salir adelante, cuando favorece la autoafirmación, la participación activa para cambiar el mundo y la asunción de riesgos en busca del éxito.

Por su parte los estudios de Inglehart, R., (1991) exponen los procesos que están incidiendo en los cambios de valores, y entre ellos en los valores locales. Como este autor defiende, el significado del trabajo está cambiando. Se ha dejado de concebir el trabajo como una obligación para entenderse como un derecho. Vinculado a ello Galindo, P., (2003) considera que en aquellas sociedades donde se entienda al individuo como agente creativo y no meramente como un instrumento de trabajo, la tendencia al emprendimiento será mayor.

La teoría de los valores culturales de Inglehart (1991) establece una dicotomía social entre las culturas promotoras de valores materialistas (asociado al mantenimiento del orden y a la estabilidad económica) frente a las que promueven valores postmaterialistas, donde las ideas cuentan más que el dinero y ser promulga una sociedad menos impersonal donde se participe más en el trabajo de modo que las sociedades donde prevalecen estos últimos tienen más a desarrollar iniciativas emprendedoras.

Galindo, P., (2003) también considera que existe un claro contraste entre los valores materialistas (o economicistas) y los post-materialistas (a los que también clasifica como sociohumanistas) asociados al trabajo y a las actitudes laborales. Fruto de sus investigaciones, destaca que en las sociedades en las que las necesidades básicas han estado garantizadas, la presencia de valores postmaterialistas es mucho mayor, es decir, hay una mayor participación social, libertad, igualdad y respeto. Por tanto, las personas socializadas en estos valores otorgarán menor importancia a la parte material de la vida. Por el contrario, en las sociedades donde el desarrollo socioeconómico es menor, apenas se manifiestan dichos valores postmaterialistas, pero sí otros de tipo materialista relativos a la seguridad, mantenimiento del orden y referentes a términos económicos.

Esta teoría, aplicada al emprendimiento, considera que aquellas sociedades en las que prevalecen los valores materialistas son menos tendentes al emprendimiento, al 
contrario que las sociedades donde están asentados los valores postmaterialistas, las cuales promueven el emprendimiento. La postmodernidad se asocia al entorno cambiante, flexible e impredecible fruto de la globalización en el que vivimos en la actualidad, lo cual choca con la visión de seguridad en el empleo que se mantiene en algunas regiones, la cual desestima el emprendimiento como alternativa laboral en pro de un trabajo estable, aunque de menor remuneración, pero sin riesgos. Desde este punto de vista, el emprendimiento se vincularía al estatus, de modo que cuanto menor sea este (y con él, mayores las necesidades económicas), se valorarán más los aspectos materialistas; y por el contrario, a medida que éste aumenta, mayor preponderancia se otorga a los valores postmaterialistas.

De este modo, en las sociedades donde la preocupación primera se mida en términos económicos, los valores fundamentales que promueva esa sociedad estarán asociados también a tal aspecto. Por el contrario, en aquellas sociedades donde las necesidades básicas de tipo fisiológico y de seguridad física estén mayoritariamente cubiertas, los valores, creencias y actitudes de la misma se proyectarán hacia fines más elevados, como la autorrealización, y ello pasa por desarrollar un trabajo caracterizado por la creatividad, espontaneidad, la adecuada resolución de problemas y gestión del riesgo, y en general, que contribuya al desarrollo personal.

La teoría de las necesidades humanas de Maslow, A., (1943) coloca a la necesidad de autorrealización en la cúspide de la pirámide, ya que ésta no es alcanzable si las necesidades anteriores no están cubiertas. Este planteamiento revalida los argumentos que defienden que se promoverá el emprendimiento en aquellas sociedades donde los valores postmaterialistas ocupen un espacio predominante en la cultura.

Hurtado, N.E., Cordón E., Senise, M.E., (2007). revalidan el argumento relativo a que la cultura nacional explica las diferencias entre los diferentes países, y esas diferencias también se encuentran vinculadas al emprendimiento.

Estos autores citan a Hofstede, G., (1980) quien propuso las siguientes dimensiones para definir la cultura de un país en lo referente al campo empresarial: la distancia al poder, la evasión de la incertidumbre, el individualismo vs colectivismo y la masculinidad. 
Con el concepto de distancia al poder el autor alude al grado en que los sujetos aceptan la distribución no equitativa del poder dentro de la sociedad, de modo que las sociedades con alta distancia al poder se caracterizan por tener estructuras de decisión muy centralizadas y formalizadas, lo que se asocia a la baja innovación.

La evasión de la incertidumbre apela al grado en que los miembros de la sociedad no se encuentran cómodos en situaciones inciertas, por lo que las sociedades con mayor tendencia a evadir la incertidumbre no promoverán la innovación, si no que opondrán más resistencia al cambio.

Por otro lado, la masculinidad hace referencia al grado en que predominan los valores tradicionalmente asociados al perfil masculino, de modo que se considera que cuanto más predominen éstos, la sociedad será más ambiciosa y competitiva, así que se vincula directamente al éxito material.

Hofstede, G., (1980) también incluye el factor individualismo al igual que Schwartz, S.H., (1992), apelando con él a valores vinculados a la independencia y a la propia toma de decisiones, de modo que revalida el argumento que afirma que a mayor individualismo, más se favorecerá el emprendimiento.

En 2001, este autor incluye una nueva dimensión, la orientación al largo plazo, es decir, la adaptación a las nuevas circunstancias, que cuanto más se favorezca, más se favorecerá paralelamente a la innovación. Por tanto, la actitud emprendedora estaría favorecida por las culturas con alto individualismo, baja evasión de la incertidumbre, baja distancia al poder y alta masculinidad.

Albertos, P. (2002) afirma que la cultura influye en varios aspectos de la economía, entre ellos, en la eficacia económica, es decir, que los valores culturales pueden favorecer o no la toma de decisiones más eficaz, una innovación rápida y mejores adaptaciones a un entorno cambiante; y en los mismos objetivos económicos, esto es, en los deseos de la población relativos al ámbito económico. Desde su punto de vista, la existencia de una cultura local fuertemente asentada que genere una alta autoestima favorecerá el desarrollo, así como la innovación y espíritu de cambio 
necesario para promulgarlo. En función de la cultura dominante, la innovación y el emprendimiento tendrán un sentido para la sociedad concreta de que se trate, por lo que se deben reforzar los comportamientos innovadores para que formen parte de la cultura local y ésta influya en las relaciones laborales, la capacidad de iniciativa, creatividad, dinamismo y en general, en el comportamiento económico de dicho área.

De este modo, una cultura local fuerte en la que se promueva el emprendimiento se asentará en la conciencia de la población, y a su vez, ésta, responderá reforzando dichos valores emprendedores. Se trata por tanto, de un círculo en el que la cultura de un área o región concreta influye en las iniciativas empresariales, pero a su vez, éstas pueden influir en la cultura existente motivando el surgimiento de otras nuevas. 
CAPITULO III METODOLOGIA 


\section{1.- JUSTIFICACION DEL PROBLEMA}

Desde la unión europea, se viene fomentando el espíritu emprendedor, cada vez con más entusiasmo, propiciando políticas económicas de empleo y también en el marco educativo. En este sentido, el Consejo Europeo de Lisboa, en el año 2000 adoptó una decisión trascendental, en el fomento del emprendedorismo; antes de que concluyera el año 2010 la Unión Europea debería convertirse en "una economía, basada en el conocimiento, más competitivo y dinámico del mundo, capaz de propiciar el crecimiento económico de manera sostenible, con más y mejores niveles de empleo y mayor cohesión social.”. En este sentido el Consejo señaló que tales cambios exigían "no solamente una transformación radical de la economía europea; sino también un ambicioso programa de modernización de los sistemas de Bienestar Social y los Planes Educativos". (Consejo Europeo de Lisboa, 2000).

Quizás este sea el momento decisivo para tomar firmes decisiones que contribuyan a poner en práctica tan altos y necesarios objetivos. La situación económica de nuestros países, sus, cada vez más elevadas tasas de desempleo, y la consiguiente pérdida sucesiva de calidad de vida de la población, obligan a ello.

Incrementar el número de emprendedores, de autoempleadores y/o generadores de empleo, ante semejante panorama, se hace imprescindible, por lo que todo lo que tenga que ver con su estudio cobra relevancia.

El interés fundamental de esta investigación se centra en poder identificar si lo que mantiene, a día de hoy, la conducta emprendedora de quienes ya han emprendido, es la tenencia de ciertos rasgos de personalidad ó variables de tipo socio cultural (zona geográfica y valores).

¿Qué es lo que determina que un emprendedor, que tiene abierto y funcionando su negocio, quiera seguir siendo emprendedor?

¿En qué medida los rasgos de personalidad y los valores culturales predicen la intención de seguir siendo emprendedores? 


\section{2.- MUESTRA}

La muestra se compone de 479 sujetos emprendedores, 262 son varones y 210 mujeres. Los 7 sujetos restantes son sujetos perdidos en relación a la variable sexo.

\begin{tabular}{|c|c|c|}
\hline & Frecuencia & Porcentaje \\
\hline Varones & 262 & 54.7 \\
\hline Mujeres & 210 & 43.8 \\
\hline Perdidos & 7 & 1.5 \\
\hline Total & 479 & 100 \\
\hline
\end{tabular}

Se codificó la muestra de emprendedores (479 sujetos) en dos grupos en función de su experiencia laboral:

-1 a 120 meses: Equivale a una experiencia entre 0 y 10 años.

-121 a 998 meses: Equivale a una experiencia mayor a 10 años.

Perdiendo varios de los sujetos (148) de nuestra muestra en esta clasificación, obtuvimos una frecuencia de 148 para el grupo de menor experiencia laboral, una frecuencia de 183 para una experiencia intermedia-alta. Un total de 331 individuos.

Si ponemos en relación las variables Experiencia y Sexo y eliminamos los casos perdidos de ambas variables tenemos un total de 326 sujetos. De estos, 194 son varones y 132 son mujeres. Del total de esta muestra:

-147 informan de una baja experiencia laboral.

-179 informan de una experiencia laboral intermedia-alta.

Veamos, en primer lugar, cómo se distribuyen estos grupos de experiencia en relación a la variable sexo si son varones: nivel bajo de experiencia (72 varones); nivel 
medio-alto de experiencia (122 sujetos). Por otro lado, para las mujeres los grupos de experiencia se distribuyen de esta forma: nivel medio-alto (57) y nivel bajo (75).

Las edades de estos sujetos oscilan entre 19 y 76 años, siendo la media 38,68 años. En cuanto a la procedencia de los 479 sujetos de la muestra: 135 sujetos pertenecen a Vizcaya, 90 a Navarra, 105 a la zona Zamora-Salamanca, 60 a Soria y 89 a Valladolid. De los 326 sujetos, 119 son de Valladolid, 58 de Navarra, 58 de ZamoraSalamanca, 29 de Soria y 62 de Valladolid. De estos, los 194 varones se distribuyen de la siguiente forma conforme a provincia de procedencia: Vizcaya (74), Navarra (42), Zamora-Salamanca (31), Soria (14) y Valladolid (33). Las 132 mujeres se distribuyen de acuerdo a la provincia: 45 son de Vizcaya, 16 son de Navarra, 27 de ZamoraSalamanca, 15 de Soria y 29 de Valladolid. Un total en la zona norte de 225 y un total en centro peninsular de 254.

\section{3.- INSTRUMENTO}

Las variables de las hipótesis que se ponen a prueba quedan todas recogidas en el COE (Cuestionario de Orientación Emprendedora), por lo que fue éste el instrumento que se le administró a la muestra para recoger los datos. El COE mide rasgos que en la literatura se consideran importantes en el comportamiento emprendedor. Podemos hablar de que la estructura del cuestionario se divide en tres bloques: un primer apartado de variables control, un segundo bloque con variables relacionadas con el perfil personal del emprendedor y un tercer bloque en el que se trabajan los valores de Schwartz.

En el primer apartado se recogen los datos personales del sujeto que podrían tener influencia en su intención emprendedora: edad, sexo, tipo de estudios, situación laboral, profesión del padre y profesión de la madre.

El segundo bloque abarca desde el apartado II al X. El segundo apartado consta de 20 ítems, en escala 0-5, de los cuales: 11 están diseñados para medir locus de control interno y 9 están diseñados para medir locus de control externo. El tercer apartado posee 23 ítems, en escala 0-10, diseñados para medir autoeficacia emprendedora. El cuarto 
apartado tiene 22 Ítems, en escala de 0 a 5, que pretenden medir Proactividad (del 1 al 10), Riesgo (del 11 al 22) e Iniciativa (del 23 al 35). En el quinto apartado, se evalúan (de 0 a 5) los motivos juzga la persona que son importantes para otros a la hora de crear una empresa. En el sexto apartado se valoran (de 0 a 5) los motivos propios en la creación de una empresa. En el apartado VII se valoran, de 0 a 5, los recursos que se consideran importantes. Las dificultades se miden en el punto VIII del COE y, en el apartado IX, se evalúan, de 0 a 5 , las variables circunstanciales que pudieran influir en la creación de una empresa. En relación a la intención laboral, se valora el grado de preferencia (de 0 a 5) de distintas opciones en el apartado X.

En el tercer bloque, se pretenden medir en 37 ítems los diferentes valores se Schwartz: Apertura al cambio, Auto-transcendencia, Auto-promoción y Conservación.

\section{4.- PROCEDIMIENTO}

Las diferentes Cámaras de Comercio e Industria de las provincias donde se han pasado los cuestionarios, nos proporcionaron listados de las empresas dadas de alta en cada zona, indicándonos persona y forma de contacto. Se procedió a hacer una selección de las mismas acudiendo personalmente para solicitar colaboración para el estudio. Dicha selección consistió en entrevistar a aquellas personas que fueran fundadoras de la empresa y siguieran manteniendo vínculos con ella.

\section{5.- HIPOTESIS}

\section{Hipótesis 1:}

Pretendemos evidenciar empíricamente que ciertas variables, en relación, intervienen en el mantenimiento de la intención emprendedora de la persona. Los procesos cognitivos de autorregulación son los que mejor predicen el comportamiento, y sitúan la intención como el mejor predictor de la conducta planificada. Si la intención es el resultado de determinados esfuerzos que un individuo está dispuesto a llevar a cabo para realizar una determinada conducta. (Azjen, I., 1991), podemos entender la apertura de un negocio o el mantenerlo abierto, como un buen ejemplo de planificación 
Siguiendo el modelo de Azjen en nuestro estudio, diferenciamos tres grandes factores que influirían y predecirían la intención emprendedora: la actitud hacia la conducta (me conviene o no seguir emprendiendo), normas subjetivas (las personas de mi entorno aprueban o desaprueban mi intención de seguir siendo emprendedor), y control conductual percibido (me resulta fácil o complicado seguir con el emprendizaje). Todos estos factores, a su vez, están mediados por los valores que tiene el sujeto, muchos de los cuales son aprendidos en el entorno social del mismo (96-101

En el primer capítulo hemos expuesto las principales características que la literatura científica define como personalidad emprendedora, pudiendo identificar sus rasgos o variables de personalidad más significativos, aquellos que se atribuyen al emprendedor. Basándonos en ese desarrollo teórico, (páginas 65 - 100), procedo a plantear mi primera hipótesis general;

H1-Planteamos que las variables de personalidad (Autoeficacia, Locus de Control Interno, Locus Control Externo, Proactividad, Riesgo e Iniciativa) contribuyen a mantener la intención de emprender.

Basándonos en nuestro desarrollo teórico, identificamos la autoeficacia como un rasgo de personalidad emprendedora (páginas 75-84), por lo tanto

\section{H1a.-Habrá una mayor Autoeficacia en los individuos con mayor intención.}

Basándonos en nuestro desarrollo teórico, identificamos el $\mathrm{LCI}^{20}$ como un rasgo de personalidad emprendedora (páginas 73-75), por lo tanto

\section{H1b.-Habrá un mayor LCI en los individuos con mayor intención.}

Basándonos en nuestro desarrollo teórico, identificamos el LCE como un rasgo de personalidad no emprendedora (páginas 73-75), por lo tanto

\footnotetext{
${ }^{20}$ LCI, Locus de Control Interno y LCE, Locus de Control Externo.
} 


\section{H1c-Habrá un menor LCE en los individuos con mayor intención.}

Basándonos en nuestro desarrollo teórico, identificamos la Proactividad como un rasgo de personalidad emprendedora (páginas 78-84), por lo tanto

H1d.-Habrá una mayor Proactividad en los individuos con mayor intención.

Basándonos en nuestro desarrollo teórico, identificamos la Tendencia a asumir riesgos como un rasgo de personalidad emprendedora (páginas 75-78), por lo tanto

H1e.-Habrá una mayor tendencia a la asunción de Riesgos en los individuos con mayor intención.

Basándonos en nuestro desarrollo teórico, identificamos la Iniciativa como un rasgo de personalidad emprendedora (páginas 84-85), por lo tanto

\section{H1f.-Habrá una mayor Iniciativa en los individuos con mayor intención.}

\section{Hipótesis 2:}

En el segundo capítulo, hemos analizado, además de los ya abordados factores socioculturales del entorno (paginas (40-58), la cultura y, en concreto, los valores culturales, como mediadores claves en el emprendizaje, eligiendo, para este estudio, el modelo de Schwartz. (119-157). En base a la revisión bibliográfica expuesta (109181), procedemos a plantear nuestra segunda hipótesis general.

Se postula que los valores socioculturales propuestos por Schwartz (Autotranscendencia, Auto-promoción, Conservación y Apertura al Cambio) contribuyen a mantener la intención de emprender, es decir, son característicos de una alta intención emprendedora.

Basándonos en nuestro desarrollo teórico, identificamos el valor autopromoción y los valores apertura al cambio como directamente vinculados a la intención de 
emprendedor, De la misma forma, los valores de Trascendencia y Conservación, a pesar de s posible carácter mixto, no están directamente vinculados a la intención de emprender (152-167).

H2a.-Menor consideración del valor Transcendencia en base al grado de intención emprendedora.

H2b.-Mayor consideración del valor Auto-Promoción en base al grado de intención emprendedora.

H2c.-Menor consideración del valor Conservación en base al grado de intención emprendedora.

H2d.-Mayor consideración del valor Apertura al Cambio en base al grado de intención emprendedora.

\section{Hipótesis 3:}

La predisposición emprendedora de una sociedad está vinculada al papel de la cultura, y de forma inversa, la cultura específica de una zona o comarca, afecta a las características de los emprendedores que en ella se encuentran. Los valores son resultado del propio contexto, de las condiciones macroeconómicas y macrosociales, responden a una forma concreta de funcionar socialmente y pueden explicar la percepción que en esa zona se tiene de las iniciativas emprendedoras. De la misma forma, es a través de los procesos de socialización, como los individuos interiorizan estos valores sociales convirtiéndolos en personales, asumiéndolos como propios, configurando la propia personalidad del sujeto (122-154). En base a la revisión bibliográfica expuesta $(41-58 ; 109-167)$, procedemos a plantear nuestra tercera hipótesis general.

El entorno sociodemográfico en el que se desarrolla el proyecto de creación de una empresa influye en los valores y la personalidad que determinan el mantenimiento de la intención de emprender. 
Basándonos en nuestro desarrollo teórico, entendemos que los emprendedores tendrán diferentes valores en función de la zona donde están ubicados (122-124).

H3a.-La zona en la que se desarrolla el proyecto de creación de una empresa influye en los valores y la personalidad que determinan el mantenimiento de la intención de emprender.

Basándonos en nuestro desarrollo teórico, entendemos que la edad del emprendedor influirá de forma diferente en el mantenimiento de la intención emprendedora, (41-58).

H3b.-La edad influye en los valores y la personalidad que determinan el mantenimiento de la intención de emprender.

Basándonos en nuestro desarrollo teórico, entendemos que el sexo del emprendedor influirá de forma diferente en el mantenimiento de la intención emprendedora, (41-58).

H3c.-El sexo influye en los valores y la personalidad que determinan la intención de emprender.

Basándonos en nuestro desarrollo teórico, entendemos que la experiencia laboral del emprendedor influirá de forma diferente en el mantenimiento de la intención emprendedora, (41-58).

H3d.-La experiencia laboral influye en los valores y la personalidad que determinan la intención de emprender.

\section{6.- ANALISIS}

Se han codificado los datos obtenidos a través del paquete estadístico SPSS versión 19.0 para Windows. Con la finalidad de responder a las distintas hipótesis planteadas se han llevado a cabo análisis correlacionales, diferencias de medias y 
análisis de regresión. Concretamente, se han realizado los siguientes análisis correlacionales:

-Correlaciones Pearson entre las variables de personalidad (autoeficacia, proactividad, riesgo, iniciativa personal, locus de control interno y locus de control externo).

-Correlaciones Pearson entre las variables de personalidad citadas y los diferentes motivos propios; las variables de personalidad y los recursos que se estiman necesarios; las variables de personalidad y los principales obstáculos para una carrera emprendedora; las variables de personalidad y variables circunstanciales; las variables de personalidad y la intención laboral.

-Correlaciones Pearson entre las variables de personalidad y las variables control (edad y duración de experiencia laboral en meses).

-Correlaciones Pearson entre las variables de personalidad y los valores de Schwartz.

-Correlaciones Pearson entre la intención laboral de trabajar en Empresa Privada, Empresa pública, Administración pública o autoemplearse.

-Correlaciones Pearson entre valores; valores e intención laboral; valores y edad; valores y experiencia.

-Correlaciones Pearson entre experiencia laboral e intención laboral; entre edad e intención laboral.

Por otra parte, se han analizado las diferencias de medias entre:

-Prueba $\mathrm{T}$ de diferencia de medias entre Sexo y variables personales.

-Prueba $\mathrm{T}$ de diferencia de medias entre Experiencia y variables personales. 
-Prueba $\mathrm{T}$ de diferencia de medias entre Zona (dicotomizada en Zona Centro-Peninsular y Zona Norte, a fin de igualar las muestras) y variables personales.

-ANOVA para grupos de edad y variables personales.

-Prueba $\mathrm{T}$ de diferencia de medias entre intención y variables personales.

-Prueba $\mathrm{T}$ de diferencia de medias entre sexo y motivos personales, de otros, dificultades, los recursos que se estiman necesarios, los principales obstáculos para una carrera emprendedora, variables circunstanciales y la intención laboral.

-Prueba $\mathrm{T}$ de diferencia de medias entre experiencia y motivos personales, de otros, dificultades, los recursos que se estiman necesarios, los principales obstáculos para una carrera emprendedora, variables circunstanciales y la intención laboral.

-Prueba $\mathrm{T}$ de diferencia de medias entre zona y motivos personales, de otros, dificultades, los recursos que se estiman necesarios, los principales obstáculos para una carrera emprendedora, variables circunstanciales y la intención laboral.

-Prueba $\mathrm{T}$ de diferencia de medias entre intención y motivos personales, de otros, dificultades, los recursos que se estiman necesarios, los principales obstáculos para una carrera emprendedora, variables circunstanciales y la intención laboral.

-Prueba T de diferencia de medias entre grupos de intención para valores.

-Prueba $\mathrm{T}$ de diferencia de medias entre sexo y valores.

-ANOVA entre edad y valores.

-Prueba $\mathrm{T}$ de diferencia de medias entre zona y valores.

-Prueba T de diferencia de medias entre experiencia y valores. 
Por último, se han llevado a cabo los siguientes Análisis de Regresión:

\section{PARA ZONA NORTE/ ZONA CENTRO PENINSULAR}

-Análisis de Regresión en el que las variables independientes fueron Autoeficacia, LCI, LCE, Proactividad, Riesgo e Iniciativa y la variable dependiente la Intención laboral para Empresa Privada.

-Análisis de Regresión en el que las variables independientes fueron Autoeficacia, LCI, LCE, Proactividad, Riesgo e Iniciativa y la variable dependiente la Intención laboral para Empresa Pública.

-Análisis de Regresión en el que las variables independientes fueron Autoeficacia, LCI, LCE, Proactividad, Riesgo e Iniciativa y la variable dependiente la Intención laboral para Administración Pública.

-Análisis de Regresión en el que las variables independientes fueron Autoeficacia, LCI, LCE, Proactividad, Riesgo e Iniciativa y la variable dependiente la Intención laboral para Autoemplearse.

-Análisis de Regresión en el que las variables independientes fueron Auto-transcendencia, Auto-promoción, Conservación y Apertura al Cambio, y la variable dependiente la Intención laboral para Empresa Privada.

-Análisis de Regresión en el que las variables independientes fueron Auto-transcendencia, Auto-promoción, Conservación y Apertura al Cambio, y la variable dependiente la Intención laboral para Empresa Pública.

-Análisis de Regresión en el que las variables independientes fueron Auto-transcendencia, Auto-promoción, Conservación y Apertura al Cambio, y la variable dependiente la Intención laboral para Administración Pública. 
-Análisis de Regresión en el que las variables independientes fueron Auto-transcendencia, Auto-promoción, Conservación y Apertura al Cambio, y la variable dependiente la Intención laboral para Autoemplearse.

\section{4.- RESULTADOS}

\section{1.- FIABILIDAD}

A fin de considerar los resultados de este estudio se ha realizado un análisis de las propiedades psicométricas del COE. A continuación presentamos los resultados obtenidos del análisis de las escalas de interés en el estudio para nuestra muestra.

-Autoeficacia: hallamos la fiabilidad para determinar si deberíamos eliminar algún elemento de nuestra escala. Vemos que nuestro índice es bueno (.932) y no es necesario eliminar ningún ítem.

-LCI: siendo los ítems del apartado II: 2, 4, 6, 8, 10, 11, 14, 15, 17, 18. La fiabilidad para esta escala es buena, con alfa de Cronbach de .848 y sin necesidad de eliminar ningún elemento.

-LCE: para LCE corresponde los ítems 3, 5, 7, 9, 12, 13, 16, 19, 20. Cronbach es bueno (.773), pero vemos que es realmente mayor si eliminamos el ítem 19 (.811), con lo cual tomamos la decisión de eliminarlo para posteriores análisis.

-Proactividad (ítems del 1 al 10): la fiabilidad es buena, de .829.

-Riesgo (ítems del 11 al 22): La fiabilidad no supera el .70, pero se queda cerca con .64. No obstante, aumentaríamos la fiabilidad a .695 si eliminamos el ítem 21.

-Iniciativa personal (ítems del 23 al 35): Obtenemos un buen índice de fiabilidad de la escala de Iniciativa Personal, .746. Ampliable ligeramente si se elimina el ítem 33 a .753. Conservaremos todos los ítems para posteriores análisis. 
-Apertura al cambio: (ítems de la escala XIV: 3, 10, 19, 27, 5, 14, 23, 25, $2,34)$ con una fiabilidad de .780

-Auto-promoción o jerarquía: (ítems de la escala XIV: 7, 17, 13, 15, 22, $28,36)$ con una fiabilidad de .635 .

-Auto-transcendencia: (ítems de la escala XIV: 8, 12, 16, 21, 30, 35, 1, $11,18,33)$ con una fiabilidad, .801.

-Conservación: $(26,24,6,20,29,32,37,4,9,31)$ con una fiabilidad de .737 .

\section{2.- CORRELACIONES}

a) Entre las variables de personalidad.

Se han llevado a cabo los análisis correlacionales entre las variables de personalidad. Encontramos fuertes correlaciones significativas entre: proactividad e iniciativa (.603), entre Autoeficacia y LCI (.485), entre Autoeficacia y Proactividad (.478), entre Autoeficacia e Iniciativa (.415), entre Autoeficacia y Riesgo (.359), entre LCI y Proactividad (.451), entre LCI y Riesgo (.283), entre LCI e Iniciativa (.304). Obtenemos correlaciones negativas y significativas de LCE con Autoeficacia (-.195), LCE y LCI (-.216), entre LCE y Riesgo (-.090). Finalmente, observamos que Proactividad y Riesgo correlacionan significativamente (.477), así como Riesgo e Iniciativa (.30)

Tabla 4.1.- Correlaciones entre las escalas LCI, LCE, Autoeficacia, Proactividad, Riesgo e Iniciativa emprendedora

\begin{tabular}{|c|c|c|c|c|c|c|}
\hline & AUTOEFICACIA & LCI & LCE & PROACTIVIDAD & RIESGO & INICIATIVA \\
\hline AUTOEFICACIA & & $.485 * *$ & $-.195 * *$ & $.478 * *$ & $.359 *$ & $.415 * *$ \\
\hline LCI & $.485 * *$ & $-.216 * *$ & $.451 * *$ & $.283 * *$ & $.304 * *$ \\
\hline LCE & $-.195 * *$ & $-.216 * *$ & & -.058 & $.090 *$ & .057 \\
\hline PROACTIVIDAD & $.478 * *$ & $.451 * *$ & -.058 & & $.477 *$ & $.603 * *$ \\
\hline RIESGO & $.359 *$ & $.283 * *$ & $-.090 *$ & $.477 *$ & $.300 * *$ \\
\hline INICIATIVA & $.415 * *$ & $.304 * *$ & .057 & $.603 * *$ & $.300 * *$ & \\
\hline
\end{tabular}


** La correlación es significativa a nivel 0.01 (bilateral)

* La correlación es significativa a nivele 0.05 (bilateral)

\section{b) Entre variables de personalidad y motivos propios}

Se han analizado las correlaciones entre las variables personales ya citadas y los motivos que se juzgan como importantes para la creación de una empresa. Obtenemos, pues, correlaciones significativas entre Proactividad y el motivo de Poder $y$ Prestigio (.139), Riesgo y el motivo de poder y prestigio (.136) y la Iniciativa y el motivo ya citado (.162).

Por otra parte, correlaciona "Éxito personal” con: Autoeficacia (.204), LCI (.205), Proactividad (.290), Riesgo (.228) y con Iniciativa (289). El motivo "Placer" correlaciona con: LCE (.107), Proactividad (.154), Riesgo (.113) y por Iniciativa (.294). $\mathrm{Y}$ con el motivo "Novedades y cambios" correlacionan las siguientes variables: Autoeficacia (.145), LCI (.114), Proactividad (.259), Riesgo (.183) y con Iniciativa (.308). En cuanto al motivo "Independencia" se manifiestan las siguientes correlaciones: con Autoeficacia (.101), con LCI (.257), con Proactividad (.182) y con Iniciativa (.136). El motivo “Rutina”, correlacionará con LCI (.097), LCE (.107), Proactividad (.149) e Iniciativa (.149). Podemos hablar, también, de que a una mayor consideración del motivo "Realización personal", mayores puntuaciones en Autoeficacia (.213), LCI (.263), Proactividad (.287) e Iniciativa (.225). Las respuestas al motivo "Mayor libertad" correlacionan con Autoeficacia (.153), LCI (.205), Proactividad (.167) e Iniciativa (.194). La "Seguridad Laboral" correlaciona con LCI(.193), LCE(.138), Proactividad (.139), Iniciativa (.146).

Tabla 4.2.- Correlaciones entre escalas/variables de Personalidad y motivos propios

\begin{tabular}{|c|c|c|c|c|c|c|}
\hline & Autoeficacia & LCI & LCE & Proactividad & Riesgo & Iniciativa \\
\hline $\begin{array}{l}\text { Poder y } \\
\text { prestigio }\end{array}$ & ,005 & ,048 &,- 030 & ,139** &, $136^{* * *}$ &, $162^{* * *}$ \\
\hline Éxito personal & $204^{* * *}$ &, $205^{* *}$ &,- 055 & ,290** & ,228** &, $289^{* *}$ \\
\hline Placer & ,079 & ,051 &, $107^{*}$ & $154^{* *}$ &, $113^{*}$ & $294^{* *}$ \\
\hline $\begin{array}{c}\text { Novedades y } \\
\text { cambios }\end{array}$ &, $145^{* *}$ &, $114^{*}$ &,- 024 & ,259** &, $183^{* * *}$ &, $\mathbf{3 0 8} 8^{* *}$ \\
\hline Independencia &, $101^{*}$ &, $257^{* * *}$ & ,019 & $182^{* * *}$ & ,073 & ,136 \\
\hline
\end{tabular}




\begin{tabular}{|c|c|c|c|c|c|c|}
\hline Rutina & ,088 &, $097^{*}$ & ,107 ${ }^{*}$ & $149^{* * *}$ & ,053 & $149^{* * *}$ \\
\hline $\begin{array}{c}\text { Realización } \\
\text { personal }\end{array}$ &, $213^{* * *}$ &, $262^{* * *}$ &,- 047 &, $287^{* * *}$ &, $174^{* * *}$ &, $225^{* *}$ \\
\hline Mayor libertad &, $153^{* *}$ &, $205^{* *}$ & ,053 & $167^{* * *}$ & ,084 &, $194^{* * *}$ \\
\hline $\begin{array}{c}\text { Seguridad } \\
\text { laboral } \\
\end{array}$ & 025 &, $193^{* *}$ &, $138^{* * *}$ &, $139^{* *}$ &,- 016 & $146^{* * *}$ \\
\hline $\begin{array}{l}\text { Último } \\
\text { recurso }\end{array}$ &,$- 107^{*}$ &,- 051 &, $171^{* *}$ &,- 048 &,$- 175^{* *}$ & ,007 \\
\hline
\end{tabular}

** La correlación es significativa a nivel 0.01 (bilateral)

*La correlación es significativa a nivele 0.05 (bilateral)

\section{c) Entre variables de personalidad y recursos}

Los análisis entre Recursos y variables personales dan lugar a las siguientes correlaciones significativas: formación con proactividad (.105) y con iniciativa (.211). En cuanto a Experiencia correlaciona significativamente con LCI (.111), LCE (.101), Proactividad (.098) e Iniciativa (.316). Recursos propios correlacionan con Riesgo (.119). En cuanto a Recursos ajenos no hay correlaciones significativas. Por otra parte, Ser creativo parece guardar relación con la Autoeficacia (.138), LCI (.102), Proactividad (.191), Riesgo (.098) e Iniciativa (.316). Capacidad previsión correlaciona con Autoeficacia (.216), LCI (.230), Proactividad (.133), Iniciativa (.185). Intuición, a este respecto, se caracteriza por la correlación con Autoeficacia (.193), LCI (.205), Proactividad (.201), Riesgo (.094), Iniciativa (.220). El recurso considerado como “Captar oportunidades” correlaciona con Autoeficacia (.305), LCI (.149), Proactividad (.149), Riesgo (.149) e Iniciativa (.272). El “Esfuerzo” correlaciona con Autoeficacia (.344), LCI (.313), Proactividad (.166), e Iniciativa (.196). "Confiar en las capacidades" correlaciona con Autoeficacia (.275), LCI (.294), Proactividad (.205), Riesgo (.126) e Iniciativa (.241). El “Asumir riesgos” correlaciona con Autoeficacia (.229), LCI (.205), Proactividad (.151), Riesgo (.133) e Iniciativa (.192). El “Tener iniciativa" correlaciona con Autoeficacia (.229), LCI (.228), Proactividad (.149), Riesgo (.128) e Iniciativa (.187). Finalmente, "Tener familia empresaria", correlaciona con Autoeficacia (-.118), con LCI (-.093) y con Riesgo (-.118). 
Tabla 4.3.- Correlaciones entre las escalas

"LCI","LCE","Autoeficacia","Proactividad", "Riesgo" e "Iniciativa emprendedora" y "Recursos"

\begin{tabular}{|c|c|c|c|c|c|c|}
\hline & Autoeficacia & LCI & LCE & Proactividad & Riesgo & Iniciativa \\
\hline Formación &, 015 & ,049 &,- 035 &, $105^{*}$ &, 005 &, $211^{* *}$ \\
\hline Experiencia &,- 050 &,$- 111^{*}$ &, $101^{*}$ &, $098^{*}$ &,- 075 &, $187^{* *}$ \\
\hline $\begin{array}{l}\text { Recursos } \\
\text { propios }\end{array}$ &,- 057 &,- 048 &, 081 &, 020 &,$- 119^{*}$ & ,090 \\
\hline Recursos ajenos & ,069 &,- 019 &, 039 &, 000 &, 031 & 041 \\
\hline Ser creativo &, $138^{* * *}$ &, $102^{*}$ &, 005 &, $191^{* * *}$ &, $098^{*}$ &, $316^{* * *}$ \\
\hline $\begin{array}{l}\text { Capacidad } \\
\text { previsión }\end{array}$ &, $216^{* *}$ &, $230^{* *}$ &, 005 &, $1^{* * *}$ &, 019 &, $185^{* *}$ \\
\hline Intuición &, $\mathbf{1 9 3}^{* *}$ &, $205^{* *}$ &, 052 &, $201^{* *}$ &, $094^{*}$ &, $220^{* *}$ \\
\hline $\begin{array}{l}\text { Captar } \\
\text { oportunidades }\end{array}$ &, $305^{* *}$ &, $242^{* *}$ &,- 082 &, $241^{* *}$ & ,087 & ,272 $2^{* *}$ \\
\hline Esfuerzo &, $344^{* *}$ &, $\mathbf{3 1 3}^{\text {** }}$ &,- 071 &, $166^{* * *}$ & ,086 &, $196^{* * *}$ \\
\hline $\begin{array}{l}\text { Confiar en } \\
\text { capacidades }\end{array}$ &, $275^{* *}$ &, $294^{* *}$ &,$- 104^{*}$ &, $205^{* *}$ &, $126^{* *}$ &, $231^{* *}$ \\
\hline Asumir riesgos &, $229^{* * *}$ &, $205^{* *}$ &,- 003 &, $151^{* *}$ &, $\mathbf{1 3 3}^{* *}$ &, $192^{* *}$ \\
\hline Tener iniciativa & ,229** &, $228^{* *}$ &,- 018 &, $149^{* *}$ &, $\mathbf{1 2 8}^{* *}$ &, $187^{* *}$ \\
\hline $\begin{array}{l}\text { Familia } \\
\text { empresaria }\end{array}$ &,$- 118^{*}$ &,$- 093^{*}$ & ,079 & ,001 &,$- 118^{*}$ &, 050 \\
\hline
\end{tabular}

** La correlación es significativa a nivel 0.01 (bilateral)

* La correlación es significativa a nivele 0.05 (bilateral)

\section{d) Entre variables de personalidad y obstáculos}

Las correlaciones entre las variables personales y los obstáculos son significativas en los siguientes niveles: Falta de ayudas con LCI (.101), Falta de Formación con Autoeficacia (-.104), Falta de Formación con Iniciativa (.116). Falta de acuerdo entre socios correlaciona con Iniciativa Personal (.149). Falta de apoyo social correlaciona con: LCI (.103), LCE (.142) e Iniciativa (.114).

Falta de asesoramiento correlacionaría significativamente con LCI (.123). Falta de experiencia correlaciona con LCE (.110). Falta de cualidades correlaciona con LCI (.156) y Burocracia con LCE (.106). 
Tabla 4.4.- Correlaciones entre variables personales y obstáculos

\begin{tabular}{|c|c|c|c|c|c|c|}
\hline & Autoeficacia & LCI & LCE & Proactividad & Riesgo & Iniciativa \\
\hline Falta financiación &,- 017 &,- 013 &, 052 &,- 026 &,- 081 & ,029 \\
\hline Falta idea negocio &, 013 & ,084 & ,006 &,- 003 &,- 074 & ,002 \\
\hline Falta ayudas &,- 026 &, $\mathbf{1 0 1}^{*}$ & ,052 & ,025 &,- 020 & ,056 \\
\hline Falta formación &,$- 104^{*}$ &, 010 & ,046 &,- 002 &,- 072 &, $116^{*}$ \\
\hline Falta acuerdo socios &,- 058 &,- 027 & ,070 & ,084 & ,088 &, $149^{* *}$ \\
\hline Falta apoyo social & ,036 &, $\mathbf{1 0 3}^{*}$ & $142^{* *}$ & ,090 &,- 032 &, $114^{*}$ \\
\hline Falta asesoramiento & ,082 &, $123^{* *}$ &, 054 & ,089 &,- 046 & 039 \\
\hline Falta experiencia &,- 022 &,- 006 &, $110^{*}$ & ,034 &, 000 & ,086 \\
\hline Falta cualidades & ,049 &, $156^{* *}$ & ,061 & ,073 &, 004 &, 055 \\
\hline Burocracia & ,008 &, 010 &, $106^{*}$ & ,034 &, 024 &, 053 \\
\hline
\end{tabular}

**La correlación es significativa a nivel 0.01 (bilateral)

* La correlación es significativa a nivele 0.05 (bilateral)

\section{e) Entre variables personales y variables circunstanciales}

Encontramos correlaciones significativas entre la importancia que se le da al “Desempleo" y el LCE (.119). La importancia que se le da a la concurrencia de la variable de "Responsabilidad familiar" y LCI (.098), además también con LCE (.188) y con Iniciativa (.099). El "Apoyo social" correlaciona significativamente con LCI (.102), LCE (.124), Proactividad (.105). e Iniciativa (.092). La importancia de la "Valoración social" se relaciona moderadamente con mayores puntuaciones en LCI (.10)., LCE (145)., Proactividad (.184) e Iniciativa (.209). Se considera relevante tener “Modelos empresariales cercanos" relacionado con LCI (.130)., Proactividad (.197) e Iniciativa (.258).. El Acceso fuentes de Información viene a relacionarse con la una mayor Autoeficacia (.133)., un mayor LCI (.158)., mayor Proactividad (.190)., mayor Riesgo (.099). y mayor Iniciativa (.241).. Por último, a la presencia de Contactos se le otorga mayor importancia moderadamente con un nivel alto de Autoeficacia (.127), de Proactividad (.140) y de Iniciativa (.182) 
Tabla 4.5.- Correlaciones entre variables personales y variables circunstanciales

\begin{tabular}{|c|c|c|c|c|c|c|}
\hline & Autoeficacia & LCI & LCE & Proactividad & Riesgo & Iniciativa \\
\hline Desempleo &,- 011 &, 075 &, $119^{* *}$ & ,028 &,- 070 & ,002 \\
\hline $\begin{array}{l}\text { Riesgo pérdida } \\
\text { ingresos }\end{array}$ & ,039 &, 084 & ,079 &,- 014 &,- 050 & ,036 \\
\hline $\begin{array}{l}\text { Responsabilidades } \\
\text { familiares }\end{array}$ &, 038 &, $098^{*}$ &, $\mathbf{1 8 8}^{* *}$ & ,063 & ,016 &, $099^{*}$ \\
\hline Apoyo social & ,014 &, $102^{*}$ &, $124^{* *}$ &, $105^{*}$ & ,008 &, $092^{*}$ \\
\hline Valoración social & ,073 &, $100^{*}$ &, $145^{* *}$ &, $184^{* *}$ & ,018 & $209^{* *}$ \\
\hline $\begin{array}{l}\text { Modelos } \\
\text { empresariales } \\
\text { cercanos }\end{array}$ & ,084 &, 130 *** & ,038 &, $197^{* *}$ & ,083 & ,258 \\
\hline $\begin{array}{l}\text { Acceso fuentes } \\
\text { Información }\end{array}$ &, $133^{* *}$ &, $158^{* * *}$ & ,030 &, $190^{* *}$ & ,099* &, $241^{* * *}$ \\
\hline Contactos &, $127^{* *}$ &, 068 &, 047 &, $140^{* *}$ & ,089 &, $182^{* *}$ \\
\hline
\end{tabular}

** La correlación es significativa a nivel 0.01 (bilateral)

*La correlación es significativa a nivele 0.05 (bilateral)

\section{f) Entre las variables de la personalidad y la intención laboral}

El tener una Autoeficacia alta parece relacionarse con un menor interés de trabajar en Empresa Pública (-.224), Administración pública (-.217) y un mayor interés a Autoemplearse (.216). Una tendencia similar se refleja en las correlaciones con LCI, donde parece relacionarse con un menor interés de trabajar en Empresa Pública (-.202), Administración pública (-.193) y un mayor interés a Autoemplearse (.196). En cuanto al LCE correlaciona con el interés en una Administración Pública (.093).

Tabla 4.6.- Correlaciones entre variables personales y la intención laboral

\begin{tabular}{|c|c|c|c|c|}
\hline & $\begin{array}{l}\text { Empresa } \\
\text { Privada }\end{array}$ & $\begin{array}{l}\text { Empresa } \\
\text { Pública }\end{array}$ & Admin.Pública & Autoempleo \\
\hline Autoeficacia &, 007 &,$- 224^{* * *}$ &,$- 217^{* *}$ & $216^{* * *}$ \\
\hline LCI &,- 084 &,$- 202^{* * *}$ &,$- 193^{* *}$ & $196^{* * *}$ \\
\hline LCE & ,013 & ,084 &, $093^{*}$ &,- 024 \\
\hline Proactividad & ,091 &,$- 122^{* *}$ &,$- 141^{* *}$ &, $281^{* *}$ \\
\hline Riesgo & ,061 &,$- 126^{* *}$ &,$- 109^{*}$ & ,276 \\
\hline Iniciativa & ,099* &,- 029 &,- 065 & ,232 ${ }^{* *}$ \\
\hline
\end{tabular}


g) Entre variables personalidad edad y experiencia

La edad parece ser susceptible a una menor asunción de riesgos (-.184). Así, la Experiencia favorece un mayor LCI (.114).

Tabla 4.7.- Correlaciones entre variables personales y la edad; variables personales y la experiencia

\begin{tabular}{|l|c|c|c|c|c|c|}
\hline & & & & & Riesg & Iniciativ \\
Edad & Autoeficacia & LCI & LCE & Proactividad & o & a \\
&, 049 &, 052 &, 040 &,- 019 & - & -.071 \\
\hline Experiencia &, 040 &, $\mathbf{1 1 4}^{* *}$ &,- 005 &, 039 &,- 092 &, 065 \\
\hline
\end{tabular}

**La correlación es significativa a nivel 0.01 (bilateral)

* La correlación es significativa a nivele 0.05 (bilateral)

\section{h) Entre variables personalidad y valores}

Una mayor Autoeficacia correlaciona con una menor consideración de la Transcendencia (-.132), así con mayor importancia a la Promoción (.123) y mayor Apertura al Cambio (.171). Mayor LCI plantea relaciones con Promoción (.174) y Apertura (.160). Por otra parte, el $L C E$ nos muestra relaciones significativas con Promoción (.127) y Conservadurismo (.106). En cuanto a la Proactividad, la Promoción (.306), el Conservadurismo (.154) y Apertura al Cambio (.363) correlacionan significativamente. El riesgo lo hace con los valores Promoción (.112) y Apertura al Cambio (.331). Finalmente, hablamos de que las puntuaciones altas en Iniciativa personal valorarán como más importantes en cierta medida los valores Transcendencia (.140), Promoción (.332), Conservación (.253) y Apertura al Cambio (.385).

Tabla 4.8.- Correlaciones entre variables personales y los valores

\begin{tabular}{|c|c|c|c|c|}
\hline & Transcendencia & Promoción & Conservación & Apertura \\
\hline Autoeficacia & $\mathbf{- , 1 3 2}^{* *}$ & $\mathbf{, 1 2 3}^{* *}$ &,- 077 & $\mathbf{1 7 1}^{* *}$ \\
\hline LCI &,- 082 & $\mathbf{, 1 7}^{* *}$ &,- 053 & $\mathbf{, 1 6 0}^{* *}$ \\
\hline LCE &, 028 & $\mathbf{, 1 2}^{* *}$ & $\mathbf{, 1 0 6}^{* *}$ &, 026 \\
\hline Proactividad &, 033 & $\mathbf{, 3 0 6}^{* *}$ & $\mathbf{1 5 4}^{* *}$ & $\mathbf{3 6 3}^{* *}$ \\
\hline Riesgo &, 012 & $\mathbf{, 1 2}^{* *}$ &,- 081 & $\mathbf{3 3 1}^{* *}$ \\
\hline Iniciativa & $\mathbf{1 4 0}^{* *}$ & $\mathbf{, 3 3 2}^{* *}$ & $\mathbf{2 5 3}^{* *}$ & $\mathbf{3 8 5}^{* *}$ \\
\hline
\end{tabular}

** La correlación es significativa a nivel 0.01 (bilateral)

* La correlación es significativa a nivele 0.05 (bilateral) 


\section{i) Entre la intención laboral}

Se han hallado las relaciones entre la intención de trabajar en Empresa Privada, Empresa Pública, Administración Pública y Autoempleo a fin de ver descriptivamente cuál es la tendencia de los emprendedores de nuestra muestra. Los resultados ratifican que un mayor interés en la empresa Privada manifestará así la misma tendencia para Empresa Pública (.261), Administración Pública (.156) y Autoemplearse (.254). Por otra parte, se manifiesta que mayor interés en trabajar en una Empresa Pública correlaciona fuertemente con el interés en la Administración Pública (.787) e inversamente, por ende con menor interés, para autoemplearse (-.179)

Tabla 4.9.-Correlaciones en Intención laboral

\begin{tabular}{|c|c|c|c|c|}
\hline & $\begin{array}{l}\text { Empresa } \\
\text { privada }\end{array}$ & $\begin{array}{l}\text { Empresa } \\
\text { pública }\end{array}$ & Admin. Pública & Autoempleo \\
\hline $\begin{array}{l}\text { Empresa } \\
\text { privada }\end{array}$ & & $.261 * *$ & $.156 * *$ & $.254 * *$ \\
\hline $\begin{array}{l}\text { Empresa } \\
\text { pública }\end{array}$ & $.261 * *$ & & $.787 * *$ & $-.179 * *$ \\
\hline Admin.Pública & $.156 * *$ & $.787 * *$ & & $-.236 * *$ \\
\hline Autoempleo & $.254 * *$ & $-.179 * *$ & $-.236 * *$ & \\
\hline
\end{tabular}

** La correlación es significativa a nivel 0.01 (bilateral)

* La correlación es significativa a nivele 0.05 (bilateral)

\section{j) Entre los valores y la intención laboral}

Otro de los análisis correlacionales pertinentes corresponde a la puesta en relación de la Intención laboral y los valores de los individuos de nuestra muestra. Así, la intención de trabajar en una empresa privada se pone en relación con la Transcendencia (.220), la Promoción (.101) y el Conservadurismo (.182). Por otra parte, la Empresa pública se relaciona positivamente con Transcendencia (.250), Conservadurismo (.111) y negativamente con Apertura al Cambio (-.095). De forma similar, la intención laboral orientada a la Administración pública se relaciona con Transcendencia (.232), Conservadurismo (.093) y de forma negativa con Apertura al 
cambio (-.108). La intención laboral orientada al Autoempleo se relaciona con la Transcendencia (.099) y la Apertura al Cambio (.192).

Tabla 4.10. Correlaciones entre valores e intención laboral

\begin{tabular}{|l|c|c|c|c|}
\hline & Transcendencia & Promoción & Conservación & Apertura \\
\hline Empresa privada & $\mathbf{, 2 0 0}^{* *}$ & $\mathbf{, 1 0 1}^{*}$ & $\mathbf{, 1 8 2}^{* *}$ &, 020 \\
\hline Empresa pública & $\mathbf{, 2 5 0}^{* *}$ &,- 017 & $\mathbf{, 1 1}^{*}$ & $\mathbf{- , 0 9 5}^{*}$ \\
\hline Admin, pública & $\mathbf{, 2 3 2}^{* *}$ &,- 014 & $\mathbf{, 0 9 3}^{*}$ & $\mathbf{- , 1 0 8}^{*}$ \\
\hline Autoempleo & $\mathbf{, 0 9 9}^{*}$ &, 083 &, 086 & $\mathbf{, 1 9 2}^{* *}$ \\
\hline
\end{tabular}

**La correlación es significativa a nivel 0.01 (bilateral)

* La correlación es significativa a nivele 0.05 (bilateral)

k) Entre los valores y la edad; valores y experiencia.

Vemos que a mayor edad, menor consideración a la Transcendencia (-.139) y a la Apertura (-.337). Por otra parte, a mayor experiencia menor puntuación en Apertura al Cambio (-.269).

Tabla 4.11.-Correlaciones entre valores y edad; valores y experiencia.

\begin{tabular}{|l|c|c|c|c|}
\hline & Transcend. & Prom. & Cons. & Apertura \\
\hline Edad & $-.139 * *$ & .020 & .077 & $-.337 * *$ \\
\hline Experiencia & -.036 & .013 & .010 & $-.269 * *$ \\
\hline
\end{tabular}

**La correlación es significativa a nivel 0.01 (bilateral)

* La correlación es significativa a nivele 0.05 (bilateral)

l) Entre los valores:

Se pone en relación la Transcendencia con la Promoción (.109) y, de forma más amplia con Conservadurismo (.557) y con Apertura (.283). Así, la Promoción se relaciona con la tendencia al Conservadurismo (.456) y a la Apertura (.411). Por último, la tendencia a ser conservador se relaciona significativamente con Apertura al Cambio (.266). 
Tabla 4.12. Correlaciones entre valores

\begin{tabular}{|c|c|c|c|c|}
\hline & Transcendencia & Promoción & Conservación & Apertura \\
\hline Transcendencia & & $\mathbf{1 0 9}^{*}$ & $\mathbf{5 5 7}^{* *}$ & $\mathbf{2 8 3}^{* *}$ \\
\hline Promoción &, $\mathbf{1 0 9}^{*}$ & & $\mathbf{4 5 6}^{* *}$ & $\mathbf{4 1 1}^{\text {** }}$ \\
\hline Conservación & $\mathbf{5 5 7}^{* *}$ & $\mathbf{4 5 6}^{* *}$ & & $\mathbf{2 6 6}^{* *}$ \\
\hline Apertura & $\mathbf{2 8 3}^{* *}$ & $\mathbf{4 1 1}^{* *}$ & $\mathbf{2 6 6}^{* *}$ & \\
\hline
\end{tabular}

** La correlación es significativa a nivel 0.01 (bilateral)

* La correlación es significativa a nivele 0.05 (bilateral)

\section{j) Entre la experiencia laboral y la intención laboral}

La correlación entre la experiencia laboral y la intención de emprender no es significativa. Asimismo, no son significativas el resto de relaciones entre experiencia laboral e intención de trabajar en Empresa privada, Empresa pública o Administración pública.

\section{k) Entre la edad y la intención laboral}

No hay correlaciones significativas a este respecto.

\section{3.- DIFERENCIAS DE MEDIAS}

Por otra parte, se han llevado los siguientes análisis de diferencias de medias:

a) Prueba T de diferencia de medias entre Sexo y variables personales.

La variable sexo produce diferencias significativas en Autoeficacia $(t=2,2$; $\mathrm{p}=.03)$, en Proactividad ( $\mathrm{t}=2,1: \mathrm{p}=.03)$ y en Riesgo $(\mathrm{t}=2 ; \mathrm{p}=.05)$ y no lo hace en cuanto a Locus de Control Interno y en cuanto al Locus de Control Externo. Todas las diferencias significativas son a favor de los hombres. 
b) Prueba $T$ de diferencia de medias entre Experiencia (2 grupos) y variables personales.

La experiencia no produce diferencias en: Autoeficacia, Locus de Control Interno, Locus de Control Externo, Proactividad y Riesgo.

c) Prueba $T$ de diferencia de medias entre Zona (dicotomizada en Zona Centro-Peninsular y Zona Norte, a fin de igualar las muestras) y variables personales.

La variable Zona Geográfica produce diferencias significativas en Autoeficacia $(\mathrm{t}=4.0 ; \mathrm{p}<.00)$ y en Locus de Control Interno $(\mathrm{t}=2.5 ; \mathrm{p}>.01)$. Las dos diferencias son favorables a los Sujetos que vivían en la Zona Norte.

\section{d) ANOVA para grupos de edad y variables personales}

Se realizaron tres grupos con la muestra en función de la edad. En el primero se incluyó a los sujetos que tenían entre 19 y 31 años, en el segundo entre 32 y 37 años y en el tercero entre 38 y 65 años. A partir de un ANOVA las diferencias encontradas fueron en la dirección de una mayor asunción de Riesgos por los más jóvenes en relación al grupo de edad más avanzada $(F=6.5 ; \mathrm{p}<=.00)$.

e) Prueba T de diferencia de medias entre intención y variables personales.

La intención produce diferencias significativas en Autoeficacia $(\mathrm{t}=5.4 ; \mathrm{p}<.00)$, en Locus de Control Interno ( $\mathrm{t}=5.4 ; \mathrm{p}<.00)$, en Proactividad $(\mathrm{t}=6.4 ; \mathrm{p}<.00)$ y en Riesgo $(\mathrm{t}=5.4 ; \mathrm{p}<.00)$. Todas las diferencias son a favor del grupo en el que están las personas con una intención más alta. 
f) Prueba $T$ de diferencia de medias entre sexo y motivos de otros (VI), personales (VII), los recursos que se estiman necesarios (VIII), dificultades (IX), variables circunstanciales $(X), y$ la intención laboral $(X I)$.

-En cuanto a los motivos de otros (VI), sólo se encontraron diferencias significativas en función de la variable sexo para el motivo "Como último recurso" $(\mathrm{t}=3.1 ; \mathrm{p}<.00)$ a favor de las mujeres.

-En cuanto a los motivos propios (VII), sólo se encontraron diferencias significativas en función de la variable sexo para los motivos "Seguridad Laboral" $(\mathrm{t}=2.1 ; \mathrm{t}=.04)$ y "Como último recurso" $(\mathrm{t}=2.2 ; \mathrm{p}<. .03)$; para los dos motivos, la diferencia es a favor de las mujeres.

-En cuanto a los recursos, sólo se encontraron diferencias significativas en el Recurso "Formación académica" a favor de las mujeres $(\mathrm{t}=2.3 ; \mathrm{p}=.22)$.

-En cuanto a las dificultades, se encontraron diferencias significativas en la Dificultad "Falta de ayudas y subvenciones" $(\mathrm{t}=3.5 ; \mathrm{p}<.00)$ y en la Dificultad "Falta de asesoramiento" $(\mathrm{t}=2.0 ; \mathrm{p}=0.4)$, en las dos a favor de la mujer.

-En cuanto a las variables circunstanciales, se encontraron diferencias significativas en la consideración de "Estar desempleado" $(\mathrm{t}=2.7 ; \mathrm{p}<.00)$ y en "Riesgo de pérdida de ingresos" $(\mathrm{t}=3.3 ; \mathrm{p}<.00)$, en los dos las diferencia fueron a favor del grupo de las mujeres.

-En cuanto a la intención laboral, se encontraron diferencias: en cuanto a la intención de trabajo en empresa pública $(\mathrm{t}=2.3 ; \mathrm{p}=.02)$ a favor del grupo de las mujeres; en cuanto a la intención de trabajo en la administración pública $(t=3.2 ; \mathrm{p}<.00)$ a favor del grupo de las mujeres; y en cuanto a la a la intención de autoempleo $(\mathrm{t}=4.0$; $\mathrm{p}<.00)$ a favor del grupo de los varones. 
g) Prueba $T$ de diferencia de medias entre experiencia y motivos de otros (VI), personales (VII), los recursos que se estiman necesarios (VIII), dificultades (IX), variables circunstanciales $(X)$, y la intención laboral $(X I)$.

-En cuanto a los motivos atribuidos a otros para ser emprendedores, no se encontraron diferencias significativas en ninguno de los que aparecen en el cuestionario.

-En cuanto a los motivos propios, no se encontraron diferencias significativas en ninguno de los que aparecen en el cuestionario.

-En cuanto a los recursos, no se encontraron diferencias significativas en ninguno de los que aparecen en el cuestionario.

-En cuanto a las dificultades, no se encontraron diferencias significativas en ninguno de los que aparecen en el cuestionario.

-En cuanto a las variables circunstanciales, no se encontraron diferencias significativas entre los dos grupos de experiencia.

-En cuanto a la intención laboral, no se encontraron diferencias significativas entre los dos grupos de experiencia.

h) Prueba $T$ de diferencia de medias entre zona y motivos de otros (VI), personales (VII), los recursos que se estiman necesarios (VIII), dificultades (IX), variables circunstanciales $(X)$, y la intención laboral (XI).

-En cuanto a los motivos atribuidos a otros, se encontraron diferencias significativas para el motivo de realización $(\mathrm{t}=2.0 ; \mathrm{p}=.04)$ a favor de las personas que vivían en la zona norte.

-En cuanto a los motivos propios, se encontraron diferencias para los motivos de realización ( $\mathrm{t}=2.3 ; \mathrm{p}=.02)$ a favor de los sujetos de la zona norte y último recurso $(\mathrm{t}=3.2 ; \mathrm{t}<.00)$ a favor de los sujetos de la zona centro. 
-En cuanto a los recursos, aparecen diferencias significativas en "Experiencia laboral" ( $\mathrm{t}=2.2 ; \mathrm{p}=.02)$ y en "La familia como empresaria" $(\mathrm{T}=2.5 ; \mathrm{p}=.01)$, las dos casos a favor de los sujetos que viven en la zona centro.

-En cuanto a las dificultades, aparecen diferencias significativas en el "Falta de formación" ( $t=2,8 ; \mathrm{p}<.00)$, en "Falta de acuerdo con socios" $(\mathrm{t}=2,8 ; \mathrm{p}<.00)$ y en el "Falta de experiencia laboral" $(\mathrm{t}=3.7 ; \mathrm{p}<.00)$, todas a favor de los sujetos que viven en la zona centro.

-En cuanto a las variables circunstanciales, no se encontraron diferencias significativas entre los dos grupos de experiencia.

-En cuanto a la intención laboral, se encontraron diferencias: en cuanto a trabajas en una empresa púbica $(\mathrm{t}=4.7 ; \mathrm{p}<.00)$ a favor de las personas que viven en la zona centro; en cuanto a trabajar en una administración pública $(\mathrm{t}=3.3 ; \mathrm{p}<.00)$ a favor de las personas que viven en la zona centro; $y$ en cuanto a autoempleo $(t=4.9 ; \mathrm{p}<.00)$ a favor de las personas que viven en la zona norte.

i) Prueba $T$ de diferencia de medias entre intención y motivos de otros (VI), personales (VII), los recursos que se estiman necesarios (VIII), dificultades (IX), variables circunstanciales $(X)$.

-En cuanto los motivos atribuidos a otros se encuentran diferencias significativas en el motivo "Búsqueda de éxito" ( $\mathrm{t}=3.4 ; \mathrm{t}<.00)$, el de "Búsqueda de novedades" $(\mathrm{t}=2.4 ; \mathrm{p}<.01)$, el de independencia $(\mathrm{t}=3.0 ; \mathrm{p}<.00)$, el de realización $(\mathrm{t}=3.8$; $\mathrm{p}<.00)$, libertad $(\mathrm{t}=3.9 ; \mathrm{t}<.00)$ y como último recurso $(\mathrm{t}=3.4 ; \mathrm{p}<.00)$. Todas las diferencias son a favor del grupo con una intención alta salvo el motivo de último recurso, que la diferencia es a favor del grupo con una menor intención.

-En cuanto a los motivos propios, hay diferencias significativas en el motivo de éxito $(\mathrm{t}=4.6 ; \mathrm{p}<.00)$, en el de independencia $(\mathrm{t}=2,4 ; \mathrm{p}=0.02)$, en el de realización $(\mathrm{t}=5.3 ; \mathrm{p}<.00)$, libertad $(\mathrm{t}=2.9 ; \mathrm{p} .00)$ y como último recurso $(\mathrm{t}=4.6 ; \mathrm{p}<.00)$. Todas las diferencias son a favor del grupo con una intención alta salvo el motivo de último recurso, que la diferencia es a favor del grupo con una menor intención. 
-En cuanto a los Recursos, hay diferencias en el "Recursos financieros propios" ( $\mathrm{t}=2,2 ; \mathrm{p}=.03)$, en el "Capacidad para captar y aprovechar oportunidades" (3,1; $\mathrm{p}<.00)$, "Capacidad de esfuerzo para conseguir objetivos" $(\mathrm{t}=2.9 ; \mathrm{p}<.00)$, "Confianza en las propias capacidades" ( $\mathrm{t}=3.5, \mathrm{p}<.00)$, "La familiar como empresaria" ( $\mathrm{t}=3.4 ; \mathrm{p}<.00)$, Todas las diferencias son favorables al grupo de mayor intención salvo para el ítem "Recursos financieros propios".

j) Prueba T de diferencia de medias entre grupos de intención de autoempleo y valores,

La variable intención de autoempleo ha producido diferencias significativas en Transcendencia $(t=.295 ; \mathrm{p}=.016$. Fueron los grupos de Alta intención los que puntuaron más alto.

k) Prueba $T$ de diferencia de medias entre sexo y valores (transcendencia, apertura al cambio, autopromoción y conservación).

La variable sexo ha producido diferencias significativas en los valores de Trascendencia $(\mathrm{t}=2.6 ; \mathrm{p}<.00)$ y Promoción $(\mathrm{t}=2.1 ; \mathrm{p}=.04)$. Para Trascendencia quienes puntuaron significativamente más alto fueron las mujeres y para Promoción lo hicieron los varones.

m) ANOVA para grupos de edad y valores. (transcendencia, apertura al cambio, autopromoción y conservación).

Se realizaron tres grupos con la muestra en función de la edad. En el primero se incluyeron a los Sujetos que tenían una edad entre 19 y 31 años; en el segundo se incluyeron a los sujetos entre los 32 y los 37 años; y en el tercero a las personas que tenían entre los 38 y los 65 años. Después e hizo una Análisis de Varianza tomando como VI a los Grupos de Edad y como VD a los valores de: trascendencia, autopromoción, conservación y apertura. Sólo se encontraron diferencias significativas para el valor de apertura $(\mathrm{F}=22.3 ; \mathrm{p}<.=.00)$. 
Se encontró que el grupo de los más jóvenes era el que tenía una mayor Apertura, seguido de grupo de edad entre 32 y 37 años y el de 38 y 65, habiendo también diferencias significativas entre estos dos grupos a favor de los Sujetos con menos edad.

n) Prueba $T$ de diferencia de medias entre zona y valores. (transcendencia, apertura al cambio, autopromoción y conservación).

En función de las diferentes zonas en las que se ha obtenido la muestra (Norte, Centro) en nuestros datos se han encontrado diferencias significativas para los valores de: Trascendencia $(\mathrm{t}=4,5 ; \mathrm{p}<.00)$ y para Apertura $(\mathrm{t}=2,7 ; \mathrm{p}<.00)$, siendo ambas diferencias favorables a las personas de la Zona Centro.

o) Prueba $T$ de diferencia de medias entre experiencia y valores. (Transcendencia, apertura al cambio, autopromoción y conservación).

La única diferencia que sale significativa se produce en el valor de apertura al cambio. Las personas que tienen una mayor experiencia también tienen una mayor apertura $(\mathrm{t}=3.1 ; \mathrm{p}<.00)$. Una explicación alternativa sería que la experiencia aparentemente produjera diferencias cuando la variable que realmente las produce es la edad, pero podemos con nuestros datos podemos descartar esta hipótesis ya que la asociación entre experiencia y edad para nuestra muestra carece de significación.

\section{4.- ANALISIS DE REGRESION}

\section{PARA ZONA NORTE/ ZONA CENTRO PENINSULAR}

a) Análisis de Regresión en el que las variables independientes fueron Autoeficacia, LCI, LCE, Proactividad, Riesgo e Iniciativa y la variable dependiente la Intención laboral para Empresa Privada.

Para comprobar la influencia de las variables Autoeficacia, Locus de Control Interno, Locus de Control Externo, Proactividad, Riesgo e Iniciativa sobre la intención laboral en empresa privada se realizó un análisis de regresión. Los datos encontrados nos dicen que el modelo es significativo $\left(\mathrm{F}=2.63 ; \mathrm{p}=.01 ; \mathrm{R}^{2}=0.03\right)$. Dentro del modelo, 
las variables que explicaban una cantidad significativa de varianza en las puntuaciones sobre la Intención Laboral en empresa privada fueron el Locus de Control Interno $(\mathrm{t}=3.0 ; \mathrm{p}<.00)$ y la Proactividad $(\mathrm{t}=2.5 ; \mathrm{p}=.01)$.

$\mathrm{ZN}$ : Los datos encontrados nos dicen que el modelo es significativo ( $\mathrm{F}=3.1$; $\left.\mathrm{p}=.00 ; \mathrm{R}^{2}=0.08\right)$. Dentro del modelo, las variables que explicaban una cantidad significativa de varianza en las puntuaciones sobre la Intención Laboral en empresa privada fueron el Locus de Control Interno $(\mathrm{t}=2.6 ; \mathrm{p}=.00)$ y la Proactividad $(\mathrm{t}=1.2$; $\mathrm{p}=.03)$.

ZC: Los datos encontrados nos dicen que el modelo no es significativo ( $\mathrm{F}=0.91$; $\left.\mathrm{p}=.4 ; \mathrm{R}^{2}=.02\right)$

b) Análisis de Regresión en el que las variables independientes fueron Autoeficacia, LCI, LCE, Proactividad, Riesgo e Iniciativa y la variable dependiente la Intención laboral para Empresa Pública

Para comprobar la influencia de las variables Autoeficacia, Locus de Control Interno, Locus de Control Externo, Proactividad, Riesgo e Iniciativa sobre la intención laboral en empresa pública se realizó un análisis de regresión. Los datos encontrados nos dicen que el modelo es significativo $\left(\mathrm{F}=5.8 ; \mathrm{p}<.00 ; \mathrm{R}^{2}=0.07\right)$. Dentro del modelo, las variables que explicaban una cantidad significativa de varianza en las puntuaciones sobre la Intención Laboral en empresa pública fueron la Autoeficacia $(\mathrm{t}=3.0 ; \mathrm{p}<.00)$ y el Locus de Control Interno ( $\mathrm{t}=2.2 ; \mathrm{p}=.02)$.

$\mathrm{ZN}$ : Los datos encontrados nos dicen que el modelo es significativo $(\mathrm{F}=4.8$; $\left.\mathrm{p}<.00 ; \mathrm{R}^{2}=.11\right)$. Dentro del modelo, sólo la Autoeficacia $(\mathrm{t}=2.62 ; \mathrm{p}<.00)$ y el Locus de Control Externo (t=2.0; $\mathrm{p}=.04)$ explicaban una parte significativa de la varianza.

ZC: Los datos encontrados nos dicen que el modelo no es significativo ( $F=1.6$; $\left.\mathrm{p}=.09 ; \mathrm{R}^{2}=.04\right)$

c) Análisis de Regresión en el que las variables independientes fueron Autoeficacia, LCI, LCE, Proactividad, Riesgo e Iniciativa y la variable dependiente la Intención laboral para Administración Pública

Para comprobar la influencia de las variables Autoeficacia, Locus de Control Interno, Locus de Control Externo, Proactividad y Riesgo sobre la intención laboral en administración pública se realizó un análisis de regresión. Los datos encontrados nos dicen que el modelo es significativo $\left(\mathrm{F}=3.7 ; \mathrm{p}<.00 ; \mathrm{R}^{2}=0.09\right)$. Dentro del modelo, la 
única variable que explicó una cantidad significativa de varianza fue la Autoeficacia $(\mathrm{t}=2.9 ; \mathrm{p}=.01)$.

$\mathrm{ZN}$ : Los datos encontrados nos dicen que el modelo es significativo ( $\mathrm{F}=3.8$; $\left.\mathrm{p}<.00 ; \mathrm{R}^{2}=.09\right)$. Dentro del modelo, sólo la Autoeficacia $(\mathrm{t}=2.9 ; \mathrm{p}<.00)$ explicaba una parte significativa de la varianza.

ZC: Los datos encontrados nos dicen que el modelo es significativo $(\mathrm{F}=2.3$; $\left.\mathrm{p}=.04 ; \mathrm{R}^{2}=.05\right)$. Dentro del modelo no hay variables que expliquen una proporción significativa de varianza.

\section{d) Análisis de Regresión en el que las variables independientes} fueron Autoeficacia, LCI, LCE, Proactividad, Riesgo e Iniciativa y la variable dependiente la Intención laboral para Autoemplearse.

Para comprobar la influencia de las variables Autoeficacia, Locus de Control Interno, Locus de Control Externo, Proactividad y Riesgo sobre Intención de Autoempleo se realizó un análisis de regresión. Los datos encontrados nos dicen que el modelo es significativo $\left(\mathrm{F}=9.9 ; \mathrm{p}<.00 ; \mathrm{R}^{2}=0.11\right)$. Dentro del modelo, las únicas variables que explicaron una cantidad significativa de varianza fueron la Proactividad $(\mathrm{t}=2.6 ; \mathrm{p}=.01)$ y el Riesgo $(\mathrm{t}=3.2 ; \mathrm{p}<.00)$

$\mathrm{ZN}$ : Los datos encontrados nos dicen que el modelo es significativo ( $\mathrm{F}=2.7$; $\left.\mathrm{p}=.01 ; \mathrm{R}^{2}=.07\right)$. Dentro del modelo, sólo la Proactividad $(\mathrm{t}=2.5 ; \mathrm{p}=.01)$ explicaba una parte significativa de la varianza.

ZC: Los datos encontrados nos dicen que el modelo es significativo $(F=8.1$; $\left.\mathrm{p}<.00 ; \mathrm{R}^{2}=.17\right)$. Dentro del modelo, sólo el riesgo $(\mathrm{t}=3.1 ; \mathrm{p}<.00)$ explicaba una parte significativa de la varianza.

e) Análisis de Regresión en el que las variables independientes fueron Auto-transcendencia, Auto-promoción, Conservación y Apertura al Cambio, y la variable dependiente la Intención laboral para Empresa Privada.

Para comprobar la influencia de las variables Auto-transcendencia, Autopromoción, Conservación y Apertura al Cambio sobre la intención laboral en empresa privada se realizó un análisis de regresión. Los datos encontrados nos dicen que el modelo es significativo $\left(\mathrm{F}=7.6 ; \mathrm{p}=<.00 ; \mathrm{R}^{2}=0.06\right)$. Dentro del modelo, la única variable que explicó una cantidad significativa de varianza fue la Trascendencia $(\mathrm{t}=3.7 ; \mathrm{p}<.00)$. 
$\mathrm{ZN}$ : Los datos encontrados nos dicen que el modelo es significativo ( $\mathrm{F}=8.8$; $\left.\mathrm{p}<.00 ; \mathrm{R}^{2}=.13\right)$. Dentro del modelo, sólo la Trascendencia $(\mathrm{t}=3.8 ; \mathrm{p}<.00)$ explicaba una parte significativa de la varianza.

ZC: Los datos encontrados nos dicen que el modelo es significativo $(F=3.2$; $\left.\mathrm{p}=.01 ; \mathrm{R}^{2}=.05\right)$. Dentro del modelo, sólo la Promoción $(\mathrm{t}=2.6 ; \mathrm{p}=.01)$ explicaba una parte significativa de la varianza.

f) Análisis de Regresión en el que las variables independientes fueron Auto-transcendencia, Auto-promoción, Conservación y Apertura al Cambio, y la variable dependiente la Intención laboral para Empresa Pública.

Para comprobar la influencia de las variables Auto-transcendencia, Autopromoción, Conservación y Apertura al Cambio sobre la intención laboral en empresa pública se realizó un análisis de regresión. Los datos encontrados nos dicen que el modelo es significativo $\left(\mathrm{F}=11.7 ; \mathrm{p}<.00 ; \mathrm{R}^{2}=0.09\right)$. Dentro del modelo, las únicas variables que explicaron una cantidad significativa de varianza fueron la Trascendencia $(\mathrm{t}=5.7 ; \mathrm{p}<.00)$ la Apertura al Cambio $(\mathrm{t}=3.8 ; \mathrm{p}<.00)$.

$\mathrm{ZN}$ : Los datos encontrados nos dicen que el modelo es significativo $(\mathrm{F}=7.0$; $\left.\mathrm{p}<.00 ; \mathrm{R}^{2}=.11\right)$. Dentro del modelo, la Trascendencia $(\mathrm{t}=4.2 ; \mathrm{p}<.00)$ y la Apertura $(\mathrm{t}=2.1 ; \mathrm{p}=.03)$ explicaban una parte significativa de la varianza.

ZC: Los datos encontrados nos dicen que el modelo es significativo ( $F=4.0$; $\left.\mathrm{p}<.00 ; \mathrm{R}^{2}=.06\right)$. Dentro del modelo, la Trascendencia $(\mathrm{t}=2.9 ; \mathrm{p}<.00)$ y la Apertura $(\mathrm{t}=3.3 ; \mathrm{p}<.00)$ explicaban una parte significativa de la varianza.

g) Análisis de Regresión en el que las variables independientes fueron Auto-transcendencia, Auto-promoción, Conservación y Apertura al Cambio, y la variable dependiente la Intención laboral para Administración Pública.

Para comprobar la influencia de las variables Auto-transcendencia, Autopromoción, Conservación y Apertura al Cambio sobre la intención laboral en la Administración Pública se realizó un análisis de regresión. Los datos encontrados nos dicen que el modelo es significativo $\left(\mathrm{F}=11.1 ; \mathrm{p}<.00 ; \mathrm{R}^{2}=0.09\right)$. Dentro del modelo, las únicas variables que explicaron una cantidad significativa de varianza fueron la Trascendencia $(\mathrm{t}=5.5 ; \mathrm{p}<.00)$ la Apertura al Cambio $(\mathrm{t}=4.0 ; \mathrm{p}<.00)$. 
$\mathrm{ZN}$ : Los datos encontrados nos dicen que el modelo es significativo ( $\mathrm{F}=5.3$; $\left.\mathrm{p}<.00 ; \mathrm{R}^{2}=.08\right)$. Dentro del modelo, solamente la Trascendencia $(\mathrm{t}=3.5 ; \mathrm{p}<.00)$ explicó una parte significativa de la varianza.

ZC: Los datos encontrados nos dicen que el modelo es significativo ( $F=6.1$; $\left.\mathrm{p}<.00 ; \mathrm{R}^{2}=.09\right)$. Dentro del modelo, la Trascendencia $(\mathrm{t}=3.5 ; \mathrm{p}<.00)$ y la Apertura $(\mathrm{t}=4.2 ; \mathrm{p}<.00)$ explicaban una parte significativa de la varianza.

h) Análisis de Regresión en el que las variables independientes fueron Auto-transcendencia, Auto-promoción, Conservación y Apertura al Cambio, y la variable dependiente la Intención laboral para Autoemplearse.

Para comprobar la influencia de las variables Auto-transcendencia, Autopromoción, Conservación y Apertura al Cambio sobre la intención laboral de Autoempleo se realizó un análisis de regresión. Los datos encontrados nos dicen que el modelo es significativo $\left(\mathrm{F}=2.73 ; \mathrm{p}=.01 ; \mathrm{R}^{2}=0.03\right)$. Dentro del modelo, la única variable que explicó una cantidad significativa de varianza fue la Apertura al Cambio $(\mathrm{t}=3.4$; $\mathrm{p}<.00)$.

$\mathrm{ZN}$ : Los datos encontrados nos dicen que el modelo es significativo $(\mathrm{F}=3.9$; $\left.\mathrm{p}<.00 ; \mathrm{R}^{2}=.07\right)$. Dentro del modelo, la Trascendencia $(\mathrm{t}=2.3 ; \mathrm{p}=.02)$ y la Apertura $(\mathrm{t}=2.2 ; \mathrm{p}<.02)$ explicaban una parte significativa de la varianza.

ZC: Los datos encontrados nos dicen que el modelo es significativo $(F=4.5$; $\left.\mathrm{p}<.00 ; \mathrm{R}^{2}=.07\right)$. Dentro del modelo, solamente la Apertura explica una parte significativa de varianza $(\mathrm{t}=3.3 ; \mathrm{p}<.00)$.

\section{5.- DISCUSION Y CONCLUSIONES}

En relación a la primera hipótesis, respaldando los resultados obtenidos a partir de la diferencia de medias, encontramos que la intención de autoemplearse correlaciona de forma significativa y positiva con Autoeficacia, LCI, Proactividad, Riesgo e Iniciativa personal. No encontramos una correlación significativa con LCE pero sí se observa que la dirección de esta es negativa, tal como estipulamos en nuestras hipótesis. Se cumplen todas nuestras hipótesis en relación a las variables personales excepto la hipótesis 1c. 
Como se observa en el apartado "j”" de correlaciones entre valores e intención, éstas son heterogéneas en la condición de autoempleo, lo cual es otra evidencia de que los valores propuestos por Schwartz no nos permiten discriminar un patrón específico y característico de los emprendedores con mayor intención emprendedora. Los grupos de alta intención puntúan más alto en el valor Transcendencia de forma significativa en relación al grupo de baja intención emprendedora. Se encuentra únicamente una correlación significativa y positiva entre la intención de autoempleo y la Trascendencia, siendo esta muy baja (.099). No obstante, puede haber aspectos moduladores que interfieren o median aquí y no hemos valorado. Schwartz propone que todos los valores existen en nuestro comportamiento pero predominan unos más que en otros. Esta predominancia está condicionada a causas externas que pueden provocar que en un momento dado predominen unos más que otros. El sistema de valores es un sistema circular y mixto, ya que en relación a esta primera característica, cada valor determina la conducta. En relación al carácter mixto de estos valores, vemos que las correlaciones en relación a la Trascendencia son mayores en los individuos con mayor intención de trabajo en empresa o administración pública, lo que es coherente con el modelo ya que se relaciona con el estatus quo, con la seguridad.

Así, siguiendo nuestro hilo argumental en estas conclusiones bajo el paraguas de las hipótesis planteadas, cabe hablar del apoyo empírico que obtenemos a nuestra tercera hipótesis. Recordemos que ésta postulaba que determinado marco sociodemográfico contribuiría al mantenimiento de la intención de emprender. Con marco socio-cultural o socio-demográfico nos referimos a los siguientes elementos analizados: zona, edad, sexo y experiencia laboral. Hemos encontrado relaciones interesantes entre las variables de personalidad y los valores propuestos (apartado h de las correlaciones). Una mayor Autoeficacia correlaciona con una menor consideración de la Transcendencia (-.132), así con mayor importancia a la Promoción (.123) y mayor Apertura al Cambio (.171). Mayor LCI plantea relaciones con Promoción (.174) y Apertura (.160). Por otra parte, el LCE nos muestra relaciones significativas con Promoción (.127) y Conservadurismo (.106). En cuanto a la Proactividad, la Promoción (.306), el Conservadurismo (.154) y Apertura al Cambio (.363) correlacionan significativamente. El riesgo lo hace con los valores Promoción (.112) y Apertura al Cambio (.331). Finalmente, hablamos de que las puntuaciones altas en Iniciativa 
personal valorarán como más importantes en cierta medida los valores Transcendencia (.140), Promoción (.332), Conservación (.253) y Apertura al Cambio (.385).

Concretando más, nos interesaba averiguar si según la zona en la que se reside se poseen ciertos valores o un perfil de personalidad característico de los emprendedores, éstos contribuyen favorablemente al mantenimiento de esa intención en nuestra muestra de emprendedores. Se evidencia empíricamente a partir de nuestros datos la siguiente tendencia: la zona geográfica en la que se desarrolla la actividad emprendedora produce diferencias en las variables de Autoeficacia y LCI, favorable a los sujetos de la Zona Norte. Así, vemos que la ubicación geográfica sí son factores que contribuyen al desarrollo de un perfil emprendedor más característico. Podemos pensar que estas diferencias se deben a las ayudas o subvenciones que se otorgan en las diferentes comunidades, a la educación que se recibe, a un aprendizaje vicario, factores que, en definitiva, son resultado de la propia cultura local; es decir, mediante su acción su acción o efecto repercuten en la propia cultura emprendedora. Asimismo, podríamos destacar el papel básico que aquí juegan las diferentes instituciones políticas y sociales, las propias políticas de empleo y las redes sociales.

Las instituciones relacionadas con aspectos sociales y culturales de la sociedad cumplen un papel muy importante respecto a la orientación emprendedora de la sociedad y a la creación y promoción del perfil emprendedor. El aumento del desarrollo del emprendimiento en una sociedad pasa porque las instituciones mejoren los posibles elementos estructurales que puedan ser desfavorables para el mismo, como el miedo o la poca capacidad de asumir riesgos. Una de las principales instituciones sociales es la educativa, la cual debe considerar como clave el emprendimiento.

El fomento de una buena educación empresarial, desde los niveles de educación secundaria y fundamentalmente universitaria, contribuye sustancialmente a modificar los esquemas cognitivos de gestión del riesgo e incertidumbre, reduciendo la aversión a ellos y aumentando la propensión a luchar por ideas innovadoras ( $\mathrm{Wu}, \mathrm{S}$, Sizong; $\mathrm{Wu}$, S., Lingfei (2008); Informe GEM, 2011).

Se trata de ascender, a través de las instituciones sociales, a la innovación como pilar de la cultura, para conseguir una sociedad en la que se valore positivamente la 
creatividad y la puesta en práctica de actividades empresariales, de que las instituciones potencien de este modo el perfil emprendedor a través del conocimiento, la cultura y los valores concretos asociados a la innovación. El desarrollo de estas habilidades empresariales influirá en la capacidad de asumir iniciativas y posturas competitivas en el mercado, sintiéndose los individuos capacitados para llevarlas a cabo. Si además se cuenta con un adecuado sistema de incentivos y programas de apoyo empresarial para la implantación y desarrollo de las ideas y proyectos innovadores, los valores emprendedores calarán más en el tejido social (Gómez, S., Delgado, J. y Vidal M.D. (2010).

Las Políticas Activas de Empleo entendidas como el conjunto de actuaciones públicas desarrolladas para aumentar el número de puestos de trabajo y mejorar su calidad y el bienestar de los trabajadores, pueden contribuir a reorientar la realidad laboral. Las medidas implementadas por las Políticas Activas de Empleo afectan a diferentes áreas laborales, y entre ellas, al fomento del empleo a través del desarrollo de iniciativas emprendedoras y a la valoración de los recursos humanos como creadores de empleo desde el punto de vista del emprendimiento. Sin embargo, hasta el momento, la mayor parte de las políticas de empleo se limitan a desarrollar medidas que incentivan el desarrollo de las iniciativas ya establecidas, pero que poco contribuyen a la puesta en marcha de nuevos proyectos emprendedores. Un cambio en la reorientación de las mismas podría contribuir a remover los valores laborales y sociales que suponen un obstáculo para el surgimiento de iniciativas emprendedoras (Galindo, P., 2003).

Teniendo en cuenta los datos expuestos anteriormente (en: análisis de regresión d), encontramos que la proactividad para la Zona Norte y la asunción de riesgos para la Zona Centro-Peninsular, explican una parte significativa de la varianza para "predecir" la intención de autoempleo. Estableciendo una comparativa con el resto de opciones de intención laboral, vemos que para una Empresa Privada (apartado "a" de Análisis de Regresión”), quizás si cabe la alternativa más cercana al autoempleo como vemos en el apartado "i" de las correlaciones, la proactividad y el LCI explican una cantidad significativa del modelo planteado. La Zona Centro Peninsular para este modelo no aporta datos significativos. Así, encontramos que ciertas variables de personalidad que encontramos en nuestros sujetos emprendedores, se encuentran de otra forma en la intención de trabajar en la empresa privada según la zona a la que se pertenezca. 
Podemos destacar a este respecto que las correlaciones entre la intención de autoemplearse (en la intención de mantener su negocio en este caso ya que hablamos de individuos emprendedores) y las demás alternativas de intención laboral sólo se obtiene una relación positiva y significativa entre Autoempleo y Empresa privada, tal como adelantábamos. La relación entre la intención de autoempleo y la intención de trabajar en Empresa Pública o Administración pública son negativas y significativas, lo que nos conduce a afirmar, a modo de descripción y de futuros intereses de investigación, que a mayor intención de autoempleo, menor interés en trabajar en una Empresa o Administración Pública.

Respecto a nuestra hipótesis 3a para los valores, encontramos un patrón similar que es condescendiente con la apreciación que hacíamos en párrafos anteriores de que los valores de Schwartz no parecen adecuarse de la forma que esperábamos a nuestras hipótesis. Si bien, los resultados obtenidos en las correlaciones y los modelos de regresión propuestos también pueden llevarnos a pensar en que no es del todo descabellado seguir esta línea de investigación. Así, vemos que Apertura y la Transcendencia son variables significativas en el modelo planteado en el apartado de análisis de regresión para el Autoempleo en la Zona Norte. Por el contrario, solamente la Apertura aportaría resultados significativos para la Zona Centro-Peninsular. Así, a la luz de nuestros datos, podemos afirmar que se han encontrado diferencias significativas en Transcendencia y Apertura en favor a los individuos del Centro Peninsular. Volviendo así a plantear que sí se observan diferencias en el patrón de valores según la zona de procedencia.

Es manifiesto, pues, que la zona de pertenencia (hipótesis 3a) parece determinar el perfil de emprendedurismo que veníamos proponiendo. Debemos, no obstante, ser cautos y no categóricos ante tales afirmaciones, ya que la evidencia empírica no nos permite sino elucubrar sobre las relaciones que se establecen y las variables que determinan estas relaciones.

En el apartado 3b se postula que la edad influiría en los valores y la personalidad que venimos proponiendo como característicos de la intención de emprender. Parece que la edad es determinante en ciertas características, concretamente, para la tendencia a asumir riesgos y para la Apertura al Cambio. No obstante, no se han encontrado 
correlaciones significativas entre la edad y ninguna de las alternativas propuestas de intención laboral. Así, se dividió a los sujetos en tres grupos de edad, lo cual determinó que la Apertura al Cambio es, como cabría esperar, un valor más característico de los individuos emprendedores más jóvenes. Lo cual se refleja también en las correlaciones establecidas entre edad y valores, resultando correlaciones negativas y significativas entre edad y Trascendencia y edad y Apertura. En lo referente a las variables personalidad y la edad referimos en el apartado correspondiente diferencias significativas en Asunción de Riesgos. Las correlaciones entre la edad y las variables de personalidad así lo muestran también, estableciéndose correlación significativa y negativa entre estas dos variables. Verificamos, pues, que sí existen diferencias en el patrón de valores y de variables personales en relación a la edad.

Atendiendo a la hipótesis 3c, no se aprecian correlaciones significativas entre el sexo y la intención de emprender. No obstante, sí se producen diferencias significativas a favor de los hombres en Proactividad, Riesgo y Autoeficacia. Así como para los valores Trascendencia y Promoción son valorados de forma más alta en hombres y mujeres respectivamente. Con lo cual, se cumple parcialmente nuestra hipótesis, ya que hay diferencias en los perfiles según al sexo al que se pertenezca, aunque esto no parece determinar diferencias en intención emprendedora en nuestro estudio. Esto puede ser debido a variables socioeducativas y planteamos para futuras investigaciones que variará en relación a variables generacionales.

Por último, la hipótesis 3d postula que la experiencia laboral influirá en valores y perfil de personalidad. No obstante, encontramos correlaciones significativas y positivas entre la experiencia y LCI; así como entre experiencia y apertura se encuentra relación significativa y negativa. Este último dato confirma los datos anteriormente comentados: mayor Apertura en los individuos jóvenes emprendedores, ya que cabría esperar que una menor experiencia la poseerán los más jóvenes. Esto nos lleva a plantearnos la siguiente cuestión: ¿Es que cuanto más tiempo en el negocio menor Apertura al Cambio? Podemos pensar en un aspecto destacable de la mentalidad humana y es que todos conocemos la expresión "cualquier tiempo pasado fue mejor". Refleja esto la lógica de que nos vamos volviendo más cerrados al cambio, más conservadores podríamos pensar. Pero quizás este razonamiento debiera verificarse con una relación del estilo entre edad y conservadurismo o edad y conservadurismo, lo cual 
no resultó en nuestro estudio. ¿Podría deberse a la fiabilidad de nuestra escala? Aparentemente no, ya que obtuvimos un alfa de Cronbach de .737.

A priori, las relaciones que principalmente establecimos en nuestra hipótesis se cumplen. Sería arriesgado inferir, por la naturaleza de nuestros datos, categóricamente esto pero es determinante conocer la verdadera relación y dirección que poseen las variables. Usar correlaciones de Pearson nos ha permitido hablar de ligazón o concomitancia entre estas variables, no de causalidad, ya que como comentamos anteriormente la naturaleza de nuestros análisis no nos permite otras conclusiones más fuertes y generalizables.

Por tanto, partiendo de los resultados obtenidos, parece lógico pensar que ante una cierta propensión al riesgo y la personalidad proactiva tengamos un sujeto con una alta intención emprendedora que le permita desarrollar una intención firme en este campo. Pensamos que la influencia de otros factores, como la variabilidad de las puntuaciones correlacionadas, perturban los resultados obtenidos. Así, obtuvimos como esperábamos diferencias en el perfil de los emprendedores según la zona de pertenencia, por ejemplo.

España es un país muy complejo, a la par que rico en recursos diversidad lo que hacen que se pueden desarrollar muchas iniciativas desde diferentes zonas pero como afirma Galindo, P., (2003) muchas de sus regiones se caracteriza por tener asentados valores que obstaculizan las potencialidades posibilidades de desarrollo laboral y económico que pueden existir en la región (Informe GEM, 2011), tales como los valores vinculados a la primacía de la seguridad, la estabilidad, la pasividad y el inmovilismo, es decir aquellos que Schwartz, S.H., (1992) asocia a las dimensiones conservadora y jerárquica e Inglehart, R., (1991) a los valores materialista, frente a los que promueven la iniciativa, el logro, la valentía, el riesgo, la proactividad, la empleabilidad, la consustancia o la movilidad, valores integrados en las dimensiones autónoma e igualitaria Schwartzianas o a los valores postmaterialistas inglhartianos. 
En estas regiones se necesita un gran cambio de mentalidad a nivel cultural y social, ya que sin ese cambio que luche por modificar la cultura emprendedora existente, no se puede concebir el desarrollo económico; por lo que para conseguirlo se necesita una intervención de carácter eminentemente cultural hacia una cultura donde se valore la iniciativa y la mentalidad empresarial. Debemos abandonar la tradicional imagen del emprendedor hombre, asumiendo que la mujer puede y de hecho, lleva tiempo ejerciendo el rol de empresaria (Gutiérrez, P, Rodríguez, M.; Fuentes, M.; Ariza, L., 2009).

Estas áreas requieren de esta nueva cultura del emprendimiento para generar por un lado, individuos muy motivados a la par que cualificados para la creación de nuevas empresas, y por otro, los mecanismos necesarios que promuevan y apoyen las iniciativas empresariales. Hay que remover los valores, creencias y costumbres en las que se asientan estas regiones, para inculcar otros nuevos orientados hacia el emprendimiento. Este es el camino hacia la mejora del empleo y desarrollo socioeconómico. La promoción de la iniciativa privada es la fuente de desarrollo por excelencia, y hacia ella se debe orientar el cambio cultural.

La gestión del riesgo es el primer desafío que afrontan los emprendedores, ya que éste es un factor intrínseco del emprendimiento (McCarthey, B. (2000). La autoestima y el amor propio están estrechamente asociados a la toma de riesgo, de modo que una baja autoestima implicará la ausencia de decisiones que impliquen altos riesgos, no obstante, el riesgo no debe vincularse únicamente a la personalidad, sino que está estrechamente relacionado con el contexto (Ray, D., 1993).

Las teorías del aprendizaje social defienden que los roles paternos influyen en las decisiones de las carreras profesionales de sus hijos. En el caso del emprendimiento a título individual, este argumento se revalida, ya que existe una estrecha relación entre la ocupación de los padres y el desarrollo de las actitudes emprendedoras en sus descendientes, ya que dicha situación familiar contribuye a la reducción del riesgo percibido; pero no se establece tal relación en el caso de los emprendedores cooperativistas. Éstos tienden a caracterizarse por la ausencia de modelos empresariales paternos, lo que incrementa la sensación de riesgo y les lleva a la búsqueda de socios para aumentar la seguridad en la creación de la nueva empresa; de modo que la ausencia 
de patrones culturales y sociales empresariales en la familia es suplida por redes sociales de micro emprendedores que se apoyarán mutuamente en la implantación de las nuevas empresas, contribuyendo a reducir de este modo la sensación de riesgo empresarial (Díaz, J.C., Hernández, R. y Barata, M., 2007; Herrera, H., 2008).

El emprendimiento es un fenómeno social y como tal, está inmerso en las estructuras y redes sociales, las cuales afectan al mismo. Las redes sociales de emprendimiento contribuyen a la creación de nuevas empresas y al desarrollo y éxito de la actividad emprendedora, ya que a través de ellas los emprendedores pueden acceder a orientación, información, conocimiento así como otro tipo de recursos de carácter material; por lo que se convierten en fomentadoras del emprendimiento, ya que las dificultades o problemas iniciales que se encuentren los emprendedores pueden compensarse con los conocimientos y experiencias ya adquiridos por otros emprendedores. De este modo permiten el desarrollo del capital social, es decir, de las relaciones que contribuyan a proveer información, ya que hacen posible la interacción entre sujetos y entidades pudiendo generar relaciones de cooperación. Cabe también destacar que además de constituir una forma de apoyo social, influyen en la cultura general aumentado los valores orientados hacia el emprendimiento y establecen una serie de normas sobre el comportamiento aceptable, las cuales socializan al emprendedor (Díaz, J.C., Hernández, R. y Barata, M., 2007; Herrera, H., 2008).

Como ya hemos comentado en capítulos anteriores, hemos escogido ciertas variables de personalidad (autoeficacia, LCI, propensión al riesgo, comportamiento proactivo e iniciativa personal) como variables intrapersonales asociadas al desarrollo y mantenimiento de la intención emprendedora. Somos conscientes de que es una pequeña parte de las variables intrapersonales influyentes en la intención de emprender. No obstante, se realizaron análisis descriptivos de factores que pueden influir o mediar entre otras características en la intención de autoempleo. Estos factores son: motivos propios que los emprendedores consideran importantes a la hora de emprender, recursos que consideran necesarios, dificultades $u$ obstáculos que serían o no incapacitantes y lo que hemos llamado "variables circunstanciales".

Vemos, pues, que la dirección de los análisis correlacionales en cuanto a los motivos propios es significativa y positiva de forma heterogénea en las variables que 
estudiamos. Los motivos poder y prestigio, éxito personal, placer, novedades y cambios, conseguir independencia, salir de la rutina, realización personal, obtener una mayor libertad y mayor seguridad laboral se relacionan de forma positiva con las variables personales analizadas. Así, atendiendo a esta dirección, el motivo calificado como "Emprender como último recurso" correlaciona de forma negativa con Autoeficacia y Riesgo. A este respecto, acontece actualmente una grave crisis socioeconómica mundial en la que la creación de empleo, la productividad y la competencia son factores principales para el resurgir de la sociedad del bienestar. El Informe GEM 2011 en España desvela el crecimiento del emprendedurismo en nuestro país durante este último período de tiempo. La tasa emprendedora en 2010 fue de 4.3\%, sin embargo en 2011 se obtuvo un porcentaje mayor, $5.8 \%$. No obstante, este dato que a simple vista puede parecer alentador lleva de la mano una apreciación alarmante: se refleja una peor calidad de emprendimiento y un gran riesgo de temporalidad. La dirección del Informe GEM nos explica que no son proyectos innovadores que modernicen nuestro mercado laboral sino que vienen determinados por la necesidad de empleo y que, de hecho, es la causa de este repunte y no de un aumento de la vocación emprendedora (Informe GEM, 2011).

Por otra parte, se analizó, a partir de correlaciones Pearson, la relación entre las variables personales y los recursos que se apreciaban como necesarios a la hora de emprender. Vemos de igual forma que hay relaciones interesantes (apartado e de las correlaciones) y que pueden ayudarnos a investigar estos aspectos en el futuro. Los recursos analizados son: formación, experiencia, recursos propios, recursos ajenos, ser creativo, capacidad de previsión, intuición, captación de oportunidades, esfuerzo, confianza en las propias capacidades, asunción de riesgos, tener iniciativa y una familia empresaria.

Los obstáculos fueron evaluados a fin de determinar cuáles son las barreras más comunes que se consideran importantes en base a los factores personales. Como es de esperar, un mayor LCE se desarrolla o relaciona con aspectos que escapan al control del individuo como la falta de apoyo social, la falta de experiencia y la burocracia. Esto debiera estudiarse más profundamente a fin de acondicionar el apoyo micro y macro social a estos elementos. Todo esto radicará en una toma de conciencia social y personal que se debe trabajar en niveles primarios de educación a fin de garantizar una red de 
recursos amplia para el emprendedurismo, base del crecimiento de un país. Un país se sostendrá si se premia y garantiza el desarrollo personal y el enriquecimiento socioeconómico, formando estos proyectos pilares básicos y fuertes que a su vez generarían una mayor satisfacción inter e intrapersonal. Como vemos, tratamos la posibilidad de emprender en su implicación máxima en el desarrollo socioeconómico a nivel estatal.

Por último, se relacionaron los factores personales con las llamadas "variables circunstanciales" en nuestros análisis. Así, el desempleo correlacionaría con LCE de forma positiva. Esta dirección nos permite sostener la necesidad de ampliar el campo de estudio para determinar la calidad del emprendorismo, tal como adelantábamos en párrafos anteriores.

Lo determinante de este aspecto es qué papel o función y en qué dirección funcionan estas variables como predictoras de la formación de la intención o del mantenimiento de ésta. Sería interesante que en otros estudios se examinara el papel de procesos psicológicos básicos como la motivación o la percepción (en cierta forma examinada aquí en aspectos de autoeficacia y propensión al riesgo). Además, aspectos de la personalidad como el documentado patrón tipo A. Dicha personalidad se caracteriza por una extrema competitividad, motivación de logro, agresividad (algunas veces contenida con esfuerzo), apresuramiento, impaciencia, inquietud, hipervigilancia, expresividad en el habla, tensión en los músculos faciales, sensación de estar bajo presión y el desafío con la responsabilidad. Las personas que tienen este patrón están usualmente entregadas a su vocación o su profesión, mientras que son relativamente descuidados en otros aspectos de su vida. Parece interesante examinar este tipo de "esquema" en tiempos de crisis. Como vemos, hay un sinfín de variables que pueden estar influyendo en el perfil del emprendedor.

En aras de ampliar nuestro campo de estudio se recogieron los datos pertenecientes a los valores socioculturales que se postulan desde el modelo de Schwartz. La heterogeneidad que encontramos coincide con las principales críticas que se realizan al modelo. Así, un perfil mixto podemos pensar que no es lo idóneo para el tratamiento de las diferentes consecuencias en juego, ya que pensamos que los valores determinan nuestras actitudes de forma directa. Por tanto, es necesario que se amplíe 
esta conceptualización en el siguiente sentido: ¿hay un perfil de valores característico para los emprendedores más eficaces?. Esto nos llevaría a analizar cuáles son estos emprendedores y en base a qué criterios los consideraríamos eficaces (capacidad de liderazgo, comunicación, rendimiento, productividad...). Y, siguiendo este mismo razonamiento, en caso de que esos emprendedores compartan un perfil de valores y características podríamos hablar de un emprendorismo de mayor calidad, así como más satisfactorio y que ayude al mantenimiento de la idea de negocio.

El objetivo de estos estudios debe ser determinar exhaustivamente cuáles son estas variables (tanto personales como socioculturales), de forma que nos permita educar a la sociedad en base a estos aspectos que permitan el crecimiento del país. Las instituciones económicas, sociales y políticas deben favorecer la creación y consolidación de redes que faciliten el evento emprendedor, no sólo, aunque sí principalmente, a los jóvenes desde los niveles educativos básicos. Es decir, el foco de atención debe centrarse en plantear un modelo que explique cómo se modulan entre sí los aspectos psicológicos y sociológicos de la intención emprendedora. Así, se abren las puertas a múltiples opciones de investigación que se apoyen en la base que se está cimentando en los estudios del campo. 


\section{BIBLIOGRAFIA}

Academia Española (1992). Diccionario de la Real Academia de la Lengua Española (RAE), $21^{\text {a }}$ Edición, Madrid, 571.

Academy of Management. (2010): Entrepreneurship general information. Retrieved 07/25, 2010, from http://division.aomonline.org/ent/EntprDivGenInfo.htm.

Acs, Z., Braunerhjelm, P., Audretsch, D., y Carlsson, B. (2009): The knowledge spillover theory of entrepreneurship, Small Business Economics, vol. 32, $\mathrm{N}^{\mathrm{o}} 1$, $15-30$.

Acs, Z.J., Arenius, P., Hay, M. y Minnity, M. (2004): Global Entrepreneurship monitor 2004 executive report. Babson College, London Business School.

Adorno, T. W. (1986). Cultura y administración. Sociológica. Edit Taurus, Madrid, España, 1986.

Allinson, CH.W;Chell, E. y Hayes, J. (2000).Intuition and entrepreneurial behavior, European Journal of Work and Organizacional Psychology,9(1), 31-43 [on ligne] .http://www.tandf.co.uk/journals/pp/1359432X.html.

Allport, G.W. (1935) Handbook of social psychology, Worcester, Clark University Press.

Adelung, J. C. (1955). Ensayo sobre la historia de la cultura de la especie humana, Barcelona, Editorial Lumen.

Adler, P. y Kwon, S. (2002). Social capital: prospects for a new concept. Academy Management Review, 27(1), 17-40.

Adorno (2009). Escritos sociológicos II. Volumen 1, Ediciones Akal,

Ajzen, I. y Fishbein, M. (1980). Understanding attitudes \& predicting socialbehavior.

Englewood Cliffs, NJ: Prentice-Hall. En Alonso, J.M. y Galve, C., (2008). El emprendedor y la empresa: una revisión teórica de los determinantes a su constitución, Acciones e Investigaciones Sociales, vol.26, 5-44.

Ajzen, I. (1991): The Theory of Planned Behavior, Organizational Behavior and Human Decision Processes, vol. 50, $\mathrm{N}^{\circ} 2,179-211$.

Alanís Huerta Antonio y Díaz Mendoza Raúl F. (1992-93). El curriculum del posgrado: efectividad administrativa y cultura organizacional". Pistas Educativas. ITC. Dic.19 92- Ene. y Feb. 93. 
Albertos, J.M. (2003). Cultura, innovación y desarrollo local. Boletín de la AGE, 34, 229-244.

Albors G., Hervas, O., Hidalgo, J.L., y Nuchera, , A., (2009. Analysing high technology adoption and impact within public supported high tech programs. empirical case. Journal of High Technology Management Research, 20 (2). 153 $-168$.

Albors, J., y Hidalgo, A. (2008). Transferencia tecnológica en programas públicos de cooperación universidad-empresa. Propuesta de un modelo basado en evidencias empíricas. Dirección Organización, (35), y 116 -124.

Aldrich, H. y Ruef, M. (2006). Organizations evolving (2nd ed.). London: Sage.

Aldrich, H.E., Zimmer E.R. (1986). Entrepreneurship through social network. In The Art and Science of Entrepreneurship, Sexton DL, Smilor RW (eds) Ballinger: Cambridge Publishing Co. MA, 3-24.

Amin, A., y Thrift, N. (2000). What kind of economic theory for what kind of economic geography?, Antipode, No 32, 4-9.

American Anthropologiy and Ethnology (1957). Vol. 47, No. 1283 y ss.

Andreu Pinillos J.C. (1998). La empresa Joven ante el reto del 2000. Dificultades para crear riqueza y empleo. Ponencia presentada en IV Congreso Nacional de Jóvenes Empresarios. Pontevedra. Mayo. Documento Inédito AJE Madrid.

Andrés Ciurana, B. y Montesa Andrés, E. (1994): Manual para emprendedores. Valencia: CEPYMEV, 22-23.

Appadurai, A. (2001). La Modernidad Desbordada, dimensiones culturales de la Globalización, Trilce Fondo de Cultura Económica.

Asch, S. (1952). Psicología Social, New York Press.

Bandura, A. (1997). Self-Efficacy: The Exercises of Control. New York: Freeman.

Bandura, A. (1991). Social Cognitive Theory of Self-Regulation, Organization al Behavior and Human Decision Processes, vol. 50, 248-287.

Bandura, A. y Wood, R. (1989): Effect of perceived controllability and performance standards on the self-regulation of complex decision making. Journal of Personality y Social Psychology, vol. 56, 805-814.

Bandura, A. (1986). The Social Foundations of Thought and Action.Englewood Cliffs. NJ: Prentice-Hall.

Baró, M, (1989). Sistema, grupo y poder. El Salvador: UCA. 
Baron, R. A. (2008): The role of affect in the entrepreneurial process, Academy of Management Review, vol. 33, $N^{o} .2,328-340$.

Baron, R. A. (2006a). Opportunity recognition as pattern recognition. How entrepreneurs connect the dots to identify new business opportunities. Academy of Management Perspectives, 20 (1), 104-119.

Baron, R.A.; Ensley, M.D. (2006b): Opportunity Recognition as the Detection of Meaningful Patterns: Evidence from Comparisons of Novice and Experienced Entrepreneurs. Management Science, vol.52,Nº 9, September, 1331-1344

Baron, R. A., y Markman, G. D. (1999). Cognitive mechanisms: Potential differences between entrepreneurs and non-entrepreneurs. In P. D. Reynolds, W. D. Bygrave, et al. (Eds.), Frontiers of Entrepreneurship Research. Wellesley, MA: Babson College.

Baron, R. A. (1998).Cognitive mechanism in entrepreneurship: why and when entrepreneurs think differently than other people. Journal of Business Venturing, $13,275-294$.

Baron, R. A. (1991). Motivation in worksettings: Reflections on the core of organizational research. Motivation and Emotions, 15, 1-43.

Barnes, J.H., Jr., (1984). Cognitive biases and their impact on strategic planning. Strategic Management Journal, 5, 129-137.

Baum, J. R. y Locke, E. A. (2004).The relationship of entrepreneurial traits, skill, and motivation to new venture growth. Journal of Applied Psychology, 89(4), 587598.

Baumol, W.J., Litan, R.E. y Schramm, C.J. (2009) Good capitalism, bad capitalism, and the economics of growth and prosperity, New Haven, CT: Yale University Press.

Baumol, W. J. (1990). Entrepreneurship: productive, unproductive and destructive. Journal of Political Economy, 98, 893-921.

Baumol, W. J. (1968). Entrepreneurship in economic theory. American Economic Review, vol.58, no.2,64.

Basabe, N., Páez, D., Valencia, J. González, J.L. Riné, B., y Diener, E. (2002). Cultural dimensions, socioeconomic development, climate and emotional hedonic level. Cognition and Emotion, vol (2), 12-25.

Baztan, A. (2004). La cultura de las organizaciones, Barcelona editorial Ariel.

Béjar, H. (1993). La cultura del Yo. Madrid Alianza Editorial. 
Béjar, (1979). Cultura nacional y cultura popular, Madrid Alianza Editorial.

Benedict Ruth. (1948). Patterns of culture. Boston, Houghton Mifflin Company,

Bird, B. (1988).Implementing entrepreneurial ideas: The case of intention. Academy of Management Review, 13. $442-453$.

Boas, F. (2008), Franz Boas: textos de antropología, Editorial Centro de Estudios Ramón Areces, Madrid.

Bonnett, C. y Furnham, A., (1991). Who wants to be an entrepreneur? A study of adolescents interested in a young enterprise scheme. Journal of Economics Psychology, 12, 465-478.

Brice, J., Jr. (2002). The role of personality dimensions and occupational preferences on the formation of entrepreneurial intentions.Unpublished doctoral dissertation, Mississippi State University.

Bouckenooghe, D., Van den Broeck, H., Cools, E. y Vanderheyden, K. (2005). In search for the heffalump: An exploration of the cognitive style profiles among entrepreneurs. Journal of Applied Management and Entrepreneurship, 10(4), 5875.

Bretones, F. y Silva, M. (2009). Cultura, sociedad, educación y comportamiento Emprendedor, en Comportamiento emprendedor en el ámbito universitario. Personas y sociedad. Granada: Editorial Universidad de Granada, 4.

Brice, J. (2004). The role of personality dimensions on the formation of entrepreneurial intentions. Hempstead. Departament of Management, Entrepreneurship, and general Business, Hostra University.

Brice, J., Jr. (2002). The role of personality dimensions and occupational preferences on the formation of entrepreneurial intentions. Unpublished doctoral dissertation, Mississippi State University.

Brockhaus, R. y Horwitz, P. (1986). The psychology of the entrepreneur. EnSixton, D., Smilor R. (Eds) The art and science of entrepreneurship. 25-48.

Brockhaus, R.H. (1982). The psychology of the entrepreneur in C.A. Kent, D.L.Sexton y K.H. Vesper (eds) . Enciclopedia of Entrepreneurship, 39-71.

Brockhaus, R.H. y Nord, W.R. (1979). An exploration of factors affecting Theentrepreneurial decision: Personal characteristics versus environmentalconditions. Proceedings of the 39th Annual Meeting of the Academy of Management, 386-373.

Brodsky, M.A. (1993). Successful Female Corporate Managers and Entrepreneurs, 
Group et organization Management. 18 (3), 366-378.

Brown, R., (1988), Group process: Dynamics within and between groups, Oxford Nueva York, Basil Blackwell.

Bruton, G.D., Ahlstrom, D. y Li, H-L. (2010). Institutional theory and entrepreneurship: Where are we now and where do we need to move in the future? Entrepreneurship Theory and Practice, vol. 34, $N^{o}$. 3. 421-440.

Burt, R. (1992). Structural Holes: The Social Structure of Competition. Cambridge, M.A.: Harvard Business Press.

Busenitz, L. W., (1999). Entrepreneurial risk and strategic decision making: it's a matter of perspective. Journal of Applied Behavioural Science, 35(3), 325-340.

Busenitz, L., y Barney, J. (1997): Differences between entrepreneurs and managers in large organizations: Biases and heuristics in strategic decisionmaking, Journal of Business Venturing, vol.12. 9-30.

Butler, J. y Hansen, G. (1991). The network evolution, entrepreneurial success, and regional development. Entrepreneurship and Regional Development, 3, 1-16.

Bygrave, W., y Minniti, M. (2000). The social dynamics of entrepreneurchip. Entrepreneurship Theory and Practice, 25, 25-42.;

Buxíó i Rey, (1984).La Cultura en el ámbito de la cognición, en Mercedes Fernández M. (Coord.) Sobre Concepto de Cultura, Ed. Mitre, 1984. 13.

Bygrave, W. y Hofer, C. (1991). Theorizing about entrepreneurship. Entrepreneurship Theory and Practice, 16(2), 13-22.

Cantillon, R. (1755). Essai sur la nature du commerce en general. New York: August M. Kelly Publishers.

Capelleras, J., Mole, K.F., Greene, F.J. y Storey, D. (2008). Do more heavily regulated economies have poorer performing new ventures? Evidence from Britain and Spain', Journal of International Business Studies, vol. 39.688-704.

Cárdenas, G. (2008): Diccionario de Ciencias Económico Administrativas. Edición Universidad de Guadalajara, Quinta edición, México, pp. 782.

Carland J.W. Boulton, W.R. y Carland, J.A.C. (1984).Differentiating entrepreneurs from small business owners: a conceptualization. Academy of Management Review 9 (2), 354-359.

Carsrud, A.L., y Johnson, R.E. (1989). Entrepreneurship: a social psychological Perspective. Entrepreneurship and Regional Development, Vol. 1, 21-31. 
Cassis, Y. Papelasis, I. (2005).Entrepreneurship in theory and history: State of the art and new perspectives. En Y. Cassis y I. Papelasis (Eds.), Entrepreneurship in Theory and History (3-21).

Casson,M.C.(1982).The Entrepreneur: An Economic Theory. Oxford: Martin Robertson.

Cateora, P.R., y Graham, J.L., (2001). Marketing International . Irwin, McGraw Hill.

Cayón, A. y Pérez, E. (2008). Estructura de valores de Schwartz en el personal directivo. Telos, Vol. 10, No. 3, 403-417.

Chell, E. (2000). Towards researching the "opportunistic entrepreneur': Asocial constructionist approach and research agenda. European Journal of Work and Organizacional Psychology 9 (1).

Chell, E., Haworth, J. y Brearley, S. (1991a). The entrepreneurial personality. London: Routledge. Small Business Series.

Chell, E., Haworth, J. y Brearley, S. (1991b). The Entrepreneurial Personality. Routledge, London.

Chen, C. P., Greene y A. Crick (1998). Does entrepreneurial self-efficacy distinguish entrepreneurs from managers? Journal of Business Venturing, 13(4), 295-316.

Choo, Chun Wei. (2008). Cultures of Knowledge: The Information Dynamics of Organizational Learning. Oxford University Press, NY.

Chung, L. H., y Gibbons P. T., (1997). The roles of ideology and social capital. Group and Organization Management, 22, 10-30.

Círculo de Empresarios. (2009). El espíritu emprendedor: Elemento esencial para afrontar la crisis económica española. Madrid: Círculo de Empresarios.

Cochran, T. (1985). Entrepreurship. International Encyclopedia of Social Sciences.

Collins, C. J., Hanges P. J. y Locke E. A. (2004). The relationship of achievement motivation to entrepreneurial behaviour: A meta-analysis. Human Performance, 17(1), 95-117.

Collins, O.F. y Moore, D.G. (1970).The Organization Makers: A Study of Independent Entrepreneurs. New York: Meredith

Collins, O.F. y Moore, D.G. (1964).The Enterprising Man. East Lansign: Bureauof Business and Economic Research, Graduate School of Business Administration. Michigan State University-MSU.

Comisión Europea (2003). Libro verde - El espíritu empresarial en Europa. COM/2003/0027 final, Bruselas, 21.1.2003. 
Comisión Europea (2002). Las pymes en Europa. Observatorio de las pymes europeas 2002. Bruselas. 2003.

Consejo económico y Social (España), (2005). El proceso de creación de empresas y el dinamismo empresarial: sección ordinaria del Pleno de 21 de septiembre de 2005. ( $1^{a}$ ed.). Madrid: Consejo Económico y Social.

Coque, J.; López, N. y Loredo, E. J. (2007). Fomento de la cultura emprendedora e innovadora entre el alumnado universitario del campus politécnico de Gijón. Forum calidad, 177,42-50.

Cooper, A.C., Gimeno-Gascon, F.J., Woo, C.Y. (1994). Initial Human and Financial Capital as Predictors of New Venture Performance. Journal of Business Venturing, 9, 371-395.

Covin, J.G. y Miles, M.P. (2008). Strategic use of corporate venturing, Entrepreneurship Theory and Practice, vol. 31, No. 2, 183-207.

Covin, J. G. y Slevin, D. P. (1997). High growth transitions: Theoretical perspectives and suggested directions. In D. L. Sexton and R. Smilor (Eds.), Entrepreneurship 2000. Chicago: Upstart. 99-126.

Covin, J.G. y Slevin, D.P. (1991) 'A conceptual model of entrepreneurship as firm behavior', Entrepreneurship Theory and Practice, vol. 16, No 1. 7-25.11

Covin, J.G., Slevin, D.P. (1989). Strategic Management of Small Firms in Hostile and Benign Environments». Strategic Management Journal, 10, 75-87.

Cox, K.R., (1972). Man, Location and Behaviour. An Introdution to Human Geography. John wley and Sons new York.

Crant J. (1996): The proactive personality scale as a predictor of entrepreneurial Intentions.Journal of Small Business Management vol. 34, $N^{o} 3,42-49$; en Espíritu, R. y Santre, M. (2007).La actitud emprendedora durante la vida académica de los estudiantes universitarios. Cuadernos de Estudios Empresariales, vol. 17,95-116.

Cromie, S. y Johns, S. (1983). Irish entrepreneurs: Some personal characteristics. Journal of Occupational Behavior.4, 317-324.

Cunningham, B. Lischeron, J. (1991) Defining entrepreneurship. Journal of Small Business Management, 29(1), 45-61.

Curtis, Jack H., (1960). La Psicología Social., Madrid, Pirámide.

Davidsson, P. (2006). Nascent entrepreneurship: Empirical studies and developments. Foundations and Trends in Entrepreneurship, vol. 2, no. 1, 1-76. 
Davidsson, P., y Honig, B. (2003): The role of social and human capital among nascent entrepreneurs, Journal of Business Venturing, vol. 18, no. 3, 301-33

Davidsson, P., y Wiklund, J. (2001). Levels of analysis in entrepreneurship research: Current research practice and suggestions for the future. Entrepreneurship: Theory y Practice, vol. 25, no. 4, 81.

De Carolis, D. y Saparito, P. (2006). Social capital, cognition, and entrepreneurial opportunities: A theoretical framework. Entrepreneurship Theory Practice, 30(1), 41-56.

De Noble, A. F., De Noble, A. F., Jung, J. y Ehrlich, S. B. (1999). Entrepreneurial selfefficacy: the development of a measure and its relationship to entrepreneurial action. In P. D. Reynols, W. D. Bygrave, S. Manigart, C. M. Manson, G. D. Meyer, H. J. Sapienza y K. S. Shaver (Eds.). Frontiers of Entrepreneurship Research-1999.Wellesley MA: Babson College, 73-87.

Díaz, J.C., Hernández, R. y Barata, M. (2007): Estudiantes universitarios y creación de empresas. Un análisis comparativo entre España y Portugal. Ayala, J.C. (coord.) conocimiento innovación y emprendedores: Camino al futuro. Grupo FEDRA, Madrid. 1338-1355.

Diaz, J.C. (2003). La creación de empresas en Extremadura. Un análisis institucional, Tesis Doctoral. Universidad de Extremadura.

Díaz, J.C (2002) La creación de empresas. Revisión histórica de teorías y escuelas. Trujillo: Ediciones la Coria

Díaz, F., García, E., Ruiz, C., Jaimez, M. y Hernández, M.J. (2009). Actitudes, valores y comportamientos emprendedores en la población universitaria. II Congreso Internacional y X Seminario Iberoamericano Motiva "La universidad y el Emprendimiento", 27-30 de Octubre.

Donaldson, T. y Dunfee, T.W. (1994). Toward a unified conception of business ethics: Integrative social contracts theory. Academy of Management Review, 19, 252.284

Donaldson T.J., (1985). The Ethical Wealth of Nations, The Wharton School, University of Pennsylvania.

Dorasammy, R. (2004). Culture and entrepreneurship in Fiji's small tourism business sector. PhD Thesis, Victoria University.

Dowse, R., y Hughes, J. (1982). Sociología Política, Aguilar, Madrid.

Drucker, P. (1986): La Innovación y el Empresario Innovador. La práctica y los 
Principios. Edhasa, Barcelona; en Cano, C., García J. y Gea. A. (2003): Actitudes emprendedoras y creación de empresas en los estudiantes universitarios Universidad de Almería.. 136.

Durerger, M (1975). Introdution to the social Sciences. Allen and Urwin. Minerra, London.

Durkheim, E., (1967), La division social du travail. Paris, Press Universitaires de France.

Eiser, J.R., (1999). Psicología Social. Madrid, Plaza y James Editorew, S.A.

Eiser, J.R., y W. Stroebe, Categorization and Social Judgement, London: Academic Press, 1972).

Elfring, T. y Hulsink, W. (2003). Networks in entrepreneurship: The case of hightechnology rms. Small Bussiness Economic, 21(4), 409-422.

Elenkov, D. S., (1998). Can American management concepts work in Russia? A crosscultural comparative study. California Management Review, 40 (4), 133-156.

Englewood Cliffs, N.Y.: Prentice Hall. En Krueger, N y Brazeal, D. (1994).

Entrepreneurial Potential and Potential Entrepreneurs. Entrepreneurship Theory and Practice, spring, 91-104

Epstein, S. y O'Brien, E. J. (1985). The person-situation debate in historical and current perspective. Psychological Bulletin, 98, 513-537.

Fayolle, A. (2005). Evaluation of entrepreneurship education: behavior performing or intention increasing, International Journal of Entrepreneurship and Small Business, vol. 2, no. 1. 89-98.

Ferraro, C. (2003). Desarrollo productivo local en Argentina. Coordinación del estudio Oficina de la CEPAL-ONU, a solicitud de la Secretaría de Política Económica, Ministerio de Economía de la Nación.

Fernández, R., Fernández C. y Baptista, P. (2007). Metodología de la investigación, Mc. Graw Hill. Cuarta edición, 850.

Filion, L. J. (2003). Emprendedores y propietarios dirigentes de pequeñas y medianas empresas (PME). Revista de Administración de Empresas, 34(2), 5-28.

Fornas, J. (1995). Cultura and Late Modernity. Sage Publications. Londres, 135.

Formichella, M. (2004). El concepto de emprendimiento y su relación con la educación, el empleo y el desarrollo local. Buenos Aires: Instituto Nacional de Tecnología Agropecuaria. 
Foucault, D.E (2005). The archeology of knowledge London: Routledge. En Veciana, J.M. y Urbano, D. (2008): The institutional approach to Entrepreneurship research. Introducción, International Entrepreneur Manager Journal, vol. 4, 365-379.

Frese, M. (2009). Towards a psychology of entrepreneurship: An action theory

Perspective. Foundations and Trends in Entrepreneurship, vol. 5, $N^{o}$. 6, 437496.

Freud, S., (2003) Obras Completas, Amorrortu Ediciones .

Fuentes, M. M. (2006). Mujeres emprendedoras: Capacidades distintivas y desempeño empresarial. Perspectivas Del Sistema Financiero, vol.86, 49-59.

Fuentes, M.M. Albacete, S. Bojica, A. Fernández, V. Ruiz, M. (2008). Descubrimiento y explotación de oportunidades: Relación con las redes sociales de los emprendedores andaluces. Perspectivas Del Sistema Financiero, vol. 1.

Fukuyama, F. (1995). Confianza: las virtudes sociales y la creación de prosperidad. Punto de lectura, Madrid.

Fukuyama, F. (2001). La gran ruptura. Punto de lectura, Madrid.

Galindo, P. (2003). Respuestas para el desarrollo de una cultura Emprendedora y el cambio de los valores laborales en los jóvenes desempleados de Andalucía: el papel de las políticas activas de empleo. Revista universitaria de Ciencias del Trabajo, 3-4, 823-842.

Garrido, E. (1992). Autoeficacia en el mundo laboral. Asociación Colombiana para el avance de las ciencias del comportamiento (ABA Colombia). (2003. Agosto). Universidad de Salamanca, Biblioteca Virtual p. 1-22 -En línea. Disponible en: http:/www.abacolombia,org.com.

Gartner, W.B. (1989). Who is an entrepreneur? Is the wrong question. Entrepreneurship Theory and Practice. Summer, 47-67.

Geertz, C., J. Clifford y otros, (1991). El surgiminto de la antropología postmoderna, México: Gedisa

Geertz, C. (1973).The interpretations of culture. New York: Basic Books.

Geertz, C. (1971). Deep play: Notes on the Balinese cockfight. In C. Geertz (Ed.), Myth, symbol, and culture. New York: Norton.

Gelderen, M., Bosma, N., Thurik, R. (2001). Settting up a business in the Netherland: Who starts, who gives up, who is still trying, Frontiers of Entrepreneurship Research, http://eee.babson.edu/entrp/fer/Babson2001/1/1G/1G.htm, 
Geertz, C. (1987). Interpretación de las culturas, Gedisa.

Giddens, A., (1991). Modernidad e identidad del yo: el yo y la sociedad en la época contemporánea, Madrid, Arial.

Giner, S., (1982). Historia del pensamiento social, Barcelona, Planeta

Ginsberg, A., Buchholtz, A. (1989). Are entrepreneurs a breed apart? A look at the evidence. Journal of General management, 15, (2), 32-40.

Global Entrepreneurship Monitor, 2003 y 2004 y Flash Eurobarometer: Entrepreneurship, 2002.

Gómez, Andrés, (2008). Sobre el carácter cultural de la emergencia de los conflictos sociales en Chile. Revista MAD No 18, Facultad de Ciencias Sociales, Universidad de Chile.

Gómez, A., Seyle, C. Huici, C. y Swann, el Banco Mundial, Jr., (2009). Buscando la verificación de la identidad del propio grupo. Revista de Personalidad y Psicología Social, 97, 1021-1044.

Gómez, S., Delgado, J. y Vidal M.D. (2010). Propuesta de aplicación de la teoría sociológica institucional como marco teórico para el análisis del emprendimiento corporativo. Gestión Joven, 5, 1-11.

Gómez, A, y Martínez Sánchez, E., (2000). Implicaciones del modelo de valores, de Schwartz para el estudio del Individualismo y el Colectivismo. Discusión de algunos datos obtenidos en muestras españolas. Revista de Psicología General y Aplicada, 53, 2, 289-301.

González, Ferrer, G. (1998). Análisis compartido de culturas de empresa en la bahía de Cádiz, Proyecto de Tesis, Universidad de Cádiz.

Goffman, E., Interaction ritual, Garden City, N.Y., Anchor Books, (1967)

Gorman, T. J., (1998). Social class and parental attitudes toward education: resistance and conformity to schooling in the family. Journal of Contemporary Ethnography, 27. $10-44$.

Groenewegen, J, Pitelis, C. y Sjöstrand, S. (1995). On Economic Institutions. Theory and appliations, Edward Elgar, Aldershot.

Gutiérrez, Paola Isabel Rodríguez; Fuentes, María del Mar Fuentes; Ariza, Lázaro Rodríguez, (2009). Características del fenómeno emprendedor femenino: una revisión teórica. Sevilla: Asociación Europea de Dirección y Economía de empresa.

Gutierrez Ortega, M. (2005). Cualidades y habilidades del emprendedor: iniciativa 
emprendedra: $4^{\circ}$ ESO: Vitamina E: proyecto Educar para emprender en Castilla y León, Valladolid, Junta de Castilla y León

Hansemark, O. C. (2003). Need for achievement, locus of control and the prediction of business start-ups: A longitudinal study. Journal of Economic Psychology, 24, 301-319.

Hansen, E., (1995). Entrepreneurial network and new organization growth.

Entrepreneurship Theory and Practice, 19, 7-19.

Hansen, E. (1995). Entrepreneurial networks and new organization growth. Entrepreneurship Theory and Practice, 19, 7-19.

Harwood, E. (1982). The sociology of entrepreneurship, in C.A. Kent et (eds.) Encyclopedia of Entrepreneurship, Englewood-Cliffs, N.J: Prentice-Hall, 98.

Hayton, J., George, G. y Zahra, S., (2002). National culture and entrepreneurship: a review of behavioral research. Entrepreneurship Theory and Practice, 26, 33-52.

Hebert, R. y Link, A. (1989): In Search of the Meaning of Entrepreneurship. Small Business Economics, vol. 1. N. 1, 39-50; en Cano, C., García, J. y Gea, A. (2003): Actitudes emprendedoras y creación de empresas en los estudiantes universitarios. Universidad de Almería, 136.

Hébert, R. y Link, A. (1988). The entrepreneur: mainstream views and radical critiques $\left(2^{\text {nd }} e d\right.$.). New York: Praeger Publishers.

Herbert Marcuse, H., (1979). Cultura y sociedad - Acerca del carácter afirmativo de la cultura, Arial.

Herrera, H. (2008). Investigación sobre redes sociales y emprendimiento: revisión de la literatura y agenda futura. Revista INNOVAR, 33 (19), 19-33.

Herron, L., Sapienza, H.J., (1992). The entrepreneur and the initiation of new venture launch activities, Entrepreneurship: Theory and Practice, vol. 17, $N^{o} .1,49-55$.

Hills, G., Lumpkin, T., y Singh, R. (1997). Opportunity Recognition: Perceptions and Behaviors of Entrepreneurs, Frontiers of Entrepreneurship Research. Wellesley, MA: Babson College.

Hisrich, Robert D., Peters, Michael P., Shepherd, Dean A. (2009). Emprendedorismo. Porto Alegre: Bookman.

Hisrich R.D., Peters M. P., Shepherd D. A. (2005). Entrepreneurship. (6 th.eds), McGraw-Hill Companies, Inc.

Hitt, M. A., Nixon, R. D., Hoskisson, R.E. y Kockhar, R. (1999). Corporate 
entrepreneurship and cross-functional fertilization: Activation, process and disintegration of a new product design team. Entrepreneurship Theory and practice, 23 (3), 145-168

Hoang. H. y Antoncic B. (2003). Network-based research in entrepreneurship. A critical review. Journal of Business Venturing, 18, 165-187.

Hofstede, G. (1998). Attitudes, values and organizational culture: disentangling the concepts. Organization Studies, 19 (3), 447

Hofstede, G. (1985). The interaction between national and organizational value systems, Journal of Management Studies, vol. 22 (4), 347-357.

Hofstede, G. (1980). Culture's consequences: International differences in wok related values. Beverly Hill: Sage

Holt, D. H. (1997). A comparative study of values among Chinese and U. S. Entrepreneurs: pragmatic convergence between contrasting cultures. Journal of Business Venturing, 12, 483-505.

Hornaday, J. y Aboud, J. (1971). Characteristics of successful entrepreneurs. Personnel Psychology, vol. 24 (2), 50-60; en Espíritu, R. y Santre, M. (2007). La actitud emprendedora durante la vida académica de los estudiantes universitarios. Cuadernos de Estudios Empresariales, vol. 17, 95-116.

Hoselitz, B.F. (1960). The early history of entrepreneurial theory. In J.J. Spengler and W.R. Allen (eds.). Essays in Economic Thought: Aristotle to Marshall (234258). Chicago: Rand McNally.

Hung, H. (2006). Formation and survival of new ventures: A path from interpersonal to interorganizational networks. International Small Business Journal, 24(4), 359378.

Hurtado, N.E., Cordón E., Senise, M.E. (2007). Efectos de la cultura nacional en la relación entre orientación emprendedora y el resultado de la innovación de producto: el caso del sector farmacéutico. Cuadernos económicos de ICE, 73, 135-150.

Ilundain J.M, Sánchez, J.C., Yurrebaso, A., (2007). Emprendiendo con Responsabilidad

Social, A Coruña, Editorial Tórculo.

Infestas, A., (2001). Sociología de la empresa, Amaru Ediciones Salamanca. 
Inglehart, R. (1998). Modernización y posmodernización: el cambio cultural, económico y político en 43 sociedades. (1 $1^{\underline{a}}$ ed.) Madrid: Centro de investigaciones sociológicas, Siglo XXI de España.

Inglehart, R. (1991). El cambio cultural en las sociedades industriales avanzadas. Madrid: Siglo XXI

Inglehart, R., (1990). Culture shift in advanced industrial society. Princeton, Princeton, University Press.

Inglehart, R., (1977). The silent revolution: Changing values and political styles among Western publics, Princeton, N. J., Princeton, University Press.

Inkeles, A., y Levison, D.J., (1969). National Character: the study of modal personality and Sociocultural System . In the handbook of Social Psycology, G. Linzey and E Aronson, Vol. 4, 418-506.

Inkeles A, y Smith, P. (1974). Becoming Modern: Individual changes in six developing countries, Cambridge (MA), Harward University Press.

Instituto de Empresa (2011). Global Entrepreneurship Monitor, Informe ejecutivo GEM España 2011, Madrid Instituot de Empresa.

Izquierdo, E., y Buelens, M. (2008). Competing Models of Entrepreneurial Intentions: Theinfluence of Entrepreneurial Self-efficacy and Attitides. Internationalizing Entrepreneruship Education and Training 2008 Conference. 17-20 July. Oxford Jackson (1996).

Jackson, T., Weiss, K.E., Ludquist, J.J., Soderlind, A., (2002). Perceptions of goaldirected activities of optimists and pessimists: a personal Projects analysis, Journal of Psychlogy, vol. 136, $N^{o} .5,521-532$.

Jackson, W., Gaster, W., y Gaulden, C. (2001). The continued saga of searching for the entrepreneur: a historical perspective. Small Business Advancement National Center. University of Central Arkansas. Paper.

Jamenson, F. (1999). El giro cultural: Escritos seleccionados sobre el posmodernismo. Buenos Aires, Manantial.

Jennings, R., Cox, C. y Cooper, C.L. (1994). Business elites: The psychology of entrepreneurs and intrapreneurs. London Routlegde.

Johannison, B. (2000). Networking and entrepreneurial growth. En D. Sexton y H. Landstrom (Eds.), The Blackwell handbook of entrepreneurship, 47-82).

Johnson, S. and Loveman, G., (1995). Starting over in Eastern Europe: 
Entrepreneurschip and economic renewal. Boston: Harvard Business Scholl Press.

Junehed, L. y Davidsson, P., (1998). Small firms and export success: Development and empirical test of an integrated model. Paper presentado, $10^{\text {th }}$ Nordic Conference on Small Business research, Caxjo, Suiza.)

Katz, J. A., y Shepherd, D. A. (2003). Cognitive approaches to entrepreneurship research (1st. Ed.). Amsterdam [etc.]: JAI

Katz, J.A. (1992). A Psychological Cognite Model of Employment Status Choice. Entrepreneurship Theory and Practice. Fall. vol. 17, $N^{o} .1,29-37$.

Kennedy, J., Drennan, J., Renfrow, P., Watson, B., (2003). Situational factors and entrepreneurial intentions. 16 th Annual Conference of Small Enterprise Association of Australia and new Zealand. 28 September - 1 October. Ballarat: Small Enterprise Associations of Australia and New Zealand.

Kickul, J., Maxfield, S., y Krueger, N.F. (2005). Measurement issues in entrepreneurship studies (editors introduction), New England Journal of Entrepreneurship, 8 (2), 5-7.

Kickul, J. y Krueger, N. A. (2004). Cognitive Processing Model of Entrepreneurial Self- Efficacy and Intentionality. Babson.

Kickul, J. y Zaper, J.A. (2000). Untying the knot: Do personal and organizational determinants influence entrepreneurial intentions? Journal of Small Business and Entrepreneurship, 15(3), 57-77.

Kilby, P. (1971). Hunting the heffalump. En Peter Kilby (Ed.), Entrepreneurship and Economic Development, 1-40.

Kimball Young (1963). Psicología Social. Paidós, Buenos Aires.

Knight, F.H., (1921). Risk, Uncertainty and Profit. Boston: Houghton Mifflin Co.

Kirzner, I. M. (1997). Entrepreneurial discovery and the competitive market process:

An Austrian approach. The Journal of Economic Literature, vol.35, $N^{o} .1,60-85$.

Kirzner, I. (1979). Perception, Opportunity, and Profit. Chicago: University of Chicago Press.

Kirzner, I.M., (1973). Competition and entrepreneurship. Chicago: University of Chicago Press.

Koh, H., (1996). Testing hypothesis of entrepreneurial characteristics: a study of Hong Kong MBA students. Journal of Managerial Psychology, 11, 5, (1-11).

Kohn, M. L., Slomczynsry, K., Janicka, M., Khmerko, V., Mach, B. W., Paniotto, V., 
Zaborowki, W., Gutierrez, R., y Heyman, C. (1997). Class, work and personality under conditions of radical social change. Annual Review of Sociology, 62, 614638.

Kogut, B. y Singh, H., (1988). The effect of national culture on the choice of entry mode. Journal of International Business Studies, 19, 411-432.

Kolvereid, L. (1996). Prediction of status employment choice intentions. Entrepreneurship Theory and Practice, 21(1), 47-57

Kolvereid, L. (1996). Organizational employment versus self-employment: Reasons for career choice intentions. Entrepreneurship Theory and Practice, 20 (3), 23-31.

Korunka, C., Frank, H., Lueger, M. Y Mugler, J. (2003).The entrepreneurial personality in the context of resources, environment, and the startup process-A configurational approach. Entrepreneurship Theory and Practice, 28(1), 23-42..

Kottak, C.P., (1997). Antropología Cultural, (9 eds). Madrid, MaGrawHill.

Krech, D., y Crutchfield, (1948). Theory and problems in social psychology, Nueva York, McGraw-Hill

Kristie, W., Seawright, Mitchell, R. K. y Smith, J. B. (2008). Comparative entrepreneurial cognitions and lagging russian new venture formation: A tale of two countries. Journal of Small Business Management, 46(4), 512-535.

Kroeber, Al. y Kluckhohn C. (1952).Culture; a critical review of concepts and definitions, American Archeology and Etnology, 1952, en Gould y Kolb, A Dictionary of Social Sciences.

Krueger, N. (2004). How we learn growth motivation: Learning to think entrepreneurially ... and actionably. Academy of Management, 15.

Krueger, N. F. Jr. (2003). The cognitive psychology of Entrepreneurship. Handbook of Entrepreneurship research: An interdisciplinary survey and Introduction, (105140). In ACS, J. A. y Audretsch, D. B.

Krueger, N. F., Reilly, M. D., y Carsrud, A. L. (2000). Competing models of entrepreneurial intentions. Journal of Business Venturing, 15(5/6), 411-432.

Krueger, N. Y Brazeal, D. (1994). Entrepreneurial potential and potential entrepreneurs. Entrepreneurship Theory and Practice, 18(1), 91-104.

Krueger, N. y Dickson, P. R. (1994). How believing in ourselves increases risk taking: Perceived self-efficacy and opportunity recognition. Decision Sciences, 25(3), $385-400$. 
Kyrö, P. y Carrier, C. (2005). Entrepreneurial learning in universities:

Bridges across borders. In P.Kyrö and C. Carrier (Eds.), The dynamics of learning entrepreneurship in a cross-cultural university context (pp. 14-43).

Landström, H. (2005). The roots of entrepreneurship and small business research. In H. Landström (Ed.), Pioneers in entrepreneurship and small business research, 2758.

Larson, A. y Starr, J. (1993). A network model of organization formation.

Entrepreneurship: Theory and Practice, 17, 5-15.

Le Bras, H., (1995). La aritmética de la población. Mundo Científico, 964-969.

Lechner, C. y Dowling, M. (2003). Firm networks: External relationships as sources for the growth and competitiveness of entrepreneurial forms. Entrepreneurship and Regional Developmen, 15, 1-26.

Linton, R., (1945). El Fondo de Cultura de la Personalidad, New York Press.

León Moriano, J.A. (2005). El perfil psicosocial del emprendedor, un estudio realizado en Castilla y León. Madrid, Consejo Económico y Social.

León, G. (2000). La creación de empresas de base tecnológica desde el sistema público, Boletín SEBBM, $N^{o} .128,12-17$.

Lévesque, M. y Minniti, M., (2008). Recent developments in the economics of entrepreneurship, Journal of Business Venturing, vol. 23, $N^{o}$. 6, 603-612.

Levesque, M. y Minniti, M. (2006). The effect of aging on entrepreneurial behavior, The journal of business venturing, vol. 21 (2), 177-194.

Levin, J., y Spates, J. (1970). Hippie values: An analysis of the underground press. Youth and Society, 2, 59-72.

Linton, R., (1936). The study of man, Nueva York, Appleton-Century-Crofts, Inc,

Lucas, W. A. y Cooper, S. Y. (2005). Measuring entrepreneurial self-efficacy. Paper Presented at the EDGE conference: Bridging the gap. Entrepreneurship in theory and practice.

Lucas, W., y Cooper, L. (2004). Enhancing sel-efficcy to enable entrepreneurship: The casmof CMI's Connections. Cambridge: MIT Sloan School of Management.

Lumpkin G. T., Dess G.G. (2001). Linking Two Dimensions Of Entrepreneurial Orientation To Firm Performance: The Moderating Role Of Environment And Industry Life Cycle; Journal Of Business Venturing, vol. 16, 429-451.

Lumpkin, G. T. and Dess, G. G. (1996). Clarifying the entrepreneurial orientation 
construct and linking it to performance, Academy of Management Review, vol. $21,135-172$.

Makino, S. y Neupert, K. E. (2000). National culture, transaction cost, and the choice between joint venture and wholly owned subsidiary. Journal of International Business Studies, 31, 705-713.

Malewicki, D. (2005). Member involvement in entrepreneur network organizations: The role of commitment and trust. Journal of Developmental Entrepreneurship, 10(2), 141-166.

Malecki, R.J.(1995). Culture as a mediator of Global and Local Forces, en Van Der Knaap, B. y Le heron, R. (eds.), Human resources and Industrial Spaces: A perspectie on Globalization and Localization, Chichester, John Wile and Son Lid, 105-127.

Malecki, J. y Velhdoen, M., (1993). Network activities, information and competitiveness in small firms. Geografiska Annater. Series B, Human Geography, 75(3), 131-147.

Malinowski, B., (1975). Magia, ciencia, religión y otros ensayos. Barcelona. Ed. Ariel.

March, I., (1998). El perfil emprendedor innovador. Iniciativa Emprendedora y Empresa Familiar, (11) 3. 10-19

March, J., y Shapira, Z. (1987). Managerial perspective on risk and risktaking.Management Science,33, 1404-1418.

Mariussen, A. (2001). Milieux and innovation in the northern periphery, Stockholm,

Markus, H.R., kitayama, S. y Heiman, R. (1996). Culture and "Basic" Psychological Principes. En E.T. Higgins \& A.W. Kruglamski (Eds.). Social Psychologival Principes. New York. The Guilford Press.

Markus, H. R., y Kitayama, S., (1991). Culture and the self: Implications for cognition, emotion and motivation. Psychological Review, 98. 224-253.

Martínez-Rodríguez, F. M. (2009). Programa socioeducativo para el desarrollo de la cultura emprendedora entre los jóvenes”. Revista Iberoamericana de Educación, vol. 50, $\mathrm{N}^{\circ} .5,1-20$.

Maslow, A. H., (1968). El hombre autorrealizado. Hacia una psicología del ser. Barcelona, Kairós.

Maslow, A. H., (1954). Motivation and personality. Nueva York, Harper and Row Pubishers.

Maslow, A. H., (1943). A theory of Human Motivation. Psychological Review, 50, 370- 
396.

Matthews, C.H. y Moser, S.B. (1995a). Family Backgraound and Gender: Implications for Interest in Small Firm Ownership. Entrepreneurship and Regional Development, vol. 7. 365-377; en Cano, C., García J. y Gea. A. (2003). Actitudes emprendedoras y creación de empresas en los estudiantes universitarios. Universidad de Almería. 136.

Matthews, C,H. y Moser, S.B. (1995b). The Impact of Family Background and Gender on Interes in Small Firm Ownership: a Longitudinal Study. Paper presented at ICSB 40th World conference. Sydney. June, 19-21.

Martens, C.D. P., Freitas, H. (2008). Influencia do ensino de empreendedorismo nas intenciones de direccinamietno profesinal dos Estudiantes. Estúdios y Debate. Lajeado, vol. 15,71-95.

Maximiniano, A. (2006). Teoría Geral da Administracao. São Paulo: Atlas.

McCarthey, B. (2000). The cult or risk taking and social learning: a study of Irish entrepreneurs.Peer Reviewed Journal, 38 (8), 563-574

Mc.Clelland, D.C. (1987), Characteristics of Successful Entrepreneurs, Journal of Creative Behaviour, vol. 21, $N^{o} .3,219-233$.

McClelland, D. C. (1976).The achievement motive (1st Ed.). Irvington: New York. Mc.Clelland, D.C. (1968). La sociedad ambiciosa, vol. I y II; Ediciones Guadarrama, Madrid.

McClelland, D. C. (1965). Achievement and entrepreneurship: A longitudinal study. Journal of Personality and Social Psychology, 1(4), 389-392.

McClelland, D. C., Atkinson, J. W., Clark, R. A. \& Lovell, E. L. (1953). The Achievement Motive. Appleton-Century-Crofts, New York.

Mead, M. (1927). Social change and cultural surrogates, Journal of Educational Sociology, Vol. 14, núm. 2

Méndez José S., Zorrilla Santiago, Monroy Fidel (1992). Dinámica social de las organizaciones. McGraw Hill, México, 1992.

Mitchell, R. K., Busenitz, L. W., Bird, B., Marie Gaglio, C., McMullen, J. S., Morse, E. A., y Smith, J.B. (2007). The Central Question in Entrepreneurial Cognition Research. Entrepreneurship Theory and Practice, 31 (1), 1-27.

Mitchell, R. K., Busenitz, L., Lant, T., McDougall, P. P., Morse, E. A., y Smith, B. (2002). Toward a theory of entrepreneurial cognition: Rethinking the people side of entrepreneurship research. Entrepreneurship Theory and Practice, 27, 93-104 
Mitchell, R. K., Busenitz, L. W., Bird, B., Marie Gaglio, C., McMullen, J. S., Morse, E. A., y Smith, J.B. (2007). The Central Question in Entrepreneurial Cognition Research. Entrepreneurship Theory and Practice, 31 (1), 1-27.

Mitchel, R.K.. Smith, B., Morse, E.A., Seawright, SH., Peredo, l.m Mckenzie, R., (2002b). Are entrepreneurial cognition universal? Assessing entrepreneurial cognitions across cultures. Entrepreneurship Theory and Practice. 32, 26-65.

Minniti M. Bygrave W. (2001). A dynamic model of entrepreneurial learning. Entrepreneurship Theory and Practice, vol. 25, $N^{o} .3,5-16$.

Miner, J. B. (1996). Evidence for the existence of a set of personality types, defined by psychological tests that predict entrepreneurial success.In R. D. Reynolds, W. D. Bygrave, S. Manigart, C. M. Mason, G. D. Meyer, H. J. Sapienze y K. G. Shaver (Eds.), Frontiers of Entrepreneurship Research. Wellesley, MA: Babson College.

Moliner, M. (1975): Diccionario de uso del español. Madrid: Gredos.

Moriano León, J.A., (2005), El perfil psicosocial del emprendedor; un estudio realizado en Castilla y León. Texto impreso ( $\left.1^{\mathrm{a}} \mathrm{Ed}\right)$. Madrid Consejo Económico y Social.

Moriano, J., Sanchez, M. y Palací, F. (2004). Un estudio descriptivo sobre los emprendedores en España, la República Checa y Bulgaría; en Roig, S.; Ribeiro, D.; Torcal, R.; De la Torre, A.; Cerver, E. (2004): El emprendedor innovador y la creación de empresas de $I+D+I$. Servei de Publibacions Universitat de Valencia, cap. 10, 161-178.

Moriano, J. A., Palací, F. J., y Trejo, E. (2001). El perfil psicosocial del emprendedor: un estudio desde la perspectiva de los valores. Revista de Psicología Social, 16(2), 229-242.

Morris, M.H. y Jones, F.F. (1999). Entrepreneurship in Established Organizations: The Case of the Public Sector, Entrepreneurship: Theory y Practice. vol. 24. $N^{a} .1,71-92$.

Morris, M..H. (1998). Entrepreneurial intensity: sustainable advantages for individuals organizations and societies. Quorum books, Westport, CT; en Espíritu, R. y Santre, M. (2007). La actitud emprendedora durante la vida académica de los estudiantes universitarios. Cuadernos de Estudios Empresariales, vol. 17, 95116.

Morris, M. H., y Sexton, D. L. (1996). The concept of entrepreneurial intensity: Implications for company performance, Journal of Business Research, vol. 
$36, N^{o} .1,5-13$.

Morris, M. H., Davis, D. L. y Allen, J. W., (1993). Fostering corporate entrepreneurship. Cross-cultural comparisons of the importance of individualism versus collectivism. Journal on International Business Studies (First Quarter), 65-89.

Navarro, J., Rojas, A. y Suárez, A. (2008). Actitudes de los estudiantes Universitarios de Andalucía ante la Creación de empresas, Universidad de Cádiz, 103.

Názar, V., (2003). Certezas silvestres: el realismo ingenuo, Perspectivas educacionales, UMCE, Facultad De Filosofía Y Educación.

Neck, H.M., Manz, C.C., y Godwin, J. (1999). I Think I Can, I Think I Can: A SelfLeadership Perspective Toward Enhancing Entrepreneur Thought. Empírica

Neck, R., Haber, G. y McKibbin, W. J. (1999). Macroeconomic policy design in the European Monetary Union: A numerical game approach. Empirica, 26, 319-33.

Newcomb, T. H. M., (1958). Attitude development as a function of reference groups: The Benninghton study. En Maccoby, Newcomb y Hartley (ed.), 265-267.

Nelson, R. y Winter, S.G. (1982). An evolutionary theory of economic change, Cambridge Massachusetts, Harvard University press; en North D.C. (1994). Economic Performance Through Time, The American Economic Review, vol. 84, $N^{o} .3,359-368$.

Newcomb, TM (1943) El cambio de personalidad y Social: la formación de actitudes en una comunidad de estudiantes. Nueva York: Dryden Press

Nieto, M., González, N., Solís, V., Roure, C., y Huerga, N. (2006). Global Entrepreneurship Monitor. Informe ejecutivo Castilla y León, 2006. Valladolid, España: Junta de Castilla y León.

Nonaka, I. (1994). A dynamic theory of organizational knowledge reaction. Organization Science, 5, 14-37.

North, D. (1990). Institutions, Institutional Change and Economic Performance. Cambridge: Cambridge University Press.

Oishi, S., Schimmark, U., Diener, E. y Suh, E.M., (1998).The measurement of values and individualism and collectivism. Personality and Social Psychology Bulletin, 24, 1177-1189.

Oliveira, M. F., Garrido, E.,y Sánchez, J. C. (2005). El impacto del entorno social en las ciencias de auto-eficacia de los emprendedores: Un estudio pragmático. En Psicología Social y Problemas Sociales ,4, 407-418. 
Paéz, D. y Gonzálesz, J.L., (2006). Social Psychology and Culture. Psicothema, vol. 12, Supl. 1, 6-15.

Paéz D., Fernández, I., Basade, N., y Grad, H., (2003). Valores culturales y motivación: creencias de auto-concepto de Singelis, actitudes de competición de Triandis, control emocional e individualismo - colectivismo, verticalhorizontal. Revista Española de Motivación y Emocióm. Spanish Journal of Motivation and Emotion, 3, 169-195.

Palich, L. y Bagby, D. R. (1995). Using cognitive theory to explain entrepreneurial risk taking: Challenging conventional wisdom. Journal of Business Venturing, 10 (6), 425-438.

Palmer, M. (1971). The application of pschylogical testing to entrepreneurial Potential en California Management Review, XIII (3), 8-38.

Parker, S. C. (2006). Entrepreneurs as producers. In S. Parker (Ed.), The life cycle of entrepreneurial venture, 337-360.

Parsons, T., (1961). An outline of the social System. En T. Parsons, E. Shils, K. D. Naegele y J. R. Pitts (ed). Theories of society, Nueva York, Free Press.

Parsons T. (1951). The social system. Free Press, New York, 1951

Pato, C., Ros, M., y Tamayo, A. (2005). Creencias y comportamiento ecológico: Un estudio empírico con estudantes brasileños [Beliefs and ecological behavior: An empirical study with Brazilian students]. Medio Ambiente y Comportamiento Humano, 6, 5-22.

Peacock, R. (2000). Entrepreneurs and small business owner-managers. Small Enterprises Series, $N^{o}$. 8. Adelaide: University of South Australia.

Pereira Roders, A. and Van Oers, Ron (2010). Outstanding Universal Value, World Heritage Cities and Sustainability: Mapping assessment processes - part 1.

Pereira Roders, A. (2007). Lifespan rehabilitation of built heritage Eindhoven: Eindhoven University of Technology, 2007.

Picot, A., Laub, U. D., y Schneider, D. (1989). Innovative unter nehmens gruendungen: eine Ökonomisch-Empirische Analyse. Berlin: Springer-Verlg.

Pinillos Costa, M.J. (2011). Cultura postmaterialista y variaciones en el espíritu emprendedor. Investigaciones Europeas de Dirección y Economía de la Empresa, 17 (1), 037-055.

Pinillos Costa, M.J y Recio, R., (2007). Influencia de la cultura individualista- 
colectivista en la creación de empresas. XX Congreso anual de AEDEM, vol. 1 , 43.

Premaratne, S.P. (2001). Network, resources, and small business growth: The Experience in Sri Lanka. Journal of Small Business Management, 39(4), 363371.

Puchol L. (2006). El libro del emprendedor, cómo crear tu empresa y convertirte en tu propio jefe. Editorial Díaz de Santos, $3^{\text {a }}$ edición, España. 152.

Putman, R., (1995). Tuning In, Tuning Out: The Strange Disappearance of Social Capital in America, Political Sciences and Politics, 664-683

Rao, D. R. (2004).Culture and entrepreneurship in Fiji's small tourism business sector. $\mathrm{PhD}$ thesis, Victoria University.

Rauch, A., y Frese, M. (2007). Let's put the person back into entrepreneurship research: A metaanalysis on the relationship between business owners'personality traits, business creation, and and success. European Journal of Eork and Organizational Psychology, 16 (4), 353-385.

Ray, D. (1993). Understanding the entrepreneur: entrepreneurial attributes, experience and skills. Entrepreneurship and Regional Development, 4 (5), 345-357.

Ray, D. (1986). Perceptions of risk and new enterprise formation in Singapore.Frontiers of Entrepreneurship Research.Babson College, Wellesley.

Ribeiro-Soriano, D. y Urbano (2009). Overview of Collaborative Entrepreneurship:

An Integrated Approach Between Business Decisions and Negotiations. Group Decision and Negotiations 18 (5), 419-430.

Ripollés, M. (1995). El emprendedor y sus mitos, Dirección y Organización, $N^{o} .15$, julio-septiembre, 36-44

Rirados Gonzalez, R.M., (2010). El problema de género en las estructuras empresariales españolas del siglo XXI. Mujeres y Economía, Enero-Febrero, $N^{o} .852$.

Robinson, P. B. y Sexton, E. A. (1994). The effect of education and experience on self employment success. Journal of Business Venturing, 9, 141-156.

Rocher, G., (2004). Introducción a la Sociología General. HeEder, Barcelona.

Rockeach, M., (1979). Undeerstanding human values: individual and societal. Nueva York, Free Press.

Rodermund, E. S. (2004). Pathways to successful entrepreneurship: Parenting, 
personality, early developmental competence and interests. Journal of Vocational Behavior, 65(3), 498-581.

Rohrmann, B. (2004). Risk attitude scales: Concepts and questionnaires. Report, Dept. of Psychology, University of Melbourne, Australia.

Rodríguez, A., García, E., Ruíz, C. y Hernández, M. 1 (2009). Economía social y comportamiento emprendedor, en Comportamiento emprendedor en el ámbito universitario. Personas y sociedad. Coordinado por Francisco Bretones. Granada: Editorial Universidad de Granada

Ros, M. (2002). Los valores culturales y el desarrollo socioeconómico: una comparación entre teorías culturales. REIS, 99, 9-33.

Ros, M., y Gouveia, V. (2001). Psicología social de los valores humanos: desarrollos teóricos, metodológicos y aplicados. Texto impreso, Madrid, Biblioteca Nueva.

Ros, M., Grad, H., y Martínez Sanchez, F., (1996). El cambio de los valores para la mejora de las estrategias de aprendizaje y rendimiento académico. Informe CIDE, Madrid.

Rotter, J. B. (1966). Generalized expectancies for internal versus external control of reinforcement. Psychological Monographs: General and Applied, 80(1), 1-28.

Ruiz, M., Fuentes, M., Rodríguez, L. y Rodríguez, S. (2009). El emprendedor potencial en España: Factores socioeconómicos, perceptuales y relacionales. Paper presented in the IV International Workshop of Research based on GEM. 22 y 23 June, Cádiz, España, 24

Sánchez Almagro, M.L. (2003). El perfil psicológico del autoempleado. Proyecto de Tesis, Universidad Complutense, Madrid.

Sánchez García, J.C. (2010). Evaluación de la Personalidad Emprendedora: Validez Factorial del Cuestionario de Orientación Emprendedora (COE). Revista Latinoamericana de Psicología, 42 (1), 41-52.

Sánchez, J. C., Tejero, B., Yurrebaso, A., y Lanero, A. (2006). La cultura organizacional: Desentrañando vericuetos. Revista de Antropología Iberoamericana, 1(3), 374-397.

Sánchez, J. C., Lanero, A., Yurrebaso, A., Villanueva, J. J. (2006). Tendencias de empleo en los universitarios hispano portugueses. Revista de Psicología Social Aplicada, 16 (2006)

Sánchez, J. C., Lanero, A., y Yurrebaso, A. (2005). Variables determinantes de la 
creación de empresas en el contexto universitario. Revista de Psicología Social Aplicada, 15(1), 37-60.

Sánchez, J. (2005). Intenciones emprendedoras en los Universitarios castellanoleoneses. Salamanca: Cátedra de Emprendedores.

Saporta, B. (2002). Famille, création dentreprises et entrepreneuriat. En J. Caby et G. Hirigoyen (dirs.). La Gestion des Entreprises Familiales.

Sayer, A. (1994). Method in Sicial Science: a Realist Approach, $2^{\mathrm{a}}$ ed., Londres, Hutchinson

Scott, M. y Twomey, F. (1988), The long-term supply of entrepreneurs: student career aspirations in relation to entrepreneurship. Journal of small business, vol. 26 (4), $5-13$;

Schneider, S. y Barsoux, J. L. (2003). Managing across Cultures, Pearson Education. Harlow, UK.

Scherer, R. F., Brodzinski, J. D., y Wiebe, F. A. (1991). Assessing perception of career role model performance: the self-employed parent. Perceptual and Motor Skills, $72,555-560$

Scholten, V., Kemp, R. y Omta, S. W. F. (2004). Entrepreneurship for life: Entrepreneurial intention among academics in the Life Sciences. Paper prepared for 2nd ESU Conference, Enschede, September 20-22.

Schultz, W. (1980). Investment in entrepreneurial ability. Scandinavian Journal of Economics. 82(4), 437-448.

Schumpeter, J. A., (1991). Die Theorie der Wirts chaftlichen Entwicklung. Munchen: Duncker y Humblot.

Schumpeter, J.A. (1963). Teoría del desenvolvimiento económico. Una investigación sobre ganancia, capital, crédito, interés y ciclo económico. Ttercera edición, Fondo de cultura económica, México.

Schumpeter, J.A. (1947). The Creative response in Economic History. Journal of Economic History, vol. VII. noviembre, 147-159; en Cano, C., García J. y Gea. A. (2003). Actitudes emprendedoras y creación de empresas en los estudiantes universitarios. Universidad de Almeria. 136.

Schumpteter, J. A. (1936). The theory of economic development: an inquiry into profits, capital credit, interest, and business cycle. Cambridge: Harvard 
University Press.

Schumpeter, J. A. (1934). The theory of economic development: An inquiry into profits, capital, credit, interest, and the business cycle. Cambridge, MA: Harvard Univesity Press.

Schwartz , S., y Smith, J., (2000). Short-term variations and long-term dynamics in commodity prices. Manage. Sci., 46(7), 893-911,

Schwartz, S. y Sagiv, L. (1995). Identifying culture specifics in the content and structure of values. Journal of Cross-Cultural Psychology, 26, 2-116.

Schwartz, Sh. (1992). Universals in the content and structure of values: Theoretical advances and empirical test in 20 countries. Advances in Experimental Social Psychology, 25, 1-65.

Schwartz, S. H., y Bilsky, W., (1990) Toward a theory of universal content and structure of values: Extensions and cross-cultural replications. Journal of Personality and Social Psychology, 58, 878-891.

Schwartz, S. H., y Bilsky, W., (1987) Toward a universal psychological structure of human values. Journal of Personality and Social Psychology, 53. 550-562.

Seaone, L., Garzón, A. (1996). El marco institucional del sistema de creencias postmodernas, Psicología y Política, $N^{o}$. 13, 81-98.

Segal, G., Borgia, D. y Schoenfeld, J. (2005). The motivation to become an entrepreneur. International Journal of Entrepreneurial Behavior \& Research, 11 (1), 42-57.

Shane, S., Lochey, E., y Collins, C,J., (2003). Entrepreneurial motivation. Human Resource Management Review, 13 (2), 257-279.

Shane S. y Cable D. (2002). Network ties, reputation, and the nancing of new ventures. Management Science, 48, 364-81

Shane, S. y Venkataraman, S. (2000). The promise of entrepreneurship as a field of research. Academy of Management review, 25(1): 217-226.

Shane, S. (2000). Prior knowledge and the discovery of entrepreneurial opportunities. Organization Science, vol. 11, No. 4, 448-469.

Shane, S. (1994), Cultural Values and the Championing Process. Entrepreneurship Theory and Practice, Winter, 25-41.

Sharma, P., Chrisman, J.J. (1999). Toward a Reconciliation of the Definitional Issues in 
the Field of Corporate Entrepreneurship. .Entrepreneurship Theory and Practice, 23, 11-27.

Shapero, A. (1982). Social dimensions of Entrepreneurship. In Kent, C., Sexton, D.y Vesper, K. (Eds.), The enciclopedia of Entrepreneurship, 72-90.

Shapero, A., y Sokol, L. (1982). The social dimensions of entrepreneurship. En C. A. Kent,

Sharma, P. y Chrisman, J.J. (1999). Toward a reconciliation of the definitional segues in the field of corporate entrepenurship. Entrepeurship theory an practice. Spring, 11-27.

Shein, E. (1990). Carer anchors: Discoverin your real values, University Associate. San Diego, CA.; en Espíritu, R. y Santre, M. (2007). La actitud emprendedora durante la vida académica de los estudiantes universitarios. Cuadernos de Estudios Empresariales, vol. 17, 95-116.

Shein, E.H. (1988). La cultura empresarial y el liderazgo. Una visión dinámica. Barcelona, Plaza and Janés.

Singh, R., Hills, G. y Lumpkin, G., (1999). Opportunity recognition though socialnetwork charactersitics. Frontiers of Entrepreneurship Research, Babson proceeding. En http://www.babson.edu/entrep/fer/papers99/C/X_B/X.Html.

Smith, J. B., Mitchell, J. R. y Mitchell, R. K. (2009). Entrepreneurial scripts and the new transaction commitment mindset: Extending the expert information processing theory approach to entrepreneurial cognition research. Entrepreneurship: Theory \& Practice, 33(4), 815.

Smith P.B., y Schwartz, D.H., (1997) Values en J. W. Berry, M. h. Segall y C. Kagitcibasi (ed.), Handbook of Cross. cultural Psychology, $2^{a}$ ed., vol. 3, Boston, Allyn and Bacon, 1997, 77-118.

Smith, N. R., y Miner, J.B., (1983). Type of entrepreneur, type of firm, and managerial motivation: Implications for organizational life cycle theory. Strategic

Management Journal, 4, 325-340

Smith, N. B., (1967). Personal values in the study of lives. The study of lives. New York, Artheton Press.

Smith, N.R. (1967): “The entrepreneur and His Firm: The relationship Berween Type of Man and Type of Company. East Lansing: Ed. Michigan State University; 
Spindler, G., (1987). La transmisión de la cultura. En VEIASCO, H. M. et al. (Eds.) 1993): Lecturas de Antropología para educadores. Trotta, Madrid, 205-242.

Spindler, G., (1982). Doing the ethnography of schooling. Educational Anthropology in action. Holt, Rinehart and Winston, New York.

Soriano Pinar I., (2005). El empresario y la función empresarial: una visión integradora. Texto Impreso Madrid; Universidad Rey Juan Carlos.

Spates, J. L., (1983). The sociology of values. Annual Review of Sociology, 9. 27-49.

Staley, E. y Morse, R., (1971). Developing Entrepreneurship: Elements for a Program. Entrepreneurship and Economic Development. Ed. Peter Kilby. New York, The Free Press, 357-384.1

Stevenson, H. H. H. I. Grousbeck, M. J. Roberts, and A. V. Bhide. (1999). New business ventures and the entrepreneur, instructor's manual. Burr Ridge, Ill., Irwin, McGraw-Hill.

Stevenson, H. H., y Jarillo, J. C. (1990). A paradigm of entrepreneurship:

Entrepreneurial management, Strategic Management Journal, vol. 11, N. 4, 1727.

Steward, W., y Roth, P. (2001). Risk taking propensity differences between entrepreneurs and, managers: A meta-analytic review. Journal of AppliedPsychology, 86 (1), 145-153.

Stewart W., Carland J. C., Carland J. W., (1998). A proclivity for Entrepreneurship: A comparison of entrepreneurs, small business owners, and corporate managers. Journal of Business Venturing, 14, 1998.

Stewart, A. (1990). The bigman metaphor for entrepreneurship. A "library tale" with morals on alternatives for further research. Organization Science, vol. 1, N ${ }^{\circ}$. 2, 143-159.

Swedberg, R. (2000). The social science view of entrepreneurship. The social science literature on entrepreneurship (Part 1): The contribution of the economists. (Part2): The contribution of mainstream economics. En R. Swedberg (Ed.), Entrepreneurship. The Social Science View (7), 24.

Swedlberg, R., (2000). The social science view of entrepreneurs chip. The contribution of mainstream economics. En R. Swedlberg, (eds), Entrepreneurship. The social Science View (7) 24. Osford Universtiy Press.

Tetloch, P.E., (1986). A value pluralism model of ideological reasoning. Journal 
of personality and Social Psychology, 50, 819-827.

Thomas, A. y Mueller, S. (2000). A case for comparative Entrepreneurship: Assessing the relevance of culture. Journal of International Business Studies, vol. 31, No.2, 287-301.

Thomas W.,y Znaniechi, F., (1988). The Polish peasant in Europe and America.

University of Chicago Press, Chicago. Winnicott, D.W.

Thomas, W. y Znanietcki, F. (1918) The polish peasant in Europe and America, Vol.1, Univ. Chicago Press.

Throsby, D. (2001A). Economía y Cultura, Madrid, Cambridge University Press.

Timmons, J. A. (1989). The entrepreneurial mind. Andover, MA: Brick House Publishing.

Throsby, D., (2001B). Economics and Culture Cambridge University Press.

Toledano, N. y Urbano, D. (2008). Promoting entrepreneurial mindsets at universities: a case study in the South of Spain, European J. International Management, vol. 2, $N^{o} .4,382-399$.

Triandis, H. C. (1996). The Psychological measurement of cultural syndromes, American Psychologist, 51. 407-415.

Trompenaars, A. (1998). Riding the wares of culture. Understanding diversity in global business. Nueva York, McGraw Hill.

Tylor, E. (1871). Primitive Culture: Researches into the Development of Mythology, Philosophy, Religion, Language, Art and Custom. London: J. Murray.

Van de Ven, A.H. (1993). The Development of an Infrastructure for Entrepreneurship. Journal of Business Venturing, 8, 211-230.

Valencia, P., y García, P. (2009). El proceso de creación de empresas: Planificación, redes sociales y ayudas públicas. Papel presentado en el XIX Congreso Nacional de Acede, Septiembre, Toledo, España, 22.

Varela, R. (2001). Innovación Empresarial: arte y ciencia de la creación de empresas. Prentice Hall, Bogotá, Colombia; en Leiva, J. (2007). Los emprendedores y la creación de empresas. Editorial Tecnológica de Costa Rica, $1^{\mathrm{a}}$ Edición.

Vázquez. A (1999). Desarrollo, redes e innovación. Lecciones sobre desarrollo endógeno. Madrid: Ediciones Pirámide, S.A. Madrid.

Vázquez. A. (1993). Política Económica Local. Madrid: Ediciones Pirámide.

Vecchio, R. P. (2003). Entrepreneurship and leadership: Common trends and common threads. Human Resource Management Review, 13(2), 303-327. 
Veciana, J.M., y Urbano, D. (2008). The institutional approach to Entrepreneurship Research introduction. International Entrepreneurship and Management Journal, vol. 4, $N^{o}, 4,365-379$.

Veciana, J.M. (2007), Entrepreneurship as a scientific research programmer. In A.

Cuervo, D. Ribeiro, y S. Roig (Eds.), Entrepreneurship: Concepts, theory and perspective. Heidelberg; Springer, 23-71).

Veciana, J. M. (1999). Creación de empresas como programa de investigación científica. Revista Europea de Dirección y Economía de la Empresa, 8, 11-36.

Veciana, J. M. (1989). Características del empresario en España. Papeles de economía española, No. 39/40; en Espíritu, R. y Santre, M. (2007). La actitud emprendedora durante la vida académica de los estudiantes universitarios. Cuadernos de Estudios Empresariales, vol. 17, 95-116.

Veciana, J. M. (1988). Empresario y proceso de creación de empresas. Revista Económica de Cataluña, 8, 19-36.

Veciana, J. M. (1985). Características del empresario en España. Papeles de Economía Española, 39-40.

Veira, J.L. (2007). Las actitudes y los valores sociales en Galicia (1 ${ }^{\mathrm{a}}$ Ed.) Madrid CIS.

Vesalainen, J. y Pihkala, T. (1999). Motivation structure and entrepreneurial intentions. In P. D. Reynolds, W. D. Bygrave, et al. (Eds.), Frontiers of Entrepreneurship Research. Wellesley, MA: Babson College.

Vesalainen, J. Y Pihkala, T. (1999). Entrepreneurial identity, intentions and the effect of the push-factor. Academy of Entrepreneurship Journal, 5(2), 1-24.

Vesper, K.H. (1982). Research on education for entrepreneurship, en, C.A. Kent and D.L. Sexton, in Encyclopedia for entrepreneurship Englewood Cliffs N.J. Prentice-Hall Inc, 321-344.

Vesper, K.H. (1980). New Venture Strategies. Englewood Cliffs, New Jersey: Prentice Hall; en Cano, C., García J. y Gea. A. (2003). Actitudes emprendedoras y creación de empresas en los estudiantes universitarios. Universidad de Almeria, 136.

Weaver, G. (1998). Culture, Comunication and Conflict.Simon Chuster Publishing. Needham Heights, 73.

Weber, M. (2004). Economía y Sociedad. Editorial Fondo de la Cultura Económica. México.

Weber, M. (1985). La Ética Protestante y el Espíritu del Capitalismo. Barcelona Orbis 
Weber, M., (1964): Historia económica general. Mexico, Fondo de cultura Económica.

Weber, M., (1903). The methodology of the social sciencies. Edward Shils and Henry Finch (eds.). New York: Free Press.

West, G. P. (2007). Collective cognition: When entrepreneurial teams, not individuals, make decisions. Entrepreneurship Theory and Practice, 31 (1), 77-101.

Williamson, O. (1991). Comparative economic organization: The analysis of discrete structural alternatives. Administrative Science Quarterly, 36, 269-296.

Williamson, O.E. (1989). Las instituciones económicas del capitalismo. Fondo de Cultura Económica, México; en Díaz, J. (2003). La creación de empresas en Extremadura: un análisis institucional. España, Universidad de Extremadura, 35

Wood, J. S. (2005). Development and present state of the Theory of Entrepreneurship in product and asset markets by Knight, Hayek, Schumpeter, Mises, Kirzner, Shackle, and Lachmann. Austrian Scholars Conference 2005.Retrieved June 6, 2008, from http://mises.org/journals/scholar/wood.pdf.

Wu, S, Sizong; Wu, S., Lingfei (2008). The impact of higher education on entrepreneurial

intentions of university students in China. Journal of Small Bussiness and Entrreprise Development, Vol.- 15 N. 4, 752-774. 2008.

$\mathrm{Wu}, \mathrm{S}$ (2007). The relationship between national culture and national entrepreneurial activity. World review of Entrepreneurship, Management Sustainable Development, 3, 127-141.

Yamada, G., (2004). Economía laboral en el Perú: avances recientes y agenda pendiente, Lima: CIUP.

Zahra, S.A., Jennings, D.F., Kuratlo, D.F. (1999). The Antecedents and Consequences of Firm-Level Entrepreneurship: The State of the Field. Entrepreneurship Theory and Practice, 24, 45-65.

Zhang, Z ET AL. (2009). The genetic basis of entrepreneurship: Effects of gender and personality. Organizational Behaviorand Human Decision Processes, 110, 93107. 2009.

Zhao, H., Seibert, S.E y Hills G.E. (2005). The mediating role of self-efficacy development of entrepreneurial intentions. Journal of Applied Psychology, vol. $90, N^{o}, 6,1265-1272$. 